\title{
Syntactic Priming and Children's Production and Representation of the Passive
}

Katherine Messenger

PhD

University of Edinburgh

2009 


\section{Declaration}

I hereby declare that this thesis is of my own composition and that it contains no material previously submitted for the award of any other degree. The work reported in this thesis has been executed by myself, except where due acknowledgement is made in the text.

Katherine Messenger

12th August 2009 


\section{Abstract}

This thesis investigates children's mental representation of syntactic structure and how their acquisition and production of syntax is affected by lexical and semantic factors, focusing on three- and four-year-old children. It focuses on a construction that has been a frequent subject of language acquisition research: the passive. It is often claimed that English-speaking children acquire the passive relatively late in language development (e.g. Horgan, 1978): previous studies have typically found unreliable comprehension and infrequent production of passives by children younger than five (e.g. Fraser et al., 1963). However, there is some evidence from studies providing an appropriate pragmatic context for passives (e.g. Crain et al., 1987) and studies which increase children's exposure to passives (e.g. Whitehurst et al., 1974) to suggest that children can produce this structure at a younger age.

Converging evidence comes from studies of syntactic priming, or the tendency to repeat syntactic structure (e.g. Bencini \& Valian, 2008). Syntactic priming effects are potentially informative about the nature of syntactic representation, as they are assumed to reflect the repeated use of the same syntactic representation across successive utterances. With respect to language acquisition, syntactic priming effects can be informative about the extent to which children have acquired an abstract representation of a structure. Specifically, if children have a syntactic representation of the passive, then it should be possible to prime their production of passives, such that they should be more likely to produce passives after hearing passives than after hearing actives. Furthermore, by examining the conditions under which such priming occurs, it is possible to draw inferences about the nature of their passive representation.

This thesis presents seven experiments, six using a syntactic priming paradigm, to examine children's knowledge of passives. Experiment 1 establishes a syntactic priming effect for actives and passives in three- and four-year-old children, and shows that priming occurs for both structures within an experimental session, using a withinparticipants design. Experiments 2, 3 and 4 examine whether young children's acquisition of the passive is semantically constrained. Experiments 2 and 3 show that children can be primed to produce passive responses by actional and non-actional passive primes. Experiment 4, a picture-sentence matching task, replicates the results of other studies, however, showing that children find subject-experiencer non-actional verb passives more difficult to understand than actional verb passives; this mis-match between the results from the different tasks suggests that some effects of verb-type may be task-related. Experiments 5 and 6 examine whether the observed priming effect could be a lexically-driven effect that is dependent on the repetition of function words (the preposition by or the passive auxiliary). They show that this explanation can be ruled out: children are more likely to produce passives following both passive primes that do not express the agent using a $b y$-phrase and passive primes involving a different auxiliary verb. Experiment 7 examines the later development of passive structure by testing passive production in six- and nine-year-old children. It finds evidence that at six, they still have difficulties with the construction, however by nine, children have an adult-like representation of the passive.

I conclude that by four, children have begun to develop a syntactic representation for the passive which is already common to a range of different possible forms 
(short, full, get and be), and which is not restricted to particular semantic classes of verb. However, these results also suggest that children do not fully master the passive construction before six: young children make morphological errors and errors mapping thematic roles to syntactic positions, even following passive primes. Hence children may acquire the purely syntactic aspects of the passive, leading to a syntactic priming effect, before they acquire other aspects of this structure, hence the children's occasional errors producing passives. 


\section{Acknowledgements}

The research I have carried out and the completion of this thesis owe much to the guidance, advice and encouragement of my supervisors, Holly Branigan, Janet McLean and Antonella Sorace. I thank them for keeping me motivated; reading and discussing the various drafts of my thesis and answering many a panicked email about nurseries, materials and statistics. I also thank Sergey Avrutin with whom I enjoyed interesting and insightful discussions on my work during my visit to the Utrecht Institute of Linguistics and I am grateful to my examiners Fernanda Ferreira and Elena Lieven for their comments, suggestions and a stimulating viva experience.

I am greatly indebted to all the participants of this research. In particular, I thank the many nurseries who allowed me to carry out my studies with their children: Forbes Nursery, Florence House Nursery, James Gillespies Primary School Nursery, South Morningside Primary School Nursery and Bruntsfield Primary School, all in Edinburgh. Special thanks are for the children and staff, Audrey Cameron in particular, at Uni-Tots Nursery of Edinburgh University, to whom I returned a number of times to collect data. I am very grateful to all the staff who were so helpful but especially to the children who took part in my experiments and who made the project so much fun.

I gratefully acknowledge the financial support I received from the Economic and Social Research Council. This research, my overseas visit to the Utrecht Institute of Linguistics and my attendance at a number of conferences were supported by an ESRC Quota Award [reference: PTA-031-2004-00280].

This work has benefited from presentation at the following Universities: University of Edinburgh (Developmental Linguistics Research Group, Psycholinguistics Coffee Group, the Psycholinguistics and the Linguistics and English Language Postgraduate Conferences, the Language at Edinburgh Lunch); University of Utrecht (Experimental Linguistics Talks in Utrecht, Kermit Lectures); as well as the following conferences: 2006 CUNY Conference on Human Sentence Processing, 2007 Child Language Seminar, 2007 and 2008 Boston University Conference on Language Development, 2008 Congress of the International Association for the Study of Child Language. The questions, comments and suggestions I have received on these occasions have been very useful in shaping my thoughts and the course of my research.

I thank my friends, near and afar, old and new, (especially Caroline who was, mid$\mathrm{PhD}$, the best bridesmaid ever), and fellow PhD students, office-mates and lunchingout companions, (particularly Frances Wilson, Evia Kainada, Anna Leonard Cook and Catherine Dickie, and from long-distance, co-Developmental Linguistics MSc's Laura de Ruiter and Ashley Fidler). They have all been great sources of friendship and support.

Finally, I would like to thank my family who have supported me in many ways through my $\mathrm{PhD}$ and to whom I dedicate this thesis. Firstly I must thank my older brother, Chris, who drew the (something like) 200 pictures that I used in my experiments and presentations to much acclaim from old and young participants and audiences alike; his huge and invaluable contribution to my thesis is very gratefully acknowledged. The making of my experiment materials became something of a wholefamily enterprise with my younger brother, Tim, taking the drawings to work to scan 
and email them to me and my parents co-ordinating the whole effort. I thank them all for their good humour over the project and their love, support and sympathetic ears; especially I thank my parents, Sue and John, who have helped in so many ways during my studies, including proof-reading my thesis in record time, and who are always at the end of the phone when cheerful support and loving reassurance are required. The last mention is for Carl, with much love, for his patience, his technological and gastronomic 'support', for keeping everything in perspective and for keeping me smiling, always.

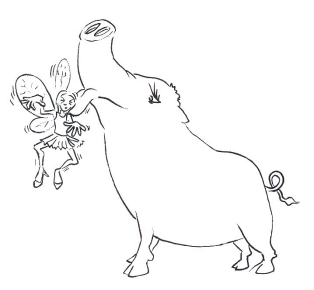


For Carl, Sue, John, Chris \& Tim. 


\section{Contents}

1 Introduction 1

1.1 Aims and Focus of the Thesis . . . . . . . . . . . . . . . 1

1.2 Overview of the Thesis . . . . . . . . . . . . . 3

2 Children's Acquisition of the Passive - A Review 6

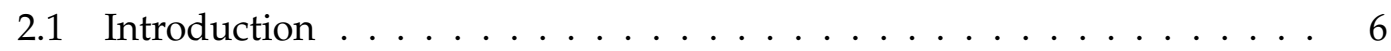

2.2 Late Acquisition of the Passive . . . . . . . . . . . . . . . 7

2.3 Acquisition of Short and Full Passives . . . . . . . . . . . . . . . . . . . . . . . .

2.4 Acquisition of Get-Passives and Be-Passives . . . . . . . . . . . . . . . 12

2.5 Acquisition of Actional and Non-Actional Verb Passives . . . . . . . . . 15

2.6 Task and Other Effects in Passive Acquisition Studies . . . . . . . . . . . . . . 25

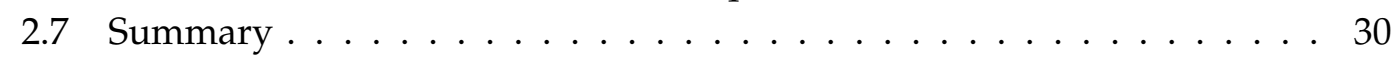

3 Syntactic Priming - A Review 32

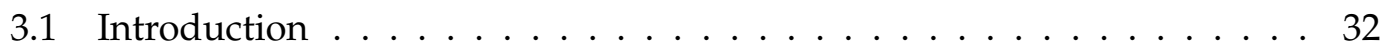

3.2 Early Syntactic Priming Studies . . . . . . . . . . . . . . . . . 33

3.3 Syntactic Priming and Abstract Syntactic Representations . . . . . . . . . 35

3.4 Syntactic Priming and Children's Syntactic Representations . . . . . . . 40

3.5 Syntactic Priming Method . . . . . . . . . . . . . . . . . . . . . . 44

3.6 Summary . . . . . . . . . . . . . . . . . 46

4 Children's Use of Passives Before and After Priming 48

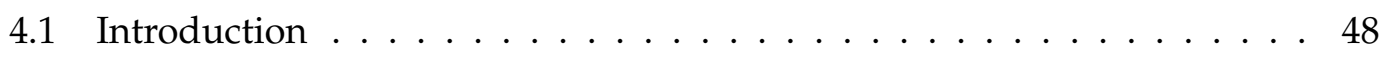

4.1 .1 Aims of Experiment One . . . . . . . . . . . . . . 50

4.1 .2 Predictions for Experiment One . . . . . . . . . . . 51

4.2 Pre-Test . . . . . . . . . . . . . . . . . . . 52

4.2 .1 Method ...................... 52

4.2 .2 Pre-Test Results . . . . . . . . . . . . . . . . . . 53

4.2 .3 Pre-Test Discussion . . . . . . . . . . . . . . . . . . . . . . 54

4.3 Experiment One: Active Primes versus Passive Primes . . . . . . . . . . . . 55

4.3 .1 Method ..................... 55

4.3 .2 Scoring Criteria . . . . . . . . . . . . . . . . . . . 59 
4.3.3 Methods of Analysis . . . . . . . . . . . . . . . . . . . . . . 64

4.3.4 Strict Scoring Results . . . . . . . . . . . . . . . . . . 66

4.3 .5 Lenient Scoring Results . . . . . . . . . . . . . . . . . 73

4.3.6 Inclusive Scoring Results . . . . . . . . . . . . . . . . 77

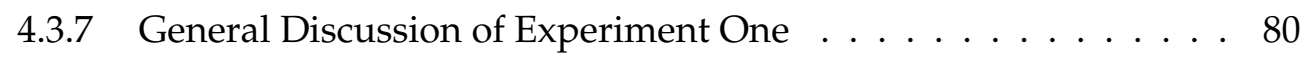

4.4 Summary and Conclusions . . . . . . . . . . . . . 87

5 Semantic Factors in Children's Early Passives 89

5.1 Introduction . . . . . . . . . . . . . . . . . . . . . . 89

5.1.1 Semantic Constraints on Children's Early Passives . . . . . . . . . 90

5.1.2 Predictions for Experiments Two and Three . . . . . . . . . . . . 94

5.1.3 Additional Analyses . . . . . . . . . . . . . . . . . . . . 96

5.2 Experiment Two: Agent-Patient Primes vs. Object-Experiencer Primes . 98

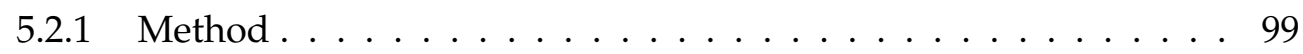

5.2 .2 Strict Scoring Results . . . . . . . . . . . . . . . . . . . . . . . . . . . . . . . . . . . . . . . . . . . . .

5.2 .3 Lenient Scoring Results . . . . . . . . . . . . . . . . . . . 105

5.2 .4 Inclusive Scoring Results . . . . . . . . . . . . . . . . . . . . . . . . . . . . . . .

5.2.5 General Discussion of Experiment Two . . . . . . . . . . . . . . 111

5.3 Experiment Three: Subject-Experiencer Primes vs. Object-Experiencer Primes . . . . . . . . . . . . . . . . . . . . . . . . . . 113

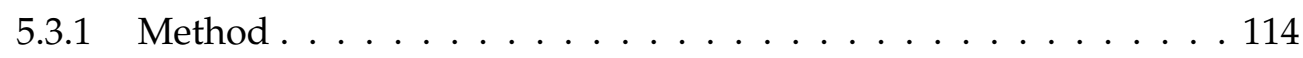

5.3 .2 Strict Scoring Results . . . . . . . . . . . . . . . . . . . . . . . 115

5.3 .3 Lenient Scoring Results . . . . . . . . . . . . . . . . . . . . . . . . . . . . . . . . . . . . . . . . . . . .

5.3 .4 Inclusive Scoring Results . . . . . . . . . . . . . . . . . . . . . . . . . . . . . . . . . . . . . .

5.3.5 General Discussion of Experiment Three . . . . . . . . . . . . . 126

5.4 Experiment Four: Picture-Sentence Matching Task . . . . . . . . . . . 128

5.4 .1 Method . . . . . . . . . . . . . . . . . . 130

5.4.2 Results and Analysis . . . . . . . . . . . . . . . . . . . 132

5.4.3 General Discussion of Experiment Four . . . . . . . . . . . . 135

5.5 General Discussion of Experiments Two, Three and Four . . . . . . . . 137

5.6 Summary and Conclusions . . . . . . . . . . . . . . . . . 141

6 Abstract Structures Underlying Children's Passives 142

6.1 Introduction . . . . . . . . . . . . . . . . . . . . . . 142

6.2 Experiment Five: Active Primes versus Short Passive Primes . . . . . . . 145

6.2.1 Predictions for Experiment Five . . . . . . . . . . . . . . 146

6.2 .2 Method . . . . . . . . . . . . . . . . . . . . . . 149

6.2 .3 Strict Scoring Results . . . . . . . . . . . . . . . . . . . . . . . 151

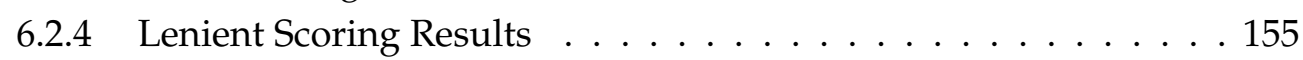

6.2 .5 Inclusive Scoring Results . . . . . . . . . . . . . . . . . 157

6.2.6 General Discussion of Experiment Five . . . . . . . . . . 157 
6.3 Experiment Six: Get-Passive Primes versus Be-Passive Primes . . . . . 160

6.3.1 Predictions for Experiment Six . . . . . . . . . . . . . . . . . . . . . . . . . . . . . . . . . . . . . . . .

6.3 .2 Method . . . . . . . . . . . . . . . . 162

6.3 .3 Strict Scoring Results . . . . . . . . . . . . . . . . . . . . . . 164

6.3 .4 Lenient Scoring Results . . . . . . . . . . . . . . . . . . . 171

6.3.5 Inclusive Scoring Results . . . . . . . . . . . . . . . . . 171

6.3.6 General Discussion of Experiment Six . . . . . . . . . . . . . 172

6.4 Summary and Conclusions . . . . . . . . . . . . . . . 175

7 Older Children's Comprehension and Production of Passives 177

7.1 Introduction . . . . . . . . . . . . . . . . . . . . . . . 177

7.2 Experiment Seven: Priming with Six- and Nine-year-olds . . . . . . . . 180

7.2 .1 Method . . . . . . . . . . . . . . . . 180

7.2 .2 Strict Scoring Results . . . . . . . . . . . . . . . . . . . . . . . . . . . . . . . . . . . . . . . . . . . . . . . . . .

7.2 .3 Lenient Scoring Results . . . . . . . . . . . . . . . . . . . . . . . . . . . . . . . . . . . . . . . . . . . .

7.2.4 Inclusive Scoring Results . . . . . . . . . . . . . . . . . . 188

7.2.5 General Discussion of Experiment Seven . . . . . . . . . . . . . 190

7.3 Summary and Conclusions . . . . . . . . . . . . . . . 193

8 Conclusions $\quad 194$

8.1 Overview of the Experiments . . . . . . . . . . . . . . . . . 195

8.2 Considerations for Future Research . . . . . . . . . . . . . . . . 197

8.3 Implications of these Findings and Directions for Further Research . . . 200

8.3.1 Size of the Priming Effect . . . . . . . . . . . . . . 203

8.3.2 Individual Variation in the Priming Effect . . . . . . . . . . . . . . . . . . . . . . . . . . . .

8.3 .3 Other Responses . . . . . . . . . . . . . . . . . . . . 205

8.3 .4 Reversible Verbs . . . . . . . . . . . . . . . . . 206

8.3.5 Psycholinguistic Investigations of Language Acquisition . . . . . 207

8.4 Conclusion . . . . . . . . . . . . . . . . . . . . . . 208

$\begin{array}{lr}\text { A Experiment One Materials } & 209\end{array}$

A.1 Pre-Test Items . . . . . . . . . . . . . . . . . . . . . . . . . . . . . . . . . . . . . . . . . . .

A.2 Experiment One: Active and Passive Primes . . . . . . . . . . . . . . 209

A.3 Targets Items . . . . . . . . . . . . . . . . . . . . . . 210

A.4 Filler Items . . . . . . . . . . . . . . . . . . . . . . . 211

A.5 Practice Items . . . . . . . . . . . . . . . . . . . . 211

B Experiments Two, Three and Four Materials 212

B.1 Experiment Two: Object-Experiencer Verb Primes . . . . . . . . . . . . . . . 212

B.2 Experiment Three: Subject-Experiencer Verb Primes . . . . . . . . . . . . 213

B.3 Experiment Four: Picture-Sentence Matching Practice Items . . . . . . . 213

B.4 Experiment Four: Picture-Sentence Matching Target Items . . . . . . . 214 
C Experiments Five and Six Materials

C.1 Experiment Five: Active and Short Passive Primes . . . . . . . . . . . . . 216

C.2 Experiment Six: Active, Get- and Be-Passive Primes . . . . . . . . . . . 217

C.3 Experiment Six: Active, Get- and Be-Passive Fillers . . . . . . . . . . . . 217

$\begin{array}{lr}\text { D Experiments Five and Six Analyses } & 218\end{array}$

D.1 Experiment Five: Inclusive Scoring Analyses . . . . . . . . . . . . . . 218

D.2 Experiment Six: Lenient Scoring Analyses . . . . . . . . . . . . . . . . . . . . . . . . 220

D.3 Experiment Six: Inclusive Scoring Analyses . . . . . . . . . . . . . . 222

$\begin{array}{ll}\text { References } & 225\end{array}$ 


\section{List of Figures}

2.1 Examples of actional verb pictures . . . . . . . . . . . . 26

2.2 Examples of non-actional verb pictures $\ldots \ldots \ldots 27$

3.1 Representation of syntactic information at the lemma level (adapted from Pickering \& Branigan (1998)). $\mathrm{T}=$ tense, $\mathrm{A}=$ aspect, $\mathrm{N}=$ number $\ldots 37$

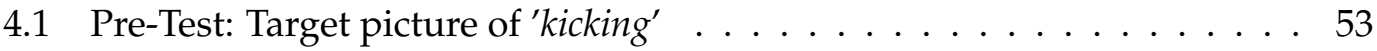

4.2 Experiment 1: Prime picture and a target item . . . . . . . . . . . 56

4.3 Experiment 1: Mean number of passives children produced following first eight and last eight primes . . . . . . . . . . . . . 71

4.4 Experiment 1: Mean number of passives adults produced following first eight and last eight primes . . . . . . . . . . . . . 71

4.5 Experiment 1: Priming effect by age of participant . . . . . . . . . . 71

4.6 Experiment 1: Number of passives participants produced by age . . . . 71

4.7 Experiment 1 : Verbs most frequently passivized $\ldots \ldots$. . . . . . . 85

5.1 Model of syntactic representation: Passive is semantically constrained to actional verbs . . . . . . . . . . . . . . . . . . . 95

5.2 Model of syntactic representation: Passive is semantically constrained to actional and object-experiencer verbs . . . . . . . . . . . . . . . 95

5.3 Model of syntactic representation: Passive is not semantically constrained 96

5.4 Experiment 2: Agent-patient and object-experiencer primes and a target item . . . . . . . . . . . . . . . . . . . 100

5.5 Experiment 2: Number of passives produced by age of participant . . 104

5.6 Experiment 3: Object-experiencer and subject-experiencer primes and a target item . . . . . . . . . . . . . . . . . . . . 115

5.7 Experiment 3: Children's BPVS scores plotted by age of participant . . . 116

5.8 Experiment 3: Number of passives produced by BPVS score . . . . . . 119

5.9 Experiment 3: Number of passives produced by age of participant . . 120

5.10 Experiment 4: Target and foil versions of a picture-sentence matching item . . . . . . . . . . . . . . . . . . . . 131

6.1 Model of syntactic representation: Short passives stored separately . . . 147

6.2 Model of syntactic representation: Short passives acquired earlier . . . . 148 
6.3 Model of syntactic representation: Priming from by . . . . . . . . . . 148

6.4 Model of syntactic representation: Adult passives . . . . . . . . . . . . . 149

6.5 Experiment 5: Active and passive prime items and a target . . . . . . . . . 151

6.6 Experiment 5: Number of passives children produced by age . . . . . . 154

6.7 Experiment 5: Numbers of full and short passives children produced by age . . . . . . . . . . . . . . . . . . . . . 159

6.8 Experiment 6: Children's responses in each priming condition . . . . . . 173

6.9 Experiment 6: Adults' responses in each priming condition . . . . . . . . 174

7.1 Experiment 7: Number of passives six-year-olds produced by age . . . . 184

7.2 Experiment 7: Number of passives nine-year-olds produced by age . . . 184 


\section{List of Tables}

4.1 Pre-Test: Frequency of active, passive and other responses (\%) . . . . . . 54

4.2 Summary of the scoring criteria: $\mathrm{Y}=$ utterance scored as passive/active, $\mathrm{N}=$ utterance scored as other, in $\mathrm{S}=$ strict, $\mathrm{L}=$ lenient, $\mathrm{I}=$ inclusive scoring. 64

4.3 Methods of analysis: Hypothetical results . . . . . . . . . . . . . . 65

4.4 Experiment 1: Frequency of active, passive and other responses according to group and prime condition . . . . . . . . . . . . 67

4.5 Experiment 1: Mean proportions of responses in the Strict scoring ('All Responses' approach) . . . . . . . . . . . . . . . . . . 67

4.6 Experiment 1: Mean proportions of responses in the Strict scoring ('Alternating Responses' approach) . . . . . . . . . . . . . . . . . . . 69

4.7 Experiment 1: Mean numbers of Other responses in the Strict scoring ('Alternating Responses' approach) . . . . . . . . . . . . . . . . . . . 69

4.8 Experiment 1: Mean proportions of responses in the Lenient scoring ('All Responses' approach) . . . . . . . . . . . . . . . . . . . . . . . . . . . 74

4.9 Experiment 1: ANOVAs of proportions of Actives in the Lenient scoring ('All Responses' approach) . . . . . . . . . . . . . . . . . . . . . . . . 74

4.10 Experiment 1: ANOVAs of proportions of Passives in the Lenient scoring ('All Responses' approach) . . . . . . . . . . . . . . . . . . . 75

4.11 Experiment 1: ANOVAs of proportions of Others in the Lenient scoring ('All Responses' approach) . . . . . . . . . . . . . . . . . . . . . . . . 75

4.12 Experiment 1: Mean proportions of responses in the Lenient scoring ('Alternating Responses' approach) . . . . . . . . . . . . . . . . 76

4.13 Experiment 1: ANOVAs of proportions of Passives in the Lenient scoring ('Alternating Responses' approach) . . . . . . . . . . . . . 76

4.14 Experiment 1: Mean numbers of Other responses in the Lenient scoring ('Alternating Responses' approach) . . . . . . . . . . . . . . . . . 76

4.15 Experiment 1: ANOVAs of numbers of Others in the Lenient scoring ('Alternating Responses' approach) . . . . . . . . . . . . . . . 77

4.16 Experiment 1: Mean proportions of responses in the Inclusive scoring ('All Responses' approach) . . . . . . . . . . . . . . . . . . . . . . 77

4.17 Experiment 1: ANOVAs of proportions of Actives in the Inclusive scoring ('All Responses' approach) . . . . . . . . . . . . . . . . . 78

4.18 Experiment 1: ANOVAs of proportions of Passives in the Inclusive scoring ('All Responses' approach) . . . . . . . . . . . . . . . . . 78 
4.19 Experiment 1: ANOVAs of proportions of Others in the Inclusive scoring ('All Responses' approach) . . . . . . . . . . . . . . . . . 78

4.20 Experiment 1: Mean proportions of responses in the Inclusive scoring ('Alternating Responses' approach) . . . . . . . . . . . . . . . . . . . 79

4.21 Experiment 1: ANOVAs of proportions of Passives in the Inclusive scoring ('Alternating Responses' approach) . . . . . . . . . . . . . . . 79

4.22 Experiment 1: Mean numbers of Others in the Inclusive scoring ('Alternating Responses' approach) _ . . . . . . . . . . . . . . . . . . . . 79

4.23 Experiment 1: ANOVAs of numbers of Others in the Inclusive scoring ('Alternating Responses' approach) . . . . . . . . . . . . . . . . . . . 80

5.1 Experiment 2: Frequency of active, passive and other responses according to group and prime condition . . . . . . . . . . . . . . 100

5.2 Experiment 2: Mean proportions of Passives in the Strict scoring . . . . . 101

5.3 Experiment 2: ANOVA of proportions of Passives in the Strict scoring . 101

5.4 Experiment 2: Mean numbers of Others in the Strict scoring . . . . . . 102

5.5 Experiment 2: ANOVA of numbers of Others in the Strict scoring . . . . 102

5.6 Experiment 2: Mean proportions of Passives in the Lenient scoring . . . 105

5.7 Experiment 2: ANOVA of proportions of Passives in the Lenient scoring 106

5.8 Experiment 2: Mean number of Others in the Lenient scoring . . . . . . . 107

5.9 Experiment 2: ANOVA of number of Others in the Lenient scoring . . 107

5.10 Experiment 2: Mean proportions of Passives in the Inclusive scoring . 109

5.11 Experiment 2: ANOVA of proportions of Passives in the Inclusive scoring109

5.12 Experiment 2: Mean proportions of Others in the Inclusive scoring . . 110

5.13 Experiment 2: ANOVA of proportions of Others in the Inclusive scoring 110

5.14 Experiment 3: Frequency of active, passive and other responses according to group and prime condition . . . . . . . . . . . . . . . . 115

5.15 Experiment 3: Mean proportions of Passives in the Strict scoring . . . . . 116

5.16 Experiment 3: ANOVA of proportions of Passives in the Strict scoring . 117

5.17 Experiment 3: Mean numbers of Others in the Strict scoring . . . . . . 118

5.18 Experiment 3: ANOVA of numbers of Others in the Strict scoring . . . . 118

5.19 Experiment 3: Mean proportions of Passives in the Lenient scoring . . . 121

5.20 Experiment 3: ANOVA of proportions of Passives in the Lenient scoring 122

5.21 Experiment 3: Mean numbers of Others in the Lenient scoring . . . . . . 122

5.22 Experiment 3: ANOVA of numbers of Others in the Lenient scoring . . . 123

5.23 Experiment 3: Mean proportions of Passives in the Inclusive scoring . 124

5.24 Experiment 3: ANOVA of proportions of Passives in the Inclusive scoring124

5.25 Experiment 3: Mean numbers of Others in the Inclusive scoring . . . . . 125

5.26 Experiment 3: ANOVA of numbers of Others in the Inclusive scoring . . 125

5.27 Experiment 4: Results of the picture-sentence matching task (mean scores out of six $\ldots \ldots \ldots$. . . . . . . . . . . . . . . 133

5.28 Experiment 4: ANOVA of picture-sentence matching results $\ldots \ldots 133$ 
5.29 Experiment 4: ANOVA of children's picture-sentence matching results . 134

5.30 Experiment 4: ANOVA of adults' picture-sentence matching results . . . 135

5.31 Experiments 1-3: Percentage priming effects . . . . . . . . . . . . . . 139

6.1 Experiment 5: Frequency of active, passive and other responses according to group and prime condition . . . . . . . . . . . . . . 152

6.2 Experiment 5: Mean proportions of Passives in the Strict scoring . . . . . 152

6.3 Experiment 5: ANOVA of proportions of Passives in the Strict scoring . 153

6.4 Experiment 5: Mean numbers of Others in the Strict scoring . . . . . . 153

6.5 Experiment 5: ANOVA of numbers of Others in the Strict scoring . . . . 153

6.6 Experiment 5: Mean proportions of Passives in the Lenient scoring . . . 156

6.7 Experiment 5: ANOVA of proportions of Passives in the Lenient scoring 156

6.8 Experiment 5: Mean numbers of Others in the Lenient scoring . . . . . . 156

6.9 Experiment 5: ANOVA of numbers of Others in the Lenient scoring . . . 157

6.10 Experiment 6: Frequency of active, passive and other responses according to group and prime condition . . . . . . . . . . . . . . 164

6.11 Experiment 6: Mean numbers of Others in the Strict scoring . . . . . . 166

6.12 Experiment 6: ANOVA of numbers of Others in the Strict scoring . . . . 166

6.13 Experiment 6: Mean proportions of Be-Passives in the Strict scoring . . . 166

6.14 Experiment 6: ANOVA of proportions of Be-Passives in the Strict scoring 167

6.15 Experiment 6: ANOVA and planned contrasts on children's Be-Passives 167

6.16 Experiment 6: ANOVA and planned contrasts on adults' Be-Passives . . 168

6.17 Experiment 6: Mean proportions of Get-Passives in the Strict scoring . 169

6.18 Experiment 6: ANOVA of proportions of Get-Passives in the Strict scoring169

6.19 Experiment 6: ANOVA and planned contrasts on children's Get-Passives 169

6.20 Experiment 6: ANOVA and planned contrasts on adults' Get-Passives . 170

6.21 Experiment 6: Percentage priming effects . . . . . . . . . . . . . . 170

6.22 Experiment 6: Number of reversed passives produced . . . . . . . . . 175

7.1 Experiment 7: Frequency of active, passive and other responses according to group and prime condition . . . . . . . . . . . . . 181

7.2 Experiment 7: Mean proportions of Passives in the Strict scoring . . . . . 182

7.3 Experiment 7: ANOVA of proportions of Passives in the Strict scoring . 182

7.4 Experiment 7: Mean numbers of Others in the Strict scoring . . . . . . 183

7.5 Experiment 7: ANOVA of numbers of Others in the Strict scoring . . . . 183

7.6 Experiment 7: Mean proportions of Passives in the Lenient scoring . . . 186

7.7 Experiment 7: ANOVA of proportions of Passives in the Lenient scoring 186

7.8 Experiment 7: Mean numbers of Others in the Lenient scoring . . . . . 187

7.9 Experiment 7: ANOVA of numbers of Others in the Lenient scoring . . . 187

7.10 Experiment 7: Mean proportions of Passives in the Inclusive scoring . 189

7.11 Experiment 7: ANOVA of proportions of Passives in the Inclusive scoring189

7.12 Experiment 7: Mean numbers of Others in the Inclusive scoring . . . . 189 
7.13 Experiment 7: ANOVA of numbers of Others in the Inclusive scoring . . 190

D.1 Experiment 5: Mean proportions of Passives in the Inclusive scoring . . 218

D.2 Experiment 5: ANOVA of proportions of Passives in the Inclusive scoring218

D.3 Experiment 5: Mean numbers of Others in the Inclusive scoring . . . . . 219

D.4 Experiment 5: ANOVA of numbers of Others in the Inclusive scoring . . 219

D.5 Experiment 6: Mean proportions of Be-Passives in the Lenient scoring . 220

D.6 Experiment 6: ANOVA of proportions of Be-Passives in the Lenient scoring . . . . . . . . . . . . . . . . 220

D.7 Experiment 6: ANOVA and planned contrasts on children's Be-Passives 220

D.8 Experiment 6: Mean proportions of Get-Passives in the Lenient scoring . 221

D.9 Experiment 6: ANOVA of proportions of Get-Passives in the Lenient scoring . . . . . . . . . . . . . . . . . 221

D.10 Experiment 6: ANOVA and planned contrasts on children's Get-Passives 221

D.11 Experiment 6: Mean proportions of Be-Passives in the Inclusive scoring . 222

D.12 Experiment 6: ANOVA of proportions of Be-Passives in the Inclusive

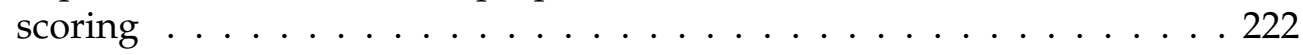

D.13 Experiment 6: ANOVA and planned contrasts on children's Be-Passives 222

D.14 Experiment 6: ANOVA and planned contrasts on adults' Be-Passives . . 223

D.15 Experiment 6: Mean proportions of Get-Passives in the Inclusive scoring 223

D.16 Experiment 6: ANOVA of proportions of Get-Passives in the Inclusive scoring . . . . . . . . . . . . . . . . . . 2223

D.17 Experiment 6: ANOVA and planned contrasts on children's Get-Passives 224

D.18 Experiment 6: ANOVA and planned contrasts on adults' Get-Passives . 224 


\section{Chapter 1}

\section{Introduction}

\subsection{Aims and Focus of the Thesis}

This thesis investigates children's mental representation and production of syntactic structure. It focuses on a construction that has been a frequent subject of language acquisition research: the passive, sentences such as (1.1a) in which a transitive verb is expressed with its patient (the girl) as the subject of the sentence rather than as the object, as in canonical active sentences (1.1b). This is just one of many constructions for which children, acquiring English, must generate an abstract syntactic representation or rule that allows them to produce such sentences with any transitive verb rather than producing the active alternative.
a. The girl was chased by the dog.
b. The dog chased the girl.

Researchers in the field of language acquisition disagree about how children acquire such abstract syntactic representations, generally (though not exclusively) falling into one of two camps: nativist positions and usage-based positions. The nativist position supposes an innate knowledge of language in the form of innate grammatical principles which guide rapid language acquisition (e.g. Pinker 1994). In contrast, the usagebased position proposes that children first acquire item-, e.g. verb-, specific schemas based on the input they hear: they generalise abstract syntactic representations from these item-based schemas once sufficient evidence for a structure has been acquired (e.g. Tomasello 2000). The two views therefore make different predictions for the path of language acquisition and place different emphasis on the role of the input children 
hear: the former predicts that children begin to analyse the input early on for evidence that allows them to switch their innate grammatical principles to the settings of the ambient language; this theory suggests that children acquire the grammar of their language, including the principles and processes which underlie actives and passives, relatively quickly with relatively little input (Cook \& Newson 1996). The latter view suggests that children form schema around the lexical items they hear in the input, thus their first passives will be based on the passives they hear. As the evidence base widens, as children hear more transitive verbs passivized, they will generate from their accumulated verb-based representations an abstract passive structure that can be applied to all transitive verbs (Tomasello 2000). As such, their acquisition of the passive, or any structure, will be closely related to the input they receive.

In the case of the passive this is particularly interesting given that the input Englishspeaking children hear typically contains very few passives, particularly full passives, (e.g. Brown 1973, p. 358). The passive is of further interest for language acquisition research as it expresses the same basic meaning as the alternative structure - the active - yet the passive structure is more complex in terms of the non-canonical mapping of thematic roles (patient to subject, agent to object), in terms of the morpho-syntactic structure and in terms of the discourse conditions that condition its use. For these reasons and the fact that there is little positive evidence from which children can build or strengthen a representation, the passive is generally considered a more difficult construction than the active that children will acquire later.

How and when children acquire the passive has, as such, been widely studied. It is often claimed that English-speaking children acquire the passive relatively late in language development (e.g. Horgan 1978) because studies have typically found unreliable comprehension and infrequent production of passives by children younger than five years of age (e.g. Fraser, Bellugi \& Brown 1963). However, there is some evidence from studies providing an appropriate pragmatic context for passives (e.g. Crain, Thornton \& Murasugi 1987) and studies which increase children's exposure to passives (e.g. Whitehurst, Ironsmith \& Goldfein 1974) to suggest that children can produce this structure at a younger age. This research has also produced a number of findings suggesting semantic and structural variations in children's acquisition of this structure: children tend to understand passives better with actional verbs at a young age and have difficulty with non-actional verb passives until relatively late in their language development (e.g. Maratsos, Fox, Becker \& Chalkley 1985). There is also evidence that children tend to comprehend and produce short passives more frequently and earlier than full passives (Harris 1976, Marchman, Bates, Burkardt \& Good 1991) and prefer get-passives to be-passives in their early language (Harris \& Flora 1982, 
Marchman et al. 1991).

This thesis examines these issues in a series of syntactic priming experiments. Syntactic priming, or the tendency to repeat syntactic structure across successive utterances (e.g. Bock 1986), is assumed to occur at the level of structural representation, thus syntactic priming effects can be informative about the nature of those structural representations (Branigan, Pickering, Liversedge, Stewart \& Urbach 1995). With respect to language acquisition, syntactic priming effects can therefore be informative about the extent to which children have acquired an abstract representation of a structure, for example, demonstrating priming between unrelated items with young children would provide strong evidence for abstract syntactic knowledge at an early age (McClure, Pine \& Lieven 2006). Specifically, if children have a structural representation of the passive, then it should be possible to prime their production of passives, such that they should be more likely to produce passives after hearing passives than after hearing actives. A few studies have shown that priming occurs for passives with children aged three to five years of age (Huttenlocher, Vasilyeva \& Shimpi 2004, Savage, Lieven, Theakston \& Tomasello 2006, Shimpi, Gamez, Huttenlocher \& Vasilyeva 2007, Bencini \& Valian 2008); however, these studies have only examined priming from full, be-passives with actional verbs. This thesis examines whether priming occurs under different conditions: from non-actional verbs, from short passives and get-passives, for evidence about the nature of young children's passive representation that may support previous findings on children's representation and production of passives.

\subsection{Overview of the Thesis}

The thesis begins with a literature review that first examines, in Chapter 2, the findings from previous research into children's acquisition of the passive, the explanations proposed for these findings and how well they account for all the available data. The literature review continues with an exposition of the experimental paradigm: syntactic priming, in Chapter 3. This details early work on syntactic priming and how, more recently, it has been used in language acquisition research. The following chapters then present the experimental work.

Chapter 4 presents the first priming study, Experiment 1, which established a priming effect using the proposed method and population as well as a method of scoring and analysis for the child priming data. As a further measure, children's descriptions of transitive event pictures were also collected before any priming manipulations and analysed to examine their baseline preferences for transitive structures. This study 
showed that when not primed, children have a clear preference to produce active transitives. The priming experiment showed that nonetheless the same participants were able to produce passive descriptions for similar pictures once they heard passive primes.

Having established that at three and four years of age, children have acquired a sufficient syntactic representation to be susceptible to priming of passives, the subsequent experiments examine whether the structural and semantic effects found in previous research into young children's passives can be replicated in priming experiments. This method allows us to draw further inferences about the nature of the children's passive representation by examining whether priming occurs following variations in the prime. If, for example, children's early passive representation is limited to actional verbs one would not expect priming from other verb types, however if children's difficulty with subject-experiencer verbs is related to previous studies' experimental methods one would expect priming to also occur from passives with these verbs. Similarly, if children store short passives or get-passives as distinct forms, one would not predict them to prime other forms, that is full passives or be-passives. If such priming did occur one could infer that young children's representation for the passive was common to these different forms.

Chapter 5 addresses the question of semantic factors in children's early passives in a series of experiments: Experiment 2 compared the effect of actional and objectexperiencer non-actional verb primes and Experiment 3 compared object-experiencer and subject-experiencer non-actional verb primes on children's description of actional verb target pictures. Both experiments showed, as in the previous priming experiments, that children are more likely to produce passive responses after passive primes than after active primes; this occurred for all three types of verb. These experiments suggest that children can process passives with varying types of verbs well enough to be reliably primed to produce passives. Since these results do not support the findings of previous research, Experiment 4 replicated previous research with a picturesentence matching task test of the same types of sentences as used in the primes. The results of this experiment replicated previous studies, showing that three- and fouryear-old children found actives easier to understand than passives and they found actional verb sentences easier to understand than subject-experiencer non-actional verb sentences, including actives. In an extension of earlier results, object-experiencer passives were found to be easier to understand than subject-experiencer passives. Adults also participated in this task: they also performed less accurately with non-actional verb sentences than with actional sentences. Taken together these results suggest that the experimental materials or task may confound the results of previous studies. 
Chapter 6 addresses structural variations in children's acquisition of the passive, examining the question of whether children acquire different passive forms early on (i.e. short passives before, or separately to, full passives and get-passives before or separately to be-passives) or whether they acquire one structural representation that underlies these passive forms from early in their language development. Experiment 5 examined priming of full passives from short passive primes and Experiment 6 examined the effect of get- and be-passive primes. In Experiment 5 three- and four-yearold children were primed to produce full passive responses following short passive primes; these results were based only on full passive responses although the children actually produced very few short passive responses to short passive primes. These results suggest that children did not rely on lexical or surface priming but rather that the short passive prime also activated a passive syntactic representation which supported production of full passives. Experiment 6 compared children's passive responses following get-passive and be-passive primes and showed that children have a common passive structure underlying the two forms; they produced more get-passive responses following be-passive primes than following active primes. However, there was also some evidence to suggest that they prefer get-passives at a young age compared to be-passives: the children only produced significantly more be-passives following the same auxiliary, be-passive, primes; get-passive primes did not differ in effect to active primes. Taken together, the experiments presented in this chapter suggest that children acquire a full passive structural representation that underlies the possible surface forms by four years of age, though it appears that get-passives are preferred at a younger age.

Chapter 7 presents Experiment 7 which examined priming in six- and nine-yearold children. Some studies have suggested that children continue to have difficulty producing passives until late in language development (Beilin 1975, Turner \& Rommetveit 1967a, Horgan 1978, Marchman et al. 1991). There was not any difference in the priming effect of the two groups: six-year-olds responded to the primes in the same way as the nine-year-olds. There were however some differences in the two groups' performance which provide evidence of continued development of their language: the younger children made more errors and different types of errors to the older children, which suggest that at six, children are still mastering their production of passives. The nine-year-olds' responses were more adult-like and they made few errors, which suggests that by this age, children have fully developed their representation and production of this structure.

The concluding chapter, Chapter 8, summarises the findings presented in the previous chapters and discuss directions for future research. 


\section{Chapter 2}

\section{Children's Acquisition of the Passive - A Review}

\subsection{Introduction}

As noted in Chapter 1, children's acquisition of the passive is an area of language acquisition research which has received a lot of attention. Early researchers in language acquisition predicted that passives should be harder than actives and consequently later acquired (see section 2.2 for further discussion). Much research certainly shows that young children have difficulty comprehending and producing this structure, particularly reversible passives ${ }^{1}$ (Slobin 1966, Turner \& Rommetveit 1967a, Harris 1976, de Villiers \& de Villiers 1973, 1979). This research has also shown a number of possible semantic and structural effects in children's acquisition of this structure. It suggests that children find short passives easier (Harris 1976, Horgan 1978) than full passives (see section 2.3) and get-passives easier than be-passives (Harris \& Flora 1982) (see section 2.4). Further research examining children's comprehension of passives with different verbs has consistently shown an effect of verb type: children find actional verb passives easier to understand than non-actional verb passives (e.g. Maratsos et al. 1985, Gordon \& Chafetz 1990, Hirsch \& Wexler 2006b), (see section 2.5). These findings have been used as evidence for various theories of how and when the passive structure is acquired in English. In this chapter I will review previous research, summarising the main findings on children's acquisition of the passive and I will discuss

\footnotetext{
${ }^{1}$ Those with verbs such as chase where the subject and object can be reversed without the sentence becoming nonsensical, e.g. the girl was chased by the dog - the dog was chased by the girl; as opposed to those, e.g. drink, where the arguments cannot logically be reversed, e.g. the milk was drunk by the boy *the boy was drunk by the milk.
} 
and evaluate the theories proposed to account for such findings.

\subsection{Late Acquisition of the Passive}

As noted above, researchers have long assumed that the passive is a more difficult construction for children than the active alternative due to various factors, such as structural complexity, markedness or change in word order or focus (see Beilin \& Sack 1975, for further discussion). This assumption led to the prediction that children will acquire the passive structure (and other similarly complex structures such as negatives or questions) later than the active (e.g. Maratsos 1979). Early research supports this prediction: young children do have difficulty comprehending passives at three, (Fraser et al. 1963, Lovell \& Dixon 1967, Turner \& Rommetveit 1967a, de Villiers \& de Villiers 1978) and four years of age (Bever 1970, Beilin 1975), by which ages they already comprehend and produce actives (Hirsh-Pasek \& Golinkoff 1996, Gertner, Fisher \& Eisengart 2006). Young children are also less likely to produce passives: Menyuk (1963) showed that children aged three to four were significantly less likely to produce passives in their spontaneous speech than children aged six to seven and Beilin (1975) found that, before seven years, very few of the children in his study produced passive descriptions of actions enacted with dolls, even when asked to begin their sentence with the grammatical object. Children also make mistakes when interpreting and producing passives until much older than three, frequently producing reversed passives ${ }^{2}$ (Hayhurst 1967, Turner \& Rommetveit 1967a, Horgan 1978) or mis-interpreting reversible passives, for example, as active sentences (Bever 1970, de Villiers \& de Villiers 1973, Baldie 1976).

The idea that children acquire the passive structure late appears then to be an accepted notion in early language acquisition research. There is however a wealth of evidence that challenges this assumption: for example, children produce passives in their spontaneous speech at around three years of age (Budwig 1990, 2001, Slobin 1994) and, importantly, use the passive productively around this age: Pinker, Lebeaux \& Frost (1987, p. 203-205) give examples of children's productive passives from spontaneous speech recordings, such as "I don't want the bird to get eated" and "it was bandaided". These are passives that the children were extremely unlikely to have heard an adult produce, containing either an incorrect participle form $\left({ }^{*}\right.$ eated $)$ or the transitive use of a nonexistent transitive verb $\left({ }^{*}\right.$ bandaided $)$ and as such are seen as evidence for children

\footnotetext{
${ }^{2}$ Reversed passives are those in which the subject and object are incorrectly mapped onto the sentence arguments positions, for example, describing a picture of a girl chasing a dog as the girl was chased by the dog.
} 
having and applying a productive, abstract, passive rule by around the age of three. At three to four years children also produce passives in a variety of elicited production experimental contexts, such as following recasting (Baker \& Nelson 1984), patientfocussing questions (Turner \& Rommetveit 1967b, Baldie 1976), modeling (Whitehurst et al. 1974, Brown 1976) or priming (e.g. Bencini \& Valian 2008, Shimpi et al. 2007). These studies show that children are able or more likely to produce passives than active sentences when placed in an experimental context where their production of passives is facilitated by increasing the input of passives through modelling or priming the structure or when a passive response is made felicitous by focussing the verb's object. This evidence further supports the notion that children have acquired the passive structure by three years of age; it would be difficult to propose a theory which allows children to be able to produce structures, and in particular to use them productively, without having already acquired a syntactic representation for that construction.

This raises another important issue in children's language acquisition in general and in the acquisition of passives in particular: the role of input. Firstly, the frequency of passives children hear in the input and therefore have evidence for this structure from is very low (e.g. Brown 1973, Svartvik 1966). Furthermore, the types of passives children tend to hear may provide restricted evidence of the full range of this structure: research suggests adults tend to produce short passives much more frequently than full passives (Svartvik 1966) and passives with certain types of verbs with restricted semantic range (Maratsos et al. 1985). Finally, different theories of language acquisition emphasise the role of this input to different extents: input-based theories place a greater importance on the input than nativist theories. Certainly the studies referenced above suggest that increased input improves children's performance with passives; the pertinent question is: do these show evidence of learning from this increased exposure or evidence of strengthening of an already-acquired representation from this increased exposure? This will be discussed further in the following chapter, which discusses the experimental method used in this thesis, syntactic priming, itself a form of modelling and increasing the input of passives children hear.

The evidence suggests that the passive is difficult for children aged three and four years but that passives are not completely absent from their speech. A possible explanation is that children's acquisition of the passive is a multi-stage process: children may acquire a syntactic representation for the passive, in terms of the phrase structure, early, which enables them to produce and comprehend (some) passive sentences by three. However, it may take longer to master the semantic or pragmatic aspects of the construction: hence children's reversal of passives in comprehension and production. As noted above younger children appear to find passives with non-reversible verbs 
easier than passives with reversible verbs (e.g. de Villiers \& de Villiers 1979); studies also show that they find passives with verbs of particular semantic classes easier to comprehend than others and they are also more likely to produce variant forms of the passive, such as short passives or get-passives rather than be-passives, early on. These factors may be indicative of the way children master this structure, for example the stages they go through or the cues that they use to identify passive structures. The following sections explore the evidence for these factors.

\subsection{Acquisition of Short and Full Passives}

The passive in English may be shortened from the full passive phrase (e.g. (2.1a) in which both arguments, subject and object, are realised) to a short, also known as truncated or agentless ${ }^{3}$, passive in which the oblique object phrase is deleted (2.1b). In fact, in English, the shortened form is the more common passive form (Svartvik 1966, p. 134) suggesting that the passive may be frequently used as a means for deleting or avoiding mention of the grammatical subject.
a. The girl was chased by the dog.
b. The girl was chased ø.

It has been suggested that children acquire short passives earlier than full passives (e.g. de Villiers \& de Villiers 1978); a number of studies show that children find short passives easier to comprehend (Baldie 1976, Harris 1976, Fox \& Grodzinsky 1998) and produce (Slobin 1968, Hayhurst 1967, Harris \& Flora 1982, Marchman et al. 1991) than full passives. For example, Harris (1976) found in a picture-sentence matching task that three- to four-year-old children correctly interpreted more short passive sentences than full passive sentences. Some production studies also show that short passives are more frequent or easier than the full passive form (Harris \& Flora 1982, Budwig 1990, Marchman et al. 1991, Budwig 2001). For example, Marchman et al. (1991) showed participants transitive scenes and asked them patient-focussing questions to elicit passive descriptions of the scenes. They found that short passives were prevalent in threeyear-old children, the youngest age-group tested, and that the use of short passives decreased with age while the use of full passives increased as age increased. Harris \& Flora (1982) showed that following patient-focussing questions, children aged four were more likely to produce short passive than full passive forms to describe scenes

\footnotetext{
${ }^{3}$ However, the term 'agentless' is something of a misnomer since verbs may carry different thematic roles such as experiencer and theme; henceforth, the term 'short' will be used to refer to these passives.
} 
acted out with toys. They tested older children as well and found, unlike Marchman et al. (1991), that this pattern was the same at ages six and eight — short passives were preferred over full passives.

Harris (1976) suggests that the short form may be more recognisably different from actives than the full passive as it contains only one argument and that therefore the deletion of the post-verbal noun phrase acts as a syntactic cue for interpreting the sentence as a passive. Others suggest that short passives are treated as distinct, simpler structures and are not related to the full passive or active alternative (e.g. Hayhurst 1967, Slobin 1968, Baldie 1976, Maratsos 1978); Baldie (1976) for example suggests that short passives may be interpreted as adjectival sentences before children fully acquire the passive construction.

Similarly Slobin (1968) suggests that short passives are stored in a form that retains the short passive structure, whereas full passives are stored in an active form and transformed to the passive in production, therefore requiring more processing stages. Thus short passives should be easier for young children to produce. He told stories containing either full or short passives to children, aged between five and twelve, and asked them to retell the stories. He showed that short passives were more likely to be retained in the retelling of the stories, whereas full passives were more likely to be retold as actives: compare on average $60 \%$ of short passives retained vs. $25 \%$ of full passives. Whilst this evidence supports his theory that short passives should be easier to recall but that full passives should be more likely to be retold as actives, there is a possible alternative explanation for these results: children could not as easily convert short passives into actives; a pleonastic noun phrase such as somebody must be inserted since these do not have an agent, (2.2a). By contrast, full passives have two arguments and therefore may be more easily converted into actives (2.2b).
a. Bob was asked $\boldsymbol{\varnothing}$ to tell...
Somebody asked Bob to tell...
b. Bob was asked by his father to tell...
His father asked Bob to tell...

Children may have retained more short passives than full passives in the retelling of the stories simply because it was easier to recall the short passive form than convert it into an active. The fact that they converted full passives into actives would suggest that actives are easier than passives but not necessarily that the two passive forms are stored as separate structures. Indeed, Slobin reports that some full passives were recalled as short passives by children of all ages (on average $13 \%$ compared to $1 \%$ 
short passives being retold as full passives) suggesting that children at least as young as five relate the two forms.

Maratsos and Abramovitch (1975) provide evidence suggesting that full passives are not acquired later than short passives. They compared children's comprehension of full and short passives in an act-out task and found that children performed equally well with each structure and in fact used features of the full passive as cues to its interpretation. They found that when the preposition by was missing, children interpreted these anomalous passive sentences as actives suggesting that they do in fact interpret full passive sentences as passives. Maratsos and Abramovitch (1975) suggest both that short passives are not acquired before full passives and that full passives are not interpreted by young children as short passives; rather, the two forms are acquired simultaneously.

In addition, Budwig $(1990,2001)$ observed that though the children in her sample of spontaneous speech produced more short passives, they also produced full passives from the earliest age (younger than three and a half). Marchman et al. (1991) also note that though young children produced more short passive descriptions of scenes than full passive descriptions, some children produced full passives at all ages, particularly when it was appropriate to name two arguments, that is, when two characters were shown in a scene. Crain and Fodor (1993) claim that the use of full passives is rarely uniquely felicitous in English and cite evidence showing that when the pragmatic context is controlled such that full passives are appropriate, three- and four-year-old children are more likely to produce full passives: Crain et al. (1987) (referenced in Crain \& Fodor (1993)) showed that when the pragmatic context made a full passive felicitous - because the patient was focussed (making it more likely that a passive would be produced) and more than one possible agent was present (requiring the correct agent to be identified) $-91 \%$ of their three- and four-year-old participants produced full passives. Their evidence suggests that children are remarkably aware of discourse constraints early on and capable of modifying their language to fit those constraints.

A number of studies of young children show that full passives appear alongside short passives. Furthermore, a number of the studies cited above found that the use of short passives actually increased rather than decreased with age (Slobin 1968, Harris \& Flora 1982) - if the short passive was a simpler form that children used as a stepping stone to the full passive form one might expect its use to decrease with age. The review of the data suggests that whilst children may be more likely to produce short passives, this may be related to other factors. The use of the full passive seems to be tied to pragmatic constraints: when it is important to name the agent of an action as well 
as the patient or to distinguish the agent from other possible agents, young children appropriately produce full passives (Crain et al. 1987). The input children receive is also likely to be a factor, since adult English contains many more short passives than full passives (Svartvik 1966). Children's predominant use of short passives may reflect both the input they hear and the nature of the English passive.

Many studies show that children find short passives easier to produce and comprehend than full passives. There is however little conclusive evidence that the two forms are acquired consecutively, the predominant use of short passives is more likely to be related to the input children receive or pragmatic factors. Further light may, I believe, be shed on this question of whether the two forms are related or not through syntactic priming experiments: priming occurs when an underlying representation is activated (e.g. Pickering \& Branigan 1998); if the two forms are in fact stored separately, for example as a full passive transitive verb structure and as an adjectival structure (Baldie 1976, Horgan 1978), short passives should not prime full passive responses from children. If however short passives are activated by the underlying full passive, they should prime full passive responses. This will be discussed further in the following chapter.

\subsection{Acquisition of Get-Passives and Be-Passives}

Another observation that has been made, though less widely studied, regarding children's early representation of the passive, is that get-passives (2.3a) tend to dominate be-passives (2.3b) in children's early comprehension and production of passives (Turner \& Rommetveit 1967a,b, Menyuk 1969, Harris \& Flora 1982, Crain \& Fodor 1993, Slobin 1994). There is less data available on this finding since many studies either subsume get- and be-passives into a single category or only examine be-passive data, treating get-passives as a colloquial or non-standard form.
a. The girl got chased by the dog
b. The girl was chased by the dog

There are a few studies, however, that have provided evidence in this area. Turner and Rommetveit (1967b) found evidence that get-passives may precede be-passives. They manipulated children's descriptions of pictures by focussing the participants' attention on a particular character through questions or by showing the child that part of the picture first. They found that the manipulations influenced the descriptions: chil- 
dren produced more passives when the patient was focussed and the younger children produced more get-passives than the older children. They also found that the task influenced the types of passives produced: the younger children produced more get-passives following a general patient-focussing question (e.g. "what is happening to the PATIENT") than when the question was in the form of a be-passive (e.g. "what is being done to the PATIENT") to which the children were more likely to respond with a be-passive. Although Turner and Rommetveit (1967b) attribute the children's choice of auxiliary to input, suggesting that children hear the 'colloquial' (sic) get-passive more frequently until the 'standard' (sic) be-passive form is emphasised through schooling, their results may be interpreted as suggesting that children's preferred, or even default, form early on is the get-passive: when no model was given but the patient was focussed (making a passive response appropriate), the youngest children tended to produce more get-passives responses; they only produced more be-passives when this precise form was modelled in the question.

Marchman et al. (1991) provide supporting evidence for a preference for get-passives, though not solely amongst the youngest participants: they found that all the children (ranging in age from three to eleven) in their study, which also elicited passive descriptions of transitive scenes using patient-focussing probes, were more likely to produce get-passives than be-passives compared to adults who produced more be-passives than get-passives. Between $80 \%$ and $100 \%$ of the three- to eight-year-olds' passives were get-passives, around $70 \%$ of the nine- to eleven-year-olds' passives were get-passives but just $8 \%$ of the adults' passives were get-passives. Marchman et al. (1991) analysed the children's use of get- and be-passives further and found that the former were more likely to be used to describe prototypically transitive scenes which involved a clear change of state (e.g. licking, hitting, biting) whereas the latter tended to be used for the non-prototypically transitive scenes (e.g. giving, throwing, crawling under). They propose that children's preference for get-passives for these scenes is related to get inherently involving a change of state in its other uses whereas be tends to encode states (Marchman et al. 1991, p. 88). It is not clear why adults ultimately settle on a preference for be-passives if this is the case, though it is possible that children use the semantic cues provided by the auxiliary get as a cue to the passive, before a general representation for the two forms is developed.

Budwig $(1990,2001)$ analysed corpora of children's spontaneous utterances and found that whilst both get-and be-passives were produced, more full passives were produced early on with get than with be. She also found evidence that children categorise the two types of passives differently: 65\% of their get-passives encoded negative consequences, compared to just $18 \%$ of be-passives, whereas $76 \%$ of their be-passives en- 
coded neutral consequences, compared to $26 \%$ of get-passives. She suggests therefore that get-passives differ to be-passives in that they tend to encode events in which the verb's object is negatively affected.

These factors (that get encodes negative consequences and changes in state) might explain why the children were more likely to use get-passives to describe certain pictures but they do not fully explain why children appear to use get-passives earlier. Harris and Flora (1982) found that four-and-a-half-year-old children in their study understood more get-passive sentences than be-passives; they were also better able to imitate get-passives than be-passives, and were much more likely to produce get-passives than be-passives (overall the children produced 423 get-passives compared to just 6 be-passives). They suggest that children may use the get auxiliary early on as a cue to distinguishing passive sentences from actives because it marks the patient role of the subject more clearly than $b e$ and therefore acts as a cue to processing passive sentences appropriately.

One line of explanation suggests that children acquire a syntactic representation that underlies both passive forms but use the get form more frequently because of the cues it provides: that the subject is the patient, it is (negatively) affected by the verb or is involved in a change in state. The get auxiliary could also provide a more salient clue to process the sentence as a passive since be is frequently used, as an auxiliary or copula, in other sentences but get is not so widely used. Children's more frequent use of get could also be related to the fact that the be auxiliary is more irregular: the child has to learn more forms to produce be auxiliaries (e.g. is, was, were, being), whereas get is more regular (get, got, getting).

Lee (1974), (referenced in Harris \& Flora (1982)) suggests an alternative hypothesis: get-passives are formed from predicate-adjective constructions as an intermediate construction before the verbal be-passive is acquired - in this theory, then, the early use of the get-passive is a stage in the construction or acquisition of an over-arching verbal passive structure. If it is the case that children first acquire a get-passive form which they later generalise to include be-passives, then this would predict that the two forms are not represented as structurally related initially. I propose that syntactic priming experiments can be used to show whether young children treat these passives as variations of the same structure or whether they treat them as distinct structures, i.e. predicate-adjectives (get-passives) and verbal passives (be-passives). If, at a young age, children use get-passives, formed as adjective phrases, as a way into the verbal passive then get-passives should not prime be-passive responses and vice-versa. If, however, children generate a passive structure that underlies both forms, regardless of their preference for one particular permutation of that structure, then both get- and 
be-passives should prime passive responses. Furthermore, if children have a preference for the get permutation of the passive structure early on then passive primes should elicit more get-passive responses from younger children.

As a final word of caution: these results are all based on studies carried out with children living in the United States; it is possible that a different pattern of usage may be predicted for children acquiring British English. Sussex (1982) suggests that getpassives are more frequent in North American English than British English; though Marchman et al. (1991) found that adults living in America tended to produce more bepassives (92\%) than get-passives and Collins (1996) suggests that the frequency of getpassives was comparable in corpora of North American English and British English, (although this was based on written data from 1961 - it's possible that more recent, spoken data would reveal different frequencies). If the nature of passives children experience from the input influences the form of passives they produce and comprehend earlier, this would explain American children's predominant use of get-passives. It would also suggest that children learning British English may not use get-passives as frequently. Meints (2003) elicited passives from children living in the United Kingdom by enacting scenes for them and asking "What happened to the PATIENT?". She found that they did not use get-passives as frequently as previous studies with children living in the United States: 91\% of children produced more be-passives than getpassives and only $5 \%$ of the children's passives were get-passives, which is not as frequently as might be predicted if children use the get as a cue to identifying passives. The studies carried out in this thesis might not show the same effects as studies with American children as British children may produce be-passives more frequently than get-passives. If, however, there is evidence that children learning British English do produce more get-passives this would suggest that children learning English, regardless of the variety, use get as a cue to the non-canonical structure of the passive.

\subsection{Acquisition of Actional and Non-Actional Verb Passives}

Children's use of get-passives before be-passives early on may be related to the semantic differences between the auxiliary: get-passives may clearly mark the patient role of the subject of passives and also how to interpret such sentences because they are typically used to encode events with negative consequences or an impact on the patient. Other studies have suggested that there is a semantic component to children's acquisition of passives: as noted in the Introduction, there is evidence that until as late as six or seven years of age, children do not reliably comprehend passives with nonactional verbs (2.4a), though they do understand actional verb passives (2.4b) before 
this age (Maratsos et al. 1985). Here the term actional is used to describe verbs, typically entailing physical action or contact and a result or change in state and typically involving agent and patient thematic roles, whereas non-actional refers to experiential, perceptual or mental state verbs typically involving experiencer and theme roles, in particular, verbs whose subject takes an experiencer role.
a. The girl was seen/loved/remembered by the boy
b. The girl was chased/hit/tickled by the boy

Maratsos et al. (1985) were the first to establish this effect which has since been replicated in numerous comprehension studies (Sudhalter \& Braine 1985, Gordon \& Chafetz 1990, Fox \& Grodzinsky 1998, Terzi \& Wexler 2002, Hirsch \& Wexler 2006b); some other studies suggest that young children are more likely to produce passives with actional verbs than with non-actional verbs (Pinker et al. 1987, Budwig 1990, Marchman et al. 1991, Budwig 2001). Different explanations have been proposed to account for this semantic effect, these are reviewed below.

\section{A-Chain Maturation Hypothesis}

Borer and Wexler (1987) suggest that children's division in comprehension of actional and non-actional passives is evidence for a maturation theory of language acquisition - in this case, the A-Chain maturation hypothesis. They suggest that certain grammatical principles appear only with maturation meaning that structures can only be acquired once the component parts are available to the language learner. Specifically, they suggest that children's ability to represent A-chains ${ }^{4}$ as grammatical is not acquired before the age of five, therefore children's ability to comprehend and produce passives (and other related sentences involving A-chains: unaccusatives, raising) is maturationally constrained. They claim that verbal passives (2.5a) are therefore analysed as adjectival passives (2.5b) early on, since the latter do not require A-chains but have the same surface form as (short) verbal passives. With this strategy children show comprehension of actional verbal passives which tend to involve participles that may be used adjectivally; however, they perform poorly with non-actional verbal passives (2.5c) since these do not make good adjectival passives (2.5d).
a. The vase $i$ was broken $t_{i}$ (by the girl)
b. The vase was broken (but still mendable)

\footnotetext{
${ }^{4}$ Object to subject chains, as, according to such linguistic theories, occur in passives, that allow argument movement of a verb's direct object from underlying object position to surface subject position, as indicated by the trace indexes in Example 2.5a.
} 
c. The $\operatorname{dog}_{i}$ was seen $t_{i}$ by the cat

d. $\quad *$ The dog was seen (but still happy)

Maturation theories should not be language specific, rather they should apply universally (since all children must start off with the same 'hardware' regardless of whatever language they are subsequently exposed to). Therefore cross-linguistically, no children should produce sentences requiring A-chains until the principle matures, which Borer and Wexler suggest is around the age of five. They support their A-chain maturational account with evidence from children acquiring Hebrew as a first language (Borer \& Wexler 1987). Terzi \& Wexler (2002) and Babyonyshev \& Brun (2003) also provide evidence in favour of this theory from Greek and Russian passive acquisition respectively and Babyonyshev, Ganger, Pesetsky \& Wexler (2001) put forward evidence from Russian unaccusatives for late A-chain maturation.

However, Pierce (1992) found mixed results in her study of Spanish-speaking children's acquisition of passives. She tested periphrastic passives (2.6a-b) in a picturesentence matching task and morphological passives $(2.6 \mathrm{c}-\mathrm{d})$ in a 'semi-imitation elicited production' task (participants heard a description of a picture and were then directed to describe a similar picture 'in the same way'). Both of these passives can appear with a pre-verbal subject (2.6a and 2.6c), which forms an A-chain with its trace in post-verbal position, or a post-verbal subject (2.6b and $2.6 \mathrm{~d})$, which is assigned nominative case without the formation of an A-chain.
a. Este libro $_{i}$ fue escrito $t_{i}$ en Mexico. this book was written in Mexico
'This book was written in Mexico.'
b. Fue escrito este libro en Mexico. was written this book in Mexico
'This book was written in Mexico.'
c. Este libro $i$ se escribo $t_{i}$ en Mexico. this book one wrote in Mexico 'This book was written in Mexico.'
d. Se escribo este libro en Mexico. one wrote this book in Mexico 'This book was written in Mexico.'

The maturation theory predicts that children should perform better with passives with post-verbal subjects, which do not require A-chains, than those with pre-verbal subjects, which do require A-chains. However, Pierce found that periphrastic passives 
with a post-verbal subject were not easier for three- to five-year-olds to comprehend (mean correct performance with these passives was 56.9\%) and that conversely - and contra the A-chain maturation hypothesis - the children performed significantly better with passives with pre-verbal subjects (mean correct performance with these passives was $63.9 \%$ ). For the morphological passives the results supported the prediction that pre-verbal subjects requiring A-chain formation would be more difficult for children than post-verbal subjects not requiring A-chains: children produced more correct passives with post-verbal subjects $(63.8 \%)$ than with pre-verbal subjects $(41.9 \%)$, although, these passives were tested in an elicited production test which makes it difficult to compare the results of the experiments with the two structures. Pierce's data does not reliably support the A-Chain maturation hypothesis. An alternative explanation is possible for these inconsistent results: they may be due to non-syntactic differences between the two constructions. The morphological passive is used frequently in spoken Spanish, whereas the periphrastic passive is a formal construction rarely used in speech. It is possible that Spanish-speaking children's varying performance is related to the amount of exposure to each structure that they have experienced: regardless of whether children can process A-chains, Spanish-speaking children may frequently hear morphological passives and therefore have no difficulty comprehending these; however they may rarely hear periphrastic passives and thus have some difficulty producing these.

There is further cross-linguistic evidence against this maturational theory from other languages (some non-Indo-European) in which children produce sentences, requiring A-chains, very early on (Pye \& Quixtan Poz 1988, Demuth 1989, 1990, Snyder, Hyams \& Crisma 1995, Allen \& Crago 1996). Demuth $(1989,1990)$ analysed both caregiver and child speech in the Sotho language Sesotho and found that children productively use verbal passives from before three years of age, which is much earlier than the age predicted by the maturation hypothesis. Similarly, Allen and Crago (1996) analysed spontaneous speech data from Inuit children acquiring Inuktitut and found that they produced passives more frequently, with greater complexity and from an earlier age (from around two to three years) than English-speaking children. Furthermore, Snyder et al. (1995) have shown that children acquiring French as a first language use other structures requiring A-chains earlier than predicted by the A-Chain maturation hypothesis. Such cross-linguistic evidence creates problems for maturational accounts which predict universal late acquisition. Though Wexler and his colleagues provide supporting evidence from Hebrew, Greek and Russian, conflicting data is also provided from French, Sesotho, Inuktitut and Kiche' Mayan, perhaps also for Spanish (periphrastic passives), undermining the universality of the maturational account. 
Finally, the A-Chain maturation hypothesis also predicts that children should not produce or comprehend full verbal passives before five years of age. As reviewed above, though short passives do seem to be prevalent amongst children's earliest passive utterances, there is evidence that children both comprehend (Maratsos \& Abramovitch 1975) and produce (Crain et al. 1987, Budwig 1990, 2001) full passives from before five years of age.

\section{Thematic-Role Transmission}

In the light of cross-linguistic evidence, the A-Chain maturation hypothesis is clearly not a satisfactory explanation for the semantic distinction found in children's comprehension of passives. Fox and Grodzinsky (1998) offer an alternative explanation (see also Fox, Grodzinsky \& Crain 1995). They argue that either maturational constraints or processing limitations prevent thematic-role transmission at a young age. That is, before five, children are unable to transmit a verb's agent thematic role to the external noun of the by-phrase and thus they are unable to properly process full passives. They tested children's comprehension of full actional passives and full and short nonactional passives in a task where children heard a story then heard a sentence (active or passive) describing that story which they had to judge as true or false. They found that overall, children correctly judged the truth value of all the active sentences, all the actional passives, most of the non-actional short passives (86.5\%) but less than half of the non-actional full passives (46.1\%).

Within the thirteen children they tested, they identify three groups of results: two children performed correctly on all sentences and eight children performed correctly on all but the non-actional full passives; the remaining three children performed poorly with non-actional short passives as well as full passives (Fox and Grodzinsky do not provide any statistical analyses for these groups nor for the group as a whole). Their account for children's difficulty with non-actional full passives in theirs and other studies is based on the performance of the group of eight children: they suggest that these eight children reliably understood short non-actional passives as these did not require thematic role transmission - there is no external noun phrase to transmit a thematic role to. They further propose that the children were able to show comprehension of full actional passives by assigning an agentive role to the external noun from the preposition by; finally, they suggest the children performed poorly on full passives with non-actional verbs since these verbs assign an experiencer role which is incompatible with the agent role the preposition by could assign.

Though such explanations appear to account for the actional - non-actional distinction in children's comprehension, Fox and Grodzinsky (1998) base their arguments on the results of just eight of the thirteen children tested, ignoring the results of two chil- 
dren who demonstrated adult-like performance and another three whose pattern of results did not fit their theory. Thus these results seem to provide a small, incomplete sample on which to base a theory. Another potential problem with the study is that they did not test short actional verb passives, these results do not allow for the possibility that children would not have understood as many short actional passives as full actional passives. Furthermore these results have not been replicated; in fact a recent attempt with more children and more items failed to reproduce these results (see Hirsch \& Wexler 2006b) and there is no evidence supporting the claim that children can use by to assign agentive thematic roles (Hirsch \& Wexler 2006a), which this theory assumes children do. Hirsch and Wexler (2006a) found no evidence in the CHILDES corpus (MacWhinney 2000) that children hear or produce agentive nominal by-phrases and even found in a comprehension test that children find agentive by-phrases (such as "the story by Minnie had Donald in it") difficult to understand. Therefore Hirsch and Wexler (2006a) found no evidence to support the theory that children are able to interpret full passives using the preposition by to assign an agentive role to the external noun phrase. Finally, they do not, as with the previous account, explain how children are able to produce full passives from a young age (though presumably the authors would argue that children use the same strategy in production as comprehension).

\section{Semantic Constraints to Acquisition}

The two accounts, discussed above, for the semantic distinction in children's comprehension of passives attribute this effect to syntactic constraints. A third line of explanation is that children's acquisition of the passive is semantically constrained (Maratsos et al. 1985). Unlike the previous two arguments, this theory does not suppose that some element of the passive structure (A-chains or thematic role transmission) is late acquired, rather that children restrict their generalisation of the structure to certain classes of verbs - actional verbs - early on. Maratsos et al. (1985) found in two comprehension experiments, one using a stimulus sentence-question task and the other using a picture-sentence matching task, that even the youngest children (fouryear-olds) performed competently with actional-verb passives (i.e. correctly answered the question or matched the sentence to a picture) but up until five to seven years of age, children still performed unreliably (around chance level) with non-actional-verb passives; only nine- and eleven-year-olds performed reliably with non-actional verb passives. They also examined corpus data for examples of adult passives and found that adult speech tended to contain passives with highly transitive verbs involving a result or change in state. They suggest that children's early passive knowledge is constrained to a semantic core of relatively high transitivity, such as verbs of result or change in state and that they spread their analysis of the productive range of the passive to less transitive verbs such as non-actional (i.e. mental state or experiential) 
verbs at a later age, hence the distinction in their comprehension of actional and nonactional verb passives early on. Note that this explanation for children's development of the passive is not incompatible with the idea that they first use get-passives, also frequently used with verbs of result or change in state (see section 2.4).

However, the actional verbs typically tested in such experiments, Maratsos et al. (1985) included, are often verbs of impact, (such as push, kick, kiss), not verbs of change in state, (such as break or fix). According to their hypothesis, therefore, one might expect children's earliest comprehension of passives to be limited to these change of state verbs before it is spread to include other actional, but less proto-typically transitive, verbs. Furthermore, Maratsos et al. (1985) found no examples of non-actional verb passives involving similar verbs to those that they tested in the adult speech data; studies of children's comprehension of actional vs. non-actional verbs have all tested subject-experiencer non-actional verbs such as see, love or remember whose grammatical subject is assigned an experiencer thematic role and whose object is a theme (see example 2.7a). The only type of non-actional verbs passivized by adults were objectexperiencer non-actional verbs: those that assign the experiencer thematic role to the grammatical object $(2.7 \mathrm{~b})^{5}$.
a. The $\operatorname{dog}_{[\text {experiencer }]}$ saw the cat $t_{\text {theme }]}$
b. The $\operatorname{dog}_{[\text {theme }]}$ scared the cat ${ }_{[\text {experiencer }]}$

This has interesting implications for the findings: the experiments that have shown this semantic distinction in children's comprehension of passives all tested subjectexperiencer non-actional verbs, such as like, remember, see, know, and all showed that children find these difficult to understand. Maratsos et al. (1985)'s study of adult passives shows that children tend not to hear these verbs passivized but do hear other non-actional verbs - object-experiencer verbs - such as surprise, scare, confuse, irritate, in the passive. Maratsos et al. (1985)'s corpus data is supported by experimental work showing that given a transitive verb and two arguments, adults are more likely to produce passives with object-experiencer verbs than with other verbs, including actional verbs (Ferreira 1994). Furthermore object-experiencer non-actional verbs tend to involve a change in state and therefore should, according to Maratsos et al. (1985)'s hypothesis, be in the scope of verbs to which the passive is early generalised. In sum, Maratsos et al. (1985)'s theory of semantic constraints makes further predictions about verbs which they did not test. That is, if children's early passives are restricted to verbs

\footnotetext{
${ }^{5}$ Note that here, and elsewhere in the thesis, subject-experiencer verbs will refer to those verbs whose subject in active sentences takes the experiencer role and object-experiencer verbs will refer to verbs whose object in active sentences takes the experiencer role.
} 
with agent-patient, not theme-experiencer thematic roles in general, then one could predict they would not comprehend object-experiencer passives. If however this semantic constraint is based on the input they hear or the semantics of the verbs, then one could predict early comprehension of object-experiencer verb passives, as well as actional verb passives.

Meints (1999) proposes a similar explanation; she suggests a prototypes theory to predict the course of children's acquisition of the passive, in which younger children's use of the passive will be based on 'prototypical' passives, such as the actional verb passives tested by Maratsos et al. (1985) and other similar studies (those which focus the patient, who is highly affected, and defocus the agent, who is highly affecting, and describe an event involving action, physical contact or a visible result). She suggests that only older children will use less prototypical passives, such as the subject-experiencer non-actional passives of previous studies. She tested two-, three- and four-year-old children's comprehension and elicited production of passives with verbs classified by degrees of prototypicality and found that correct responses increased with increased prototypicality and that the use of less prototypical passives increased with age. Meints (1999) does not provide details of her stimuli, that is, which verbs she classified and tested as giving highly and least prototypical passives, however the theory suggests that psychological non-actional verbs such as the object-experiencer verbs surprise, scare, confuse, irritate - could be classified as more prototypically transitive (they involve a highly affected patient and highly affecting agent and an event with a visible result) than subject-experiencer non-actional verbs (which are not highly affecting and do not involve physical contact, action or visible result). According to this approach then one might also expect subject-experiencer non-actional passives to be poorly comprehended by young children but one would expect object-experiencer non-actional passives to be understood.

These semantic accounts of children's restricted comprehension of passives appear to provide a better account of the data than the syntactic constraints accounts. These accounts also allow for the evidence that children comprehend and produce full passives as well as short passives and are even compatible with the suggestion that children's early passives may be get-passives.

\section{Usage-based Acquisition}

The theories discussed above emphasise syntactic constraints (maturation of A-chains or thematic role transmission) and semantic constraints as explanations for young children's difficulty comprehending non-actional verb passives. Another line of explanation emphasises the importance of the nature and frequency of passives in the input that children hear. For example, Gordon and Chafetz (1990) suggest a usage-based 
account for the finding that children comprehend non-actional passives later than actional: they suggest that children acquire the passive structure on an item-by-item basis according to the input they receive. Their analysis of child-directed speech revealed that adults' passives are more frequently actional than non-actional, they found $93 \%$ actional-verb compared to 7\% non-actional-verb passives in the input children hear. Such data however, as Gordon and Chafetz (1990) also admit, is not sufficient to rule out semantic class based accounts such as that proposed by Maratsos et al. (1985). Whilst their analysis of CHILDES transcripts could indicate that children learn the passive structure through early item-based actional verb passives, based on the input they receive, the data could also be interpreted as showing that children's early generalisation of the passive structure is restricted to the evidence they receive, as Maratsos et al. (1985) suggest; children may infer from the input that the passive can be used with actional class verbs and it may take them longer in the absence of evidence to generalise the passive to non-actional class verbs.

Therefore, Gordon and Chafetz (1990) also present experimental evidence from a study with children aged three and four, which compared children's comprehension of actional and non-actional verb passives at a first test and at a re-test a week later for evidence of consistency in their performance which could suggest item-based passive schemas. They presented children with a short story describing a picture, the story included an active sentence such as "John hated the peas", the test then reformulated this sentence as a question, active or passive, which the children had to answer. They found the same distinction in the children's comprehension of actional and nonactional verb passives as previous tests - children understood actional verb questions better (mean correct responses 67\%) than non-actional (mean correct responses 39\%); they also found a high consistency for both actional and non-actional verb comprehension scores (that is, they compared the number of verbs that showed the same score (correct or incorrect) in both tests). They suggest that this consistency in the results at test and re-test is due to the fact that children's comprehension of passives was based on item-specific representations formed from passives they have already heard.

The children in Gordon and Chafetz (1990)'s study ranged in age from three to five years, six months. One possible problem with this study is that it claims that children of this age still have item-specific knowledge of the passive; however, other studies carried out with children aged three, four and five suggest abstract knowledge of the passive by this age: syntactic priming studies which found priming effects between structures with different verbs suggest abstract knowledge of the passive from three years upwards (Shimpi et al. 2007, Bencini \& Valian 2008); see Chapter 3 for further discussion of these studies. If children acquired the passive according to the 
verbs they heard passivized they should only be primed to produce passives from the same verb passive but, at three and four years, they produce passives without repeated verbs between prime and target. Finally, as noted above, this study also tested subject-experiencer non-actional verbs rather than object-experiencer verbs. A usage-based account would predict that subject-experiencer non-actional verbs would be late understood in the passive given the lack of evidence for these in the input. It would also predict that object-experiencer non-actional verbs would be acquired earlier, given that adults do passivize these; however, like other previous studies, Gordon and Chafetz (1990) did not test these.

The accounts for the actional versus non-actional verb findings vary in their ability to explain all the available data on young children's comprehension and production of passives. The maturational and thematic-role transmission accounts predict that young children should not be able to comprehend or produce full passives; however, other studies show that children can indeed comprehend (Maratsos \& Abramovitch 1975) and produce (Crain et al. 1987) full passives as young three to four years of age. Gordon and Chafetz (1990)'s input-based account predicts that three- to five-year-old children's knowledge of the passive structure is verb-based which is contradicted by data from priming studies suggesting abstract knowledge of the structure as young as three (see Bencini \& Valian 2008, and Chapter 3 for further discussion). Semantic constraints accounts (e.g. Maratsos et al. 1985, Meints 2003) predict that young children should comprehend and produce actional-verb passives and possibly objectexperiencer verb passives; whilst this finding is not contradicted by results from production studies which tend to test only actional-verb passives, it has only been tested for in traditional comprehension tests assessing children's comprehension through their selection of a picture or their answering a question after hearing a test sentence.

Another question is whether this finding is not an artefact of the methods used to test children's comprehension of passives; this is discussed in the following section, however I again propose that syntactic priming experiments may be able to shed further light on this issue. If children's early syntactic representation for the passive is not generalised beyond actional verbs then only these should prime and be primed by passives. If, however, the results of these studies reveiwed above are related to the method of testing, and children's passive representation is not constrained to actional verbs, then passives with other verb types should prime and be primed by passives. 


\subsection{Task and Other Effects in Passive Acquisition Studies}

An important factor in child language acquisition studies is ensuring that the method for testing their state of knowledge does not interfere with children's ability to demonstrate their knowledge of language (Crain \& Fodor 1993). One possible explanation for children's poor performance on comprehension tests of non-actional verb passives may be that the task used to investigate this may favour their comprehension of actional verb passives but impede their understanding of non-actional-verb passives; in fact different methods of testing comprehension have shown variations in results.

Some studies, such as that carried out by Sudhalter and Braine (1985), use complicated tasks to test children's comprehension which may favour actional-verb passives over non-actional passives. Sudhalter and Braine (1985) obtained the actional - nonactional distinction in a task in which children heard an active or passive sentence describing an action of which two toys were the participants. These toys were placed in front of the children who were then asked to "pick up the animal which VERB-ed the other. Pick up the animal which VERB-ed" (Sudhalter \& Braine 1985, p. 464). These instructions may be more felicitious with actional verbs than non-actional, for example, compare "The owl was kicked by the cow. Pick up the animal which kicked the other, pick up the animal which kicked" with "The owl was seen / liked by the cow. Pick up the animal which saw / liked the other, pick up the animal which saw / liked" (a similar method - stimulus plus question - was also used by Gordon and Chafetz (1990)). 'Seeing' or 'liking' are not really actions that characters do or not do, as in the case of 'hitting': an owl that is being seen by a cow is also itself seeing, whereas an owl that is being kicked by a cow is not doing any kicking itself.

Maratsos et al. (1985, p. 171) found in piloting their experiment that questions such as "who liked whom/someone?" were more confusing than asking "who did it?". They used this latter question in their first experiment but still found overall lower accuracy scores (even with actional verbs: mean action passives understood $66 \%-67 \%$ ) than when a simpler, picture-sentence matching task was used in their second experiment (mean action passives understood $84 \%-91 \%$ ). This is perhaps not surprising: "who did it?" is a less felicitous question for a verb like like than a verb like hit. Beilin (1975) reports that the youngest children who took part in his study (four-year-olds) performed worse, even with active sentences, in a picture-sentence matching task $(73.8 \%$ active sentences correctly matched to pictures) than in an enactment task ( $84.5 \%$ active sentences correctly enacted). He attributes the difference in scores to difficulty created by "2-dimensional depiction of objects and the pictorial representation of action" (Beilin 1975, p. 45). These findings suggest that the task used may influence children's performance 
and the results obtained.

Other studies found the actional - non-actional distinction in children's comprehension of passives using the picture-sentence matching task (e.g. Maratsos et al. 1985, Hirsch \& Wexler 2006b) in which the child hears an active or passive description that matches one of two pictures they are shown. The pictures differ only in that the characters swap roles (see for example, Figure 2.1 where one pair of pictures shows a monkey hitting a builder and the other shows a builder hitting a monkey).
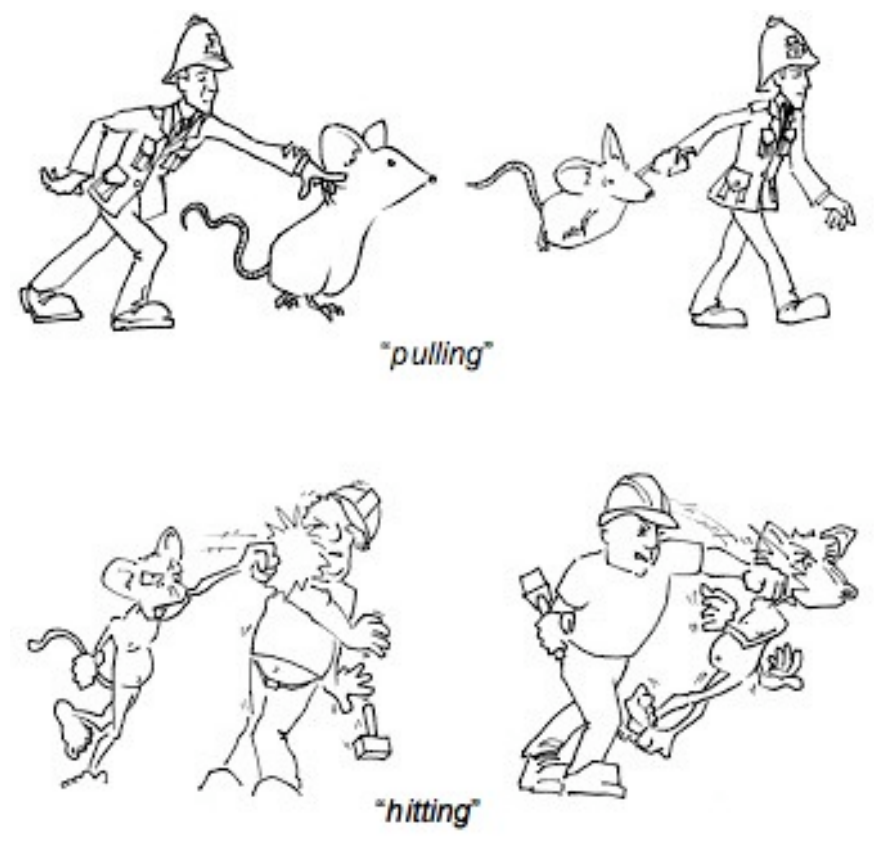

Figure 2.1: Examples of actional verb pictures

One possible problem associated with this method is that it necessarily requires reversible verbs which are harder for children to understand in the passive than nonreversible verbs (Harris 1976). It is also possible that with actional verb pictures, the distinction between agent and patient is more clear (consider the depiction of pulling and hitting in Figure 2.1), whereas with non-actional verbs the distinction between, for example, a see-er (the experiencer) and the seen (the theme), or the one who loves and the one who is loved (see Figure 2.2), is more difficult to depict. Therefore the difference observed in children's performance might, at least in part, be related to their visual interpretation of the pictures rather than a semantic constraint on their language. It may be that children find minimally different non-actional-verb pictures more difficult to interpret than non-actional-verb passive sentences. Clearly, this issue would benefit from testing with alternative methods to rule out the possibility that the task may be responsible for children's comprehension of actional-verb, but not non-actional-verb, passives. 

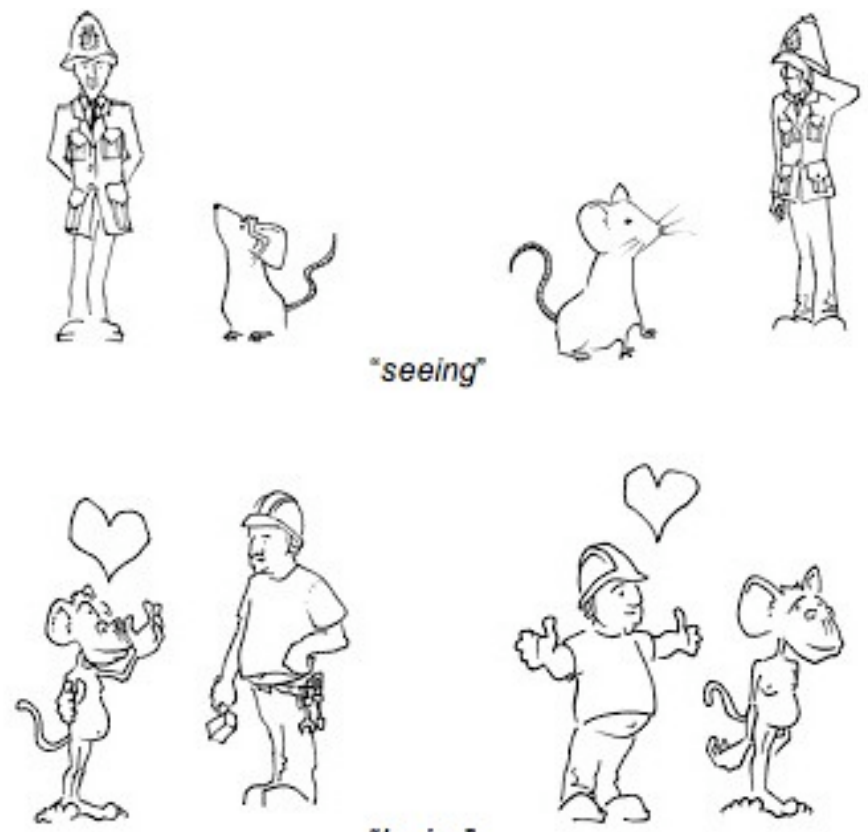

"loving"

Figure 2.2: Examples of non-actional verb pictures

For each area of findings on children's acquisition of the passive reviewed above there is a certain amount of conflicting evidence, I suggest that some of these discrepancies may be related to different methods of testing. For example, some studies suggest children use or acquire short passives before full passives; however, Crain et al. (1987) showed that when the pragmatic context made a full passive felicitous, $91 \%$ of their three- and four-year-old participants produced full passives. Their evidence shows that task design is important to properly test children's knowledge of language. A number of other studies have shown that not only are children more likely to demonstrate their knowledge of the passive successfully when a method which makes passives more appropriate is used, but they are also able to demonstrate sophisticated knowledge of the use of the passive to suit the pragmatic context from a young age. For example a number of studies asked children questions about visually-presented scenes that focussed or topicalised the grammatical object, for example, "what is happening/has happened to the PATIENT?" or "tell me about the PATIENT" (Harris \& Flora 1982, Marchman et al. 1991), and also, in some cases, emphasised the verb's object through presenting it first (Turner \& Rommetveit 1967b) or in bolder colours or larger size (Baldie 1976). These studies all showed that children were more likely to use passives when the grammatical object was emphasised; since the passive is one way in English to keep the grammatical object in focus by moving it to the beginning of a sen- 
tence, this was an appropriate way to respond to such a question. When asked similar questions that focussed the agent or grammatical subject, active responses were correspondingly more likely.

These studies illustrate that young children are more able to demonstrate their knowledge of the passive when the context is appropriate for passives. This suggests a sophisticated pragmatic knowledge of this structure, further suggesting that children's failure to use the passive in experimental contexts which do not control for discourse constraints may indicate a preference to respect discourse constraints rather than a lack of knowledge of the construction. These studies also provide evidence that even very young children are able to adapt their language to the pragmatic context of the discourse; in some studies the youngest children also used other non-passive constructions which place the verb's object in sentence subject position, such as unaccusatives (2.8a) (Harris \& Flora 1982), two clause constructions (2.8b) or cleft constructions (2.8c) (Marchman et al. 1991). That younger children (three-year-olds in Marchman et al.'s study and four-year-olds in Harris and Flora's) do not always use passives to maintain the grammatical object in subject position does however suggest that passives may be harder to use at a young age than other object-focussing constructions.
a. "John fell."
b. "The tiger is just sitting there and the bear licks him."
c. "It was the tiger that the bear licked."

Another factor which may impair children's performance in experiments is the prior frequency of exposure to the test items. Passives are notoriously rare in spoken English, particularly full passives (Brown 1973), giving children little exposure to reinforce either their knowledge of the construction or their efficient processing of the structure in an experiment task. Those studies which used methods which increased the number of passives the children heard tended to show better performance with younger children (Whitehurst, Ironsmith \& Goldfein 1974, Baker \& Nelson 1984, Brooks \& Tomasello 1999, Vasilyeva, Huttenlocher \& Waterfall 2006); it may be therefore that children perform better on passives when the input is artificially raised during the experiment because this increased exposure boosts their experience of the structure. For example, Baker and Nelson (1984) examined the effect of recasting or modelling passives on children's language acquisition; recasting involves the content of one interlocutor's utterance being reformulated and reproduced by another speaker, for example a statement, such as "I'm painting a bear!" might be recast as a 
question, as in "You've painted a bear, haven't you?". They found that both recasting and modelling increased the use of passives compared to a baseline assessment of the participants' language.

More recently, Vasilyeva et al. (2006) also found that children exposed to an input of story-reading sessions containing a high proportion of passives produced a higher proportion of passive sentences in post-test sessions. They also made fewer errors and showed better comprehension of the passive compared to their pre-exposure results and compared to those children exposed to an input of mostly active sentences. These studies show that manipulating the input to contain more passive exemplars than is generally found in English appears to boost children's use of this form, supporting the argument that children may acquire a syntactic representation for the passive much earlier than previously thought but require more experience of the construction to strengthen that representation and increase their use of the structure early on.

This is supported by data from Brooks and Tomasello (1999), who taught three year old children to use novel (or nonce) verbs in passive constructions. Brooks and Tomasello (1999) used elicitation questions to test three year old children's mastery of the passive following training sessions with novel verbs. They found that the proportion of children who productively used the passive tripled when they had received exposure to it in the training sessions compared to when no passive, only active, sentence training was given. This again suggests that increased exposure to the passive increases its use: whilst many were able to use the passive productively (i.e. following active training), the use of the passive increased three-fold when children received prior exposure to the passive form. Whitehurst et al. (1974) also found that four- and five-year-old children who heard passive models, produced more passives and understood passives significantly better than a control group who did not receive any models. The control group did not produce any passives when asked simply to describe pictures and did not perform as well on comprehension tests of passive sentences. This effect of increased use and better comprehension of a structure following modeling of that structure essentially reproduces the same effect as syntactic priming studies in which the experimenter models their own utterances in order to influence the successive structure produced by the participant. These experiments show that children who are exposed to models of the passive are more likely to comprehend and produce passive sentences than children who do not receive such modelling either in the experimental context or more generally. That they do this productively, as in Brooks and Tomasello (1999)'s study, suggests that they have already acquired the passive construction and that increased experience of the structure facilitates or boosts their own use of it. 
The studies discussed in this section show that these factors are interrelated - tasks, which are simpler to follow, that meet the discourse constraints which make passive responses appropriate or that increase the input of passives, allow children to demonstrate better knowledge of the passive at a younger age. Given some of the findings discussed above have been shown in only one style of experiment, such as the actional - non-actional verb effect, it is clear that further work employing alternative research methods is necessary in order to obtain more conclusive findings on these issues. As will be explained in the following chapter, this thesis examines these issues using a syntactic priming method which has the advantage of facilitating children's production of passives through increased exposure (Huttenlocher et al. 2004, Shimpi et al. 2007) as well as providing a means of testing younger children's underlying syntactic representations (Branigan et al. 1995).

\subsection{Summary}

In this chapter various issues arising from research into children's acquisition of the passive have been discussed. To summarise: The claim that children acquire the passive late on in their language acquisition is challenged by further research showing children can use the structure productively from a young age (around three years). The evidence suggests that children do not acquire a short passive form before the full passive, rather that their prevalent use of the short passive reflects input or discourse factors. Furthermore there is evidence to suggest that children prefer or first acquire the passive with get as the auxiliary rather than be, though it is not clear whether children treat these as two versions of the same structure or as separate structures. Finally a number of accounts for the semantic distinction in children's comprehension of passives have been reviewed, whilst some clearly fail to account for other available evidence, there is scope for further research in this area, for example, on whether children comprehend object-experiencer non-actional verb passives.

When this previous research is reviewed together an interesting picture emerges; there are some connections between the various findings that different researchers have concentrated on. Whilst it seems that the passive structure is acquired earlier than previously assumed, the other findings reviewed suggest that children's mastery of this construction may be protracted. Children may find get-passives and actional-verb passives easier to understand, as these factors act as cues to the passive, and therefore form an initial representation for the passive which centres around these versions. When processing passive sentences children must learn to interpret the subject of the sentence as the verb's object and the use of the get auxiliary or verbs involving clear 
actions may make this more clear. As noted above, this area of children's language acquisition would profit from further research using a different experimental paradigm. In the following chapter I will review the syntactic priming literature and discuss how this paradigm may be applied to the investigation of the issues examined in this chapter. 


\section{Chapter 3}

\section{Syntactic Priming - A Review}

\subsection{Introduction}

Syntactic priming is the tendency by speakers to implicitly repeat the syntactic structure irrespective of the content (open-class) words of a previous utterance, when an alternative structure is possible (Bock 1986). For example, a speaker would be more likely to use a passive structure to describe an event after hearing or saying a passive than after hearing or saying an active sentence. Syntactic priming experiments involve eliciting the implicit repetition of a particular syntactic structure by a speaker through their immediately previous comprehension or production of that structure; these effects are typically more pervasive in production.

This paradigm derives from observations of conversations showing that speakers tend to repeat material in speech (Schenkein 1980, Levelt \& Kelter 1982, Weiner \& Labov 1983). For example, Schenkein (1980) reported a variety of instances of repeated features in recordings of natural dialogue, from single words (3.1) to inflectional and syntactic features (3.2) of previous utterances.

\section{Speaker A: What happens if you are sighted?}

Speaker B: I should think I've got a good chance of not being sighted.

Speaker A: You've got to hear and witness it to realise how bad it is.

Speaker B: You have got to experience exactly the same position as me, mate, to understand how I feel.

Further research into these repetition effects lead to the development of the syntactic priming experimental paradigm which, as will be explained below, has proved a use- 
ful method for investigating speakers' syntactic representations involved in language processing. In this chapter I will review the history of syntactic priming and the theory behind its application to the study of speakers' syntactic representations. I will then review the syntactic priming work that has been carried out with children to date and explain how the present thesis aims to build on previous research.

\subsection{Early Syntactic Priming Studies}

Levelt and Kelter (1982) carried out an experimental analysis of what they termed the 'correspondence effect': the tendency for speakers to repeat earlier material, such as single words, whole clauses or sentence structures, across utterances. Through a series of experiments on question-answer situations they showed that speakers were more likely to use a single word - a preposition - in their answer to a question that contained that word, in both natural conditions (telephoning shops) and test conditions. For example, when asked (in Dutch) "At what time does this shop close", speakers were more likely to reply "At five o'clock" rather than "Five o'clock", compared to when they were asked the question "What time does this shop close?". They present this as evidence that speakers tend to repeat single words (rather than syntactic structures) from prior utterances, although, as Bock (1986) points out their results may be interpreted as syntactic priming of prepositional phrases rather than lexical priming of just a preposition.

Another early study that found evidence of syntactic repetition was a multivariate analysis of active and passive agentless clauses by Weiner and Labov (1983). They examined the effect of sociolinguistic factors (age, gender, ethnicity, class) and linguistic factors (given vs. new information, parallel structure) on the likelihood of a speaker producing an agentless passive clause (i.e. a short passive) rather than an agentless active clause. The factor that best predicted the use of a passive clause was in fact the occurrence of a preceding passive sentence in the dialogue; their subjects were most likely to produce an agentless passive when they had effectively been syntactically primed to in the prior discourse. Other linguistic factors such as givenness of the logical object and parallel structure - where the logical object/sentence subject of the passive clause appeared in subject position of preceding clauses - had lesser effects on the likelihood of a passive clause being used, whilst none of the sociolinguistic factors had a significant effect on the choice of syntactic structure. The authors conclude that "the choice of agentless passive is conditioned by syntactic considerations" (Weiner \& Labov 1983, p. 54); that is, they find syntactic priming of short passives in adults' spontaneous speech. 
These two studies provide evidence that speakers tend to repeat structural material across natural dialogue; Bock (1986) provided the first experimental work specifically on syntactic priming. She implemented a procedure for eliciting primed utterances from participants in a task designed to mask the linguistic manipulations. She presented her participants aurally with one of two alternative dative or transitive prime structures, which they repeated, and then asked them to describe a picture depicting the same sort of event as they had just heard (dative or transitive). The participants were told that these actions - i.e. the priming manipulations of repeating descriptions and describing pictures - were to act as memory aids to a picture-recognition memory task. The prime structures that the participants heard were prepositional (3.3a) and double object (3.3b) datives and active (3.4a) and passive (3.4b) transitives.
a. The secretary is baking a cake for her boss.
b. The secretary is baking her boss a cake.
a. One of the fans punched the referee.
b. The referee was punched by one of the fans.

Bock found that the structure of the second sentence the subjects produced (their picture description) was strongly influenced by the structure of the sentence they had heard and repeated: they were more likely to describe their picture using a prepositional dative if the prime sentence was a prepositional dative than when it was a double object dative. The same effect was found with passive and active primes: passive descriptions increased in frequency following passive primes compared to active primes.

Further research by Bock and her colleagues (Bock 1989, Bock \& Loebell 1990, Bock et al. 1992) suggests that this repetition effect is related to abstract syntactic information rather than repetition of lexical items or of thematic roles or metrical, rhythmic or other superficial similarities between sentences. For example Bock (1989) found that closed-class words do not influence the likelihood of a primed structure being produced: she compared to- (3.5a) and for-prepositional (3.5b) dative primes and found that both were equally likely to prime the production of a to-prepositional dative sentence; Bock concludes that syntactic repetition is not caused by repetition of lexical items, rather the effect is due to more abstract syntactic frames or skeletons.
a. A cheerleader offered a seat to her friend.
b. A cheerleader saved a seat for her friend. 

a. The construction worker ${ }_{[p a t i e n t]}$ was hit by the bulldozer $[$ agent $]$.
b. The construction worker ${ }_{[a g e n t]}$ was digging by the bulldozer $[$ locative] .

Bock and Loebell (1990) examined whether information - thematic, metrical or superficial sentence features - could be responsible for syntactic priming. They found that sentences with different thematic roles but the same phrase structures (i.e. NP VP PP), such as passives (3.6a) and locatives (3.6b) had equivalent priming effects on transitive targets: passive descriptions were equally likely following passive and locative primes compared to active primes.

They also showed that these findings were not related to similar surface features of sentences such as the sentence rhythm or the position or phonological similarity of closed-class words by comparing the priming effect of prepositional datives (3.7a) and infinitives (3.7b) on dative targets. Prepositional dative target responses were more likely after prepositional dative primes than after infinitive or double object dative targets, despite the fact that on the surface, both contained to in a similar position. This suggests that the priming effect could not be interpreted in terms of these superficial features but was related to abstract syntactic features of the prime.
a. Susan brought a book to Stella.
b. Susan brought a book to study.

Bock and her colleagues interpreted these results in terms of the procedures that control the creation of syntactic forms: the prior production of a form - when the participants repeated the prime in the experiments - raises the level of activation of these procedures or rules which increases the likelihood of the procedures being applied again and that form being repeated in subsequent production, when the participants described the target picture (Bock 1986, 1989, Bock \& Loebell 1990).

\subsection{Syntactic Priming and Abstract Syntactic Representations}

Others however have claimed that the locus of priming is not at the level of producing the utterance but in fact at the level of syntactic representation. Branigan et al. (1995) suggested that the linguistic processes involved in language comprehension and production both draw upon a common level of syntactic representations at which the priming effect occurs. They argued that the syntactic priming paradigm can be used to investigate the mental representation of linguistic knowledge since it is precisely 
this that is being tapped into or manipulated. A number of syntactic priming studies (e.g. Pickering \& Branigan 1998, Branigan, Pickering \& Cleland 2000) have supported this theory with evidence of priming a speaker's production of a structure from that person's comprehension of the structure (i.e. without the speaker producing the prime themselves).

For example, Branigan et al. (2000) employed a novel priming experimental method, termed 'confederate-scripting' in which two participants alternately described pictures to each other in a picture sorting task. One participant was a naïve experiment participant, the other was a confederate of the experimenter who read their descriptions from a pre-determined script; these scripted descriptions acted as a primes for the naïve participant's subsequent description of their own picture. Branigan et al. (2000) found that participants tended to reproduce the structure of the prime description in their own description, for example, for trials involving different verbs in the prime and target, $26 \%$ more of their utterances repeated the prime structure than did not. These findings rule out theories based on priming of the processes of production since comprehension and production rely on different cognitive procedures leaving syntactic representations as the only common factor for the priming effect.

Understanding how syntactic priming may be informative of a speaker's syntactic representations requires examining how such information may be stored and accessed within the language production system. Models of language production typically posit a two-stage system based on sequential levels of functional and positional processing, preceded by the message level at which the concepts are stored and followed by the phonological encoding level at which the message is turned into sounds for production. In this system of language production, once the lexical concepts are selected, in the form of lemmas carrying grammatical information such as form class, the first stage of syntactic processing (functional processing) assigns grammatical functions, such as subject or object, to the lemmas and the second stage (positional processing) sets the order of the utterance (see e.g. Bock \& Levelt 1994). This model of two-stage processing is supported by evidence from speech errors and psycholinguistic experiments (see Ferreira \& Engelhardt 2006, for a review).

Pickering and Branigan (1998) propose an extension to the lemma level of this model (see Figure 3.1) suggesting that further syntactic information for the lemma, other than the category or class information, is encoded in a system of linked nodes. They hypothesise that syntactic features such as tense, aspect, number, case, gender are also encoded and linked to each lemma, as is the combinatorial information specifying the possible constructions a lemma can appear in. Importantly, each featural, categorical or combinatorial node is linked to each lemma that it corresponds to and both the 
nodes and links for a given lemma become activated when a sentence is processed.

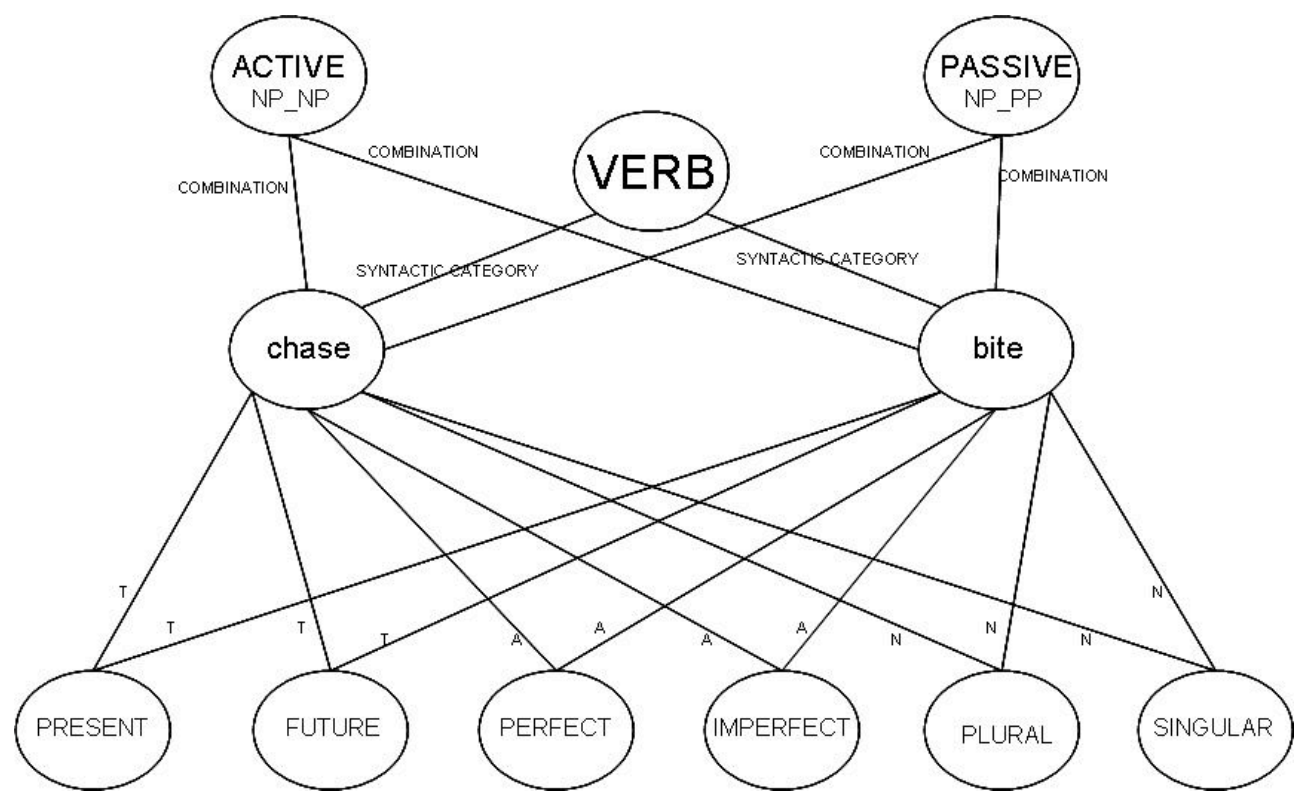

Figure 3.1: Representation of syntactic information at the lemma level (adapted from Pickering \& Branigan (1998)). T = tense, $\mathrm{A}=$ aspect, $\mathrm{N}=$ number

To illustrate: it is assumed that if a person hears a passive phrase such as " $a$ dog was chased by a cat", then the concepts and therefore the lemmas for dog, chase and cat would be activated as well as the noun and verb categorical nodes, the nodes representing past tense, perfective aspect and singular number and the nodes representing the combinatorial information for the passive transitive. If they then need to describe a picture of, for example, a cat biting a dog they could use either structure represented by the combinatorial nodes active, " $a$ cat bit a dog", and passive, "a dog was bitten by a $c a t^{\prime \prime}$, but would be more likely to produce the latter than if they had not recently heard a passive phrase, since the combinatorial node for that structure has been recently activated. If they had to describe another picture involving chasing, (for example, a boy chasing a girl) the repetition of the first structure would be even more likely according to this model: this time the residual activation of the verb chase's lemma node as well as the combinatorial node and the links between the two would make the system more likely to re-select the structure of the sentence just processed (passive: a dog was chased by a cat) and repeat it in the production of the second sentence (thus: a girl was chased by a boy).

Pickering and Branigan (1998) argue that priming takes place within the system due to residual activation of particular nodes and strengthening of the links between them: when a sentence is processed and its lemmas and combinatorial node become activated they, and the link between them, may retain residual activation between utter- 
ances that boosts the likelihood of the same syntactic structure being selected in a subsequent utterance. Pickering and Branigan (1998) support their account with evidence from a series of written priming studies examining (prepositional object and double object) dative structures. Participants read sentence fragments and completed them; prime fragments contained a subject, verb and post-verbal noun phrase such that they led the participant to complete the fragment as either prepositional object or double object datives ${ }^{1}$. Target fragments, which followed the prime fragment, contained just a subject and verb such that the participant was free to complete it with either dative structure. Pickering and Branigan (1998) found that participants completed more target fragments with the same dative structure as the prime than with the alternative dative structure. Furthermore, they showed stronger priming of datives when the verb was repeated between prime and target, which suggests that activation of the link between the verb and its combinatorial feature is important and can be primed. They also found that the priming effect persisted between primes and targets with different verbs, which supports their argument that combinatorial information is shared between lemmas. Finally they found that the priming effect was not affected by repeated tense or aspect features, which suggests that featural information is contained in separate nodes and that the combinatorial information links directly, therefore, to unspecified lemmas.

Pickering and Branigan's (1998) account of priming is called a 'transient-activation' account: priming is related to transient activation of representations which make the re-selection of a structure for production more likely. Others suggest an alternative mechanism for priming: 'implicit learning' accounts in which priming is related to longer-term changes within the language production system (see e.g. Bock \& Griffin 2000, Chang, Dell, Bock \& Griffin 2000, Ferreira \& Bock 2006). Repeated exposure to the same structure increases the weight of that particular process of encoding of a message within the system making its use more likely, not just immediately but in the long term; this learning within the system of producing structures is termed 'implicit' because it occurs unconsciously. Evidence for this account comes from studies which show that a priming effect persists beyond an immediate repetition effect and when a number of other trials intervene between the prime and target utterance (e.g. Bock \& Griffin 2000). Since transient activation accounts only predict immediate or short-term repetition, these results suggest that exposure to a prime led to longer term changes in the system. Savage et al. (2006) found a long-term priming effect for four-year-old children: they carried out a priming experiment in which children heard and repeated

\footnotetext{
${ }^{1}$ That is, the post-verbal noun was either the verb's direct object, which should induce prepositional object completions - The racing driver showed the torn overall. . . to the mechanic) - or its indirect object, which should induce double object completions - The racing driver showed the helpful mechanic...(the overall).
} 
primes before describing their own pictures. Savage et al. (2006) tested children's description of the target pictures again, a month later (half the children also re-described the target pictures one week after the priming experiment). They found that children who had the one week reinforcement session used more passives to describe the target pictures a month after the priming experiment than control participants or those who did not receive the reinforcement. They suggest therefore that exposure to the primes in the original session had a long-term, implicit learning effect within the children's production system. Nonetheless, they did also find stronger immediate priming effects in the original test session which suggests that despite this potential long-term learning, there is also short-term priming, presumably related to transient activation of their syntactic representations.

These accounts for priming - transient activation and implicit learning - are not necessarily mutually exclusive and can account for different aspects of priming. Implicit learning accounts cannot explain the stronger priming effect when the verb of the prime is repeated in the target, though they do provide an explanation for the longer-term priming effects observed. It is not implausible that immediate priming can occur at the representation level, whilst this exposure to and repeated production of a structure has the long-term effect of also causing changes in the grammatical encoding system. In this thesis priming is used as a method for examining children's developing syntactic representations. If children have a syntactic representation, for example, which underlies their comprehension and production of passives, then priming should occur for passives. That is, hearing a passive should lead to activation of this syntactic representation (if it has been formed) which should make children more likely to produce passives than if they have heard an active. It is possible to investigate the nature of this representation - whether it is restricted to certain forms (short or full passives, get or be passives) or classes of verbs (actional verbs or object-experiencer verbs) - by examining whether priming occurs when the type of prime is varied. If children can comprehend these different forms of passives one would predict that they would produce more passives, than if they have heard active primes; if they cannot comprehend these different forms of passives one would predict that they would not produce more passives. The following section discusses the evidence for priming with children. 


\subsection{Syntactic Priming and Children's Syntactic Representa- tions}

Over the past twenty years syntactic priming research with adult participants has shown robust priming effects for noun phrases (Cleland \& Pickering 2003), active and passive transitives (Bock 1986, Bock \& Loebell 1990, Bock et al. 1992) and double object and prepositional datives (Bock 1986, 1989, Bock \& Loebell 1990, Pickering \& Branigan 1998) in written experiments (Pickering \& Branigan 1998), production to production experiments (Bock 1986) and dialogue experiments (Branigan et al. 2000, Cleland \& Pickering 2003). Given the occurrence of priming between comprehension and production in these latter experiments it has since been proposed that priming taps into a shared level of linguistic representation, as discussed in section 3.3, and can therefore be informative about speakers' syntactic representations: by examining the conditions under which priming occurs it is possible make hypotheses about the nature of the representations underlying this effect. Consequently, other researchers have used this paradigm to investigate the syntactic representations of speakers other than native, adult speakers such as aphasia patients (Hartsuiker \& Kolk 1998), second language learners and bilinguals (Hartsuiker, Pickering \& Veltkamp 2004, Flett 2006) and children (e.g. Branigan, McLean \& Jones 2005, Thothathiri \& Snedeker 2008, Bencini \& Valian 2008).

For example, Hartsuiker and Kolk (1998) investigated reasons for the simplified syntactic structure of Broca's aphasia patients' speech. They used syntactic priming to examine whether increased exposure to complex structures would alleviate hypothesised processing limitations; by increasing the activation of a structure through priming they investigated whether Broca's aphasics were facilitated to produce the same structure. They found that Broca's aphasics were unlikely to produce passives and datives in their spontaneous speech but did produce these complex structures following priming. Moreover, they showed stronger priming effects than the control adult group. They interpret their results as showing that priming increases the availability of a syntactic structure automatically - they found no evidence that aphasics could consciously repeat the structure when instructed to do so - and facilitates grammatical processing.

In a similar vein, priming has also been used to study children's syntactic representations. In the case of the passive structure this seems particularly appropriate since, as discussed in the previous chapter, it is generally considered a harder structure for children to understand or produce and it is rare in spoken English. If children have difficulty producing or comprehending this structure early on but nonetheless have 
begun to acquire it - have some form of a passive representation - then priming should, if it does indeed facilitate the processing of complex structures, be an appropriate method to show children's underlying syntactic knowledge. If they do not acquire a representation of the structure until they are older, due to its complexity or due to item-based learning for instance, then priming effects should not be observed in younger children given different verbs in the prime and target items. Note that the model of linked combinatorial verbs and lexical items does predict priming of itembased representations given the opportunity to produce the same verb in the target as in the prime. Likewise, if children's early knowledge of the passive is restricted to short passives, get-passives or actional verb passives, as previous research suggests, then only these forms should prime passive targets. If however they acquire a general passive structure that underlies these forms, then syntactic priming should facilitate their production of the less preferred forms - full passives or be-passives for instance.

There have been a number of studies to date investigating children's syntactic representations through priming which have replicated syntactic repetition effects found with adults: Branigan et al. (2005) showed that English-speaking children have acquired syntactic representations for noun phrases that can be primed from children aged three and four and Thothathiri and Snedeker (2008) found priming effects for prepositional and double object dative structures with three-year-olds. To date, there have also been a few priming experiments that have tested children's acquisition of the passive (Whitehurst et al. 1974, Savage et al. 2003, Huttenlocher et al. 2004, Savage et al. 2006, Shimpi et al. 2007, Bencini \& Valian 2008); these will be reviewed below.

Whitehurst et al. (1974) carried out an early study that used a method essentially the same as syntactic priming. They showed children a picture and described it (with a passive or active sentence), they then showed the children another picture and asked them to describe it; they called children's repetition of the abstract structure but not the content of the first sentence 'selective imitation through modelling'. They found that modelling passives to four- and five-year-old children led to their production of this construction and significantly better comprehension compared to a control group who did not receive any models and did not produce any passives when asked simply to describe pictures.

More recently Savage, Lieven, Theakston and Tomasello (2003) tested three-, four- and six-year-old children's production of active and passive sentences to assess the abstractness of their syntactic representations. The experimenter and children described cartoons of transitive actions taking place; Savage et al. (2003) compared responses to prime sentences that had a high lexical overlap (the subject and object of the sentence were described using the same pronoun, for example "it is pushing it") with responses 
to primes that had a low lexical overlap (the subject and object of the sentence were described using full noun phrases (and different lexical items) such as "the digger pushed the bricks"). The subjects received each type of prime, active and passive, in separate blocks on separate days, that is, on one day the children would be primed only by active sentences, on another day, at least a week later, they heard only passive sentences.

Savage et al. (2003) reported a syntactic priming effect for the noun phrase of the prime sentences, that is, for the alternation between nouns and pronouns. The children were more likely to use a full noun phrase rather than just a pronoun after hearing a prime containing full noun phrases (the low lexical overlap condition) and they were more likely to use pronouns in the high lexical overlap condition, when the priming phrase contained only pronouns. Their results for the verb phrase priming were, however, less consistent. The verb phrase priming effect was restricted to the older children: the six-year-olds produced more passives in the low lexical overlap condition, as well as the high overlap condition, whereas the three- and four-year-old children only showed priming effects for either active or passive phrases in the high lexical overlap condition. Savage et al. (2003) concluded therefore that while six-year-olds may have generalised abstract syntactic representations for transitive sentences, three- and four-year-olds only have lexical, item-specific representations for syntactic constructions (this would however be very late for the active if not the passive).

However, the authors do not explain how lexical overlap of the noun phrases would constitute item-specific representations for the transitive structures: for this one would expect to see evidence of a priming effect only when the verb was repeated between prime and target. An effect of priming only from the same verb in the prime and target would provide strong evidence that children's early syntactic representations for the passive are item-based; however, it is not clear how repeated lexical items in the noun phrase would induce priming of either an active or passive form in the verb phrase and would therefore constitute item-based priming. The fact that the researchers did find a distinction for high and low overlap sentences may be due to the fact that reducing the noun phrase to a simple pronoun eased the processing and therefore facilitated production of a passive sentence for the younger children.

Savage et al. (2006) found evidence suggesting that abstract syntactic representations emerge between four and five years of age: they found that children who heard passive primes tended to describe target pictures with passives involving different verbs. Huttenlocher et al. (2004) also found that four- and five-year-old children who heard passive prime utterances were more likely to produce passive utterances, in the absence of repeated lexical items in the prime and target sentences, than children who heard active prime utterances. That a priming effect was consistently found from 
prime sentence to target sentence allowed Huttenlocher et al. (2004) to conclude that the children were primed by the syntactic structure, rather than the lexical items themselves, and therefore that they have abstract syntactic representations by the age of four. Other studies showed that younger children who heard passive primes were more likely to produce passives than children who heard active primes: Shimpi et al. (2007) replicated Huttenlocher et al.'s (2004) experiments with younger children and produced priming effects with three- and four-year-olds. Bencini and Valian (2008) also carried out a priming experiment with three-year-olds and observed significant priming effects for passives in the absence of repeated lexical items. These data suggest that children acquire an abstract syntactic representation for the passive by three years.

Both Savage et al. (2003) and Huttenlocher et al. (2004) compared priming when the participants repeated the prime structure before describing the target picture and when they did not; both found that this did not affect the priming effect. Like adults, children are primed after just comprehending a structure; they do not require to also produce it, as Savage et al. (2003, p. 564) also conclude: "the priming observed in the first study does indeed involve children's linguistic representations, not simply peripheral production mechanisms". This suggests, importantly, that as with adults, priming can be used to investigate their syntactic representations activated by comprehending and producing structures. Furthermore Huttenlocher et al. (2004) measured the children's spontaneous use of the primed structures prior to the experiments and found that the use of passive sentences was highly infrequent and restricted in the children's spontaneous language. That these forms were produced during the course of the priming experiment suggests that syntactic priming is indeed an effective way of tapping into a child's abstract syntactic knowledge for rare and complex structures, as Huttenlocher et al. (2004, p. 192) concluded: "children may demonstrate the use of an abstract form in a priming study even when that form is not fully available for on-line use". Similarly to Hartsuiker and Kolk's (1998) findings with aphasic patients, these results seem to suggest that children may be particularly facilitated by priming: residual activation of their syntactic representations through comprehending a priming sentence facilitates their accessing this information when they need to produce a sentence expressing the same concept; prior exposure to a syntactic form would appear to facilitate their production of rarely used structures.

The results from priming studies with children generally suggest that children acquire a syntactic representation for the passive by around three years and they show that syntactic priming is a useful tool for investigating and eliciting more difficult structures from younger children. Previous studies of priming with children have 
not examined whether the observed priming effects could be influenced by superficial features of the prime, such as phonological similarity or the position of words in the sentence, or whether they could be related to repeated thematic features or repeated function words. Though studies with adults exclude these explanations for the priming effects it is not necessarily the case that children's language comprehension and production is the same.

Furthermore, none of the previous priming studies with children have investigated the effect of different semantic classes of verbs that have been shown to have an effect on children's performance with the passive in other studies. Nor have they systematically compared priming from be- and get-passives or short passives. It is possible that younger children's representations for the passive are restricted to verbs with certain semantic properties and would therefore not be primed by verbs not sharing those properties. Also if children acquire get-passives or short passives as separate forms, different to a verbal passive, these forms would not prime passive responses as found in previous studies. The syntactic priming experiments detailed in the following chapters investigate these issues.

\subsection{Syntactic Priming Method}

Previous priming studies with children have treated 'prime' as a between-participants factor: participants experienced either active or passive primes (Huttenlocher et al. 2004, Shimpi et al. 2007, Bencini \& Valian 2008). These previous studies then measured whether participants who heard, for example, passive primes were more likely to produce passives, than participants who heard active primes. With this method, there is a risk that individual differences would confound the results because participants are not tested in all conditions. This is particularly important in studies with children who may be at different stages of language development. Furthermore, the strength of the priming effect in previous experiments could be inflated because it is measured from children's production of a structure after they heard only that structure. In the experiments reported in this thesis, 'prime' was treated as a within-participants factor such that all participants experienced all priming conditions; these experiments measured whether the participants could vary the structure of their response in line with variations in the prime structure throughout the experiment.

Most of the experiments reported in these previous studies also use a method similar to Bock (1986) in which participants repeat the prime before describing the target picture. Though previous experiments have shown equivalent priming effects 
from comprehension-to-production priming as from production-to-production priming with adults (e.g. Bock, Dell, Chang \& Onishi 2007) and with children (Huttenlocher et al. 2004, Savage et al. 2003), a potential disadvantage of this method is that if participants fail to repeat the prime correctly, which may be more likely with children participants, the trial will be lost. Branigan et al. (2005) also demonstrated that children's comprehension of a single prime was sufficient to reliably elicit primed targets.

The method used in the experiments reported here is based on the experiment design of Branigan et al. (2005), which is a confederate-scripted method, adapted from Branigan et al. (2000) to be suitable for children participants. Branigan et al. (2005)'s method involves the experimenter and participants playing a game of 'Snap' and describing their picture cards. Snap is a children's game in which two players each have a set of picture cards that are placed face-down in front of them. They take it in turns to turn over their top card to reveal its picture - when each player reveals the same picture on their cards it is the first player to shout "snap" who wins all the cards in play. The game continues until one player has won all the cards. In the experiment the only variations to the game were that the players described their picture as they turned it over, before a 'snap' judgement was made, and the game ended when all cards had been turned over once. In each priming experiment, the experimenter's descriptions of her cards were, unknown to the participant, primes for their subsequent description of their own card, that is, the experimenter acted as the confederate and used a script to describe her 'snap' cards with the appropriate prime. The next picture the participant turned over and described was therefore the target item, and their description the target response.

There are a number of advantages to this method: unlike other child priming experiments, the children do not have to repeat the prime sentence themselves before producing their target, therefore target utterances are not lost because the participant fails to repeat the prime (e.g. Bencini \& Valian 2008). Furthermore, it is less test-like for the children and more effective for the purpose of the game not to have to repeat the prime. A game was used to mask the priming and to make the task easy and more appealing to children. The experimental items are interspersed with filler items that form matching pairs - Snap items - that preserve the guise of a game, which helps to ensure the children's continued co-operation throughout the experiment. It was also hoped to elicit more natural language behaviour from the children; though the task itself demands a very restricted scope of linguistic structures, the language is elicited in a less experiment-like environment, the children are not under pressure to provide 'correct' answers and are in fact taking part in a fairly naturalistic task - playing a game and talking about pictures. 
The materials for the experiments in this thesis did not involve repetition of verbs (or nouns) between the primes and targets. Though this has been shown to increase the priming effect (Pickering \& Branigan 1998), in studying children's language acquisition this would leave open the possibility that the priming effect reflected itembased representations not abstract syntactic representations (e.g. Savage et al. 2003, Tomasello 2000). In order to show that priming reflects abstract syntactic representations, there is no repetition of lexical items across the primes and targets.

As yet, there has been no real consensus over how child priming studies should be analysed. Adult studies usually exclude any non-target utterances and examine the proportions of target utterances and alternative structure utterances - in the case of transitives, the passive might be the target utterance, the active would be the alternative structure. Priming is measured as the difference between the proportion of target utterances following the target prime and the proportion of target utterances following the alternative prime. Some child priming studies calculate the priming effect in the same manner, others calculate priming as the proportion of target utterances from the sum of target utterances, alternative structure utterances and 'other' responses. The potential advantages and disadvantages of these two methods are discussed and compared further in the following chapter.

\subsection{Summary}

This chapter reviews the syntactic priming literature: previous research has shown that speakers tend to repeat material - lexical items and syntactic structures - across utterances. Priming studies show that speakers' use of a structure can be influenced by recent exposure to sentences with similar syntactic structures but not to phonetically similar sentences or sentences with similar surface word order or function words. Furthermore this repetition of structure in speakers' language production occurs following participants' comprehension of the structure, it does not require their prior production. Thus priming can be used to investigate speakers' syntactic representations which are common to comprehension and production processes. More recently this paradigm has been used to test children's syntactic representations. With regards to the passive, experiments have generally shown that three-, four- and five-year-old children are more likely to produce passive descriptions following passive primes than following active primes, suggesting, since this syntactic repetition occurred in the absence of repeated lexical items, that children have indeed acquired an abstract representation for the passive at three. None of the studies with children have used syntactic priming to address some of the issues from previous research on children's 
acquisition of the passive; the following chapters present priming experiments which aim to replicate and extend both the priming literature as well as the language acquisition literature. 


\section{Chapter 4}

\section{Children's Use of Passives Before and After Priming}

\subsection{Introduction}

Language acquisition researchers have often assumed that the passive structure is acquired late in English: a number of studies show that young children find passives harder to understand than actives (Fraser et al. 1963, Lovell \& Dixon 1967, Turner \& Rommetveit 1967a, Bever 1970, Baldie 1976, de Villiers \& de Villiers 1978, Fox \& Grodzinsky 1998) and that they are more likely to produce active sentences than passive sentences (Menyuk 1963, Beilin 1975, Budwig 1990, Marchman et al. 1991, Budwig 2001). However, passives are rarely used in spoken English: adults produce very few passives in their spontaneous speech (Svartvik 1966, Brown 1973, Gordon \& Chafetz 1990). This suggests that children may continue to perform poorly with passive until later in their language development because they have relatively little experience with the structure, not because they acquire the passive structure late. Evidence from other studies supports this suggestion: some studies show that when the discourse context is manipulated to make the use of the passive felicitous, three- and four-yearold children do produce passives (Crain et al. 1987, Marchman et al. 1991) suggesting that they have acquired this structure by this age. Other studies show that when the level of passives children hear is artificially raised, for example through recasting or modelling, children comprehend passives better (compared to control groups) and produce more passives (Turner \& Rommetveit 1967b, Whitehurst et al. 1974, Baker \& Nelson 1984, Tomasello et al. 1998, Brooks \& Tomasello 1999, Vasilyeva et al. 2006).

More recently, some researchers have employed the syntactic priming paradigm to 
study children's early syntactic representations (Savage et al. 2003, Huttenlocher et al. 2004, Savage et al. 2006, Shimpi et al. 2007, Bencini \& Valian 2008). This method has the advantage of raising the level of passives children hear, facilitating their production of this structure. Furthermore, adult priming studies have shown that this is an appropriate method for studying speaker's syntactic representations: priming occurs between comprehension and production of a structure, suggesting that the locus of the priming effect is a speaker's syntactic representations (Branigan et al. 1995, Pickering \& Branigan 1998). Studying priming with children can therefore be informative of the syntactic representations they have developed by a given age (McClure et al. 2006, Huttenlocher et al. 2004, Shimpi et al. 2007, Bencini \& Valian 2008). Thus priming can be used to study, for example, whether children have acquired a syntactic representation for the passive by the age of three or four, by examining whether three- and four-year-old children are primed to produce passives.

As discussed in Chapter 3 there are a few studies which have shown reliable priming of passives with children of this age (Huttenlocher et al. 2004, Shimpi et al. 2007, Bencini \& Valian 2008) which provide further evidence supporting the suggestion that the passive structure is acquired earlier than previously thought. These studies all employed a method in which prime structure was manipulated as a between-participants factor; that is, these studies measured how participants described pictures after hearing either active or passive primes. One potential problem of these experiments is that they may be confounded by individual differences between participants as they only experience one of the experimental conditions. Furthermore it measures their use of a structure after exposure to only that structure; the strong priming effects typically observed in these studies may be related to a cumulative priming effect. The present experiment examined whether a single exemplar was sufficient to activate children's syntactic representations and induce priming. This experiment therefore examines whether previously demonstrated strong priming effects were simply the result of intensive exposure to a single structure or whether children can, at this age, alternate their production of transitive structures following single primes. In doing so this experiment extends previous research by examining priming of passives from a single exposure to the structure and adds to the body of evidence which suggests that by four years of age, children have, earlier than previously thought, a syntactic representation for the passive.

This chapter also examines and discusses how child priming studies should be analysed. Adult priming studies normally examine priming as the increase in the production of a structure following the same structure prime compared to following primes of the alternative structure (for example, passives following passive and active primes) 
(Bock 1986). Child priming studies however have tended to examine the production of the target structure relative to all the utterances children produce in the experiment (e.g. Huttenlocher et al. 2004). This chapter discusses the advantages and disadvantages of these two methods for analysing children's results and examines the results that both analyses yield when applied to the same priming data in order to determine an appropriate method for analysing future child priming experiments.

\subsubsection{Aims of Experiment One}

The aim of this experiment was three-fold. Firstly this experiment aimed to establish whether priming occurs when the prime structure is manipulated as a withinparticipants factor with three- and four-year-old children: it examined whether young children are able to alternate the structure of their descriptions in line with alternations in the structure of the prime and whether the priming effect is of a similar magnitude as found in between-participants priming experiments. To verify that the children did not need to hear a build-up of passive examples before they produced passives, the number of passives produced at the beginning was compared to the number produced at the end of the experiment. If the observed priming effects reflect implicit learning during the experiment, one would predict more passives to be produced at the end of the experiment. Furthermore, unlike previous child priming studies, a group of adult participants also completed the experiment using the same method, providing a control against which to compare the children's performance.

Secondly this experiment was a means for piloting the materials and methodology for future experiments. The method used is based on Branigan et al. (2005): participants played a variation of the children's game 'Snap', in which the experimenter and the child alternated turning over and describing picture cards, looking for identical pictures. Previously, this has been used successfully to show priming of noun phrases but has not been used to test priming of verb phrases. This experiment aimed to establish that the card game method worked when the children were required to produce descriptions of transitive events.

The third aim of the study presented in this chapter was to examine children's baseline use of active and passive descriptions before the priming manipulations and their subsequent use of these sentence structures during the priming task. As noted above, children rarely produce passives in spontaneous speech and this has been taken as evidence that the passive structure is acquired late, although other studies suggest that when the number of passives children hear is raised, this boosts the number of passives that they produce. A free picture description task tested this to establish 
children's choice of sentence structure to describe transitive events without priming. This was then compared to their use of sentence structures to describe the same types of pictures following priming to see whether the same children were more or less likely to produce passives in the different tasks.

\subsubsection{Predictions for Experiment One}

The pre-test was included to record what structures participants used to describe pictures when there was no other influence on their language production. Shimpi et al. (2007) showed that passive structures were rare in children's un-primed speech and studies of children's spontaneous speech also support this finding (e.g. Budwig 1990). It was predicted therefore that children would tend to produce active sentence descriptions of the pictures in the pre-priming, free picture description task and would be unlikely to produce passive sentence descriptions, indeed if they produced any at all. However, this prediction is not to be interpreted as suggesting that children of this age cannot produce passives, rather it would show that English-speaking children, like adults, tend to use active sentences ${ }^{1}$ and that passives are rare when there is no contextual reason, such as the patient being the focus of the utterance, to promote their use. That is, the pre-test establishes their baseline preferences for sentence structures: what sentences they do produce, not what sentences they can produce. Thus it was also predicted that the adult participants would be unlikely to produce passives in the pre-test.

If it is the case that by three to four years of age children have formed (or at least begun to form) a representation for the passive, it was predicted that children would produce passive descriptions when they took part in the priming task, for the same types of pictures as they had described in the pre-test. Therefore, despite the rarity of passives in spontaneous speech, it was predicted that children would produce passives following passive primes.

Finally it was predicted that the children would show stronger priming effects than has typically been found for adults in previous priming studies. For actives and passives, the priming effects tend to be quite small in adult experiments (e.g. $8 \%$ increase in passives following passive primes compared to active primes (Bock 1986)) compared to studies with children (14\% to 33\% increase depending on the method of scoring and analysing (Bencini \& Valian 2008)). This increase in the magnitude of priming is predicted in line with other studies showing stronger priming effects in non-proficient populations, such as aphasic patients (Hartsuiker \& Kolk 1998) and

\footnotetext{
${ }^{1}$ Active is considered the canonical voice in (spoken) English (Greenbaum \& Quirk 1990)
} 
non-native speakers (Flett 2006), compared to the magnitude of priming typically observed in priming studies with unimpaired, native adult speakers (e.g. Bock 1986). These results were, however, obtained in different studies, therefore comparison is limited; here both children and adults participate in the experiment so that direct comparison is possible.

\subsection{Pre-Test}

\subsubsection{Method}

\section{Participants}

Eight children (two girls) from an Edinburgh nursery took part. They were aged between 3;5 and 4;6 (mean age 4;0). Eight adults (all female) also participated in the experiment as controls (mean age 18.9 years). All participants spoke English as their first and only language, and none were reported to have any language or developmental difficulties.

\section{Materials}

The pre-test materials (see Appendix A.1 for a full list) were based on the materials for the Experiment 1 priming task (see section 4.3 .1 below for a complete description of the priming experiment items). The materials consisted of the twelve monotransitive verbs (chase, hug, kick, kiss, lick, pinch, punch, push, scratch, shake, tickle, wash) that were used for the target items of the priming experiment. These were depicted with different pairs of the 24 characters from the priming experiment to create the twelve target pictures for the pre-test. The twelve pictures (such as Figure 4.1) were printed onto A4 paper, coloured and inserted into plastic wallets, bound in a folder to create a picture book. Each participant received a randomized presentation order for the pictures.

\section{Procedure}

First the participant (children only) was shown individual pictures of each of the characters and asked to try to name them - this verified that the participants had the vocabulary for the characters used in the experiment and also provided a useful warmup exercise for the children. Then the participant was shown the picture book and asked to look at it with the experimenter and describe each picture. The only prompts given to the participant were neutral questions along the lines of "what's happening in this picture" to encourage the participants to describe the action taking place as well as the characters, without leading the participants to mention a particular character first and thus influence their sentence structure. The participants' descriptions were 


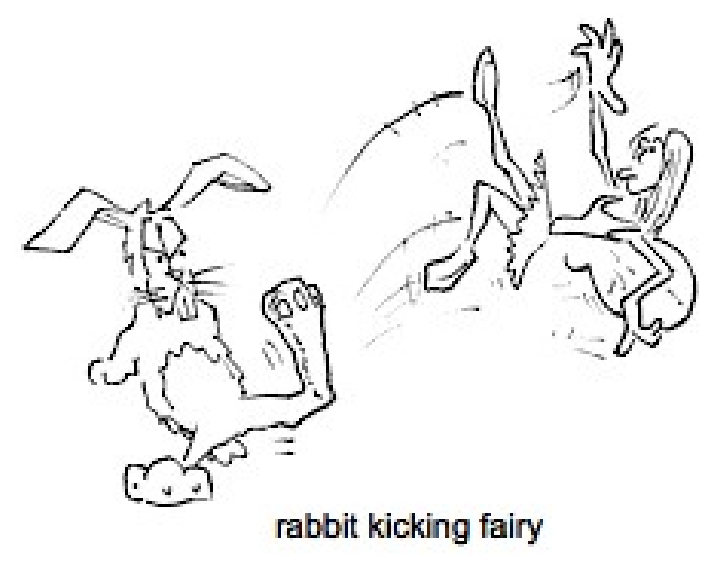

Figure 4.1: Pre-Test: Target picture of 'kicking'

audio-recorded on a Mini-Disc player and transcribed after the experiment; they were scored according to the criteria set out below.

\section{Scoring}

Responses containing a transitive verb phrase were coded for whether they were active or passive. Sentences were scored as Active if they contained an agent as the subject, a transitive verb and a patient expressed as the object (e.g. 4.1a); and as Passive if they contained a patient in subject position, a passive auxiliary ( $g e t$ or be) and past participle form of a transitive verb, followed by an agent expressed in a post-verbal prepositional phrase (e.g. 4.1b).
a. "a pig is soaking a girl"
b. "she's getting soaked by - what's that - a pig"
c. "the lion attacking -"
d. "he's running away"
e. "a cow and a boy"

The remaining descriptions were scored as Other: incomplete descriptions (4.1c), those containing an intransitive verb (4.1d) or which were simply noun phrases (4.1e).

\subsubsection{Pre-Test Results}

Table 4.1 shows how each group described the 96 pictures (twelve pictures $\mathrm{x}$ eight participants). One of the children's descriptions was lost due to a recording fault and 
one child did not describe one of the pictures.

Table 4.1: Pre-Test: Frequency of active, passive and other responses (\%)

\begin{tabular}{lrrrr}
\hline Response & \multicolumn{2}{c}{ Children } & \multicolumn{2}{c}{ Adults } \\
\hline \hline Active & 64 & $(67 \%)$ & 90 & $(94 \%)$ \\
Passive & 0 & $(0 \%)$ & 1 & $(1 \%)$ \\
Other & 30 & $(31 \%)$ & 5 & $(5 \%)$ \\
Unscored & 2 & $(2 \%)$ & 0 & $(0 \%)$ \\
\hline
\end{tabular}

The children produced between 5 and 12 active descriptions each $(M=8)$. They did not use any passive sentences to describe these pictures, nor could any of their Other responses be considered as passive-like utterances: they did not produce short or reversed passives. Their Other responses consisted of 15 non-transitive verb phrases, 9 noun phrase descriptions and 6 incomplete descriptions. The adults produced either 11 or 12 active descriptions each $(M=11.25)$. Only one adult produced one Passive; their 5 Other descriptions consisted of 3 other verb phrases, 1 noun phrase and 1 incomplete description.

\subsubsection{Pre-Test Discussion}

When the children were simply asked to describe depictions of transitive events, they never produced passive descriptions, rather they generally described these events with active sentences - $67 \%$ of their utterances - demonstrating a clear preference for active structures in spontaneous speech; this is mirrored in the adults' results. These results are very similar to a pre-test carried out by Shimpi et al. (2007) in which children described ten pictures of transitive events; they found that four-year-olds produced no passives and used active descriptions for $64 \%$ of the pictures (36\% of their utterances were scored as Other). Given that passives are generally rare in spoken English and that there were no discourse or pragmatic reasons to promote the use of the passive, it is unsurprising that neither children nor adults produced many (or, in the case of the children, any) passives. The same participants completed the priming experiment outlined below, in order to examine the effect of priming on their description of the same types of pictures.

On a methodological note, the pre-test also established that this type of picture would be suitable for eliciting target descriptions in the priming experiments: the descriptions that participants gave for the pictures in the pre-test demonstrate that these pictures are appropriate for eliciting transitive descriptions from both children $(67 \%$ of their descriptions) and adults (95\% of their descriptions). 


\subsection{Experiment One: Active Primes versus Passive Primes}

\subsubsection{Method}

\section{Design}

This experiment crossed Prime (active vs. passive) as a within-participants and -items factor, and Group (children vs. adults) as a between-participants but within-items factor. The active primes took the form: An AGENT is VERB-ing a PATIENT ${ }^{2}$. The passive primes took the form: A PATIENT is being VERB-ed by an AGENT ${ }^{3}$.

\section{Participants}

The participants were the same as those who completed the pre-test. The priming experiment took place approximately one week after the pre-test.

\section{Materials}

The materials consisted of a set of Snap cards created from 24 experimental (target and prime) items and eight filler items. Twelve actional transitive verbs were used twice each for the 24 target items: chase, hug, kick, kiss, lick, pinch, punch, push, scratch, shake, tickle, wash (see Appendix A.3 for a list of the target items); previous studies suggest that young children understand actional verbs better than non-actional verbs (e.g. Maratsos et al. 1985) and are more likely to produce passives with such verbs (e.g. Budwig 1990, 2001). Furthermore, where possible, the experiment items consisted of verbs that had been used in previous experiments of children's acquisition of the passive and - or that had a suitable age of acquisition rating for the children participating in the study (Morrison, Chappel \& Ellis 1997) to ensure that, as far as possible, the target items were appropriate to elicit target responses from the children.

Each target item was paired to an unrelated verb prime, avoiding any repetition of verbs between prime and target to ensure that any priming effect was related to abstract, not item-specific, syntactic representations (Tomasello 2000). Furthermore, to avoid, as much as possible, the possibility of the child repeating the prime verb in his or her target response, each of the six prime verbs was paired to semantically unrelated target verbs (Levin 1993); see example (4.2). The 24 prime items consisted of six different actional verbs, (bite, carry, hit, pat, pull, squash), used four times each (see Appendix A.2 for a full list of the primes).

\footnotetext{
${ }^{2}$ This choice of tense and aspect morphology is in line with the descriptions given by the children and adults in the pre-test which were mostly (91\% of the children's and $92 \%$ of the adults' verb phrases) present progressives.

${ }^{3}$ The one example of a passive produced in the pre-test was, like the active descriptions, also a present progressive. Meints (2003) suggests that children acquiring British English tend to produce more bepassives than get-passives therefore this should be an appropriate form of the prime to use.
} 
a. Prime: a bear is patting a girl/ a girl is being patted by a bear Target: tiger shaking doctor

b. Prime: a dog is patting a king/a king is being patted by a dog Target: elephant shaking witch

c. Prime: a cat is patting a witch/a witch is being patted by a cat Target: rabbit hugging girl

d. Prime: a rabbit is patting a soldier/a soldier is being patted by a rabbit Target: sheep hugging boy

Each pair of prime and target items was depicted with different agents and patients (see example (4.2) and Figure 4.2). There were twelve different animals (bear, cat, cow, dog, elephant, frog, horse, lion, pig, rabbit, sheep, tiger) and twelve different human characters (boy, clown, doctor, fairy, fireman, girl, king, nurse, queen, robber, soldier, witch) used four times each - twice in the targets and twice in the primes. These were the agents and patients of the prime and target items, chosen (where available) according to suitable age of acquisition ratings (Morrison et al. 1997). Animacy was controlled by having the same configuration in all primes and all targets; an animal character was always the agent of the prime and target sentences and a human character was always the patient ${ }^{4}$. There was no repetition or semantic relation in the pairings of prime and target nouns; target items never contained any of the same, or semantically related (e.g. king and queen), characters as the prime items.

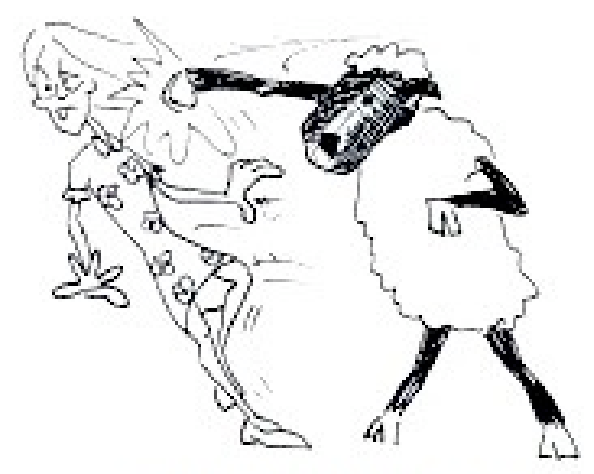

A sheep is hitting a girl A girl is being hit by a sheep

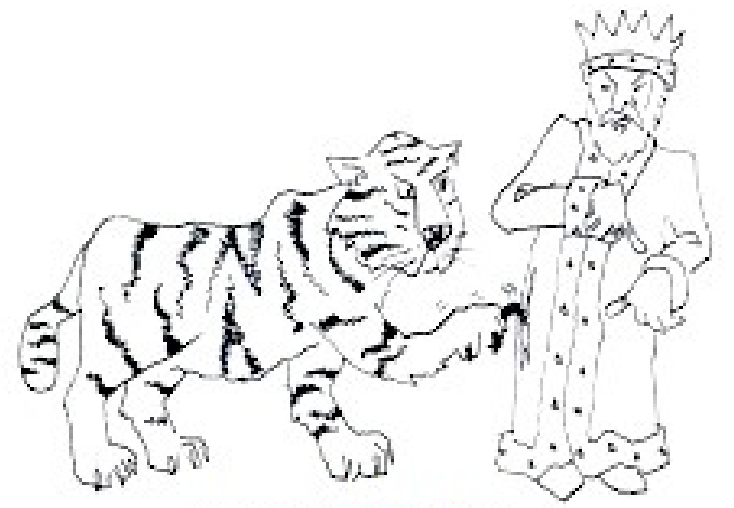

tiger scratching king

Figure 4.2: Experiment 1: Prime picture and a target item

\footnotetext{
${ }^{4}$ I used this arrangement to promote the speakers' production of passives given passives are so rare in speech. Speakers tend to prefer to mention the more animate entity first in an utterance; since human characters are more animate than animals, participants may be likely to produce the human patient first and therefore produce more passives (Harris 1978).
} 
A set of eight filler items formed the Snap cards of the game: the same verb and entities appeared in the prime and target, such that the same picture occurred in each player's set; these items were therefore excluded from the scoring. The Snap items consisted of four new verbs, each used once in the passive and once in the active (e.g. example 4.3, see also Appendix A.4). Eight of the animal and human characters used in the experiment items were randomly selected to be used for the filler items as well, again avoiding pairing any characters that had already been used together. The filler items were actives and passives to avoid creating items that were obviously different to the experiment items.
a. A cat is poking a queen
A clown is being poked by an frog
b. A dog is dropping a fairy
A robber is being dropped by a tiger

Finally there was a set of four practice items (Appendix A.5) using different verbs and nouns to the experiment and filler items, though they followed the same format: an animal agent carrying out a transitive event with a human patient. These practice items were used as a warm-up exercise to give the children a practice at playing the game whilst describing their pictures. The first two items were described by the experimenter with an active sentence, the third and fourth were described with a passive sentence so that the participant had heard both sentence types before the experiment began. The fourth item was a snap item to check the participants understood the game.

To create a set of Snap picture cards from these items, line drawings of the items were printed onto paper, these were coloured in bright colours (for continuity, the same colours were used for each picture of a given character) and laminated to create the playing cards. The prime and target pictures were counterbalanced such that half of the pictures had the agent depicted on the right, and half had the agent pictured on the left, of the picture. Then two sets of the experiment and filler items were created such that across the two sets each target occurred once in each of the priming conditions and, within a set, an even number of the targets (twelve) occurred in each priming condition. Four randomized experiment lists were created from each of the sets according to which the playing cards were organised prior to the experiment, this ensured that the prime and target cards would be turned over in the correct order. During the experiment, the experimenter used the randomized lists covertly as a priming script to ensure that she gave the correct prime for each card without the participant knowing it was read from a pre-determined list. 


\section{Procedure}

The experiment began with a practice session: again, by way of a warm-up, the participants were shown the individual pictures of each of the characters and asked to try to name them. Then they played a very short game of Snap with the practice items: each player alternated turning over and describing the pictures before deciding whether or not they constituted a Snap with the previous card. This preliminary session introduced the participant to the materials and the task: if the participant understood and was able to complete both parts of the practice session then they played the full game using the experiment materials.

The experimenter placed the pre-arranged playing cards face-down in front of the players (the experimenter and the participant): the target items were placed in front of the participant and the experiment items were placed in front of the experimenter. The experimenter began each game by turning over the card on the top of her pile, placing it face-up between the two players and describing it according to the script this constituted the prime. The participant then took their first card, placed it face-up between the two players and described it - this constituted the target response. Each prime and subsequent response constituted an individual experiment trial; priming is therefore measured on a trial-by-trial basis depending on whether or not the participant repeats the syntactic structure he heard in the prime in his immediately following response description. When two cards had the same picture the first person to shout "snap!" would win the cards; the game continued until all the cards had been turned over and described once.

The experiment game was recorded on a Mini-Disc player and the participants' responses were transcribed after the experiment (no record of the responses was kept manually during the experiment since the task was too quick to allow this). I scored the data according to three different sets of criteria - Strict, Lenient, Inclusive - outlined below ${ }^{5}$. I then analysed the results for each scoring, Strict (4.3.4), Lenient (4.3.5) and Inclusive (4.3.6), using two methods of analysis: the 'All Responses' method, which analysed the passive responses as proportions of all the participants' utterances in each condition, and the 'Alternating Responses' method, which analysed the passive responses as proportions of just the alternative transitive responses. The following sections set out the details of these scorings (Section 4.3.2) and analyses (Section 4.3.3).

\footnotetext{
${ }^{5}$ The scoring criteria set out here are used for all subsequent priming experiments; to avoid later repetition, the full scoring criteria that encompass all responses produced across all experiments are laid out here. Therefore some of the types of Other responses listed here were produced in later experiments not by the children taking part in the first experiment.
} 


\subsubsection{Scoring Criteria}

The three sets of scoring criteria were each increasingly lenient: the first, Strict, scored utterances that were complete, full transitives only, i.e. those containing a subject and an object ${ }^{6}$. The second, Lenient, scored some incomplete but otherwise correct utterances as Active or Passive as these might reflect the structure the child first selected following the prime even if they did not manage to complete the utterance; the children's difficulty completing the utterance might be related to general language processing difficulties and therefore these incomplete utterances might also reflect a priming effect. The third criteria set, Inclusive, scored complete and incomplete, correct and incorrect descriptions as Active or Passive to examine whether the pattern of results changed when any utterances that the child produced were scored if part of or a complete transitive. This scoring checked whether the children were being primed more frequently or differently than suggested by their complete, correct utterances. This also scored responses such as reversed passives as target responses, where the children produced the constituent structure of the prime but did not map the appropriate arguments to the structure. A number of studies of children's passives show that young children frequently produce these (Hayhurst 1967, Turner \& Rommetveit 1967a, Horgan 1978), this scoring examines whether these frequently occur following primes which might indicate a split in the children's language processing between syntactic structure and semantic mappings.

\section{Strict Scoring Criteria}

Responses were coded as either complete or incomplete utterances; only complete utterances, those containing a transitive verb with a subject and object, were counted in the Strict scoring. Utterances were scored as incomplete if the participant began a sentence but either gave up or changed it part-way through and, crucially, where there was enough material in the initial utterance to judge what the structure of the sentence was going to be. For example, if they produced a subject and a verb that was active (4.4a) before changing or stopping, or if they produced a subject and passive auxiliary (and passive participle) (4.4b), these utterances were coded as incomplete utterances, regardless of whether or not the participant then produced a correct, full description, since it was clear that they had started to produce one of the target structures.

\section{a. "er a pig lick-"}

\footnotetext{
${ }^{6}$ Note that these criteria are stricter than most previous child priming studies which score short passives (without an agent expressed) and short actives (without a patient expressed) as Passive and Active respectively, not as Other, as in this scoring. The Lenient scoring (see 4.3.5) used in this thesis is closer to previous priming experiments.
} 


$$
\begin{aligned}
& \text { b. "a girl being hug-is he hugging him or scratching him?" } \\
& \text { c. "elephant is - a witch being picked up by a elephant" } \\
& \text { d. "a lion - a bear is pinching a fireman" } \\
& \text { "a horse pull-er kicking the fireman" }
\end{aligned}
$$

If however the participant produced just a noun, or a noun and just the aspect auxiliary (such as the is in $4.4 \mathrm{c}$ which could occur in a present progressive active or passive) and then re-started their response, the initial utterance was disregarded as it did not contain enough material to be judged as the beginning of either an active or a passive. In this case, the second part of the utterance was scored, for example, in the case of example 4.4c, as a complete passive. If the participant changed a lexical item, the verb or a noun, halfway through the sentence, but did not change the structure (4.4d) then the sentence was coded as a complete utterance.

The complete responses were coded as Active or Passive only if they contained a monotransitive verb. The pictures were designed to elicit monotransitive verb utterances, in concordance with previous priming experiments which have tended to study active and passive monotransitive sentences separately to ditransitives (e.g. Bock 1986, Huttenlocher et al. 2004). The children sometimes produced active sentences with ditransitive verbs (4.5a) but they never passivized ditransitive verbs, though ditransitives may be passivized. Throughout the passive acquisition literature, studies uniformly examine monotransitive verb passives and as such it is not clear whether children learn to passivize ditransitive verbs simultaneously to or later than monotransitives. For these reasons, the few ditransitive responses produced in these experiments are coded as Other and not scored as Active or Passive.
a. "an elephant giving the robber a shower"
b. "a soldier's running from a horse"
c. "a horse is chasing after a huntsman"
d. "a man is being ribbited by a frog"7

Occasionally the children produced an utterance containing a subject and an intransitive verb with the second character in the picture described in a post-verbal prepositional phrase (4.5b). These utterances were coded as Other: though they share surface similarities with transitives, they do not share syntactic similarities and as such, these

\footnotetext{
${ }^{7}$ This was a description of a picture of a frog kissing a doctor: the child presumably interpreted it as a frog making a noise - 'ribbiting' — which had an effect on the doctor.
} 
intransitive utterances should not be the result of priming from transitive primes, even though they contained a subject, verb and post-verbal noun phrase. However, the children also sometimes produced sentences containing a transitive prepositional verb (e.g. chase after, pick up, push over); these utterances were coded as Active or Passive (4.5c). In addition, children's productive verbs (4.5d) were accepted (these were very rare).

A further check for the scoring was that the response must be possible in the alternative structure. An active sentence could only be scored as Active if it could be paraphrased by a passive sentence and vice versa for passive responses: (4.6a) was scored as Passive since it is possible to paraphrase it with an active (4.6b), whereas (4.6c) and other responses like it were not scored as Active since the passive alternative (4.6d) is not possible in English.
a. "a fairy that's being licked by a pig"
b. Active alternative: a pig that's licking a fairy
c. "a pig is trying to eat the fairy"
d. Passive alternative: $*$ the fairy is being tried to be eaten by a pig

The participant's first complete target utterance for a given item was scored as either Active or Passive; incomplete or anomalous utterances were scored as Other (see below). Responses were scored as Active if the utterance contained an agent in subject position, an appropriate verb and a patient in direct object position (4.7a). Minor errors, such as the participant omitting the aspect auxiliary $(4.7 \mathrm{~b})$ or making a morphological error with the main verb were disregarded since it was considered that these did not reflect the selection of a different underlying structure.
a. "a horse is hitting a fireman"
b. "and a pig $ø$ eating a fairy"

Responses were scored as Passive if the utterance contained a patient in sentencesubject position, a passive auxiliary (either get or be), an appropriate verb and an agent expressed in a by-phrase (4.8a). Again, the participants' morphological errors $(4.8 \mathrm{~b})$ and omissions of the aspect auxiliary (4.8c) were disregarded.

\footnotetext{
a. "a queen is being kissed by a sheep"

"a king is getting licked by a cow"
} 

b. " "a soldier's being holded by a bear"
"a girl's been huggen by a rabbit"
c. "a witch øeing grabbed by a elephant"

All other descriptions were scored as Other: incomplete utterances as described above $(4.4 a-b)$, reversed passives $(4.9 a)$ or actives $(4.9 b)$, where the participant produced a sentence with the argument roles reversed; short passives, where the participant omitted to produce a by-phrase (4.9c); and any utterances that were syntactically correct but not a monotransitive verb phrase (4.9d), such as ditransitives, intransitives or conjunctions.
a. "a cow's being licked by a king" to describe a picture of a cow licking a king
b. " "and a man carrying a sheep" to describe a picture of a sheep hugging a man
c. 'a robber being watered"
d. "a bear is putting water on a clown"
e. "and he's pinching him"
f. " "a doctor scratching a nurse's suit"

In addition, actives and passives which contained two pronominal noun phrases for the arguments (4.9e) were scored as Other since these were ambiguous. Inappropriate descriptions of the arguments (4.9f), such as a human character for both agent and patient, were also scored as Other since it was not clear whether the participant had got confused or changed utterance part way through these sentences. Descriptions containing one full noun phrase and one pronominal noun phrase for the arguments were scored as either Active or Passive if otherwise correct, as were those in which the child made a vocabulary error such as describing a tiger as a lion or a king as a queen.

The scoring criteria are summarised in Table 4.2 below: this shows the criteria used to code the participants' utterances, example utterances for each criterium and in which scoring (Strict, Lenient and/or Inclusive) the utterances were coded as a target response.

\section{Lenient Scoring Criteria}

The data were scored a second time according to slightly more lenient criteria: in this scoring some incomplete utterances were included in the active or passive scoring, if they were the beginning of a syntactically and thematically correct utterance, that is, actives beginning with an agent and passives beginning with a patient. 
The participants' first complete utterance for an item was scored as either Active or Passive as per the Strict scoring criteria. In addition, targets were scored if they had, minimally, a patient in subject position, a passive auxiliary and a matrix verb and, optionally, an agent expressed in a prepositional phrase, i.e. not necessarily a byphrase (4.10a). This meant that short passives (4.9c) were included in this scoring of the data as well as full passives.

\section{a. "This is a king being annoyed from a cow"}

Incomplete utterances were included in the active/passive scoring where there was enough material to judge that the child had started to produce an active or passive: incomplete utterances were scored as Active if the child produced a subject and verb in the active voice (4.4a) and Passive if the child produced a patient and at least a passive auxiliary or a passive auxiliary and main verb $(4.4 \mathrm{~b})$ before restarting or changing their sentence. These were included as they reflect the underlying structure that the participant first selected after the prime. Some children produced incomplete utterances that would have resulted in a reversed passive had the sentence been completed, that is, where they used the agent in subject position but produced a passive verb phrase (4.11a); these incomplete utterances were still scored as Other.

$$
\text { a. "a cat being scratched - a cat scratching the doctor" }
$$

Responses where the participant produced pronominal phrases not full noun phrases (4.9e) were scored as Active or Passive in the Lenient scoring. All other target responses were scored as Other as in the Strict scoring; see Table 4.2 for a summary of these criteria.

\section{Inclusive Scoring Criteria}

In the third scoring system the criteria were much more lenient: both complete and incomplete utterances were scored for active or passive structure; however, this time errors with thematic role assignment were ignored and the scoring was made purely on the basis of the syntactic structure, i.e. constituent order, of the utterance. Therefore reversed passives (4.9a) were also scored as Passive as long as they complied with the syntactic structure of the passive scoring criteria (subject, passive auxiliary, passive verb and, optionally, a by-phrase). Incomplete utterances that would have resulted in a reversed passive were also scored as Passive (4.11a); similarly complete or incomplete utterances that would have resulted in a reversed active sentence $(4.9 \mathrm{~b})$ were scored as Active as long as they were structurally a correct active sentence (subject, verb, and optionally, object). 
In addition, those utterances that were excluded from the previous scorings because they could not be paraphrased using the alternative structure $(4.6 \mathrm{c}-\mathrm{d})$ were included in this scoring. Items still scored as Other were those that were not a complete transitive sentence, or the beginning of one $(4.5 \mathrm{a}-\mathrm{b})$. See Table 4.2 for a summary of these criteria.

Table 4.2: Summary of the scoring criteria: $\mathrm{Y}=$ utterance scored as passive/active, $\mathrm{N}$ $=$ utterance scored as other, in $\mathrm{S}=$ strict, $\mathrm{L}=$ lenient, $\mathrm{I}=$ inclusive scoring.

\begin{tabular}{|c|c|c|c|c|c|}
\hline Criteria & Example Utterance & No. & $\mathbf{S}$ & $\mathbf{L}$ & I \\
\hline Full actives & a horse is hitting a fireman & $\overline{44.7 a}$ & $\mathrm{Y}$ & $\overline{\mathrm{Y}}$ & $\bar{Y}$ \\
\hline \multirow[t]{2}{*}{ Full passives } & a queen is being kissed by a sheep & $4.8 \mathrm{a}$ & $\mathrm{Y}$ & $\mathrm{Y}$ & Y \\
\hline & a king is getting licked by a cow & & $\mathrm{Y}$ & $\mathrm{Y}$ & Y \\
\hline Actives minus aspect auxiliary & a pig eating a fairy & $4.7 \mathrm{~b}$ & Y & $\mathrm{Y}$ & Y \\
\hline Passives minus aspect auxiliary & a witch being grabbed by a elephant & $4.8 \mathrm{c}$ & $\mathrm{Y}$ & $\mathrm{Y}$ & Y \\
\hline Morphological errors & a soldier's being holded by a bear & $4.8 \mathrm{~b}$ & $\mathrm{Y}$ & $\mathrm{Y}$ & Y \\
\hline Paraphrasable & a fairy that's being licked by a pig & $4.6 \mathrm{a}$ & Y & $\mathrm{Y}$ & Y \\
\hline \multirow[t]{2}{*}{ Change of lexical item } & a lion - a bear is pinching a fireman & $4.4 \mathrm{~d}$ & Y & $\mathrm{Y}$ & Y \\
\hline & a horse pull-er kicking the fireman & & $\mathrm{Y}$ & $\mathrm{Y}$ & Y \\
\hline Transitive with prepositional verb & a man is being chased away by a cat & $4.5 c$ & $\mathrm{Y}$ & $\mathrm{Y}$ & Y \\
\hline Productive verb & a man is being ribbited by a frog & $4.5 \mathrm{~d}$ & $\mathrm{Y}$ & $\mathrm{Y}$ & Y \\
\hline \multirow[t]{2}{*}{ Correct incomplete utterance } & a pig lick- & $4.4 \mathrm{a}$ & $\mathrm{N}$ & $\mathrm{Y}$ & $\mathrm{Y}$ \\
\hline & a girl being hug- & & $\mathrm{N}$ & $\mathrm{Y}$ & $\mathrm{Y}$ \\
\hline Short passive & a robber being watered & $4.9 \mathrm{c}$ & $\mathrm{N}$ & $\mathrm{Y}$ & $\mathrm{Y}$ \\
\hline Two pronouns & he's pinching him & $4.9 \mathrm{e}$ & $\mathrm{N}$ & $\mathrm{Y}$ & Y \\
\hline Passives with prep. other than by & a king being annoyed from a cow & $4.10 \mathrm{a}$ & $\mathrm{N}$ & $\mathrm{Y}$ & $\mathrm{Y}$ \\
\hline Not paraphrasable & a pig is trying to eat the fairy & $4.6 \mathrm{c}$ & $\mathrm{N}$ & $\mathrm{N}$ & $\mathrm{Y}$ \\
\hline Reversed passive & a cow's being licked by a king & $4.9 \mathrm{a}$ & $\mathrm{N}$ & $\mathrm{N}$ & Y \\
\hline Reversed active & a man carrying a sheep & $4.9 b$ & $\mathrm{~N}$ & $\mathrm{~N}$ & Y \\
\hline Incorrect incomplete utterance & a cat being scratched- & $4.11 \mathrm{a}$ & $\mathrm{N}$ & $\mathrm{N}$ & Y \\
\hline Intransitive with post-verbal NP & a soldier's running from a horse & $4.5 b$ & $\mathrm{~N}$ & $\mathrm{~N}$ & Y \\
\hline Ditransitive verb & an elephant giving the robber a shower & $4.9 \mathrm{~d}$ & $\mathrm{~N}$ & $\mathrm{~N}$ & $\mathrm{~N}$ \\
\hline Incorrect referents & doctor scratching a nurse's suit & $4.9 f$ & $\mathrm{~N}$ & $\mathrm{~N}$ & $\mathrm{~N}$ \\
\hline
\end{tabular}

\subsubsection{Methods of Analysis}

For the analysis, the numbers of responses were converted into proportions of the summed responses following each prime. These proportions were calculated twice: first as proportions of the sum of Active, Passive and Other responses in each priming condition, which I will term the 'All Responses' method; and second ('Alternating Responses' method) as proportions of the sum of Active and Passive responses only in each priming condition. Adult priming experiments typically use the second of these approaches, examining participants' responses as proportions of the sum of the alternating structures, excluding any Other responses (Bock, 1986). There has been some discussion in the children's syntactic priming literature on an acceptable method of analysis (Bencini \& Valian 2008) though there has, as yet, been no consensus. 
Some studies with children also use the 'Alternating Responses' method: Shimpi et al. (2007, p. 1341) state for both their experiments that they used "the proportion of passives out of all transitive responses as the dependent variable" (i.e. the 'Alternating Responses' method). In their study with child participants, Huttenlocher et al. (2004) state that they calculated the primed responses as proportions of all the responses the children produced (i.e. the 'All Responses' method), although their analyses for two of their experiments are conducted as in adult experiments with the proportions of actives or passives from the sum of transitive responses (Huttenlocher et al. 2004, p. 188), this corresponds to the 'Alternating Responses' method. Bencini \& Valian (2008) compared the two methods of calculating proportions and found that the priming effect was larger with the 'Alternating Responses' method. They do not however provide any conclusions as to how child priming studies should be analysed.

It is not surprising that the 'Alternating Responses' approach (passives as proportions of only transitive, not all, responses) shows larger effects, given that this method calculates the results as proportions of just the alternating structures. If the Other responses are included, then the results are calculated as proportions of a much larger sample, particularly as children tend to produce many Other responses (see, for example, Table 4.4), which renders the proportion that are passives much smaller than when they are calculated from a smaller sample. Compare for example the hypothetical results presented in Table 4.3 below.

Table 4.3: Methods of analysis: Hypothetical results

\begin{tabular}{lccc}
\hline \multirow{2}{*}{ Prime } & \multicolumn{3}{c}{ Responses } \\
\cline { 2 - 4 } & Active & Passive & Other \\
\hline Active & 8 & 2 & 2 \\
Passive & 4 & 3 & 5 \\
\hline \multirow{4}{*}{ 'Alternating Responses' } \\
\cline { 2 - 4 } Active & 0.80 & 0.20 & - \\
Passive & 0.57 & 0.43 & - \\
Priming Effect: & 0.23 \\
\hline \multicolumn{4}{c}{ 'All Responses' } \\
\cline { 2 - 4 } Active & 0.66 & 0.17 & 0.17 \\
Passive & 0.33 & 0.25 & 0.42 \\
Priming Effect: & 0.08 \\
\hline
\end{tabular}

Using the 'Alternating Responses' approach the proportions would be analysed as 0.20 passives in the active condition and 0.43 passives in the passive condition, giving a priming effect, calculated as the difference between the proportion of passives following active primes and following passive primes, of 0.23 for passives. Using the 'All Responses' method, the proportions of passive responses would be reduced to 
0.17 and 0.25 in the active and passive conditions respectively, giving a much-reduced priming effect of just 0.08 for passives.

In adult studies the 'Alternating Responses' approach is commonly used: Other responses are first checked for any effects and then excluded; priming is then examined as the likelihood of a structure being produced rather than its alternative. In the child data however, the Other responses contain target descriptions that may be related to the prime: since the children are not proficient speakers, the prime may activate their passive representation, however processing limitations or an incomplete or weak passive representation may lead them to produce an incorrect passive. For example, in this experiment the children produced seven reversed passives, all of which followed passive primes: some of their responses scored as Other are perhaps primed, albeit anomalous, responses. This is perhaps a reason for including the Other responses in the calculations of the proportions when studying priming with children. However, it could also be argued that the analysis should only examine instances of complete syntactic priming and therefore these anomalous responses, though potentially related to the prime, should be excluded from the analysis.

I therefore report both methods in this study and compare the results that they yield. For the 'All Responses' analyses I test the proportions of Active, Passive and Other responses separately to examine whether there is an effect of prime on these proportions and also whether the proportions of responses each group produced differed (an effect of group) or whether the priming effect for each group differed (an interaction between prime and group). For the 'Alternating Responses' analyses I test the proportions of Passive responses only, calculated from the sum of Active and Passive responses in each condition. Though the proportions of Active responses are also calculated, the statistical analyses are only performed with the Passive results since, due to the way the proportions are calculated, the Active and Passive results are in complementary distribution. In this analyses I also test the raw numbers of Other responses to examine whether the effects found in the 'All Responses' method are also found in this method.

\subsubsection{Strict Scoring Results}

\section{Results}

Out of the 192 target items, the children produced 132 (68\%) responses that could be scored as either Active (91) or Passive (40) and 47 (25\%) responses that were scored as Other; $13(7 \%)$ trials were eliminated because the wrong prime was given, the child failed to respond or the response was lost due to recording problems or misplaced 
cards. By comparison, the adults produced $181(94 \%)$ responses that could be scored as either Active (135) or Passive (46) and 8 (4\%) responses that were scored as Other; $3(2 \%)$ trials were eliminated because the wrong prime was given. Table 4.4 shows the raw total of Active, Passive and Other responses in each priming condition.

Table 4.4: Experiment 1: Frequency of active, passive and other responses according to group and prime condition

\begin{tabular}{llllllllc}
\hline & & \multicolumn{6}{c}{ Response } \\
\cline { 3 - 8 } Group & Prime & \multicolumn{2}{c}{ Active } & \multicolumn{2}{c}{ Passive } & \multicolumn{2}{c}{ Other } & Total \\
\hline \hline \multirow{2}{*}{ Children } & Active & 58 & $(65 \%)$ & 13 & $(15 \%)$ & 18 & $(20 \%)$ & 89 \\
& Passive & 33 & $(37 \%)$ & 27 & $(30 \%)$ & 30 & $(33 \%)$ & 90 \\
\hline \multirow{2}{*}{ Adults } & Active & 73 & $(77 \%)$ & 19 & $(20 \%)$ & 3 & $(3 \%)$ & 95 \\
& Passive & 62 & $(66 \%)$ & 27 & $(29 \%)$ & 5 & $(5 \%)$ & 94 \\
\hline
\end{tabular}

\section{Analysis}

'All Responses' Analysis

The first analysis was carried out using the 'All Responses' approach, with the Active and Passive responses expressed as proportions of all the responses, Other responses included. Table 4.5 shows these proportions for each group by priming condition ${ }^{8}$. What is clear from this table is that each group produced more Active responses to active primes, +0.30 for the children and +0.12 for the adults. Similarly both groups produced a higher proportion of Passive responses following passive primes compared to active primes, +0.14 for the children and +0.09 for the adults. Also, the children produced many responses scored as Other and a larger proportion of these followed passives primes than active primes $(+0.15)$, whilst the adults produced very few Other responses (Table 4.5). To examine these differences, the proportions of each group's Active, Passive and Other responses in each condition were analysed.

Table 4.5: Experiment 1: Mean proportions of responses in the Strict scoring ('All Responses' approach)

\begin{tabular}{lcccccc}
\hline & \multicolumn{3}{c}{ Children } & \multicolumn{3}{c}{ Adults } \\
\cline { 2 - 7 } Prime & Active & Passive & Other & Active & Passive & Other \\
\hline \hline Active & 0.66 & 0.14 & 0.20 & 0.77 & 0.20 & 0.03 \\
Passive & 0.36 & 0.28 & 0.35 & 0.65 & 0.29 & 0.05 \\
\hline
\end{tabular}

\section{ACTIVE RESPONSES}

First I present the analysis of the Active data: these were tested in repeated measures Analyses of Variance (ANOVAs), treating participants $\left(F_{1}\right)$ and items $\left(F_{2}\right)$ as random effects, with Prime (active vs passive) as a within-participants and within-items fac-

\footnotetext{
${ }^{8}$ This table and all subsequent tables report the proportions as calculated by participants; all analyses were conducted with both participants $\left(F_{1}\right)$ and items $\left(F_{2}\right)$ treated as random effects.
} 
tor and Group (children vs adults) as a between-participants but within-items factor. These showed a significant effect of Prime $\left(F_{1}[1,14]=7.57, p<.05\right.$, partial $\eta^{2}=0.35$, $F_{2}[1,46]=18.56, p<.001$, partial $\left.\eta^{2}=0.29\right)$; participants were more likely to produce Actives following active primes $(\mathrm{M}=0.71)$ than following passive primes $(\mathrm{M}=$ $0.51)$. There was also a main effect of $\operatorname{Group}\left(F_{1}[1,14]=4.72, p<.05\right.$, partial $\eta^{2}=0.25$, $F_{2}[1,46]=19.73, p<.001$, partial $\left.\eta^{2}=0.30\right)$ : adults produced more Actives $(\mathrm{M}=0.71)$ than children $(\mathrm{M}=0.51)$. There was however no interaction of Prime with Group $(F \mathrm{~s}<$ 1.5): neither group produced significantly more Actives following active primes than following passive primes than the other group. However, simple main effects showed a significant effect of Prime for the children only $\left(F_{1}[1,14]=7.73, p<.05\right.$, partial $\eta^{2}=$ $0.36, F_{2}[1,46]=20.06, p<.001$, partial $\left.\eta^{2}=0.30\right)$; the effect of Prime was not significant for the adults $(F \mathrm{~S}<3)$.

\section{PASSIVE RESPONSES}

The same repeated measures ANOVAs analysed the Passive data. This showed a significant effect of Prime (marginal by Participants) $\left(F_{1}[1,14]=4.1, p=.062\right.$, partial $\eta^{2}$ $=0.23, F_{2}[1,46]=9.18, p<.01$, partial $\left.\eta^{2}=0.17\right)^{9}$; participants were more likely to produce Passives following passive primes $(\mathrm{M}=0.29)$ than following active primes $(\mathrm{M}=0.17)$. There was no interaction of Prime with Group $(F \mathrm{~s}<1)$ or main effect of Group $(F \mathrm{~s}<1)$ : neither group produced significantly more passives overall or was more likely than the other group to produce passives following passive primes than following active primes. However, simple main effects again showed a significant effect of Prime for the children only, marginal by participants $\left(F_{1}[1,14]=2.92, p=.11\right.$, partial $\eta^{2}=0.17, F_{2}[1,46]=7.89, p<.01$, partial $\left.\eta^{2}=0.15\right)^{10}$; the effect of Prime did not approach significance for the adults $\left(F_{\mathrm{S}}<2.2\right)$.

\section{OTHER RESPONSES}

A third set of repeated measures ANOVAs compared the children and adults' proportions of Other responses. There was a main effect of Group $\left(F_{1}[1,14]=14.61, p<.01\right.$, partial $\eta^{2}=0.51, F_{2}[1,46]=47.01, p<.001$, partial $\left.\eta^{2}=0.51\right)$, the children produced significantly more utterances scored as Other than the adults, see Table 4.5 . The effect of Prime approached significance $\left(F_{1}[1,14]=3.47, p=.08\right.$, partial $\eta^{2}=0.2, F_{2}[1,46]=$ $5.43, p<.05$, partial $\left.\eta^{2}=0.11\right)$ but the interaction between Prime and Group was not significant $\left(F_{\mathrm{S}}<2\right)$. Simple main effects showed there was a significant effect of Prime on the children's Other responses $\left(F_{1}[1,14]=5.37, p<.05\right.$, partial $\eta^{2}=0.28, F_{2}[1,46]$ $=6.74, p<.05$, partial $\left.\eta^{2}=0.13\right)$, but not on the adults' $(F \mathrm{~s}<1)$. Children produced significantly more Others than adults and significantly more Other responses follow-

\footnotetext{
${ }^{9}$ Given the clear significant effect in the items analysis, it seems the marginal $p$ value for the participants result is a result of power, with only eight participants in each group.

${ }^{10}$ Again there are issues with power because of the small groups.
} 
ing passive primes than following active primes. These results are discussed below following the second analysis.

\section{'Alternating Responses' Analysis}

The second analysis was carried out using the 'Alternating Responses' approach, with the passive responses as proportions of the active and passive responses only. Table 4.6 shows these proportions for each group by priming condition. Again, the children and adults produced a higher proportion of passive utterances following passive primes compared to active primes, +0.21 for the children and +0.12 for the adults.

Table 4.6: Experiment 1: Mean proportions of responses in the Strict scoring ('Alternating Responses' approach)

\begin{tabular}{lcccc}
\hline \multirow{2}{*}{ Prime } & \multicolumn{2}{c}{ Children } & \multicolumn{2}{c}{ Adults } \\
\cline { 2 - 5 } & Active & Passive & Active & Passive \\
\hline \hline Active & 0.81 & 0.19 & 0.80 & 0.20 \\
Passive & 0.60 & 0.40 & 0.68 & 0.32 \\
\hline
\end{tabular}

\section{PASSIVE RESPONSES}

The statistical analyses were repeated using these proportions. These showed a significant effect of Prime $\left(F_{1}[1,14]=5.86, p<.05\right.$, partial $\eta^{2}=0.29, F_{2}[1,46]=14.47, p$ $<.001$, partial $\eta^{2}=0.24$ ); participants produced significantly more passives following passive primes $(\mathrm{M}=0.36)$ than following active primes $(\mathrm{M}=0.19)$. However, there was no main effect of Group ( Fs $<1)$, neither group produced more passives overall. In this analysis, the interaction of Prime with Group was not significant though it approached significance by items $\left(F_{1}[1,14]=0.40, p=.54\right.$, partial $\eta^{2}=0.03, F_{2}[1,46]=$ 3.69, $p=.06$, partial $\left.\eta^{2}=0.07\right)$. In addition, the simple main effects again showed a significant effect of Prime for the children only $\left(F_{1}[1,14]=4.66, p<.05\right.$, partial $\eta^{2}=$ $0.25, F_{2}[1,46]=16.38, p<.001$, partial $\left.\eta^{2}=0.26\right)$, not for the adults $(F \mathrm{~s}<2)$.

\section{OTHER RESPONSES}

Since the Other responses were excluded from the calculation of the proportions in the 'Alternating Responses' analysis, I analysed the raw numbers of Other responses to check for an effect of Prime and Group as observed in the previous analysis. The mean number of Other responses are shown in Table 4.7.

Table 4.7: Experiment 1: Mean numbers of Other responses in the Strict scoring ('Alternating Responses' approach)

\begin{tabular}{lcc}
\hline Prime & Children & Adults \\
\hline \hline Active & 2.25 & 0.38 \\
Passive & 3.75 & 0.63 \\
\hline
\end{tabular}


Repeated measures ANOVAs indeed showed a significant effect of Prime (marginal by participants: $F_{1}[1,14]=3.61, p=.08$, partial $\eta^{2}=0.21, F_{2}[1,46]=4.96, p<.05$, partial $\eta^{2}=0.1$ ); participants produced more Other responses following passive primes than following active primes. There was again a main effect of Group $\left(F_{1}[1,14]=12.73, p<\right.$ .01 , partial $\eta^{2}=0.48, F_{2}[1,46]=41.07, p<.001$, partial $\left.\eta^{2}=0.47\right)$; however there was no interaction of Prime with Group ( $\left.F_{\mathrm{S}} \leq 2.5\right)$. Simple main effects showed a significant effect of Prime for the children only $\left(F_{1}[1,14]=5.31, p<.05\right.$, partial $\eta^{2}=0.27, F_{2}[1,46]$ $=7.29, p=.01$, partial $\left.\eta^{2}=0.14\right)$ not for the adults $(F \mathrm{~s}<1)$. See the Discussion below.

\section{Additional Analyses}

Additional analyses examined other possible effects. Paired samples $t$-tests examined whether there was evidence of a longer-term or cumulative effect of exposure to passives during the experiment, that would be consistent with implicit learning. I examined this by comparing the number of passives that they produced at the beginning and end of the experiment. If there is learning during the experiment one would expect more passives to be produced at the end of the experiment. This analysis is speculative however as the order of the primes was randomized thus different participants would have heard different numbers of passive primes at the beginning and end of the experiment, though this should be balanced over all the participants of each group. The $t$-test showed that the children did not produce more passives following the last eight primes of the experiment $(M=1.88, S D=1.25)$ than following the first eight primes $(\mathrm{M}=1.63, \mathrm{SD}=1.51, t(7)=-.47, p=.32$, 1-tailed $)$; see Figure 4.3. The children were not more likely to produce passives at the end of the experiment than at the beginning suggesting that the observed priming effects were not the result of implicit learning from cumulative exposure to passives. The adults were also no more likely to produce passives at the end of the experiment $(\mathrm{M}=2.13, \mathrm{SD}=2.29)$ than at the beginning $(\mathrm{M}=1.38, \mathrm{SD}=1.99, t(7)=-.83, p=.22$, 1-tailed $)$; see Figure 4.4 .

I also examined whether there was any relationship between the age of the children and their individual priming effect (calculated as the proportion of their responses to passive primes that were Passive minus their proportion of responses to active primes that were Passive). The individual priming effects ranged widely from -0.13 to +0.56 . One possible explanation is that older children within the group have a stronger representation for the passive based on more experience, which should lead to more priming than younger children with a weaker representation. There was a strong correlation between the children's age and individual priming effect $(r=.71, p$ $<.05$, 1-tailed). This relationship is depicted in Figure 4.5 which shows that there was a positive correlation between age and priming effect: older children tended to show a stronger priming effect. However one participant's priming effect was negative which 


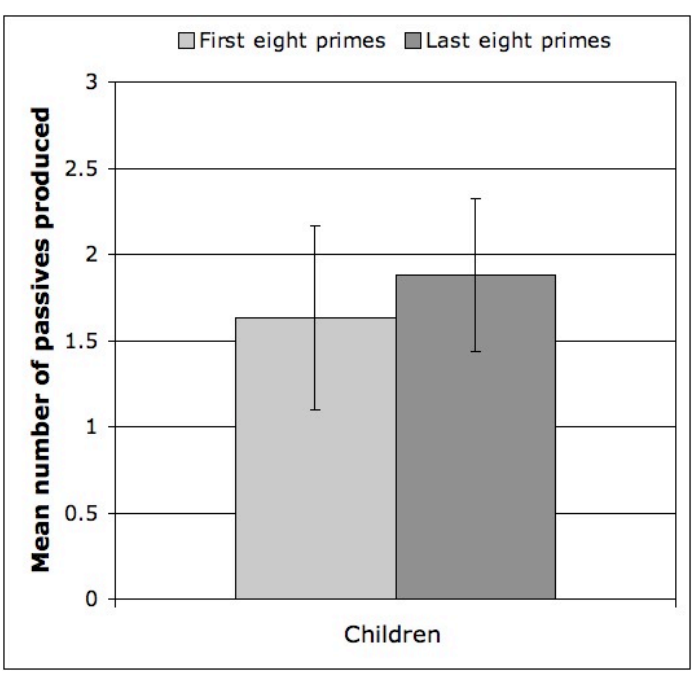

Figure 4.3: Experiment 1: Mean number of passives children produced following first eight and last eight primes

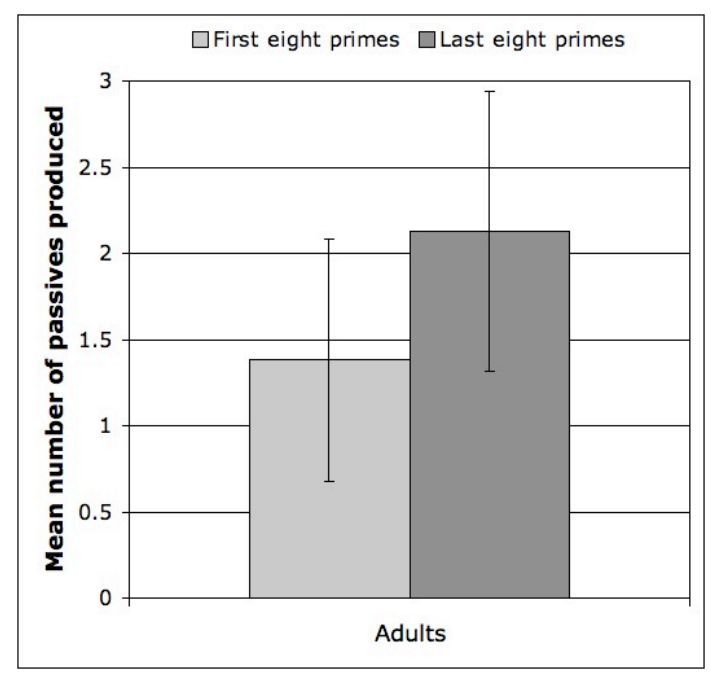

Figure 4.4: Experiment 1: Mean number of passives adults produced following first eight and last eight primes

means they actually produced more passives following active primes than following passive primes. Therefore the test does not reflect the fact that this participant (the youngest participant in fact) did produce passives.

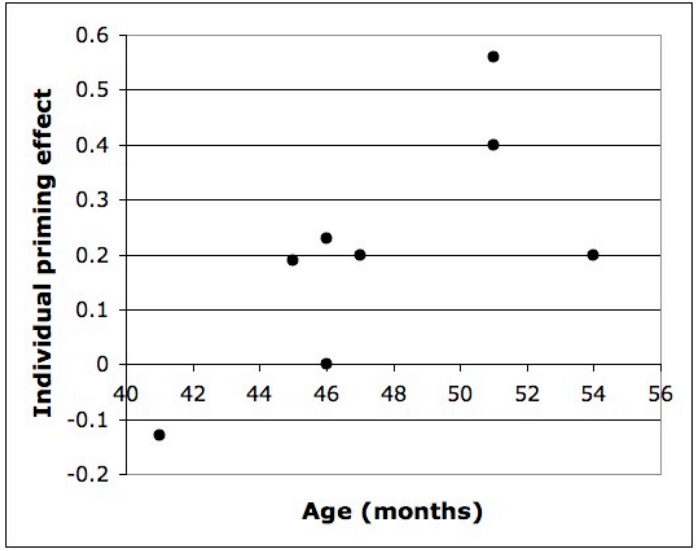

Figure 4.5: Experiment 1: Priming effect by age of participant

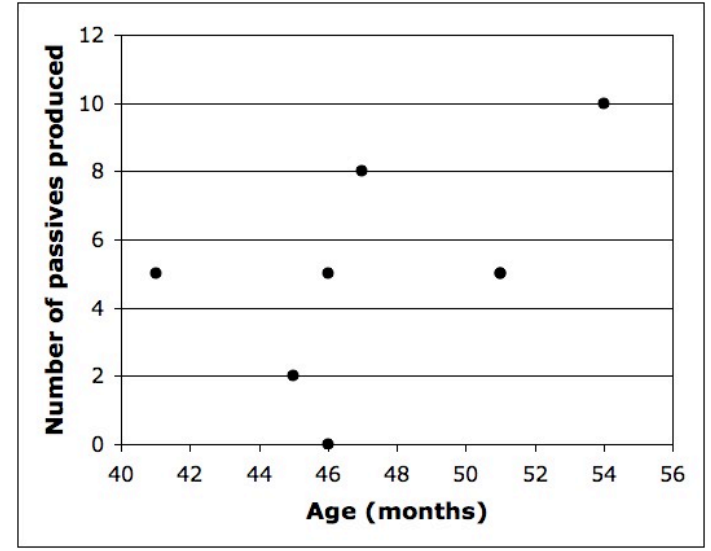

Figure 4.6: Experiment 1: Number of passives participants produced by age

Therefore I also examined whether there was a relationship between the participants' age and the number of passives produced: older children may be more likely to produce passives than younger children. Bivariate correlations did not show a relationship between number of passives and participant age $(r=.51, p<.10,1$-tailed); see 
also Figure 4.6. Given the small sample, these results should be interpreted with caution; to be confident that there is a relationship between age and the performance in these experiments, this test will be repeated in subsequent experiments with more participants.

\section{Discussion}

This experiment shows that children are more likely to produce actives after hearing active primes than after hearing passive primes and to produce passives after hearing passive primes than after hearing active primes. The fact that this syntactic repetition occurred in the absence of repeated lexical items suggests that by this age children have a generalized and abstract, not item-specific, representation for the passive (and active). In addition this effect occurred when children heard both active and passive primes: three- and four-year-old children can be primed to alternate their sentence structure in line with alternations of single primes. The comparison between the number of passives produced at the beginning and at the end of the experiment suggests that the children were not learning to encode transitive verbs as passives during the experiment. Although it is not possible to compare directly the results of this experiment with previous child priming studies, due to the differences in methodology, it is interesting to note that the percentage increases in the children's passive responses, which are of interest here, for the two different analyses are very similar to those reported by Bencini and Valian (2008). They reported increases of $14 \%$ and 33\% for their analyses with all responses and only alternating responses respectively, which are comparable to the $14 \%$ and for $21 \%$ found in this study, particularly given the stricter scoring used in this analysis which did not allow short actives or passives to be scored as transitive responses. These results suggest that manipulating prime as a within-participants factor and measuring children's descriptions after a single instance of a prime does not decrease the priming effect.

The different methods of analysis showed slightly different results: the 'Alternating Responses' analysis showed stronger significance. As discussed above, the 'Alternating Responses' approach produces larger differences between the proportions of passives in each condition therefore it is not surprising that the results of the statistical analysis are clearer in this analysis than in the 'All Responses' analysis. These results show the advantage of using the 'Alternating Responses' approach: in line with the discussion above, the priming effect is larger following this method of analysis (compare +0.21 with +0.14 in the 'All Responses' analysis). The two methods are discussed further in the General Discussion.

Only in the 'Alternating Responses' analysis did the Prime by Group interaction approach significance. However, this appears to be a problem with power as there were 
only eight participants in each group; future experiments will test more participants with the aim of obtaining clearer effects. This problem of power seems to be particularly exacerbated in the 'All Responses' analysis: this method of calculation effectively watered-down the results and therefore the effects. For example, even though the adults produced numerically more passives following passive primes than following active primes $(+9 \%)$ there was not a significant priming effect for adults, with more participants however this effect may have achieved significance.

Nonetheless, the increases in the adults' proportions of passives are similar to those found in adult experiments and the adults produced many more passives in the priming task than in the free description task suggesting an influence of prime even if this did not achieve statistical significance. This experiment demonstrates that eight participants per group was not sufficient to achieve significant effects in all the analyses, therefore, future experiments will test larger groups in order to be more confident of the findings. This might in addition show stronger effects that were predicted but not found: for example, the interaction of Group with Prime was not significant even though numerically, the children's proportions of passives increased to a greater extent than the adults.

Alternatively, these effects may appear with the results from the more lenient scorings, particularly given that the children, but not the adults, produced more utterances that were scored as Other in the Strict scoring but Active or Passive in the more lenient scorings. There was also an effect of Prime on children's Other responses: this reflects the fact that children produced a number of reversed passives and incomplete passives following passive primes, coded as Other in this scoring. The data were scored two further times with more lenient criteria to see whether this influenced the pattern of results. Given the children produced more utterances scored as Other than the adults and some of these appear to be related to the primes, it might be predicted that more lenient scorings would show an interaction between Prime and Group.

\subsubsection{Lenient Scoring Results}

\section{Results and Analysis}

This scoring did not result in many changes to the scores ( +4 actives and +3 passives for the children, +2 actives for the adults). Participants did not produce any short passives in this experiment; the increase in the scores was due to incomplete utterances being scored as actives or passives. Because of the minimal change, the raw numbers are not presented here, only the mean proportions for the two methods of analysis - 'All Responses': proportions of all responses and 'Alternating Responses': 
proportions of the transitive responses (see Tables 4.8 and 4.12).

'All Responses' Analysis

Table 4.8 shows the mean proportions of Active, Passive and Other responses from the sum of all responses in each priming condition. The statistical tests, conducted in the Strict scoring, were repeated with these proportions. Given the number of analyses and scorings, for brevity and ease of exposition, the results of the ANOVAs are presented in table-form.

Table 4.8: Experiment 1: Mean proportions of responses in the Lenient scoring ('All Responses' approach)

\begin{tabular}{lcccccc}
\hline & \multicolumn{3}{c}{ Children } & \multicolumn{3}{c}{ Adults } \\
\cline { 2 - 7 } Prime & Active & Passive & Other & Active & Passive & Other \\
\hline \hline Active & 0.71 & 0.15 & 0.14 & 0.78 & 0.20 & 0.02 \\
Passive & 0.36 & 0.30 & 0.33 & 0.66 & 0.29 & 0.04 \\
\hline
\end{tabular}

\section{ACTIVE RESPONSES}

The same analyses used on the Strict scored data were repeated with the data from the Lenient Scoring. The results of these ANOVAs, shown in Table 4.9, again showed a significant effect of Prime; the effect of Group was significant by items, marginal by participants, and the interaction between Prime and Group was significant by items only. Again, there are clear issues of power, however these results suggest that participants produced more Actives following active primes than following the passive primes and that adults produced more Actives than children; finally the priming effect may have been stronger for children. Simple main effects again showed a significant effect of Prime for the children only.

Table 4.9: Experiment 1: ANOVAs of proportions of Actives in the Lenient scoring ('All Responses' approach)

\begin{tabular}{lcclccrrrc}
\hline & \multicolumn{4}{c}{ F1 Results } & \multicolumn{4}{c}{ F2 Results } \\
\cline { 2 - 9 } Effect & $d f$ & $\boldsymbol{F 1}$ & $\boldsymbol{p}$ & partial $\eta^{2}$ & $\boldsymbol{d f}$ & $\boldsymbol{F 2}$ & $\boldsymbol{p}$ & partial $\eta^{2}$ \\
\hline \hline Prime & 1,14 & 8.57 & $<.05$ & 0.38 & 1,46 & 23.69 & $<.001$ & 0.34 \\
Group & 1,14 & 3.93 & $=.07$ & 0.22 & 1,46 & 17.41 & $<.001$ & 0.27 \\
Prime x Group & 1,14 & 2.06 & n.s. & 0.13 & 1,46 & 6.48 & $<.05$ & 0.12 \\
Prime (Children) & 1,14 & 9.52 & $<.01$ & 0.40 & 1,46 & 27.48 & $<.001$ & 0.37 \\
Prime (Adults) & 1,14 & 1.11 & n.s. & 0.07 & 1,46 & 2.69 & n.s. & 0.05 \\
\hline
\end{tabular}

\section{PASSIVE RESPONSES}

The results of the ANOVAs, shown in Table 4.10, again showed a significant effect of Prime but not of Group on the Passive responses in the 'All Responses' analysis. Nor was there an interaction of Prime with Group. Simple main effects again showed a significant effect of Prime, marginal by participants, for the children only. 
Table 4.10: Experiment 1: ANOVAs of proportions of Passives in the Lenient scoring ('All Responses' approach)

\begin{tabular}{lcclccccc}
\hline & \multicolumn{4}{c}{ F1 Results } & \multicolumn{4}{c}{ F2 Results } \\
\cline { 2 - 8 } Effect & $d f$ & $\boldsymbol{F 1}$ & $\boldsymbol{p}$ & partial $\eta^{2}$ & $\boldsymbol{d f}$ & $\boldsymbol{F 2}$ & $\boldsymbol{p}$ & partial $\eta^{2}$ \\
\hline \hline Prime & 1,14 & 4.26 & $=.06$ & 0.23 & 1,46 & 9.86 & $<.01$ & 0.18 \\
Group & 1,14 & 0.05 & n.s. & 0.00 & 1,46 & .001 & n.s. & 0.00 \\
Prime x Group & 1,14 & 0.22 & n.s. & 0.01 & 1,46 & 1.21 & n.s. & 0.03 \\
Prime (Children) & 1,14 & 3.21 & $=.09$ & 0.19 & 1,46 & 8.99 & $<.01$ & 0.16 \\
Prime (Adults) & 1,14 & 1.27 & n.s. & 0.08 & 1,46 & 2.08 & n.s. & 0.04 \\
\hline
\end{tabular}

\section{OTHER RESPONSES}

Table 4.11 shows the results of the ANOVAs with the Other responses following the Lenient scoring; there was still an effect of Group and an effect of Prime (marginal by participants). The interaction was significant by items only. Simple main effects showed there was a significant effect of Prime on the children's Other responses but not on the adults'.

Table 4.11: Experiment 1: ANOVAs of proportions of Others in the Lenient scoring ('All Responses' approach)

\begin{tabular}{lcrlcrrrr}
\hline & \multicolumn{4}{c}{ F1 Results } & \multicolumn{4}{c}{ F2 Results } \\
\cline { 2 - 9 } Effect & $d f$ & $\boldsymbol{F 1}$ & $\boldsymbol{p}$ & partial $\eta^{2}$ & $\boldsymbol{d f}$ & $\boldsymbol{F 2}$ & $\boldsymbol{p}$ & partial $\eta^{2}$ \\
\hline \hline Prime & 1,14 & 3.78 & $=.07$ & 0.21 & 1,46 & 8.76 & $<.01$ & 0.16 \\
Group & 1,14 & 18.11 & $<.01$ & 0.56 & 1,46 & 41.28 & $<.001$ & 0.47 \\
Prime x Group & 1,14 & 2.40 & $=.14$ & 0.15 & 1,46 & 5.24 & $<.05$ & 0.10 \\
Prime (Children) & 1,14 & 6.10 & $<.05$ & 0.30 & 1,46 & 13.77 & $<.001$ & 0.23 \\
Prime (Adults) & 1,14 & 0.08 & n.s. & 0.01 & 1,46 & 0.22 & n.s. & 0.00 \\
\hline
\end{tabular}

The results from the more lenient scoring of the data yielded the same pattern as the Strict scoring: the participants' production of passive responses was affected by the structure of the prime; they were more likely to produce passives following passive primes than following active primes. In addition, the children produced more Other responses than the adults and they produced more Other responses following passive primes than following active primes (see Table 4.8).

\section{'Alternating Responses' Analysis}

\section{PASSIVE RESPONSES}

The second analysis was carried out with the passive responses as proportions of the active and passive responses only, shown in Table 4.12. These showed the same pattern of results as the first analysis (see the results of the ANOVA reported in Table 4.13). There was a significant effect of Prime though the main effect of Group was not significant. The interaction of Prime with Group was significant for items only. As 
in previous analyses, simple main effects showed a significant effect of Prime for the children but not for the adults.

Table 4.12: Experiment 1: Mean proportions of responses in the Lenient scoring ('Alternating Responses' approach)

\begin{tabular}{lcccc}
\hline \multirow{2}{*}{ Prime } & \multicolumn{2}{c}{ Children } & \multicolumn{2}{c}{ Adults } \\
\cline { 2 - 5 } & Active & Passive & Active & Passive \\
\hline \hline Active & 0.81 & 0.19 & 0.80 & 0.20 \\
Passive & 0.58 & 0.42 & 0.68 & 0.32 \\
\hline
\end{tabular}

Table 4.13: Experiment 1: ANOVAs of proportions of Passives in the Lenient scoring ('Alternating Responses' approach)

\begin{tabular}{lcclccrlcc}
\hline & \multicolumn{4}{c}{ F1 Results } & \multicolumn{4}{c}{ F2 Results } \\
\cline { 2 - 9 } Effect & $\boldsymbol{d f}$ & $\boldsymbol{F 1}$ & $\boldsymbol{p}$ & partial $\eta^{2}$ & $\boldsymbol{d f}$ & $\boldsymbol{F 2}$ & $\boldsymbol{p}$ & partial $\eta^{2}$ \\
\hline \hline Prime & 1,14 & 6.17 & $<.05$ & 0.31 & 1,46 & 17.29 & $<.001$ & 0.27 \\
Group & 1,14 & 0.25 & n.s. & 0.02 & 1,46 & 1.72 & n.s. & 0.04 \\
Prime x Group & 1,14 & 0.61 & $=.45$ & 0.04 & 1,46 & 5.40 & $<.05$ & 0.10 \\
Prime (Children) & 1,14 & 5.34 & $<.05$ & 0.28 & 1,46 & 21.01 & $<.001$ & 0.31 \\
Prime (Adults) & 1,14 & 1.45 & n.s. & 0.09 & 1,46 & 1.68 & n.s. & 0.03 \\
\hline
\end{tabular}

\section{OTHER RESPONSES}

Analyses of the raw numbers of Other responses again checked for an effect of Prime. The mean number of Other responses are shown in Table 4.14. These showed the same pattern of results as the first analysis (see Table 4.15). There was a significant effect of Prime and Group though the interaction of Prime with Group was significant for items only. As in previous analyses, simple main effects showed a significant effect of Prime for the children but not for the adults.

Table 4.14: Experiment 1: Mean numbers of Other responses in the Lenient scoring ('Alternating Responses' approach)

\begin{tabular}{lcc}
\hline Prime & Children & Adults \\
\hline \hline Active & 1.63 & 0.25 \\
Passive & 3.50 & 0.50 \\
\hline
\end{tabular}

\section{Discussion}

Under the Lenient scoring, the mean proportion of passives the children produced following passive primes increased by 0.15 and 0.23 (depending on the analysis) compared to following active primes. In the 'All Responses' approach there was also a priming effect of Actives. The analyses produced the same pattern of results as the Strict scoring but this is perhaps not surprising given the very small changes produced by the Lenient scoring. The final scoring involved very lenient criteria which allowed many of the participants' Other responses to be scored as Active or Passive. 
Table 4.15: Experiment 1: ANOVAs of numbers of Others in the Lenient scoring ('Alternating Responses' approach)

\begin{tabular}{lcrlcrrrr}
\hline & \multicolumn{4}{c}{ F1 Results } & \multicolumn{4}{c}{ F2 Results } \\
\cline { 2 - 9 } Effect & $\boldsymbol{d f}$ & $\boldsymbol{F 1}$ & $\boldsymbol{p}$ & partial $\eta^{2}$ & $\boldsymbol{d f}$ & $\boldsymbol{F 2}$ & $\boldsymbol{p}$ & partial $\eta^{2}$ \\
\hline \hline Prime & 1,14 & 4.05 & $=.06$ & 0.22 & 1,46 & 9.40 & $<.01$ & 0.17 \\
Group & 1,14 & 15.68 & $<.01$ & 0.53 & 1,46 & 33.11 & $<.001$ & 0.42 \\
Prime x Group & 1,14 & 2.37 & $=.15$ & 0.14 & 1,46 & 5.50 & $<.05$ & 0.11 \\
Prime (Children) & 1,14 & 6.31 & $<.05$ & 0.31 & 1,46 & 14.64 & $<.001$ & 0.24 \\
Prime (Adults) & 1,14 & 0.11 & n.s. & 0.01 & 1,46 & 0.26 & n.s. & 0.01 \\
\hline
\end{tabular}

\subsubsection{Inclusive Scoring Results}

\section{Results and Analysis}

Following this scoring of the data, the number of children's responses scored as Active increased by +12 and the number scored as Passive increased by +6 (the adult scores increased by +2 Active and +4 Passive).

'All Responses' Analysis

Tables 4.16 shows the mean proportions of responses following the Inclusive scoring.

Table 4.16: Experiment 1: Mean proportions of responses in the Inclusive scoring ('All Responses' approach)

\begin{tabular}{lcccccc}
\hline & \multicolumn{3}{c}{ Children } & \multicolumn{3}{c}{ Adults } \\
\cline { 2 - 7 } Prime & Active & Passive & Other & Active & Passive & Other \\
\hline \hline Active & 0.77 & 0.15 & 0.08 & 0.79 & 0.21 & 0.00 \\
Passive & 0.45 & 0.38 & 0.18 & 0.67 & 0.33 & 0.00 \\
\hline
\end{tabular}

\section{ACTIVE RESPONSES}

The analyses from the previous scorings were repeated with the data from the Inclusive Scoring. The results of these ANOVAs, shown in Table 4.17, again showed a significant effect of Prime on the participants' active responses in the 'All Responses' analysis. The effect of Group and the interaction of Prime with Group were significant by items only. Simple main effects again showed a significant effect of Prime for the children only.

\section{PASSIVE RESPONSES}

When the proportion of passives, as shown in Table 4.16, was calculated from the sum of all responses in each priming condition, the analyses showed a significant effect of Prime (reported in Table 4.18) but no main effect of Group or interaction of Prime with 
Table 4.17: Experiment 1: ANOVAs of proportions of Actives in the Inclusive scoring ('All Responses' approach)

\begin{tabular}{lcclccrrrc}
\hline & \multicolumn{4}{c}{ F1 Results } & \multicolumn{4}{c}{ F2 Results } \\
\cline { 2 - 9 } Effect & $d f$ & $\boldsymbol{F 1}$ & $\boldsymbol{p}$ & partial $\eta^{2}$ & $\boldsymbol{d f}$ & $\boldsymbol{F 2}$ & $\boldsymbol{p}$ & partial $\eta^{2}$ \\
\hline \hline Prime & 1,14 & 8.89 & $<.05$ & 0.39 & 1,46 & 21.19 & $<.001$ & 0.31 \\
Group & 1,14 & 1.87 & n.s. & 0.12 & 1,46 & 7.04 & $<.05$ & 0.13 \\
Prime x Group & 1,14 & 1.87 & n.s. & 0.12 & 1,46 & 5.38 & $<.05$ & 0.10 \\
Prime (Children) & 1,14 & 9.46 & $<.01$ & 0.40 & 1,46 & 23.96 & $<.001$ & 0.34 \\
Prime (Adults) & 1,14 & 1.30 & n.s. & 0.08 & 1,46 & 2.61 & n.s. & 0.05 \\
\hline
\end{tabular}

Group. Simple main effects again showed a significant effect of Prime for the children but not for the adults.

Table 4.18: Experiment 1: ANOVAs of proportions of Passives in the Inclusive scoring ('All Responses' approach)

\begin{tabular}{lcllcrrrc}
\hline & \multicolumn{4}{c}{ F1 Results } & \multicolumn{4}{c}{ F2 Results } \\
\cline { 2 - 8 } Effect & $\boldsymbol{d f}$ & $\boldsymbol{F 1}$ & $\boldsymbol{p}$ & partial $\eta^{2}$ & $\boldsymbol{d f}$ & $\boldsymbol{F 2}$ & $\boldsymbol{p}$ & partial $\eta^{2}$ \\
\hline \hline Prime & 1,14 & 5.8 & $<.05$ & 0.29 & 1,46 & 17.13 & $<.001$ & 0.27 \\
Group & 1,14 & 0.00 & n.s. & 0.00 & 1,46 & 0.10 & n.s. & 0.00 \\
Prime x Group & 1,14 & 0.57 & n.s. & 0.04 & 1,46 & 2.87 & n.s. & 0.06 \\
Prime (Children) & 1,14 & 5.0 & $<.05$ & 0.26 & 1,46 & 17.02 & $<.001$ & 0.27 \\
Prime (Adults) & 1,14 & 1.37 & n.s. & 0.09 & 1,46 & 2.99 & n.s. & 0.06 \\
\hline
\end{tabular}

\section{OTHER RESPONSES}

The proportions of Other responses following the Inclusive scoring are shown in Table 4.16; the analysis of these, reported in Table 4.19, showed that there was still an effect of Group however the effect of Prime was no longer significant. Simple main effects showed a marginal effect of Prime for the children but not the adults'. Note that in this scoring the adults had no Other responses and the children had very few remaining Other responses.

Table 4.19: Experiment 1: ANOVAs of proportions of Others in the Inclusive scoring ('All Responses' approach)

\begin{tabular}{lcclcrrrr}
\hline & \multicolumn{4}{c}{ F1 Results } & \multicolumn{4}{c}{ F2 Results } \\
\cline { 2 - 9 } Effect & $\boldsymbol{d f}$ & $\boldsymbol{F 1}$ & $\boldsymbol{p}$ & partial $\eta^{2}$ & $\boldsymbol{d f}$ & $\boldsymbol{F 2}$ & $\boldsymbol{p}$ & partial $\eta^{2}$ \\
\hline \hline Prime & 1,14 & 1.47 & n.s. & 0.09 & 1,46 & 2.47 & n.s. & 0.05 \\
Group & 1,14 & 9.42 & $<.01$ & 0.40 & 1,46 & 16.09 & $<.001$ & 0.26 \\
Prime x Group & 1,14 & 1.47 & n.s. & 0.09 & 1,46 & 2.47 & n.s. & 0.05 \\
Prime (Children) & 1,14 & 2.94 & $=.11$ & 0.17 & 1,46 & 4.94 & $<.05$ & 0.10 \\
Prime (Adults) & 1,14 & 0.00 & n.s. & 0.00 & 1,46 & 0.00 & n.s. & 0.00 \\
\hline
\end{tabular}




\section{'Alternating Responses' Analysis \\ PASSIVE RESPONSES}

Table 4.20 shows the mean proportions of active and passive responses in the Inclusive scoring. When the results of the Inclusive scoring were analysed as proportions of the active and passive responses only, the same results were found; see Table 4.21. There was a significant effect of Prime however the effect of Group was not significant. The interaction of Prime with Group was again significant by items only. As in previous analyses, simple main effects showed a significant effect of Prime for the children only, not for the adults.

Table 4.20: Experiment 1: Mean proportions of responses in the Inclusive scoring ('Alternating Responses' approach)

\begin{tabular}{lcccc}
\hline & \multicolumn{2}{c}{ Children } & \multicolumn{2}{c}{ Adults } \\
\cline { 2 - 5 } Prime & Active & Passive & Active & Passive \\
\hline \hline Active & 0.83 & 0.17 & 0.79 & 0.21 \\
Passive & 0.57 & 0.43 & 0.67 & 0.33 \\
\hline
\end{tabular}

Table 4.21: Experiment 1: ANOVAs of proportions of Passives in the Inclusive scoring ('Alternating Responses' approach)

\begin{tabular}{lcclcrrrr}
\hline & \multicolumn{4}{c}{ F1 Results } & \multicolumn{4}{c}{ F2 Results } \\
\cline { 2 - 9 } Effect & $\boldsymbol{d f}$ & $\boldsymbol{F 1}$ & $\boldsymbol{p}$ & partial $\eta^{2}$ & $\boldsymbol{d f}$ & $\boldsymbol{F 2}$ & $\boldsymbol{p}$ & partial $\eta^{2}$ \\
\hline \hline Prime & 1,14 & 6.61 & $<.05$ & 0.32 & 1,46 & 22.64 & $<.001$ & 0.33 \\
Group & 1,14 & 0.09 & n.s. & 0.01 & 1,46 & 1.54 & n.s. & 0.03 \\
Prime x Group & 1,14 & 0.92 & $=.35$ & 0.06 & 1,46 & 6.28 & $<.05$ & 0.12 \\
Prime (Children) & 1,14 & 6.23 & $<.05$ & 0.31 & 1,46 & 26.39 & $<.001$ & 0.36 \\
Prime (Adults) & 1,14 & 1.30 & n.s. & 0.08 & 1,46 & 2.54 & n.s. & 0.05 \\
\hline
\end{tabular}

\section{OTHER RESPONSES}

The mean number of Other responses following the Inclusive scoring are shown in Table 4.22. These showed the same pattern of results as the first analysis (see Table 4.23). There was an effect of Group but no effect of Prime or interaction of Prime with Group. Simple main effects showed a significant effect of Prime for the children (by items only) but not for the adults.

Table 4.22: Experiment 1: Mean numbers of Others in the Inclusive scoring ('Alternating Responses' approach)

\begin{tabular}{lcc}
\hline Prime & Children & Adults \\
\hline \hline Active & 1.00 & 0.00 \\
Passive & 1.75 & 0.00 \\
\hline
\end{tabular}

\section{Discussion}

Following this scoring, the proportion of children's passives following passive primes 
Table 4.23: Experiment 1: ANOVAs of numbers of Others in the Inclusive scoring ('Alternating Responses' approach)

\begin{tabular}{lcclcrrrr}
\hline & \multicolumn{4}{c}{ F1 Results } & \multicolumn{4}{c}{ F2 Results } \\
\cline { 2 - 9 } Effect & $\boldsymbol{d f}$ & $\boldsymbol{F 1}$ & $\boldsymbol{p}$ & partial $\eta^{2}$ & $\boldsymbol{d f}$ & $\boldsymbol{F 2}$ & $\boldsymbol{p}$ & partial $\eta^{2}$ \\
\hline \hline Prime & 1,14 & 1.23 & n.s. & 0.08 & 1,46 & 2.38 & n.s. & 0.05 \\
Group & 1,14 & 8.56 & $<.05$ & 0.38 & 1,46 & 14.57 & $<.001$ & 0.24 \\
Prime x Group & 1,14 & 1.23 & n.s. & 0.08 & 1,46 & 2.38 & n.s. & 0.05 \\
Prime (Children) & 1,14 & 2.47 & $=.14$ & 0.15 & 1,46 & 4.76 & $<.05$ & 0.09 \\
Prime (Adults) & 1,14 & 0.00 & n.s. & 0.00 & 1,46 & 0.00 & n.s. & 0.00 \\
\hline
\end{tabular}

compared to active primes increased by 0.23 and 0.26 (depending on the analysis). Again the same pattern of results was found as for previous scorings with both methods of analysis. Even though the children produced more Other responses than the adults, and even though previous scorings showed that their Other responses were influenced by the prime (more were produced following passive primes), there was still no effect of Group in the Inclusive scoring when most of these Other responses were scored as Active or Passive. These findings are discussed in the General Discussion below.

\subsubsection{General Discussion of Experiment One}

Experiment 1 tested children's descriptions of pictures of transitive events with and without the influence of active and passive primes: in a free picture-description task and in a primed picture-description game. The pre-test showed that in their free description of such pictures, children produce either active transitive responses or Other responses (for example, involving intransitive verbs or just noun phrases) but they did not produce passives, full or short. Once exposed to passives in the priming task, the same children used passives to describe $21 \%$ of the pictures they saw; this experiment demonstrated a priming effect with young children who did not spontaneously produce passives in the pre-test. This experiment therefore replicates the findings of previous child priming studies (Huttenlocher et al. 2004, Shimpi et al. 2007, Bencini \& Valian 2008) but it also extends the previous literature by using a different, withinparticipants, method to obtain these results. It shows that a single instance of a prime is sufficient exposure to that structure to induce three- and four-year-olds' repetition of that structure and that, unlike previous studies, children can alternate their description of pictures of transitive events with alternations in the prime structure $(47 \%$ of their utterances repeated the structure - active or passive - of the immediately 
preceding prime). This alternation occurred throughout the course of the experiment; recall that further comparisons of the children's utterances during the course of the experiment showed that passives were as frequent at the beginning of the experiment as at the end.

This priming effect occurred in the absence of repeated verbs or nouns: the prime and target pictures were paired such that the verb used to describe the prime picture could not be appropriately repeated to describe the target picture. Out of the 384 trials in the experiment there was only one instance of a participant repeating the verb of the immediately preceding prime: one child produced a passive with squash after hearing a passive prime with squash. This suggests that these children could access an abstract and generalised syntactic representation which they could use to produce passives with different nouns and verbs to the primes. For priming to occur the child must process the prime sentence in order to activate a representation that they then re-use in the production of a target response. That this repetition occurred in the absence of repeated lexical items suggests this representation is abstract, not itemspecific, by four. Therefore these results add to the body of literature which suggests that children, by four years of age, have already acquired a syntactic representation for the passive (e.g. Crain et al. 1987, Budwig 1990, Tomasello et al. 1998, Brooks \& Tomasello 1999, Bencini \& Valian 2008) and challenge the widely accepted notion that children acquire the passive late in their language development (e.g. Horgan 1978, de Villiers \& de Villiers 1979).

The observed increase in the production of passives following priming, compared to the pre-test, suggests that this method is an effective way of eliciting passives from young children. As noted above, English speakers rarely use passives in spontaneous speech unless for discourse reasons it is felicitous to promote the patient of the verb to subject position. Data such as these suggest that though passives are rare, they can be elicited. By using a method which temporarily increases children's exposures to rare constructions, such as priming, it is possible to elicit this construction from young children and therefore to examine children's syntactic representations at a younger age than previously thought.

Unlike previous child priming studies, this study also tested a control group of adults using the same method. Although this did not show a significant effect of Prime for the adults' responses, the adults did produce (numerically) more passives following passive primes providing a further validation of this priming method. The absence of a significant effect is probably due to low power - in order to obtain clearer results, future experiments will test a larger sample. 


\section{Effects of Design}

One aim of this experiment was to test whether a within-participants manipulation of priming was as effective as a between-participants manipulation for experiments with children. The priming effects (as measured as the difference between the proportions of passives following passive primes and following active primes) were $14 \%$ and $21 \%$ in the Strict scoring (depending on whether the proportions were calculated out of the sum of transitive responses or all responses) and $15 \%$ and $23 \%$ in the Lenient scoring (note that the Lenient scoring was closer to the scoring used in other studies). These effects are of a similar magnitude to other priming studies examining children's production of passives: Huttenlocher et al. (2004) report priming effects of $14 \%$ and $23 \%$ in different experiments and Bencini and Valian (2008) report priming effects of $9 \%, 14 \%$ and $33 \%$ for different scorings. The similarity between these and the present results suggests that the priming effect is not weakened by the within-participants experiment design and that children are able to alternate the choice of sentence structure following single, alternative primes.

One effect of the within-participants design is that there is more 'bleeding' of the priming effect: previous experiments, where subjects heard either active or passive primes, found that those who only heard active primes produced very few passive responses - typically around 1-2\% of responses (Huttenlocher et al. 2004, Shimpi et al. 2007, Bencini \& Valian 2008): however, in this experiment the priming effect sometimes persisted beyond a single trial and by comparison with previous experiments, participants produced more passives following active primes (7\% of the children's responses). This in turn appears to have the potential effect of reducing the measurable priming effect since the difference between the proportions of passives produced following passive and active primes is reduced ${ }^{11}$. However, despite this, as noted above, the priming effect of this experiment remained comparable to previous studies.

Despite this one potential disadvantage, it is possible to conclude that the withinparticipants priming method is an effective method to use in child priming studies. In addition to obtaining similar effect sizes as between-participants studies, it also avoided some of the potential issues associated with the between-participants method. For example, by testing all children's production of the target structures, the possibility that our results are confounded by individual differences in the children's language development is reduced. The child is not required to repeat the prime utterance therefore data are not lost if the child fails to do this. Furthermore, exposing children to

\footnotetext{
${ }^{11}$ This may explain the lack of a significant effect in the adult data despite them producing a number of passives comparable to the children: a large proportion of their responses to active primes were passive $(0.20)$ which rendered the difference with the proportion of responses to passive primes that were passive (0.29) much smaller.
} 
only one structure during the experiment may result in cumulative priming effects, that is, children may be more likely to produce passives only because they hear several instances of passives; the present study shows however that a single exemplar is sufficient to induce priming. Finally, although direct comparisons with other studies are not possible due to differences in methodology, the method used here does more closely resemble adult priming studies.

\section{Method of Analysis}

The different methods of analysis, based on proportions of passive responses calculated out of all responses or all transitive responses, yielded similar patterns of results despite the difference in magnitude of priming, the only difference being that an interaction between Group and Prime only emerged in the second method. The question remains therefore, which analysis should be used for child priming experiments? Whilst there is an argument for including all the responses the children produce in the calculation of the proportions this does mean that utterances unrelated to the priming effect will be included in the calculation of the priming effect. Some of the children's Other responses, such as reversed passives and incomplete (reversed) passives or actives, appear to be related to the primes, however others are clearly not, such as those in which they just named the characters in the pictures and those in which they produced other structures. These are clearly not instances of priming, which is usually calculated as the difference between the proportion of occurrences of a structure following the same structure prime and the proportion of occurrences of the structure following the alternative structure prime. To include other, unrelated, utterances in this calculation would be to water down the results, which may explain why no interaction between Group and Prime was observed in the first analysis. This is also in evidence in the results of the first analysis for each scoring which showed smaller effects than the second analysis for each scoring. In order to obtain clearer effects it seems imperative to follow the method of analysis of adult experiments - the 'Alternating Responses' method used here.

Clearly, though, the children's Other responses are of interest in language development research: some of their responses suggest an effect of the prime even when the output was not adult-like. However, the successive scoring set out in this chapter appear to be sufficient for investigating whether the priming effect alters when less-adult-like utterances are considered as primed responses. The more lenient scorings include forms such as short and reversed passives and incomplete utterances that were the beginning of a passive, reversed or not. By including these in subsequent analyses it is possible to examine whether these reflect different behaviour to that shown by the Strict scoring: if, for example, the children were producing a large 
number of short or reversed passives this might widen the difference between groups and give a significant interaction between the participants' age and priming effect in subsequent scorings. Using more lenient scorings of the data to include the Other responses in the analysis, rather than including all the Other responses in the calculation of the proportions, appears to provide a cleaner yet comprehensive analysis of the children's data. As such, the method of analysis for subsequent experiments will be to follow the calculation of proportions of adult experiments - the 'Alternating Responses' analysis - with the results of the three, progressively more lenient, scorings of the data.

\section{Reversed Passives}

The children produced seven complete and two incomplete reversed passives, the adults by comparison produced four incomplete reversed passives but no complete reversed passives. This is not necessarily an unusual finding: previous studies of children's production of passives shows that young children often produce reversed passives with reversible verbs (Hayhurst 1967, Turner \& Rommetveit 1967b, Horgan 1978). What is unclear is why, or how, this occurs following priming and what sort of representation this suggests is being primed. In producing reversed passives the speaker has failed to assign the arguments to the correct positions, does this mean that the children develop a syntactic representation that does not include thematic role information? An alternative possibility is that the child has competing processing strategies: on the one hand they may have selected a passive structure following the activation from the prime however this may compete with a tendency to use an agent-first strategy for production of sentences (Bever 1970). Little can be inferred on this subject given only seven occurrences of reversed passives; this issue will also be examined further across subsequent experiments for any trends in the children's reversed passives which may indicate likely causes for these utterances.

\section{Passive Tokens}

In Experiment 1 the children produced 40 passives. Figure 4.7 shows the verbs most frequently passivized by the children ${ }^{12}$ and the number of passives the adults ${ }^{13}$ produced with these verbs. It is clear from Figure 4.7 that the verbs the children most frequently passivize were not necessarily the same as those that the adults produced most passives with. The adults frequently passivized two other verbs: punch (5 passives) and soak (4 passives) each of which the children only passivized once.

Six of the twelve target verbs that were depicted for the children to describe are among

\footnotetext{
${ }^{12}$ The other verbs that the children used in the passive occurred only once each: crush, do, grab, hug, punch, push, ribbit, soak, spray, squash.

${ }^{13}$ The other verbs that the adults used in the passive were: punch (5), soak (4) hug (3), pinch (2), push (1), carry (1), hose (1), knock over (1), shove (1).
} 


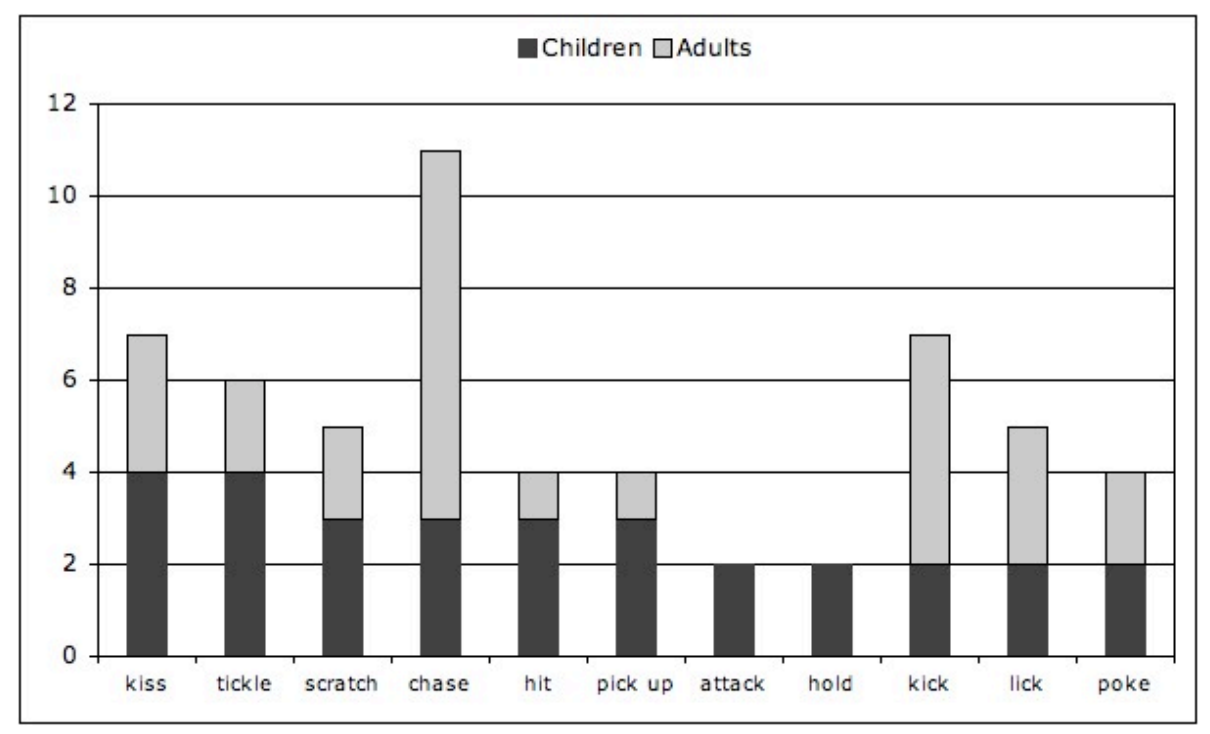

Figure 4.7: Experiment 1: Verbs most frequently passivized

the most frequently passivized verbs (kiss, scratch, tickle, chase, kick, lick). In this experiment the children (and adults) only produced passives with actional verbs, which is not surprising since the target picture depicted actional events. Some previous studies suggest however that children's early passives are restricted semantically to this type - actional - of verb; a number of studies show that children's comprehension of subject-experiencer non-actional verbs is at chance level until at least five year of age (Maratsos et al. 1985, Sudhalter \& Braine 1985, Gordon \& Chafetz 1990, Fox \& Grodzinsky 1998, Hirsch \& Wexler 2006b). The evidence from this priming experiment does not contradict or add to research in this area. The children tended to produce actional verb passive responses after hearing actional verb passive primes, providing supporting evidence that they can comprehend and produce actional verb passives before five; the fact that they did not produce non-actional verb passives simply reflects the fact that the target pictures were designed to elicit actional verb passives, it does not provide evidence that they cannot produce non-actional verb passives. Similarly this experiment did not test whether or not they can comprehend non-actional verb passives. This issue is investigated in a series of experiments in the following chapter, Chapter 5, which examines whether primes involving non-actional verbs have the same priming effect as actional verb primes.

\section{Passive Types}

The syntactic repetition effect observed in this study occurred in the absence of repeated open-class lexical items (argument NPs and the passive participle verb forms) 
and therefore is interpreted as showing evidence that three- and four-year-old children have already acquired an abstract syntactic representation for the passive. However, there are potentially other sources of lexical priming that could contribute to the observed repetition effect. In this experiment the passive primes were always of the form: A PATIENT is being VERB-ed by an AGENT, that is they had a be form of the passive auxiliary and always expressed the underlying subject in a by-phrase. However in English, the passive occurs in other forms: with a get form for the auxiliary (i.e. A PATIENT is getting VERB-ed by an AGENT). Additionally, the passive is more frequently shortened in spoken English (i.e. A PATIENT is getting/being VERB-ed) (Svartvik 1966, p. 134). As discussed in Chapter 2 there is evidence to suggest that the form of children's early passives is different to that used in the experiment: children tend to find short passives easier to comprehend (Baldie 1976, Harris 1976, Fox \& Grodzinsky 1998) and produce (Slobin 1968, Hayhurst 1967, Harris \& Flora 1982, Marchman et al. 1991) than full passives. In addition, they are more likely to use a get form for the auxiliary than be (Harris \& Flora 1982, Marchman et al. 1991) ${ }^{14}$.

Yet, in Experiment 1 all of the children's 40 passives were full (expressing the logical subject in a by-phrase), be-passives, (as were $89 \%$ of the adults' 46 passive responses, $11 \%$ were full get-passives). Neither the adults nor the children used any preposition other than by for the post-verbal noun phrase. Huttenlocher et al. (2004) also noted in their first experiment that nearly half of the passives produced following passives primes were full passives compared to following actives when the only passives children produced were short passives. In addition Turner and Rommetveit (1967b) found that children would use be as the passive auxiliary to describe pictures when be-passives were modelled to them in passive-eliciting questions (i.e. what is being done to the PATIENT?) but switched to get when a neutral form (i.e. what is happening to the PATIENT?) was modelled. These data suggest that the surface form of the primes (or the questions in the case of Turner and Rommetveit (1967b)) may have influenced the children's responses. Bock and Loebell (1990) found that passive primes (the plane was radioed by the control tower) and locative primes (the plane was landing by the control tower) were equally good primes of passive responses. They suggest that the syntactic similarities of passives and locatives, in terms of constituent structures, were responsible for the priming effect, however the possibility remains that participants formed lexically based frames using the repeated items such as the preposition by.

This poses the problem: is the observed priming effect related to or influenced by lexical priming? Savage et al. (2006) suggest that young children could have rep-

\footnotetext{
${ }^{14}$ Although recall that Meints (2003) suggests that British children tend to produce be-passives rather than get-passives; children's use of be-passives in Experiment 1 may simply reflect their regional variety of English.
} 
resentations based on closed-class lexical items, such as the auxiliary or preposition by. I investigate these issues in Chapter 6, which presents two experiments examining whether the surface form of the primes influences the form of the utterance or whether different passive forms all relate to, and all activate, the same underlying structure and therefore elicit similar passive responses to those found in this experiment, irrespective of the surface form of the prime.

\subsection{Summary and Conclusions}

This chapter has presented the first priming experiment and a pre-test. To summarize the findings: the pre-test showed that active sentences are preferred by children and adults alike to describe pictures of transitive events. The priming experiment showed that both groups produce (numerically) more passives once exposed to passive primes, though the effect of the primes was only significant in the children's group. This experiment found a stronger priming effect for children than is usually found in priming experiments with adults, this is in line with findings from other child priming studies and other studies of non-proficient language users. The results were comparable to previous priming studies with children despite the fact that prime was a within-participants, not between-participants, factor showing that children can alternate their choice of sentence structure in line with alternations in the prime structure. This alternation occurred throughout the experiment; the participants did not require a build-up of exposure to passive primes before they produced this structure.

These results support previous findings, from both priming studies and studies employing different elicitation techniques, which suggest that by around four years of age, English-speaking children have formed a syntactic representation for the passive which is not specific to particular lexical items but is abstract enough to be reproduced with different verbs. However, like previous studies, this experiment found that at three and four, children have not fully mastered the construction: they produce some complete and incomplete reversed passives. They also produce erroneous but passive-like utterances (e.g. 'a rabbit been hugging by a girl" and "a queen is being with a rabbit tickled with a feather"). Nonetheless, like studies which employ a modelling technique (Tomasello et al. 1998, Turner \& Rommetveit 1967b), the priming method appears to facilitate children's access to and production of this syntactic representation, early in their language development. This experiment demonstrates that this an effective method for eliciting passives: seven out of the eight children tested produced at least one passive and very little data was lost from the experiment. 
This experiment establishes the methodology for the subsequent experiments in this thesis, including an appropriate method of analysis: in order to carry out a comprehensive analysis of the children's responses, I will score the proceeding experiment data according to the three sets of increasingly lenient criteria. The Passive results of these scorings will be analysed as proportions of the sum of Active and Passive responses only ('Alternating Responses' method) to ensure that priming is not weakened by the inclusion of unrelated responses. 


\section{Chapter 5}

\section{Semantic Factors in Children's Early Passives}

\subsection{Introduction}

The previous experiment suggests that by four years of age, English speaking children have acquired a syntactic representation for the passive which is abstract and adult-like: there was priming between passives with unrelated verbs. Though the evidence suggests that, at this age, children have a syntactic representation for the passive which is not based around specific lexical items, previous priming experiments, here and in the literature, only examined priming from one semantic class of verb - actional verbs, involving agent and patient thematic roles. There is evidence in the language acquisition literature to suggest that children's acquisition of the passive is constrained to actional verbs first and only generalised to non-actional verbs, involving theme and experiencer thematic roles, later (after five years) in their language development (e.g. Maratsos et al. 1985). The results of the priming experiments do not contradict this evidence: if children's syntactic representation is only generalised to actional verbs then one would expect priming from actional verb passives to actional verb targets. Chapter 5 therefore examines priming from passives with different verb types to examine whether children comprehend and are primed by passives involving non-actional verbs. If their early passive representation does not include these verbs one would not expect priming from these passives. Previous studies have found this semantic distinction between children's comprehension of (agent-patient) actional verb passives and subject-experiencer non-actional verb passives; in this chapter I also examine a second type of non-actional verb passive - object-experiencer - which 
there is evidence to suggest adults are more likely to produce passives with compared to other verb types (Ferreira 1994). If children's generalisation of the passive is related to the adult input, then one would expect children to understand object-experiencer passives as well as agent-patient passives, however if children have difficulty with non-actional verb passives in general one would not expect children to understand these.

Experiment 2 compares priming from actional verb passives (as used in Experiment 1) and object-experiencer non-actional verb passives; these involve psychological verbs, (such as surprise, confuse or irritate) that project a theme role to the verb's underlying subject and an experiencer role to its underlying object. Experiment 3 compares priming from object-experiencer non-actional verb passives and subject-experiencer non-actional verb passives; these involve psychological (e.g. remember), experiential (e.g. love) or perceptual (e.g. see) verbs that project an experiencer thematic role to the verb's underlying subject and a theme role to its underlying object. Experiment 4 tested children's understanding of all three types of passive - agent-patient actional, object-experiencer and subject-experiencer non-actional - using an alternative method which is frequently used in language acquisition research: a picture-sentence matching task. This experiment compared the children's comprehension of these passives in an alternative task to the priming method to examine whether this method of testing could account for the semantic effects in children's understanding of passives.

\subsubsection{Semantic Constraints on Children's Early Passives}

A number of studies investigating children's early understanding and use of the passive have shown that children comprehend and tend to produce passives with certain types of verbs earlier than with other types. For example, Maratsos et al. (1985) tested children's comprehension of sentences, first in a task which presented the child with the stimulus sentence then asked the question "Who did it?" and then in a picturesentence matching task, in which children heard a sentence and had to find the picture, of a choice of two with the characters' roles swapped ${ }^{1}$, that matched it. They reported that even at five years of age, children find (subject-experiencer) mental verb nonactional passives, such as (5.1a), more difficult to understand than actional verb passives, sentences such as (5.1b). They report that four- and five-year-old children comprehend actives with either verb type better than passives. Furthermore, their comprehension of actional verb passives was above chance in both tasks - around $67 \%$ in the stimulus sentence-question task and $83 \%-91 \%$ in the picture-sentence matching

\footnotetext{
${ }^{1}$ For example, they heard the sentence: "Donald is held by Batman" and saw the pictures: Batman holding Donald Duck and Donald Duck holding Batman (Maratsos et al. 1985, p. 178).
} 
task - but their comprehension of the non-actional verb passives was unreliable around chance level in the stimulus sentence-question task and below chance for the four-year-olds in the picture-sentence matching task and above chance, but lower than the actional passive scores, for the five-year-olds.
a. The girl was seen by the boy.
b. The girl was kissed by the boy.

Clearly the method of testing had a further effect on the results, as Maratsos et al. (1985) acknowledge, with the children performing better in the picture-sentence matching task than in the stimulus sentence-question task; this is discussed further below. Nonetheless, both tasks showed the distinction between children's comprehension of actional verb passives and mental verb non-actional passives. This finding has been replicated in a number of studies testing children's comprehension of passives (Sudhalter \& Braine 1985, Gordon \& Chafetz 1990, Fox \& Grodzinsky 1998, Hirsch \& Wexler 2006b). Some studies of children's production of passives also suggest they tend to produce passives with actional rather than psychological or experiential nonactional verbs (Budwig 1990, 2001, Marchman et al. 1991).

A number of theories have been proposed to account for this finding. For example, Borer and Wexler (1987) suggest that children acquire the passive late because certain grammatical principles required to process structures, in this case Argument-chain (A-chains) formation, are maturationally constrained, that is, they appear late in language development. They propose that before five, children cannot process A-chains and thus cannot process full passives, however they perform well with actional verb passives in comprehension tests because these share a similar surface form with adjectival passives which do not require A-chains. Borer and Wexler suggest that children understand these actional verb passives as adjectival passives but this analogy is not felicitous with subject-experiencer verb participles which do not make good adjectives, hence children's unreliable comprehension of subject-experiencer passives.

Fox and Grodzinksy (1998) propose an alternative possibility: children's difficulty understanding subject-experiencer verb passives is related to a difficulty transmitting the verb's thematic-role to the external noun phrase because of either processing or maturational constraints. They suggest that children successfully interpret actional verb passives however because they assign an agentive thematic role to the external noun from the preposition by. Since this is compatible with the thematic role that the verb would assign, they arrive at the correct interpretation for these passives. However they are unable to comprehend subject-experiencer non-actional verb passives using 
this strategy as these would assign an experiencer role, not an agentive role, to the external noun.

These two proposals suggest that the passive syntax is acquired late and that the semantic effect is a result of the strategies children use to process passive sentences, however there is evidence to suggest that children do acquire the syntax of passives before this age (Bencini \& Valian 2008, Shimpi et al. 2007) and should thus be able to process passive sentences as passives, not as adjectival phrases or using the preposition by for thematic role assignment. The priming results reported in the previous experiment and in other experiments challenge these theories which suggest that before five, children do not have a syntactic representation for the passive and therefore cannot process the syntax of full passives properly; the evidence from syntactic priming experiments is that they can do this at four years and younger (Bencini \& Valian 2008).

Alternatively, Maratsos et al. (1985) propose that children's development of the passive construction may be semantically constrained such that they generalise their knowledge of the passive structure to proto-typically transitive verbs (e.g. action verbs such as 5.1b) first, and to less proto-typically transitive verbs (such as subjectexperiencer non-actional verbs (5.1a)) later. Maratsos et al. (1985) suggest that this generalisation may be guided by adult use of the passive: they report a brief analysis of adults' child-directed speech in which they found very few passives, most of which occurred with resultative action verbs. They report no adult passives with subjectexperiencer non-actional verbs, which were the kind that children tended to comprehend poorly. If children's generalisation of the passive is related to the passives that adults produce, this evidence would support their experimental findings. In addition, they did find that adults produce passives with object-experiencer non-actional verbs. If children's generalisation of the passive is guided by adult use of the passive, this would suggest that children would comprehend object-experiencer verb passive earlier than subject-experiencer; however, Maratsos et al. (1985) do not test this, nor have any other studies tested these types of verbs.

Ferreira (1994) provides experimental evidence which also suggests that adults produce more object-experiencer passives than other verb types. She asked adults to produce a sentence with a given verb and a given subject and object. She found that adult English-speakers were more likely to produce passives with object-experiencer non-actional verbs (31\% of sentences that adults produced with these verbs) than with actional and subject-experiencer verbs, which she grouped together into one category, (4\% of sentences with these verbs). Ferreira (1994) suggests that adults' preference for passives with object-experiencer verbs may be consistent with thematic-role hierar- 
chies (e.g. Jackendoff, 1972): the thematic role assignment of object-experiencer passive sentences matches the order of these hierarchies having the experiencer, which is at the top of the hierarchy, in sentence-subject position and the theme, which is at the bottom of the hierarchy, in post-verbal position (5.2a).
a. The $\operatorname{girl} \mathrm{l}_{[\text {experiencer }]}$ was scared by the boy $[$ theme $]$
b. The $\operatorname{girl}_{[\text {patient }]}$ was kissed by the boy ${ }_{[a g e n t]}$
c. The $\operatorname{girl}_{[\text {theme }]}$ was seen by the boy ${ }_{[\text {experiencer }]}$

However, the thematic role assignment of actional verb (5.2b) and subject-experiencer verb (5.2c) passives is in the opposite order to the hierarchy with the patient/theme in sentence-subject position and the agent/experiencer at the end of the utterance. Thus, actives with these two verb types conform to the order of the hierarchy, not passives. If adults do have a tendency to place certain thematic roles in subject position, this would explain their tendency to produce certain passives more than others; it might also account for children's difficulty with subject-experiencer passives: this may be related to the mapping of particular thematic roles on to particular sentence positions, such as an experiencer role to subject position. But this would predict that they should find agent-patient actional verb passives harder too, which is not supported by previous research. Alternatively, as Maratsos et al. (1985) suggest, children may generalise their syntactic representation for the passive to subject-experiencer verbs late because these verbs are less prototypically transitive.

None of the studies noted above, which have reported children's poor understanding of subject-experiencer non-actional verb passives, have studied children's comprehension of object-experiencer non-actional verb passives. However these provide an interesting test case: if, early on, children do not generalise the passive to non-actional verbs in general (those involving theme and experiencer roles in any configuration), one would expect them to perform as poorly with object-experiencer verb passives as with subject-experiencer; however, if it is the case that subject-experiencer verb passives are more difficult (because of their thematic role assignment or the paucity of these passives in adults' speech), children should perform comparatively better with object-experiencer passives. One aim of the present study therefore was to examine whether children also have difficulty comprehending this type - object-experiencer — of non-actional verb passive or not.

An alternative possible explanation is that children's difficulty with subjectexperiencer verb passives is confounded by the tasks previously used to test this; recall that Maratsos et al. (1985) found different results in two different tasks testing 
the same types of sentences: children performed better in a picture-sentence matching task than in a stimulus sentence-question task. It is further possible that the picturesentence matching task also has a negative impact on children's performance; Beilin (1975) reports that the children in his study performed better in an enactment task than in a picture-sentence matching task. Difficulty may be caused by the task which involves depicting sentences with subject-experiencer verbs because such verbs are harder to depict than other types of verbs such as actional verbs. In order to rule out this alternative possibility - that the results of previous studies are an artefact of the task that is used - a different task to previous studies is used to test children's comprehension. Hence, I tested children's comprehension of passives with different verb types in a syntactic priming experiment to see whether this replicates the findings of previous experiments: that children find subject-experiencer verb passives harder to understand than actional verb passives.

\subsubsection{Predictions for Experiments Two and Three}

It is possible to use priming to test children's comprehension of structures implicitly: it follows that if children cannot process the structure of a (comprehended) passive prime, it should not prime them to produce passive descriptions. They should be more likely to repeat the structure if they can comprehend, i.e. retrieve an appropriate syntactic representation for it. Previous research has shown that actional verb passives prime passive descriptions from three-, four- and five-year-old children (e.g. Huttenlocher et al. 2004, Shimpi et al. 2007, Bencini \& Valian 2008). This does not contradict the research reviewed above which suggests that the passive is acquired with actional verbs early on. The priming experiments presented in this chapter examine whether children younger than five comprehend subject- and object-experiencer passives by measuring whether these primes elicit passive responses.

If children restrict their generalisation of the passive construction to a core class of verbs early on, for example proto-typically actional verbs as Maratsos et al. (1985) suggest, they would have an early syntactic representation for the passive that is only linked to these verbs, i.e the verbs carrying the features that define that verb class. Therefore only verbs from the same class should prime passive responses. This is illustrated in Figure 5.1, using an adaptation of the model set out by Pickering and Branigan (1998) and discussed in Section 3.3: hit and push are both proto-typically actional verbs and so children should generalise the passive to these earlier than to love or scare. Thus, in the representational system, hit and push are linked to the passive combinatorial node and so either should prime the other; love and scare however are not 
linked to the combinatorial node and so should not prime or be primed by passives, if children's generalisation of the passive is restricted to actional verbs.

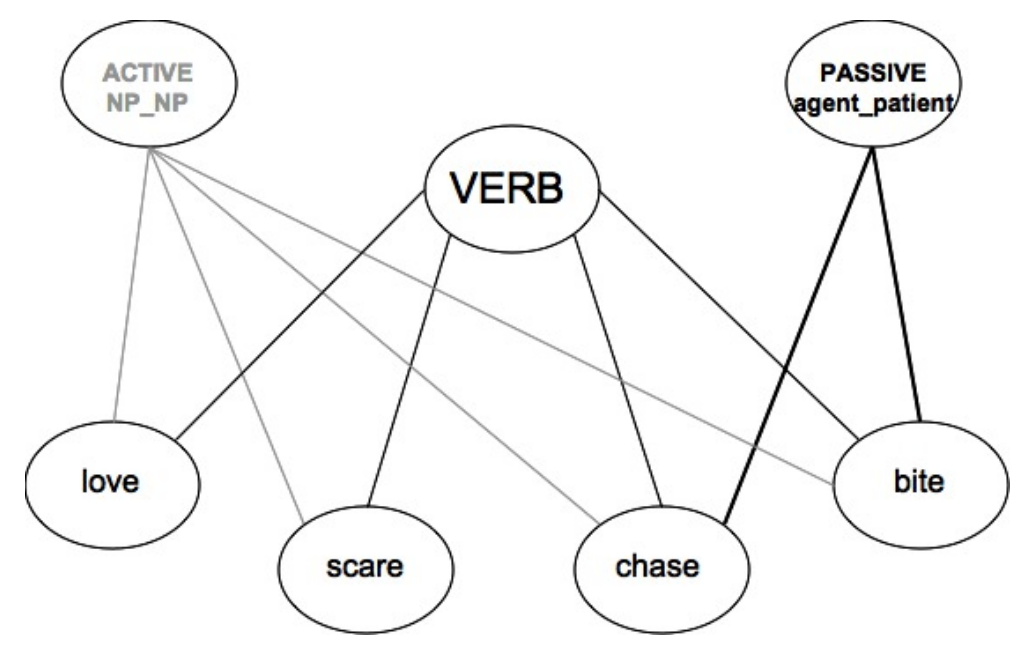

Figure 5.1: Model of syntactic representation: Passive is semantically constrained to actional verbs

An alternative hypothesis is that children acquire the passive with object-experiencer verbs as early as, or indeed earlier than, action verbs (since adult evidence suggests that passives are preferred with this non-actional verb type) but do not extend this structure to subject-experiencer non-actional verbs until much later, as previous child language research suggests. In this case, one would expect the same priming effect from both actional and object-experiencer non-actional primes, but no priming effect from subject-experiencer non-actional primes (see Figure 5.2).

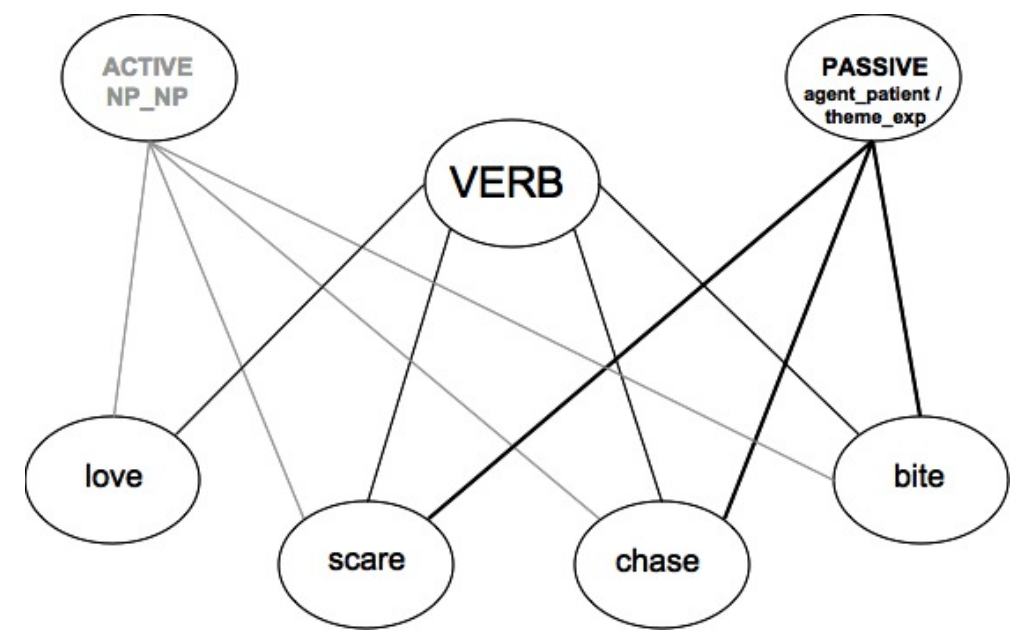

Figure 5.2: Model of syntactic representation: Passive is semantically constrained to actional and object-experiencer verbs

A final hypothesis is that children's early passive representation is not constrained to 
particular semantic classes of verbs, rather, it is linked, or generalised, to verbs of all semantic classes, (see Figure 5.3). In this case one would expect young children to be primed by all verbs from all semantic classes from a young age.

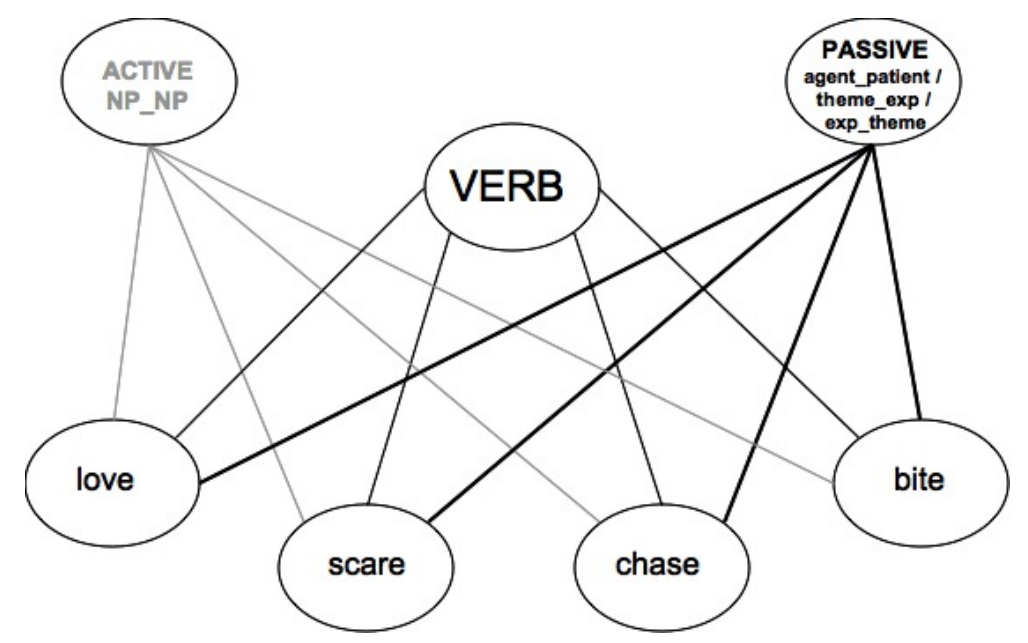

Figure 5.3: Model of syntactic representation: Passive is not semantically constrained

I tested these hypotheses using the 'Snap' priming task by manipulating the characteristics of the prime sentence that children heard and examining how this affected their description of a subsequent picture depicting a transitive action. If children have a genuine difficulty comprehending subject-experiencer verb passives, because their syntactic representation does not extend to verbs of this type, these should not prime passive responses. If however children can comprehend these passives early on, because their representation for the passive is not restricted to particular types of verbs, and their previous poor performance is related to the task used to test them, then subject-experiencer passives should prime passive responses.

\subsubsection{Additional Analyses}

In addition, in the experiments reported in this chapter I also carried out additional analyses in order to rule out confounding factors in these experiments; some of these factors were tested in Experiment 1 however the participant groups were very small in that experiment therefore these and other tests are repeated in order to be more confident that the results reflect genuine relationships. Given the large age range of the children in each experiment, it is possible that the results mask differing effects within the group. To exclude this possibility, I examine whether there is any relationship between the participants' age and the number of passives participants produced. If younger children within the group cannot understand some of the primes (e.g. non- 
actional passives), one could predict that they will produce fewer passives than older children. I measure the number of passives produced rather than their individual priming effect because a negative priming effect may be found if a participant's tendency to produce passives bleeds into other trials and they produce more passives following active primes - a participant who shows a strong tendency to produce passives may end up with a negative priming effect which would confound the correlation. Experiment 1 (pre-test) shows that children tend not to produce passives when they have not heard passive primes, therefore children's production of passives following passive primes in these experiments suggests they have comprehended these primes.

I also examined whether there is any evidence of a learning effect across the experiment. As in Experiment 1, I compared whether participants were more likely to produce passives at the end of the experiment, following the last eight primes, than at the beginning, following the first eight primes. Accounts which relate priming to implicit learning mechanisms predict that participants should be more likely to produce passives when the system has experienced more, that is, at the end of the experiment (e.g. Savage et al. 2006). In the case of subject-experiencer verbs, this may be particularly important: adults tend not to produce subject-experiencer verb passives therefore the experiment will provide a large increase in children's exposure to such passives. They may generalise their constrained passive representation during the course of the experiment, in which case one would predict more passives would be produced at the end of the experiment. If this does not occur, this may be interpreted as further evidence that children's syntactic representation underlies passives with any verb by four years of age.

I also obtained an independent measure of the children's language development to examine whether this accounts for the variation in the number of passives that children produce: I administered the British Picture Vocabulary Scale II test (hence forth referred to as BPVS; Dunn et al. (1997)) to obtain a measure of the children's receptive vocabulary size (Experiment 3 ). The variation in priming effect and number of passives individuals produced, observed in Experiment 1, may be related to the level of language development of the individual participants. Children whose language is more developed, as characterised by a larger vocabulary, may be more likely to have stronger or more abstract syntactic representations than children whose language is less developed. Those who have developed abstract syntactic representation may be more susceptible to priming and so may be more likely to produce more passives. Thus I examined whether any variation in the number of passives children produce relates to their vocabulary size. 
Finally, I examined whether the materials themselves influence the pattern of results by examining whether participants are more likely to produce passives when the patient is depicted on the left of the picture than when it is depicted on the right, note that half of the target pictures depicted the patient on the left and half depicted it on the right. There is evidence that adults (whose language has a left-to-right writing system) tend to also process images from left to right, though children who are of a pre-reading and writing age do not show the same influence (Dobel, Diesendruk \& Bölte 2007). If the way participants scan the pictures — from left to right — influences their formulation of an utterance they may be more likely to produce passives when the patient is the first entity they see, or rather, they may be less likely to produce a passive, even following a prime, if the agent is the first entity they see. I therefore compare whether adults and children showed a tendency to produce more passives when the patient was depicted on the left than when it was on the right; one might predict less of an effect for the nursery-aged children most of whom will not have begun to read or write, though are likely to have some experience of being read to and the left-to-right nature of reading.

\subsection{Experiment Two: Agent-Patient Primes vs. Object- Experiencer Primes}

Experiment 2 compared children's comprehension of agent-patient actional and object-experiencer non-actional passives by examining whether they produced passive descriptions following these primes. The target items all depicted actional verb events to be confident that if children did not describe these with passives it was related to a difficulty understanding the prime not a difficulty describing the picture; I used the same target items from the previous experiments. According to previous priming studies and studies of children's comprehension of passives, children can comprehend actional verb passive primes, that is, they have access to a passive representation that they can use in their subsequent production. Therefore, following actional verb passive primes, children should be more likely to produce passive descriptions for pictures of (actional) transitive events. If children's difficulty comprehending subject-experiencer verb passives in previous studies is related to a general difficulty with non-actional passives involving theme and experiencer roles in general, then object-experiencer primes should not prime passive responses. If however children's acquisition of the passive is constrained to the classes of verbs with which adults tend to produce passives, or if previous results reflect particular task demands, then both types of prime should elicit passive responses. 


\subsubsection{Method}

\section{Design}

All participants experienced all levels of the priming conditions: the repeated measures factors were: Prime (active vs. passive) and Verb Type (agent-patient actional vs. object-experiencer non-actional); Group (children vs. adults) was a betweenparticipants factor. As previously, the form of the active test sentences was: $A$ SUBJECT is VERB-ing an OBJECT and the form of the passive test sentences was: $A$ SUBJECT is being VERB-ed by an OBJECT.

\section{Participants}

I recruited more participants for each group in this experiment with the aim of obtaining clearer effects than found in Experiment 1. The participants were 20 pre-school children (10 girls), ranging in age from 3;1 to 4;11 (mean age 4;2) and a control group of 20 adult, native speakers of English (15 female; mean age 21;6).

\section{Materials}

The Snap items consisted of the agent-patient actional verb primes (bite, carry, hit, pat, pull, squash, each used four times) from Experiment 1 (see Appendix A.2) and an object-experiencer non-actional version using six verbs: annoy, frighten, scare, shock, surprise, upset, each used four times, (see Appendix B.1 for a full list of these nonactional primes). Thus there was an agent-patient and an object-experiencer version of each prime depicted with the same two entities (see Figure 5.4); each picture had an associated active and passive description. Experiment 2 used the same 24 target pictures (Appendix A.3) and the same filler and practice items (see Appendices A.4 and A.5) as used in Experiment 1. Four sets of the experiment and filler items were created such that across the four sets each target occurred once in each of the priming conditions and within a set an even number of the targets (six) occurred in each priming condition. Five randomized experiment lists were created from each of the four sets which acted as priming scripts during the experiment.

\section{Procedure}

This experiment followed the same procedure employed in the previous priming experiments. Once again, I scored and analysed the data according to the three different sets of criteria set out in Chapter 4, Strict (5.2.2), Lenient (5.2.3) and Inclusive (5.2.4). 


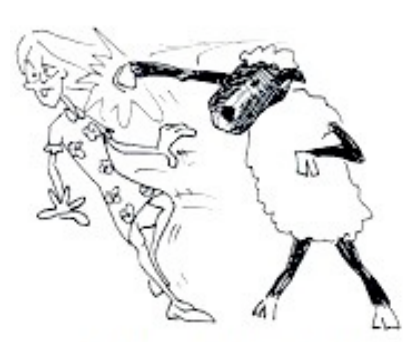

A sheep is hitting a girl A girl is being hit by a sheep

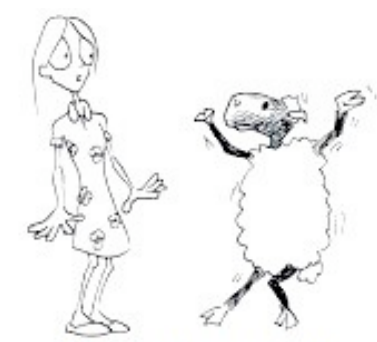

A sheep is shocking a girl A girl is being shocked by a sheep

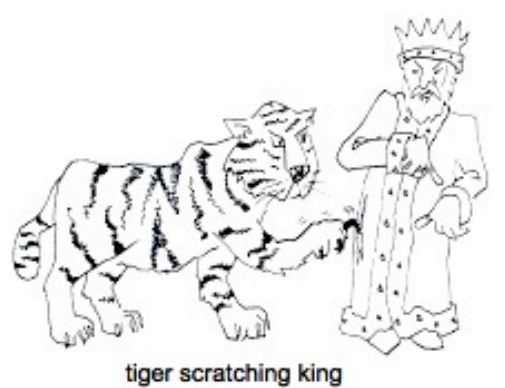

tiger scratching king

Figure 5.4: Experiment 2: Agent-patient and object-experiencer primes and a target item

\subsubsection{Strict Scoring Results}

\section{Results}

Out of each group's 480 target items, 12 (3\%) of the children's trials and 7 (1.5\%) of the adults' were eliminated because the wrong prime was given, the participant failed to respond or the response was lost due to recording problems or misplaced cards. The children produced 317 (66\%) transitive responses scored as either Active (238, 50\%) or Passive $(79,16 \%)$ and $151(31 \%)$ responses scored as Other. The adults produced $445(93 \%)$ transitive responses scored as Active $(361,75 \%)$ or Passive $(84,17.5 \%)$ and $28(6 \%)$ responses scored as Other; see Table 5.1 for a breakdown of the responses by structure and verb type.

Table 5.1: Experiment 2: Frequency of active, passive and other responses according to group and prime condition

\begin{tabular}{|c|c|c|c|c|c|c|c|c|}
\hline \multirow[b]{2}{*}{ Group } & \multirow{2}{*}{\multicolumn{2}{|c|}{ Prime }} & \multicolumn{6}{|c|}{ Response } \\
\hline & & & \multicolumn{2}{|c|}{ Active } & \multicolumn{2}{|c|}{ Passive } & \multicolumn{2}{|c|}{ Other } \\
\hline \multirow{4}{*}{ Children } & \multirow{2}{*}{ Active } & Agent-Patient & 73 & 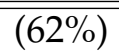 & 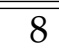 & $\overline{(7 \%)}$ & 37 & $\overline{~(31 \%)}$ \\
\hline & & Object-Experienc & 77 & $(66 \%)$ & 11 & $(9 \%)$ & 29 & $(25 \%)$ \\
\hline & \multirow{2}{*}{ Passive } & Agent-Patient & 41 & $(36 \%)$ & 31 & $(27 \%)$ & 42 & $(37 \%)$ \\
\hline & & Object-Experien & 47 & $(39 \%)$ & 29 & $(24 \%)$ & 43 & $(36 \%)$ \\
\hline \multirow{4}{*}{ Adults } & \multirow{2}{*}{ Active } & Agent-Patie & 103 & $(88 \%)$ & 10 & $(9 \%)$ & 4 & $(3 \%)$ \\
\hline & & Obje & 99 & $(83 \%)$ & 11 & $(9 \%)$ & 10 & $(8 \%)$ \\
\hline & \multirow{2}{*}{ Passive } & Agen & 79 & $(67 \%)$ & 35 & $(30 \%)$ & 4 & $(3 \%)$ \\
\hline & & Object-Experiencer & 80 & $(68 \%)$ & 28 & $(24 \%)$ & 10 & $(8 \%)$ \\
\hline
\end{tabular}

\section{Analysis}

Following the discussion in Experiment 1, in this and subsequent experiments I conduct the analyses on the Passive target descriptions in each condition as proportions 
of the total number of transitive (active and passive) targets in that condition; separately, I analyse the Other responses as raw numbers to examine whether there were any effects.

\section{Passive Responses}

Table 5.2 shows the mean proportions of Passive responses following the Strict scoring. Repeated measures ANOVAs treating participants $\left(F_{1}\right)$ and items $\left(F_{2}\right)$ as random effects analysed these results. Prime (active vs passive) and Verb Type (agent-patient vs object-experiencer) were within-participants and within-items factors; Group (children vs adults) was a between-participants but within-items factor. The results of these ANOVAs are presented in Table 5.3 below.

Table 5.2: Experiment 2: Mean proportions of Passives in the Strict scoring

\begin{tabular}{llcccc}
\hline & & \multicolumn{2}{c}{ Children } & \multicolumn{2}{c}{ Adults } \\
\cline { 3 - 6 } & Prime & M & (SD) & M & (SD) \\
\hline \hline \multirow{2}{*}{ Active } & Agent-Patient & 0.16 & $(0.32)$ & 0.09 & $(0.12)$ \\
& Object-Experiencer & 0.18 & $(0.31)$ & 0.10 & $(0.17)$ \\
\multirow{2}{*}{ Passive } & Agent-Patient & 0.44 & $(0.33)$ & 0.31 & $(0.28)$ \\
& Object-Experiencer & 0.38 & $(0.36)$ & 0.25 & $(0.23)$ \\
\hline
\end{tabular}

Table 5.3: Experiment 2: ANOVA of proportions of Passives in the Strict scoring

\begin{tabular}{lrrlllrll}
\hline & \multicolumn{4}{c}{ F1 Results } & \multicolumn{5}{c}{ F2 Results } \\
\cline { 2 - 9 } Effect & $d f$ & $\boldsymbol{F 1}$ & $\boldsymbol{p}$ & $\boldsymbol{p .} \eta^{2}$ & $\boldsymbol{d f}$ & $\boldsymbol{F 2}$ & $\boldsymbol{p}$ & $\boldsymbol{p} . \eta^{2}$ \\
\hline \hline Prime & 1,38 & 24.34 & $<.001$ & 0.39 & 1,46 & 69.95 & $<.001$ & 0.60 \\
Verb Type & 1,38 & 0.69 & n.s. & 0.02 & 1,46 & 1.19 & n.s. & 0.02 \\
Group & 1,38 & 2.74 & $=.11$ & 0.07 & 1,46 & 4.38 & $<.05$ & 0.09 \\
Prime x Group & 1,38 & 0.38 & n.s. & 0.01 & 1,46 & 3.77 & n.s. & 0.08 \\
Verb Type x Group & 1,38 & 0.01 & n.s. & 0.00 & 1,46 & 0.20 & n.s. & 0.00 \\
Prime x Verb Type & 1,38 & 1.24 & n.s. & 0.03 & 1,46 & 2.05 & n.s. & 0.04 \\
PrimexVerbTypexGroup & 1,38 & 0.02 & n.s. & 0.00 & 1,46 & 0.35 & n.s. & 0.01 \\
\hline Prime (Children) & 1,38 & 15.38 & $<.001$ & 0.29 & 1,46 & 53.10 & $<.001$ & 0.54 \\
Prime (Adults) & 1,38 & 9.33 & $<.01$ & 0.20 & 1,46 & 20.62 & $<.001$ & 0.31 \\
Verb Type (Children) & 1,38 & 0.42 & n.s. & 0.01 & 1,46 & 1.18 & n.s. & 0.02 \\
Verb Type (Adults) & 1,38 & 0.27 & n.s. & 0.01 & 1,46 & 0.20 & n.s. & 0.00 \\
Prime (Agent-Patient) & 1,38 & 25.16 & $<.001$ & 0.40 & 1,46 & 45.14 & $<.001$ & 0.49 \\
Prime (Object-Experiencer) & 1,38 & 8.82 & $<.01$ & 0.19 & 1,46 & 23.88 & $<.001$ & 0.34 \\
\hline
\end{tabular}

These showed a significant effect of Prime but no effect of Verb Type: overall, the participants produced more passives after hearing passive primes $(M=0.35)$ than after hearing active primes $(\mathrm{M}=0.13)$, regardless of whether they contained an agentpatient verb $(M=0.25)$ or an object-experiencer verb $(M=0.23)$. There was a main effect of Group, by items only; the children produced more passives $(M=0.29)$ than the adults $(M=0.19)$. No other effects or interactions were significant. Simple main effects showed a significant effect of Prime for both the children and the adults but no effect 
of Verb Type for either group: both groups produced more passives following passive primes than following active primes, however neither group produced more passives following agent-patient primes than following object-experiencer primes. There was also a simple main effect of Prime for both the agent-patient verb primes and the object-experiencer verb primes: participants were more likely to produce passive targets following agent-patient passive primes than agent-patient active primes and likewise for object-experiencer primes.

\section{Other Responses}

I then analysed the raw numbers of Other responses to check for an effect of Prime or Verb Type which might indicate underlying difficulties understanding the primes. The mean number of Other responses are shown in Table 5.4. The $2 \times 2 \times 2$ ANOVAs were repeated with the Other responses, the results of these are reported in Table 5.5 below.

Table 5.4: Experiment 2: Mean numbers of Others in the Strict scoring

\begin{tabular}{llcccc}
\hline & \multirow{2}{*}{ Prime } & \multicolumn{2}{c}{ Children } & \multicolumn{2}{c}{ Adults } \\
\cline { 3 - 6 } Active & M & (SD) & M & (SD) \\
\hline \hline \multirow{2}{*}{ Passive } & Object-Expatient & 1.85 & $(1.27)$ & 0.20 & $(0.41)$ \\
& Agent-Patient & 2.10 & $(1.62)$ & 0.20 & $(0.41)$ \\
& Object-Experiencer & 2.15 & $(1.69)$ & 0.50 & $(0.61)$ \\
\hline
\end{tabular}

Table 5.5: Experiment 2: ANOVA of numbers of Others in the Strict scoring

\begin{tabular}{lrrlrrrrr}
\hline & \multicolumn{4}{c}{ F1 Results } & \multicolumn{4}{c}{ F2 Results } \\
\cline { 2 - 9 } Effect & $d f$ & $\boldsymbol{F 1}$ & $\boldsymbol{p}$ & $\boldsymbol{p} . \eta^{2}$ & $\boldsymbol{d f}$ & $\boldsymbol{F 2}$ & $\boldsymbol{p}$ & $\boldsymbol{p} . \eta^{2}$ \\
\hline \hline Prime & 1,38 & 3.27 & -.08 & 0.08 & 1,46 & 2.34 & $=.13$ & 0.05 \\
Verb Type & 1,38 & 0.24 & n.s. & 0.01 & 1,46 & 0.19 & n.s. & 0.00 \\
Group & 1,38 & 32.10 & $<.001$ & 0.46 & 1,46 & 86.15 & $<.001$ & 0.65 \\
Prime x Group & 1,38 & 3.27 & n.s. & 0.08 & 1,46 & 2.34 & n.s. & 0.05 \\
Verb Type x Group & 1,38 & 3.52 & n.s. & 0.08 & 1,46 & 2.72 & n.s. & 0.06 \\
Prime x Verb Type & 1,38 & 0.97 & n.s. & 0.02 & 1,46 & 1.22 & n.s. & 0.03 \\
PrimexVerbTypexGroup & 1,38 & 0.97 & n.s. & 0.02 & 1,46 & 1.22 & n.s. & 0.03 \\
\hline Prime (Children) & 1,38 & 6.53 & $<.05$ & 0.15 & 1,46 & 4.68 & $<.05$ & 0.09 \\
Prime (Adults) & 1,38 & 0.00 & n.s. & 0.00 & 1,46 & 0.00 & n.s. & 0.00 \\
Verb Type (Children) & 1,38 & 0.96 & n.s. & 0.02 & 1,46 & 0.74 & n.s. & 0.02 \\
Verb Type (Adults) & 1,38 & 2.81 & n.s. & 0.07 & 1,46 & 2.17 & n.s. & 0.04 \\
Prime (Agent-Patient) & 1,38 & 0.44 & n.s. & 0.01 & 1,46 & 0.37 & n.s. & 0.01 \\
Prime (Object-Experiencer) & 1,38 & 4.87 & $<.05$ & 0.11 & 1,46 & 4.49 & $<.05$ & 0.09 \\
\hline
\end{tabular}

These showed a significant effect of Group: as in the previous experiment, the children produced more Other responses $(M=1.89)$ than the adults $(M=0.35)$. No other main effects or interactions were significant though the effect of Prime approached significance: overall, participants did not produce more Other responses following active 
or passive primes or following agent-patient or object-experiencer primes. However simple main effects did show an effect of Prime on the children's Other responses: they produced more Other responses following passive primes $(\mathrm{M}=2.12)$ than following active primes $(M=1.65)$. As in previous experiments, this reflects the fact that children, but not adults, produced reversed and incomplete passives and these tended to occur following passive primes. There was no simple main effect of Verb Type suggesting that neither children nor adults produced more Other responses following object-experiencer primes than following actional primes. There was a simple main effect of Prime for object-experiencer verbs: more Other responses occurred following object-experiencer passive primes $(\mathrm{M}=1.32)$ than following object-experiencer active primes $(\mathrm{M}=0.97)$; given the lack of an effect of Verb Type elsewhere it is not clear that this indicates any genuine problem in the participants' performance.

\section{Additional Analyses}

Given the large age range of the children's group (3;1-4;11), I examined whether there was any relationship between the age of the participant and the number of passives they produced: whether the younger children within the group produced fewer passives than the older children or whether the group's behaviour was homogeneous. Recall that Experiment 1 showed a correlation between the participants' ages and priming effects but not between age and the number of passives produced ${ }^{2}$, though it was noted that the group was small. In this experiment there were more than twice as many participants, however there was still no correlation between the number of passives participants produced in Experiment 2 and the participants' age $(r=.08, p=$ .37, 1-tailed); see Figure 5.5. Given the lack of correlation I assume that the observed effects were not confounded by the large age range: it was not the case that older children produced more passives and masked the fact that younger children did not because they could not comprehend the primes.

I also examined whether there was any evidence of a learning effect across the experiment, as characterised by an increase in the number of passives produced at the end of the experiment compared to at the beginning of the experiment. A paired-samples $t$-test showed that the children did not produce significantly more passives following the last eight primes $(\mathrm{M}=1.35, \mathrm{SD}=1.14)$ than following the first eight primes $(\mathrm{M}=$ $1.15, \mathrm{SD}=1.50, t(19)=-.52, p=.31,1$-tailed).

I also checked whether participants showed a tendency to produce more passives when the patient was depicted on the left-hand side of the target picture than when it was on the right. Though the adults produced numerically more passives when the

\footnotetext{
${ }^{2}$ As discussed in Section 5.1.3 'Additional Analyses' above, here I use the number of passives participants produce to avoid the problem of negative priming effects.
} 


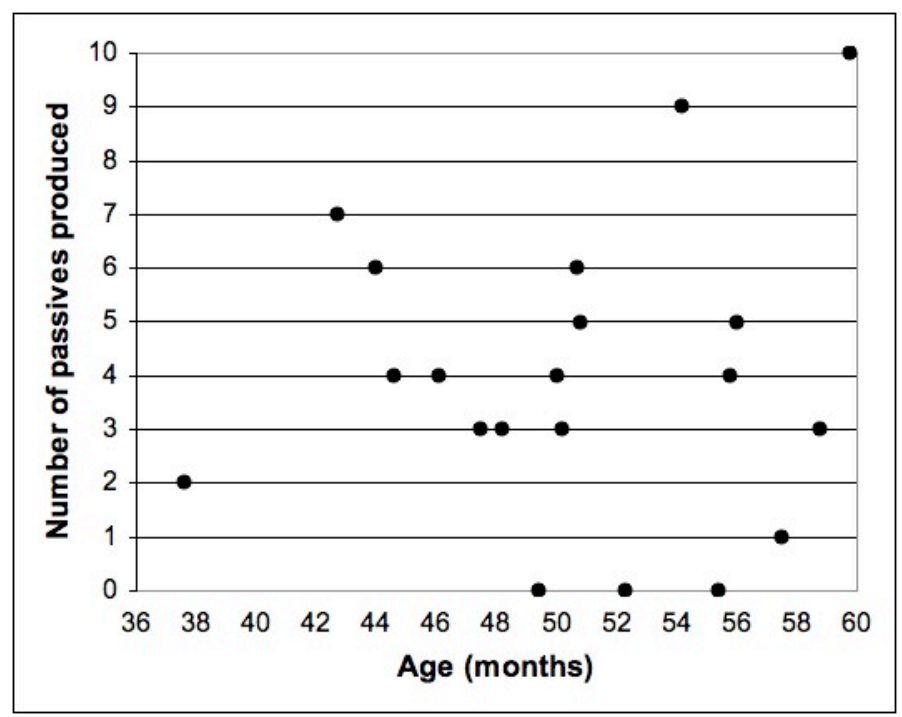

Figure 5.5: Experiment 2: Number of passives produced by age of participant

patient was depicted on the left $(\mathrm{M}=3.92, \mathrm{SD}=1.73)$ than when it appeared on the right $(\mathrm{M}=3.08, \mathrm{SD}=1.56)$, the difference was not significant $(t(22)=1.24, p=.11$, 1-tailed). For comparison I examined the children's results too: the children also produced numerically more passives when the patient was on the left of the picture (M $=3.83, \mathrm{SD}=2.25)$ than when it was on the right $(\mathrm{M}=2.75, \mathrm{SD}=1.42)$ but again the difference was not significant $(t(22)=1.41, p=.09,1$-tailed $)$.

\section{Discussion}

Experiment 2 tested the effect of Structure and Verb Type on children and adults' description of the pictures of transitive events. Participants were more likely to produce passives after hearing passive primes than after hearing active primes. These effects were clearer with twice as many participants as in Experiment 1 . This effect of prime structure was significant for both groups: both three- and four-year-old children and adults produced more passives after hearing passive primes.

In addition there was no effect of Verb Type, overall or within either group: participants produced more passives following passive primes irrespective of whether the prime contained an agent-patient actional verb or an object-experiencer non-actional verb. Crucially there was also an effect of Prime within both verb types: actional verb primes and object-experiencer non-actional verb primes elicited passive targets.

The additional analyses did not show any effect of age on the number of passives produced, nor any learning effect across the experiment or influence of the target pic- 
tures. The implications of these results are discussed in the General Discussion (section 5.2.5). First, I examine whether the more lenient scorings produce different effects: importantly, whether an effect of Verb Type or an interaction between Prime and Verb Type is observed when the children's non-standard passive responses are scored as Passive.

\subsubsection{Lenient Scoring Results}

\section{Results and Analysis}

I re-scored the data and repeated the analyses in order to check that the results did not show any effect of Verb Type once incomplete and short passives were included in the scoring. Following this scoring, the children's responses increased by +5 Active and +13 Passive whilst the adults' responses increased by +8 Active only.

\section{Passive Responses}

Table 5.6 shows the proportions of Passive responses following the Lenient scoring. These proportions were analysed as in the Strict scoring, the results of which are presented in Table 5.7). These showed no change in the pattern of results: there was still a main effect of Prime but, again, no effect of Verb Type; following the Lenient scoring, the participants still produced more passives after hearing passive primes $(\mathrm{M}=0.35)$ than after hearing active primes $(\mathrm{M}=0.13)$ regardless of whether they contained an agent-patient verb $(\mathrm{M}=0.25)$ or an object-experiencer verb $(\mathrm{M}=0.24)$.

Table 5.6: Experiment 2: Mean proportions of Passives in the Lenient scoring

\begin{tabular}{llcccc}
\hline & \multirow{2}{*}{ Prime } & \multicolumn{2}{c}{ Children } & \multicolumn{2}{c}{ Adults } \\
\cline { 3 - 6 } Active & Agent-Patient & (SD) & M & (SD) \\
\hline \hline \multirow{2}{*}{ Passive } & 0.17 & $(0.32)$ & 0.09 & $(0.12)$ \\
& Object-Experiencer & 0.19 & $(0.32)$ & 0.09 & $(0.15)$ \\
& Agent-Patient & 0.43 & $(0.31)$ & 0.31 & $(0.28)$ \\
& Object-Experiencer & 0.43 & $(0.35)$ & 0.25 & $(0.23)$ \\
\hline
\end{tabular}

The effect of Group was significant in the items analysis, marginal by Participants, suggesting that the children produced more passives $(M=0.30)$ than the adults $(M=$ 0.18). No other effects or interactions were significant (except the interaction between Prime and Group which was only significant by items). Simple main effects again showed a significant effect of Prime for both the children and the adults but no effect of Verb Type for either group: both groups produced more passives after passive primes than after active primes but not more passives after agent-patient primes than after object-experiencer primes. There was still a simple main effect of Prime for both the agent-patient verb primes and the object-experiencer verb primes: participants were 
Table 5.7: Experiment 2: ANOVA of proportions of Passives in the Lenient scoring

\begin{tabular}{lrrlllllll}
\hline & \multicolumn{4}{c}{ F1 Results } & \multicolumn{5}{c}{ F2 Results } \\
\cline { 2 - 10 } Effect & $d f$ & $\boldsymbol{F 1}$ & $\boldsymbol{p}$ & $\boldsymbol{p} \cdot \eta^{2}$ & $\boldsymbol{d f}$ & $\boldsymbol{F 2}$ & $\boldsymbol{p}$ & $\boldsymbol{p} . \eta^{2}$ \\
\hline \hline Prime & 1,38 & 29.46 & $<.001$ & 0.44 & 1,46 & 80.35 & $<.001$ & 0.64 \\
Verb Type & 1,38 & 1.20 & n.s. & 0.00 & 1,46 & 0.51 & n.s. & 0.01 \\
Group & 1,38 & 3.65 & $=.06$ & 0.09 & 1,46 & 8.27 & $<.01$ & 0.15 \\
Prime x Group & 1,38 & 0.57 & $=.45$ & 0.01 & 1,46 & 4.02 & $=.05$ & 0.08 \\
Verb Type x Group & 1,38 & 0.48 & n.s. & 0.01 & 1,46 & 0.01 & n.s. & 0.00 \\
Prime x Verb Type & 1,38 & 0.33 & n.s. & 0.01 & 1,46 & 1.48 & n.s. & 0.03 \\
PrimexVerbTypexGroup & 1,38 & 0.10 & n.s. & 0.00 & 1,46 & 0.11 & n.s. & 0.00 \\
\hline Prime (Children) & 1,38 & 19.11 & $<.001$ & 0.33 & 1,46 & 60.16 & $<.001$ & 0.57 \\
Prime (Adults) & 1,38 & 10.92 & $<.01$ & 0.22 & 1,46 & 24.21 & $<.001$ & 0.34 \\
Verb Type (Children) & 1,38 & 0.06 & n.s. & 0.00 & 1,46 & 0.32 & n.s. & 0.01 \\
Verb Type (Adults) & 1,38 & 0.54 & n.s. & 0.01 & 1,46 & 0.20 & n.s. & 0.00 \\
Prime (Agent-Patient) & 1,38 & 26.51 & $<.001$ & 0.41 & 1,46 & 44.52 & $<.001$ & 0.49 \\
Prime (Object-Experiencer) & 1,38 & 11.32 & $<.01$ & 0.23 & 1,46 & 28.18 & $<.001$ & 0.38 \\
\hline
\end{tabular}

more likely to produce passive targets following agent-patient passive primes than agent-patient verb active primes and likewise for object-experiencer verb primes.

\section{Other Responses}

I also analysed the raw numbers of Other responses following the Lenient scoring, presented in Table 5.8. Table 5.9 shows the results of the mixed ANOVAs; these showed a significant effect of Group: the children produced more Other responses $(\mathrm{M}=1.66)$ than the adults $(\mathrm{M}=0.25)$. The interaction between Verb Type and Group was significant: Table 5.8 shows that this effect is based on low numbers but furthermore, that the adults produced more Others following object-experiencer primes than actional primes whereas the children did not show this effect; these results are probably not, therefore, due to developmental effects. No other effects were significant: following the Lenient scoring there was no evidence that participants produced more Other responses following active or passive primes or following agent-patient or object-experiencer primes. Simple main effects no longer showed an effect of Prime on the children's Other responses; note however that more of their Other responses were scored as Passive in this scoring. No other effects were significant. 
Table 5.8: Experiment 2: Mean number of Others in the Lenient scoring

\begin{tabular}{llcccc}
\hline & & \multicolumn{2}{c}{ Children } & \multicolumn{2}{c}{ Adults } \\
\cline { 3 - 6 } & Prime & $\mathbf{M}$ & SD & M & SD \\
\hline \hline \multirow{2}{*}{ Active } & Agent-Patient & 1.75 & 1.29 & 0.15 & 0.37 \\
& Object-Experiencer & 1.25 & 1.12 & 0.35 & 0.49 \\
\multirow{2}{*}{ Passive } & Agent-Patient & 1.85 & 1.56 & 0.15 & 0.37 \\
& Object-Experiencer & 1.80 & 1.44 & 0.35 & 0.59 \\
\hline
\end{tabular}

Table 5.9: Experiment 2: ANOVA of number of Others in the Lenient scoring

\begin{tabular}{lrrlrrrrr}
\hline & \multicolumn{4}{c}{ F1 Results } & \multicolumn{5}{c}{ F2 Results } \\
\cline { 2 - 9 } Effect & $d f$ & $\boldsymbol{F 1}$ & $\boldsymbol{p}$ & $\boldsymbol{p} \cdot \eta^{2}$ & $\boldsymbol{d f}$ & $\boldsymbol{F 2}$ & $\boldsymbol{p}$ & $\boldsymbol{p} . \eta^{2}$ \\
\hline \hline Prime & 1,38 & 1.66 & n.s. & 0.04 & 1,46 & 0.93 & n.s. & 0.02 \\
Verb Type & 1,38 & 0.10 & n.s. & 0.00 & 1,46 & 0.10 & n.s. & 0.00 \\
Group & 1,38 & 32.21 & $<.001$ & 0.46 & 1,46 & 76.82 & $<.001$ & 0.62 \\
Prime x Group & 1,38 & 1.66 & n.s. & 0.04 & 1,46 & 0.93 & n.s. & 0.02 \\
Verb Type x Group & 1,38 & 3.91 & $=.05$ & 0.09 & 1,46 & 3.87 & $=.05$ & 0.08 \\
Prime x Verb Type & 1,38 & 1.12 & n.s. & 0.03 & 1,46 & 1.35 & n.s. & 0.03 \\
PrimexVerbTypexGroup & 1,38 & 1.12 & n.s. & 0.03 & 1,46 & 1.35 & n.s. & 0.03 \\
\hline Prime (Children) & 1,38 & 3.33 & n.s. & 0.08 & 1,46 & 1.86 & n.s. & 0.04 \\
Prime (Adults) & 1,38 & 0.00 & n.s. & 0.00 & 1,46 & 0.00 & n.s. & 0.00 \\
Verb Type (Children) & 1,38 & 2.62 & n.s. & 0.06 & 1,46 & 2.60 & n.s. & 0.05 \\
Verb Type (Adults) & 1,38 & 1.39 & n.s. & 0.03 & 1,46 & 1.37 & n.s. & 0.03 \\
Prime (Agent-Patient) & 1,38 & 0.07 & n.s. & 0.00 & 1,46 & 0.06 & n.s. & 0.00 \\
Prime (Object-Experiencer) & 1,38 & 3.97 & $=.05$ & 0.09 & 1,46 & 2.23 & $=.14$ & 0.05 \\
\hline
\end{tabular}

\section{Additional Analyses}

I again checked that there was no relation between the age of the participant and the number of passives they produced. Bivariate correlations showed no relationship between the children's age and the number of passives they produced $(r=-.04, p=$ .43 , 1-tailed) suggesting that the observed effects were not confounded by the large age range.

Paired-samples $t$-tests did not show any evidence of a learning effect across the experiment; the children did not produce significantly more passives at the end of the experiment, following the last eight primes, $(\mathrm{M}=1.60, \mathrm{SD}=1.31)$ than at the beginning of the experiment, following the first eight primes, $(\mathrm{M}=1.35, \mathrm{SD}=1.53, t(19)=-.610$, $p=.27,1$-tailed).

Finally, I checked whether participants produced more passives when the patient was depicted on the left-hand side of the target picture than when it was on the right. Following the Lenient scoring, the adults' Passive scores did not change from the Strict scoring in which no effect of the pictures was found. Though numerically more of the 
children's responses scored as Passive were produced when the patient appeared on the left $(\mathrm{M}=4.17, \mathrm{SD}=2.44)$ than when it appeared on the right $(\mathrm{M}=3.50, \mathrm{SD}=1.45)$, the difference was again not significant $(t(22)=0.81, p=.21$, 1-tailed).

\section{Discussion}

Including the participants' incomplete utterances or short passives in the scored responses brought no change to the overall pattern of results other than an increase in the difference between the two groups' performance; this is due to the fact that the children produced more non-standard passive responses following passive primes, scored as Passive in the Lenient scoring, than the adults. Importantly, there was no relationship between this change and Verb Type. There was still an effect of the prime's structure on participants' descriptions of the target picture but there is no evidence of an effect of the prime's verb type; both groups still produced more passives after hearing passive primes than after hearing active primes, regardless of whether the prime contained an agent-patient verb or an object-experiencer verb.

\subsubsection{Inclusive Scoring Results}

\section{Results and Analysis}

The final scoring scored the participants' incomplete and reversed utterances as Active or Passive. This scoring lead to +33 Active and +44 Passive responses for the children and +8 Active and +5 Passive responses for the adults.

\section{Passive Responses}

Table 5.10 shows the mean proportions of Passive responses following the Inclusive scoring. Table 5.11 reports the results of the repeated measures ANOVAs. These again showed a significant effect of Prime but no effect of Verb Type: the participants produced more passives after hearing passive primes $(M=0.38)$ than after hearing active primes $(\mathrm{M}=0.13)$ regardless of whether they contained an agent-patient verb $(\mathrm{M}=$ $0.26)$ or an object-experiencer verb $(M=0.26)$. The effect of Group was significant: the children produced more passives $(M=0.33)$ than the adults $(M=0.19)$ - this reflects the fact that the children produced more reversed passives or incomplete passive fragments than the adults. These were only scored as Passive in the Inclusive scoring thus boosting the children's proportions of passives in this scoring but not the adults'.

No other effects or interactions were significant except the Prime $x$ Group interaction which was again significant by items only. Simple main effects showed a significant effect of Prime for both the children and the adults but no effect of Verb Type for either group. There was also a simple main effect of Prime for both the agent-patient 
Table 5.10: Experiment 2: Mean proportions of Passives in the Inclusive scoring

\begin{tabular}{llcccc}
\hline & & \multicolumn{2}{c}{ Children } & \multicolumn{2}{c}{ Adults } \\
\cline { 3 - 6 } & Prime & $\mathbf{M}$ & (SD) & M & (SD) \\
\hline \hline \multirow{2}{*}{ Active } & Agent-Patient & 0.17 & $(0.28)$ & 0.09 & $(0.12)$ \\
& Object-Experiencer & 0.19 & $(0.24)$ & 0.10 & $(0.15)$ \\
\multirow{2}{*}{ Passive } & Agent-Patient & 0.48 & $(0.30)$ & 0.31 & $(0.28)$ \\
& Object-Experiencer & 0.48 & $(0.31)$ & 0.26 & $(0.24)$ \\
\hline
\end{tabular}

Table 5.11: Experiment 2: ANOVA of proportions of Passives in the Inclusive scoring

\begin{tabular}{lcrlrrrrr}
\hline & \multicolumn{4}{c}{ F1 Results } & \multicolumn{5}{c}{ F2 Results } \\
\cline { 2 - 9 } Effect & $d f$ & $\boldsymbol{F 1}$ & $\boldsymbol{p}$ & $\boldsymbol{p} . \eta^{2}$ & $\boldsymbol{d f}$ & $\boldsymbol{F 2}$ & $\boldsymbol{p}$ & $\boldsymbol{p} \cdot \eta^{2}$ \\
\hline \hline Prime & 1,38 & 36.22 & $<.001$ & 0.49 & 1,46 & 96.38 & $<.001$ & 0.68 \\
Verb Type & 1,38 & 0.00 & n.s. & 0.00 & 1,46 & 0.00 & n.s. & 0.00 \\
Group & 1,38 & 5.85 & $<.05$ & 0.13 & 1,46 & 25.55 & $<.001$ & 0.36 \\
Prime x Group & 1,38 & 1.68 & $=.20$ & 0.04 & 1,46 & 5.38 & $<.05$ & 0.10 \\
Verb Type x Group & 1,38 & 0.44 & n.s. & 0.01 & 1,46 & 0.23 & n.s. & 0.01 \\
Prime x Verb Type & 1,38 & 0.59 & n.s. & 0.01 & 1,46 & 0.61 & n.s. & 0.01 \\
PrimexVerbTypexGroup & 1,38 & 0.15 & n.s. & 0.00 & 1,46 & 0.02 & n.s. & 0.00 \\
\hline Prime (Children) & 1,38 & 26.76 & $<.001$ & 0.41 & 1,46 & 73.66 & $<.001$ & 0.62 \\
Prime (Adults) & 1,38 & 11.14 & $<.01$ & 0.23 & 1,46 & 28.10 & $<.001$ & 0.38 \\
Verb Type (Children) & 1,38 & 0.20 & n.s. & 0.00 & 1,46 & 0.12 & n.s. & 0.00 \\
Verb Type (Adults) & 1,38 & 0.23 & n.s. & 0.01 & 1,46 & 0.11 & n.s. & 0.00 \\
Prime (Agent-Patient) & 1,38 & 35.65 & $<.001$ & 0.48 & 1,46 & 56.27 & $<.001$ & 0.55 \\
Prime (Object-Experiencer) & 1,38 & 18.49 & $<.001$ & 0.33 & 1,46 & 41.64 & $<.001$ & 0.47 \\
\hline
\end{tabular}

verb primes and the object-experiencer verb primes: participants were more likely to produce passive targets following agent-patient passive primes than agent-patient verb active primes and likewise for object-experiencer verb primes.

Other Responses

Table 5.12 presents the mean number of Other responses following the Inclusive scoring. These were analysed as in previous experiments, the results of the ANOVAs are shown in Table 5.13. There was a significant effect of Group: the children produced more Other responses $(M=0.70)$ than the adults $(M=0.09)$ showing that even when any non-standard active and passive responses were scored as Active or Passive the children still had more responses scored as Other than the adults. Table 5.13 shows that some of the interactions and simple main effects which were previously not significant were significant in this scoring. However, given how few Other responses were left it seems unlikely that these effects are due to systematic variance.

\section{Additional Analyses}

I checked that there was no relationship between the age of the participant and the 
Table 5.12: Experiment 2: Mean proportions of Others in the Inclusive scoring

\begin{tabular}{llcccc}
\hline & & \multicolumn{2}{c}{ Children } & \multicolumn{2}{c}{ Adults } \\
\cline { 3 - 6 } & Prime & $\mathbf{M}$ & (SD) & M & (SD) \\
\hline \hline \multirow{2}{*}{ Active } & Agent-Patient & 1.15 & $(0.93)$ & 0.10 & $(0.31)$ \\
& Object-Experiencer & 0.45 & $(0.60)$ & 0.10 & $(0.31)$ \\
Passive & Agent-Patient & 0.55 & $(0.60)$ & 0.05 & $(0.22)$ \\
& Object-Experiencer & 0.65 & $(0.67)$ & 0.10 & $(0.31)$ \\
\hline
\end{tabular}

Table 5.13: Experiment 2: ANOVA of proportions of Others in the Inclusive scoring

\begin{tabular}{lrrlrrrrr}
\hline & \multicolumn{4}{c}{ F1 Results } & \multicolumn{4}{c}{ F2 Results } \\
\cline { 2 - 9 } Effect & $d f$ & $\boldsymbol{F 1}$ & $\boldsymbol{p}$ & $\boldsymbol{p} . \eta^{2}$ & $\boldsymbol{d f}$ & $\boldsymbol{F 2}$ & $\boldsymbol{p}$ & $\boldsymbol{p} . \eta^{2}$ \\
\hline \hline Prime & 1,38 & 2.15 & n.s. & 0.05 & 1,46 & 1.93 & n.s. & 0.04 \\
Verb Type & 1,38 & 3.62 & n.s. & 0.09 & 1,46 & 1.90 & n.s. & 0.04 \\
Group & 1,38 & 30.11 & $<.001$ & 0.44 & 1,46 & 21.65 & $<.001$ & 0.32 \\
Prime x Group & 1,38 & 1.30 & n.s. & 0.03 & 1,46 & 1.16 & n.s. & 0.02 \\
Verb Type x Group & 1,38 & 5.06 & $<.05$ & 0.12 & 1,46 & 2.66 & $=.11$ & 0.05 \\
Prime x Verb Type & 1,38 & 7.20 & $<.05$ & 0.16 & 1,46 & 6.25 & $<.05$ & 0.12 \\
PrimexVerbTypexGroup & 1,38 & 5.60 & $<.05$ & 0.13 & 1,46 & 4.87 & $<.05$ & 0.10 \\
\hline Prime (Children) & 1,38 & 3.40 & n.s. & 0.08 & 1,46 & 3.04 & n.s. & 0.06 \\
Prime (Adults) & 1,38 & 0.05 & n.s. & 0.00 & 1,46 & 0.05 & n.s. & 0.00 \\
Verb Type (Children) & 1,38 & 8.62 & $<.01$ & 0.18 & 1,46 & 4.53 & $<.05$ & 0.09 \\
Verb Type (Adults) & 1,38 & 0.06 & n.s. & 0.00 & 1,46 & 0.03 & n.s. & 0.00 \\
Prime (Agent-Patient) & 1,38 & 8.13 & $<.01$ & 0.18 & 1,46 & 4.91 & $<.05$ & 0.10 \\
Prime (Object-Experiencer) & 1,38 & 0.88 & n.s. & 0.02 & 1,46 & 1.64 & n.s. & 0.03 \\
\hline
\end{tabular}

number of passives they produced when all possible passive responses, standard and non-standard, were scored as Passive. Bivariate correlations still showed no relationship between the children's age and the number of passives they produced $(r=-.15$, $p=.26$, 1-tailed). Even in this scoring, there was no evidence that the observed effects were confounded by the large age range.

Nor is there any evidence of a learning effect: the children did not produce more passives, standard or otherwise, at the end of the experiment $(\mathrm{M}=2.35, \mathrm{SD}=1.66)$ than at the beginning $(\mathrm{M}=2.25, \mathrm{SD}=1.65, t(19)=-.26, p=.40,1$-tailed $)$. And there was no evidence that the depiction of the items led to more passives: adults did not produce significantly more passives when the patient was on the left of the picture $(\mathrm{M}=4.17, \mathrm{SD}=1.95)$ than when it was on the right of the picture $(\mathrm{M}=3.25, \mathrm{SD}=$ $1.54, t(22)=1.28, p=.11,1$-tailed). Children also did not produce significantly more passives when the patient was on the left of the picture $(\mathrm{M}=5.83, \mathrm{SD}=1.80)$ than when it was on the right of the picture $(\mathrm{M}=5.50, \mathrm{SD}=1.98, t(22)=.43, p=.33$, 1-tailed $)$. 


\section{Discussion}

Even when all the participants' potentially primed responses are scored as Active or Passive, the results show the same pattern of results as the Strict scoring with regards the effect of the prime's verb and structure. There is an effect of the prime's structure on participants' descriptions of the target picture but there is no evidence of an effect of the prime's verb type; the participants still produced more passives after hearing passive primes than after hearing active primes regardless of whether they contained an agent-patient verb or an object-experiencer verb. There is no evidence that objectexperiencer verb primes had a different effect than agent-patient for either group.

\subsubsection{General Discussion of Experiment Two}

Experiment 2 compared children's comprehension of agent-patient and objectexperiencer verb passives in a priming task: it measured whether participants produced more passives following these passive primes compared to following active primes and whether they produced more passives following agent-patient primes compared to following object-experiencer primes. This experiment showed that threeand four-year-old children produced more passives following passive primes than following active primes regardless of whether the prime contained an agent-patient or object-experiencer verb. Even when their non-standard passives are included in the calculation of the proportions of each response there is no evidence for an influence of the prime verb; that is, there is no evidence that they produced more passive targets following agent-patient primes when passive fragments, reversed and short passives were scored as Passive. This also suggests that participants did not produce more anomalous passives following object-experiencer primes.

I extend the results of previous priming experiments, which have typically involved agent-patient verb primes and targets, (Huttenlocher et al. 2004, Shimpi et al. 2007, Bencini \& Valian 2008) by showing that object-experiencer non-actional verb passives are also good primes of passive responses. These effects were observed for both children and adults. There was a significant difference between the groups in the more lenient scorings but this is because, as in the previous experiments, the children, but not the adults, produced a number of non-standard passive responses scored as Other in the previous scorings; the adults by contrast tended to produce standard, full passives.

These results support the findings from previous studies which show that before five, children comprehend actional verb passives. They extend these findings by showing that by four, children have a syntactic representation for the passive which is not 
restricted to agent-patient verbs but is also generalised to object-experiencer verbs. Thus these results suggest that young children do not have difficulty with non-actional verb passives (involving theme and experiencer thematic roles in any configuration) in general. Some of the explanations for the finding that children do not understand subject-experiencer passives suggest however that children should understand objectexperiencer passives: they are more proto-typically transitive involving a change in state on the verb's object and they are more frequent in the input. The results of Experiment 2 are therefore in line with such explanations. Experiment 3 tests children's comprehension of subject-experiencer primes. According to previous studies, children do not understand these before five; if this is the case one would not expect priming from these verbs.

\section{Additional Analyses}

I also examined whether more passives occurred at the end of the experiment than at the beginning or whether there was any relationship between the number of passives the children produced and their age or the position of the patient in the target picture. There were no significant relationships within this data. This suggests that though the age range of the group was large, the younger children did not behave differently compared to the older children, in terms of producing fewer passives because they did not comprehend the primes. The results do not suggest that the depiction of the items influenced the number of passives produced or that there was a learning effect across the experiment: children's exposure to the passive primes throughout the course of the experiment did not increase the number of passives they produced.

\section{Passive Tokens}

In this experiment the children and adults actually produced a number of passives involving non-actional verbs, despite the fact that the target pictures were intended to depict actional verbs. Though most of the actional verbs they heard in the actional verb prime conditions would be inappropriate to describe their target picture, the object-experiencer verbs that they heard in this experiment could appropriately be used to describe many of the target pictures: the children most frequently passivized frighten, annoy and scare, which could conceivably describe a character's feelings towards a number of the target actions (being punched, chased, licked, shaken, pushed, kicked, scratched, pinched or even washed or tickled), as could even upset.

The adults produced two passives with scare, neither of which occurred after a prime with that verb. The children produced 14 non-actional verb passives ${ }^{3}$. Importantly, only five, not all, of these occurred after a passive prime containing the same verb; one occurred after an active prime containing the same verb. The fact that the children pro-

\footnotetext{
${ }^{3}$ These verbs were: frighten (4), annoy (3), scare (3), surprise (2), love (1), upset (1).
} 
duced non-actional verb passives (one of which involved a subject-experiencer verb) as well as actional verb targets, and that most of these passives were produced following primes with different verbs, adds further weight to the argument that children's early passive representation is not restricted to actional verbs or item-specific schemas.

\subsection{Experiment Three: Subject-Experiencer Primes vs. Object- Experiencer Primes}

To investigate whether children's difficulty is with subject-experiencer verb passives in particular I examined whether subject-experiencer verb passives also prime passive descriptions. According to previous studies of children's comprehension of passives, children do not reliably comprehend these passives before the age of five. If children do restrict their generalisation of the passive to agent-patient actional verbs and objectexperiencer non-actional verbs (the types of verbs with which adults tend to produce passives) they should not be able to process subject-experiencer primes. That is, the syntactic representation used in their comprehension of actional verb and objectexperiencer verb passives would not be accessed when they hear a subject-experiencer verb prime therefore they would not have this representation available when they produce a description of a target picture. One would not therefore expect them to produce passive target descriptions following subject-experiencer passive primes.

Alternatively, if the difficulty observed in previous studies that children have comprehending subject-experiencer verb passives is an artefact of the experimental method and children in fact do not restrict their generalisation of the passive to certain semantic classes of verbs then one would expect to see priming from both object-experiencer and subject-experiencer passives. That is, if, before five, children have a passive representation which is common to verbs with any thematic roles (agent-patient, themeexperiencer) in any configuration, the passive primes that they hear should access this representation, irrespective of the class of verb with which that passive is produced. This representation would therefore be available when the child produces a target description and one would therefore expect children to produce passive descriptions of the target pictures following either type of prime.

Thus, using the same method as Experiment 2, I compared children's comprehension of object-experiencer and subject-experiencer non-actional passives by using these as primes for their description of the same actional verb targets as previous experiments. 


\subsubsection{Method}

\section{Design}

The repeated-measures factors were Prime (active vs. passive) and Verb Type (subjectexperiencer vs object-experiencer), creating four priming conditions; Group (children vs. adults) was a between-participants factor. As in the previous priming experiments, the form of the active test sentences was: A SUBJECT is VERB-ing an OBJECT and the form of the passive test sentences was: A SUBJECT is being VERB-ed by an OBJECT. Though the progressive may be less felicitous with some verbs (e.g. A cat is liking a queen) than with others, it was used for consistency with the previous priming experiments.

\section{Participants}

Twenty-four three- and four-year-old children (14 girls), ranging in age from 3;4 to $4 ; 11^{4}$ (mean age 4;2), took part in the experiment. A control group of 24 adults (23 females, mean age 18.8, range 18-26) also took part.

\section{Materials}

The Snap items consisted of the object-experiencer items from Experiment 2 and a subject-experiencer version created using six verbs: hear, ignore, like, love, remember, see, each used four times, (see Appendix B.2 for a list of the subject-experiencer primes, the object-experiencer primes are listed in Appendix B.1). I used subject-experiencer verbs that previous studies also tested. Thus, in this experiment, there was an objectexperiencer and a subject-experiencer version of each prime depicted with the same two entities (see Figure 5.6). Experiment 3 used the same 24 target pictures (Appendix A.3) and the same filler and practice items (Appendices A.4 and A.5) as used in the previous experiments. Four sets of the experiment and filler items were created such that across the four sets each target occurred once in each of the priming conditions and within a set an even number of the targets (six) occurred in each priming condition. There were six randomized experiment lists created from each of the four sets which acted as priming scripts during the experiment.

\section{Procedure}

This experiment followed the same procedure as the previous priming experiments. In addition, during the experimental session I administered and scored the BPVS test, as per the BPVS II instructions (Dunn et al. 1997) to obtain a standardized score of the children's vocabulary level. I scored and analysed the data according to the three different sets of criteria, Strict (5.3.2), Lenient (5.3.3) and Inclusive (5.3.4).

\footnotetext{
${ }^{4}$ The age range of the children is again large, though not dissimilar to the previous experiment (3;1$4 ; 11)$, for confidence in the results, this is again checked in the additional analyses.
} 

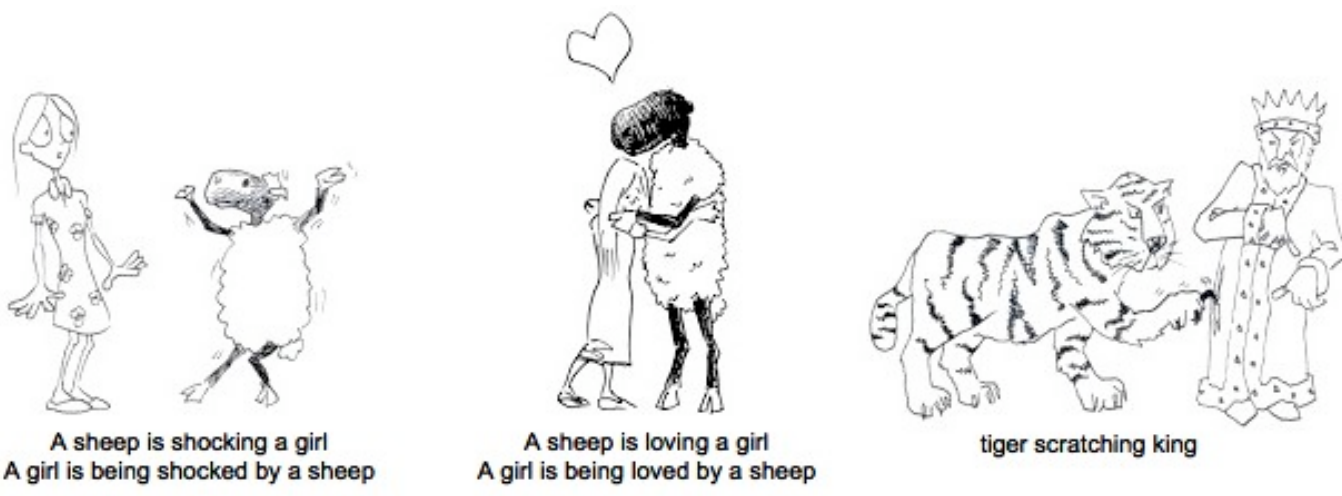

Figure 5.6: Experiment 3: Object-experiencer and subject-experiencer primes and a target item

\subsubsection{Strict Scoring Results}

\section{Results}

Out of each group's 576 target items, $32(6 \%)$ of the children's trials and $21(4 \%)$ of the adults' trials were eliminated because the wrong prime was given, there was no response or the response was lost due to recording problems or misplaced cards. The children produced $346(60 \%)$ transitive responses: 272 Active (47\%) and 74 Passive $(13 \%)^{5}$; and $198(34 \%)$ Other responses; the adults produced $527(91 \%)$ transitive responses: 446 Active (77\%) and 81 Passive (14\%); and 28 (5\%) Other responses, (see Table 5.14).

Table 5.14: Experiment 3: Frequency of active, passive and other responses according to group and prime condition

\begin{tabular}{|c|c|c|c|c|c|c|c|c|}
\hline \multirow[b]{2}{*}{ Group } & \multirow{2}{*}{\multicolumn{2}{|c|}{ Prime }} & \multicolumn{6}{|c|}{ Response } \\
\hline & & & & tive & & ssive & & ther \\
\hline \multirow{4}{*}{ Children } & \multirow{2}{*}{ Active } & Subject-Experiencer & 79 & $(59 \%)$ & 10 & $(7 \%)$ & $\overline{446}$ & $(34 \%)$ \\
\hline & & Object-Experiencer & 86 & $(63 \%)$ & 8 & $(6 \%)$ & 43 & $(31 \%)$ \\
\hline & \multirow{2}{*}{ Passive } & Subject-Experiencer & 54 & $(39 \%)$ & 25 & $(18 \%)$ & 58 & $(42 \%)$ \\
\hline & & Object-Experiencer & 53 & $(39 \%)$ & 31 & $(23 \%)$ & 51 & $(38 \%)$ \\
\hline \multirow{4}{*}{ Adults } & \multirow{2}{*}{ Active } & Subject-Experiencer & 119 & $(87 \%)$ & 12 & $(9 \%)$ & 6 & $(4 \%)$ \\
\hline & & Object-Experiencer & 126 & $(88 \%)$ & 13 & $(9 \%)$ & 5 & $(3 \%)$ \\
\hline & \multirow{2}{*}{ Passive } & Subject-Experiencer & 106 & $(77 \%)$ & 22 & $(16 \%)$ & 9 & $(7 \%)$ \\
\hline & & Object-Experiencer & 95 & $(69 \%)$ & 34 & $(25 \%)$ & 8 & $(6 \%)$ \\
\hline
\end{tabular}

All but one child completed the BPVS test; one child refused to take part. The re-

\footnotetext{
${ }^{5}$ Note that these are very similar to the percentages of Active and Passive responses produced by the children (50\% Active, 16\% Passive) and by the adults (75\% Active, 17.5\% Passive) in Experiment 2.
} 
maining 23 children's BPVS standardized ${ }^{6}$ scores ranged from 87 to 119 (see Figure 5.7 for the participants' scores plotted against their age) with a mean score of 104.4, slightly over the standardized average score (100). I compared this with the number of passives individuals produced to see whether their use of the passive structure was related to their language development as measured by their vocabulary size (see Additional Analyses below).

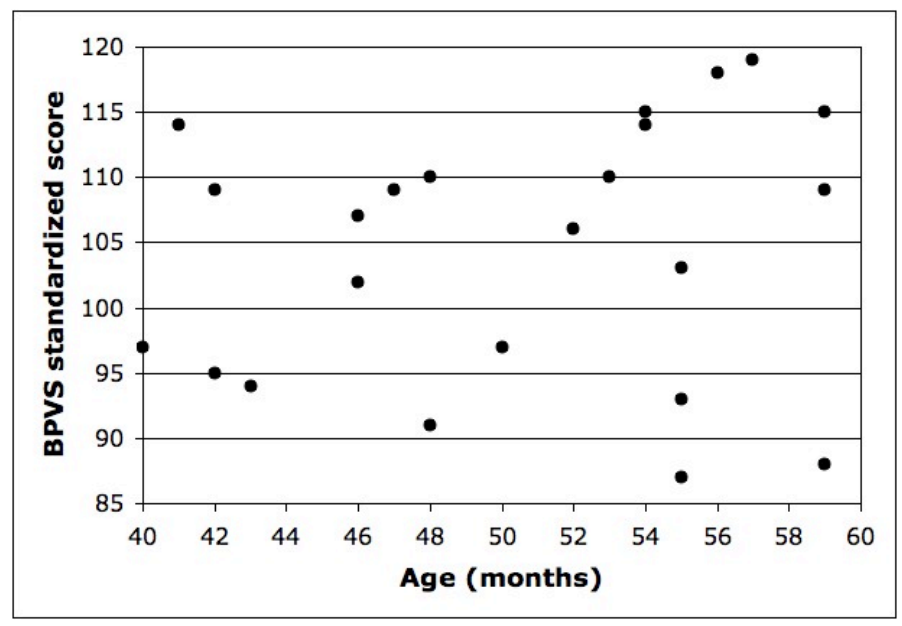

Figure 5.7: Experiment 3: Children's BPVS scores plotted by age of participant

\section{Analysis}

\section{Passive Responses}

The mean proportion of passive responses are shown in Table 5.15. As in Experiment 2 I analysed these proportions in repeated measures ANOVAs treating participants $\left(F_{1}\right)$ and items $\left(F_{2}\right)$ as random effects. Prime (active vs passive) and Verb Type (subjectexperiencer vs object-experiencer) were within-participants and within-items factors and Group (children vs adults) was a between-participants but within-items factor.

Table 5.15: Experiment 3: Mean proportions of Passives in the Strict scoring

\begin{tabular}{llrrrr}
\hline & & \multicolumn{2}{c}{ Children } & \multicolumn{2}{c}{ Adults } \\
\cline { 3 - 6 } & Prime & $\mathbf{M}$ & (SD) & M & (SD) \\
\hline \hline \multirow{2}{*}{ Active } & Subject-Experiencer & 0.16 & $(0.29)$ & 0.09 & $(0.17)$ \\
& Object-Experiencer & 0.10 & $(0.23)$ & 0.09 & $(0.20)$ \\
\multirow{2}{*}{ Passive } & Subject-Experiencer & 0.32 & $(0.33)$ & 0.18 & $(0.23)$ \\
& Object-Experiencer & 0.39 & $(0.36)$ & 0.27 & $(0.31)$ \\
\hline
\end{tabular}

Table 5.16 presents the results of these ANOVAs, which showed a significant effect of Prime: overall, the participants produced more passives after hearing passive primes

\footnotetext{
${ }^{6}$ The children's raw score (their ceiling item number minus the number of errors they made) is converted to a standardized score based on their age.
} 
Table 5.16: Experiment 3: ANOVA of proportions of Passives in the Strict scoring

\begin{tabular}{lrrlrrrrr}
\hline & \multicolumn{4}{c}{ F1 Results } & \multicolumn{5}{c}{ F2 Results } \\
\cline { 2 - 9 } Effect & $\boldsymbol{d f}$ & $\boldsymbol{F 1}$ & $\boldsymbol{p}$ & $\boldsymbol{p} \cdot \eta^{2}$ & $\boldsymbol{d f}$ & $\boldsymbol{F 2}$ & $\boldsymbol{p}$ & $\boldsymbol{p} \cdot \boldsymbol{\eta}^{2}$ \\
\hline \hline Prime & 1,46 & 32.25 & $<.001$ & 0.41 & 1,46 & 41.15 & $<.001$ & 0.47 \\
Verb Type & 1,46 & 1.36 & n.s. & 0.03 & 1,46 & 3.34 & n.s. & 0.07 \\
Group & 1,46 & 1.72 & $=.20$ & 0.04 & 1,46 & 5.60 & $<.05$ & 0.11 \\
Prime x Group & 1,46 & 2.13 & $=.15$ & 0.04 & 1,46 & 5.21 & $<.05$ & 0.10 \\
Verb Type x Group & 1,46 & 0.91 & n.s. & 0.02 & 1,46 & 0.09 & n.s. & 0.00 \\
Prime x Verb Type & 1,46 & 5.75 & $<.05$ & 0.11 & 1,46 & 4.26 & $<.05$ & 0.08 \\
PrimexVerbTypexGroup & 1,46 & 0.10 & n.s. & 0.00 & 1,46 & 0.04 & n.s. & 0.00 \\
\hline Prime (Children) & 1,46 & 25.48 & $<.001$ & 0.36 & 1,46 & 37.82 & $<.001$ & 0.45 \\
Prime (Adults) & 1,46 & 8.90 & $<.01$ & 0.16 & 1,46 & 8.54 & $<.01$ & 0.16 \\
Verb Type (Children) & 1,46 & 0.02 & n.s. & 0.00 & 1,46 & 1.16 & n.s. & 0.02 \\
Verb Type (Adults) & 1,46 & 2.25 & n.s. & 0.05 & 1,46 & 2.28 & n.s. & 0.05 \\
Prime (Subject-Experiencer) & 1,46 & 12.72 & $<.01$ & 0.22 & 1,46 & 11.97 & $<.01$ & 0.21 \\
Prime (Object-Experiencer) & 1,46 & 29.01 & $<.001$ & 0.39 & 1,46 & 33.94 & $<.001$ & 0.42 \\
\hline
\end{tabular}

$(\mathrm{M}=0.29)$ than after hearing active primes $(\mathrm{M}=0.11)$. However, there was no effect of Verb Type: participants produced as many passives following subject-experiencer verb primes $(M=0.19)$ as following object-experiencer verb primes $(M=0.21)$. The main effect of Group and the interaction between Group and Prime were significant by items only. The interaction between Prime and Verb Type was significant suggesting that the priming effect was stronger for object-experiencer verb primes than subjectexperiencer verb primes (participants produced $24 \%$ more passives following objectexperiencer passive primes than following active primes whereas they produced just $12 \%$ more passives following subject-experiencer passives compared to actives). No other effects were significant. In particular, there was no interaction between Group, Prime and Verb Type: the difference between the priming effect of object-experiencer passives and subject-experiencer passives was not significantly larger for the children which one would expect if they are late to generalise the passive to these verbs.

Simple main effects showed a significant effect of Prime for both the children and the adults but no effect of Verb Type for either group: both groups produced more passives following passive primes, however neither group produced significantly more passives following object-experiencer primes than following subject-experiencer primes. Importantly, despite the interaction between Verb Type and Prime, there was a simple main effect of Prime for both the subject-experiencer verb primes and the object-experiencer verb primes: participants were more likely to produce passive targets following subject-experiencer passive primes than subject-experiencer verb active primes and likewise for object-experiencer verb primes. 
Other Responses

I repeated the ANOVAs with the raw numbers of Other responses, shown in Table 5.17, to check for an effect of Prime or Verb Type which might indicate underlying difficulties understanding the primes. Table 5.18 presents the results of these ANOVAs, which showed a significant effect of Group: as in Experiment 2, the children produced more Other responses $(M=2.06)$ than the adults $(M=0.29)$. The effect of Prime was significant by items only, however the main effect of Verb Type was not significant: overall, participants did not produce more Other responses following subjectexperiencer than following object-experiencer primes. Simple main effects did show an effect of Prime on the children's Other responses (which probably accounts for the main effect of Prime approaching significance): they produced more Other responses following passive primes $(M=2.27)$ than following active primes $(M=1.85)$. This reflects the fact that children, but not adults again, produced reversed and incomplete passives, and these tended to occur following passive primes. No other effects were significant; children did not produce more Others following subject-experiencer primes than following object-experiencer primes and participants did not produce more Others after subject-experiencer passives than after subject-experiencer actives (and likewise for object-experiencer primes).

Table 5.17: Experiment 3: Mean numbers of Others in the Strict scoring

\begin{tabular}{llcccc}
\hline & & \multicolumn{2}{c}{ Children } & \multicolumn{2}{c}{ Adults } \\
\cline { 3 - 6 } & Prime & M & (SD) & M & (SD) \\
\hline \hline \multirow{2}{*}{ Active } & Subject-Experiencer & 1.92 & $(1.44)$ & 0.25 & $(0.44)$ \\
& Object-Experiencer & 1.79 & $(1.50)$ & 0.21 & $(0.41)$ \\
\multirow{2}{*}{ Passive } & Subject-Experiencer & 2.42 & $(1.53)$ & 0.37 & $(0.58)$ \\
& Object-Experiencer & 2.13 & $(1.80)$ & 0.33 & $(0.56)$ \\
\hline
\end{tabular}

Table 5.18: Experiment 3: ANOVA of numbers of Others in the Strict scoring

\begin{tabular}{lrrrrrrrr}
\hline \multirow{2}{*}{ Effect } & \multicolumn{4}{c}{ F1 Results } & \multicolumn{5}{c}{ F2 Results } \\
\cline { 2 - 9 } & $\boldsymbol{d}$ & $\boldsymbol{F 1}$ & $\boldsymbol{p}$ & $\boldsymbol{p} . \eta^{2}$ & $\boldsymbol{d f}$ & $\boldsymbol{F 2}$ & $\boldsymbol{p}$ & $\boldsymbol{p} . \eta^{2}$ \\
\hline \hline Prime & 1,46 & 3.64 & $=.06$ & 0.07 & 1,46 & 4.63 & $<.05$ & 0.09 \\
Verb Type & 1,46 & 0.91 & n.s. & 0.02 & 1,46 & 0.90 & n.s. & 0.02 \\
Group & 1,46 & 50.01 & $<.001$ & 0.52 & 1,46 & 117.44 & $<.001$ & 0.72 \\
Prime x Group & 1,46 & 1.06 & n.s. & 0.02 & 1,46 & 1.34 & n.s. & 0.03 \\
Verb Type x Group & 1,46 & 0.40 & n.s. & 0.01 & 1,46 & 0.40 & n.s. & 0.01 \\
Prime x Verb Type & 1,46 & 0.12 & n.s. & 0.00 & 1,46 & 0.13 & n.s. & 0.00 \\
PrimexVerbTypexGroup & 1,46 & 0.12 & n.s. & 0.00 & 1,46 & 0.13 & n.s. & 0.00 \\
\hline Prime (Children) & 1,46 & 4.31 & $<.05$ & 0.09 & 1,46 & 5.48 & $<.05$ & 0.11 \\
Prime (Adults) & 1,46 & 0.39 & n.s. & 0.01 & 1,46 & 0.49 & n.s. & 0.01 \\
Verb Type (Children) & 1,46 & 1.26 & n.s. & 0.03 & 1,46 & 1.25 & n.s. & 0.03 \\
Verb Type (Adults) & 1,46 & 0.05 & n.s. & 0.00 & 1,46 & 0.05 & n.s. & 0.00 \\
Prime (Subject-Experiencer) & 1,46 & 3.44 & n.s. & 0.07 & 1,46 & 3.68 & n.s. & 0.07 \\
Prime (Object-Experiencer) & 1,46 & 1.32 & n.s. & 0.03 & 1,46 & 1.66 & n.s. & 0.03 \\
\hline
\end{tabular}




\section{Additional Analyses}

The additional analyses in Experiment 2 did not show significant relationships between the number of passives participants produced and the participants' age or the layout of the target picture, nor a significant difference between the number of passives produced at the beginning or end of the experiment. In this experiment I examined a further possible relationship: whether an independent measure of the children's language development, their vocabulary size, showed any relationship with the number of passives they produced. Bivariate correlations showed a positive correlation between the children's BPVS score and the number of passives they produced $(r=.36$, $p<.05$, 1-tailed); children with larger vocabularies produced more passives (see also Figure 5.8).

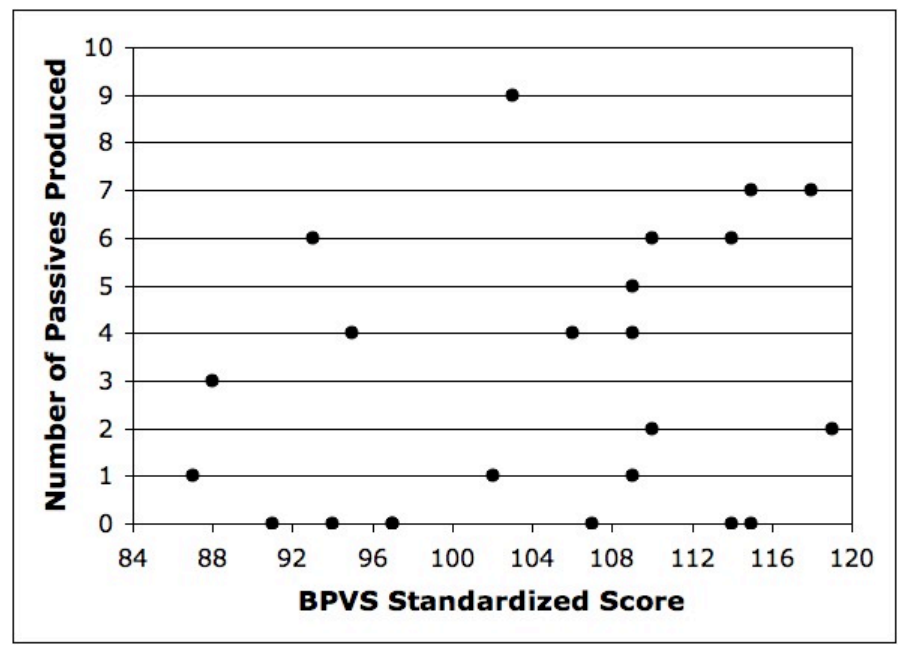

Figure 5.8: Experiment 3: Number of passives produced by BPVS score

As in Experiment 2, the age range of the children's group was large, therefore I again examined whether there was any relationship between the age of the participant and the number of passives they produced, given this could be an important factor in children's generalisation of the passive: older children may more reliably comprehend more of the primes and therefore produce more passives. However, as in previous analyses, there was no correlation between the children's age and the number of passives they produced ( $r=.09, p=.33,1$-tailed); see Figure 5.9. Given the lack of correlation I once again assume that the observed effects were not confounded by the large age range of the nursery group.

I also examined whether there was any evidence of a learning effect across the experiment, as characterised by an increase in the number of passives produced at the end of the experiment compared to at the beginning of the experiment. Given children rarely hear subject-experiencer passives it is possible that until they have heard many 


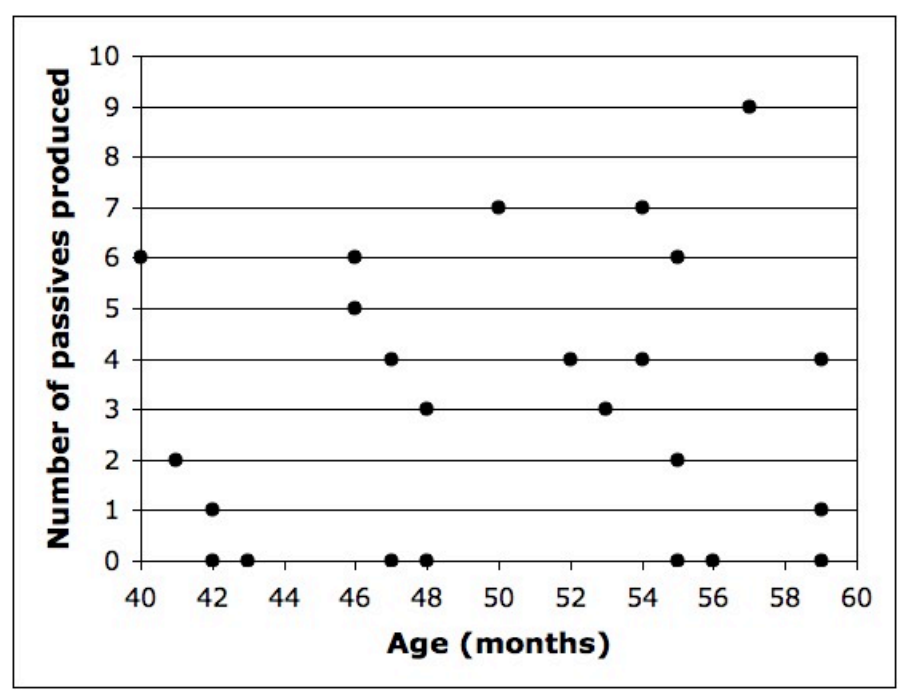

Figure 5.9: Experiment 3: Number of passives produced by age of participant

of these passives across the course of the experiment, they will not produce as many passives. I checked for an implicit learning effect using a paired-samples $t$-test. This showed that the children did not produce significantly more passives following the last eight primes $(\mathrm{M}=0.88, \mathrm{SD}=1.03)$ than following the first eight primes $(\mathrm{M}=1.13$, $\mathrm{SD}=1.19, t(23)=1.46, p=.08,1$-tailed). Although the difference approaches significance, the means suggest that more passives were in fact produced at the beginning of the experiment rather than the end.

\section{Discussion}

The results of the Strict scoring of Experiment 3 show that as in the previous experiment, children and adults produced more passives after hearing passive primes than after hearing active primes; there is some suggestion (by items only) that this may be stronger for the children than for the adults. As in Experiment 2, this repetition effect occurred for primes with both verb types: participants produced more passives following object-experiencer passives than following object-experiencer actives and likewise for subject-experiencer passives and actives although the effect was stronger for object-experiencer primes. These results suggest that children understood both objectexperiencer and subject-experiencer primes; this is discussed further in the Discussion of Experiment 3 (5.3.5). First, I scored the data according to more lenient criteria to check that there was still no effect of Verb Type when the participants' non-standard (short, incomplete, reversed) passive responses were scored as Passive. 


\subsubsection{Lenient Scoring Results}

\section{Results and Analysis}

The children's responses increased by +9 Active and +7 Passive following the Lenient scoring and the adults' responses increased by +16 Active and +2 Passive. I re-analysed the mean proportions of passives following this scoring to check that the results did not show any effect of Verb Type once incomplete and short passives were scored as Passive.

\section{Passive Responses}

Table 5.19 shows the mean proportions of Passive responses following the Lenient scoring. The analyses conducted in the Strict scoring were repeated with the results of the Lenient scoring, see Table 5.20. These showed no change in the pattern of results: there was still a main effect of Prime but no effect of Verb Type; following the Lenient scoring, the participants still produced more passives after hearing passive primes $(M=0.29)$ than after hearing active primes $(M=0.12)$, whether they contained a subject-experiencer verb $(\mathrm{M}=0.19)$ or an object-experiencer verb $(\mathrm{M}=0.21)$. The effect of Group and the interaction between Prime and Group were again significant by items only - the difference in the means reported in Table 5.19 suggests that the children produced more passives than the adults; they also produced more after passive primes than after active $(+0.22)$ compared to the adults $(+0.12)$. The interaction between Prime and Verb Type was significant by participants (marginal by items): the priming effect appears to be stronger for object-experiencer verbs $(+0.23)$ than subjectexperiencer $(+0.11)$. Nonetheless, simple main effects again showed a significant effect of Prime for both the children and the adults and no effect of Verb Type for either group. Furthermore, there was still a simple main effect of Prime for both the subjectexperiencer verb primes and the object-experiencer verb primes: participants were more likely to produce passive targets following subject-experiencer passive primes than subject-experiencer verb active primes and likewise for object-experiencer verb primes.

Table 5.19: Experiment 3: Mean proportions of Passives in the Lenient scoring

\begin{tabular}{llcccc}
\hline & & \multicolumn{2}{c}{ Children } & \multicolumn{2}{c}{ Adults } \\
\cline { 3 - 6 } & Prime & $\mathbf{M}$ & (SD) & M & (SD) \\
\hline \hline \multirow{2}{*}{ Active } & Subject-Experiencer & 0.18 & $(0.29)$ & 0.09 & $(0.16)$ \\
& Object-Experiencer & 0.10 & $(0.23)$ & 0.10 & $(0.20)$ \\
\multirow{2}{*}{ Passive } & Subject-Experiencer & 0.32 & $(0.33)$ & 0.17 & $(0.22)$ \\
& Object-Experiencer & 0.41 & $(0.35)$ & 0.25 & $(0.29)$ \\
\hline
\end{tabular}


Table 5.20: Experiment 3: ANOVA of proportions of Passives in the Lenient scoring

\begin{tabular}{lrrlrrrrr}
\hline & \multicolumn{4}{c}{ F1 Results } & \multicolumn{5}{c}{ F2 Results } \\
\cline { 2 - 9 } Effect & $\boldsymbol{d} \boldsymbol{f}$ & $\boldsymbol{F 1}$ & $\boldsymbol{p}$ & $\boldsymbol{p} \cdot \eta^{2}$ & $\boldsymbol{d f}$ & $\boldsymbol{F 2}$ & $\boldsymbol{p}$ & $\boldsymbol{p} \cdot \boldsymbol{\eta}^{2}$ \\
\hline \hline Prime & 1,46 & 33.98 & $<.001$ & 0.42 & 1,46 & 38.85 & $<.001$ & 0.46 \\
Verb Type & 1,46 & 1.44 & n.s. & 0.03 & 1,46 & 2.98 & n.s. & 0.06 \\
Group & 1,46 & 2.40 & $=.13$ & 0.05 & 1,46 & 5.57 & $<.05$ & 0.11 \\
Prime x Group & 1,46 & 3.17 & $=.08$ & 0.06 & 1,46 & 5.09 & $<.05$ & 0.10 \\
Verb Type x Group & 1,46 & 0.69 & n.s. & 0.01 & 1,46 & 0.18 & n.s. & 0.00 \\
Prime x Verb Type & 1,46 & 6.33 & $<.05$ & 0.12 & 1,46 & 3.69 & $=.06$ & 0.07 \\
PrimexVerbTypexGroup & 1,46 & 1.01 & n.s. & 0.02 & 1,46 & 0.27 & n.s. & 0.01 \\
\hline Prime (Children) & 1,46 & 28.96 & $<.001$ & 0.39 & 1,46 & 36.03 & $<.001$ & 0.44 \\
Prime (Adults) & 1,46 & 8.19 & $<.01$ & 0.15 & 1,46 & 7.91 & $<.01$ & 0.15 \\
Verb Type (Children) & 1,46 & 0.07 & n.s. & 0.00 & 1,46 & 0.84 & n.s. & 0.02 \\
Verb Type (Adults) & 1,46 & 2.07 & n.s. & 0.04 & 1,46 & 2.32 & n.s. & 0.05 \\
Prime (Subject-Experiencer) & 1,46 & 11.81 & $<.01$ & 0.20 & 1,46 & 10.66 & $<.01$ & 0.19 \\
Prime (Object-Experiencer) & 1,46 & 29.04 & $<.001$ & 0.39 & 1,46 & 33.17 & $<.001$ & 0.42 \\
\hline
\end{tabular}

\section{Other Responses}

Table 5.21 shows the raw numbers of Other responses following the Lenient scoring. The analyses were repeated, the results of which are reported in Table 5.22; these showed a significant effect of Group: the children produced more Other responses $(\mathrm{M}=1.90)$ than the adults $(\mathrm{M}=0.10)$. No other main effects or interactions were significant except the main effect of Prime which again approached significance; simple main effects showed a significant effect of Prime on only the children's Other responses. No other simple main effects were significant. Following the Lenient scoring there was no evidence that participants produced more Other responses following subject-experiencer or object-experiencer primes though the children produced more Other responses following passive primes than following active primes.

Table 5.21: Experiment 3: Mean numbers of Others in the Lenient scoring

\begin{tabular}{llcccc}
\hline & \multirow{2}{*}{ Prime } & \multicolumn{2}{c}{ Children } & \multicolumn{2}{c}{ Adults } \\
\cline { 3 - 6 } & $\mathbf{M}$ & (SD) & $\mathbf{M}$ & (SD) \\
\hline \hline \multirow{2}{*}{ Active } & Subject-Experiencer & 1.67 & $(1.40)$ & 0.08 & $(0.28)$ \\
& Object-Experiencer & 1.71 & $(1.43)$ & 0.08 & $(0.28)$ \\
Passive & Subject-Experiencer & 2.17 & $(1.34)$ & 0.13 & $(0.34)$ \\
& Object-Experiencer & 2.04 & $(1.78)$ & 0.13 & $(0.34)$ \\
\hline
\end{tabular}

\section{Additional Analyses}

I again examined whether there was any relation between the participants' BPVS scores and the number of passives following the Lenient scoring. The correlation between vocabulary and number of passives produced only approached significance ( $r$ 
Table 5.22: Experiment 3: ANOVA of numbers of Others in the Lenient scoring

\begin{tabular}{lrrlrrrrr}
\hline & \multicolumn{4}{c}{ F1 Results } & \multicolumn{5}{c}{ F2 Results } \\
\cline { 2 - 9 } Effect & $\boldsymbol{d} \boldsymbol{F}$ & $\boldsymbol{F 1}$ & $\boldsymbol{p}$ & $\boldsymbol{p} \cdot \eta^{2}$ & $\boldsymbol{d f}$ & $\boldsymbol{F 2}$ & $\boldsymbol{p}$ & $\boldsymbol{p} \cdot \eta^{2}$ \\
\hline \hline Prime & 1,46 & 3.38 & $=.07$ & 0.07 & 1,46 & 3.96 & $=.05$ & 0.08 \\
Verb Type & 1,46 & 0.03 & n.s. & 0.00 & 1,46 & 0.03 & n.s. & 0.00 \\
Group & 1,46 & 56.51 & $<.001$ & 0.55 & 1,46 & 233.02 & $<.001$ & 0.83 \\
Prime x Group & 1,46 & 2.26 & n.s. & 0.05 & 1,46 & 2.65 & n.s. & 0.05 \\
Verb Type x Group & 1,46 & 0.03 & n.s. & 0.00 & 1,46 & 0.03 & n.s. & 0.00 \\
Prime x Verb Type & 1,46 & 0.13 & n.s. & 0.00 & 1,46 & 0.17 & n.s. & 0.00 \\
PrimexVerbTypexGroup & 1,46 & 0.13 & n.s. & 0.00 & 1,46 & 0.17 & n.s. & 0.00 \\
\hline Prime (Children) & 1,46 & 5.59 & $<.05$ & 0.11 & 1,46 & 6.54 & $<.05$ & 0.12 \\
Prime (Adults) & 1,46 & 0.06 & n.s. & 0.00 & 1,46 & 0.06 & n.s. & 0.00 \\
Verb Type (Children) & 1,46 & 0.07 & n.s. & 0.00 & 1,46 & 0.06 & n.s. & 0.00 \\
Verb Type (Adults) & 1,46 & 0.00 & n.s. & 0.00 & 1,46 & 0.00 & n.s. & 0.00 \\
Prime (Subject-Experiencer) & 1,46 & 3.18 & n.s. & 0.06 & 1,46 & 3.45 & n.s. & 0.07 \\
Prime (Object-Experiencer) & 1,46 & 1.04 & n.s. & 0.02 & 1,46 & 1.38 & n.s. & 0.03 \\
\hline
\end{tabular}

$=.30, p=.08,1$-tailed). There was no relationship between the age of the participant and the number of passives they produced, $(r=.05, p=.40,1$-tailed $)$ and there was no evidence of a learning effect across the experiment: a paired-samples $t$-test showed that the children did not produce significantly more passives following the last eight primes $(\mathrm{M}=0.96, \mathrm{SD}=1.16)$ than following the first eight primes $(\mathrm{M}=1.21, \mathrm{SD}=1.25$, $t(23)=1.37, p=.09,1$-tailed).

\section{Discussion}

Including the participants' incomplete utterances or short passives in the scored responses brought no change to the overall pattern of results. There is still an effect of the prime's structure on their descriptions of the target picture and participants still produced more passives following subject-experiencer passives than following subject-experiencer actives and following object-experiencer passives than following object-experiencer actives.

\subsubsection{Inclusive Scoring Results}

\section{Results and Analysis}

The final scoring also scored the participants' incomplete and reversed utterances as Active or Passive. This scoring lead to +23 Active and +67 Passive responses for the children and +4 Active and +1 Passive responses for the adults. 


\section{Passive Responses}

The mean proportions of passives following the Inclusive scoring are presented in Table 5.23. The repeated measures ANOVAs again showed a significant effect of Prime, as reported in Table 5.24, but no effect of Verb Type: the participants still produced more passives after hearing passive primes $(M=0.32)$ than after hearing active primes $(M=0.15)$ regardless of whether they contained a subject-experiencer verb $(M=0.23)$ or an object-experiencer verb $(M=0.25)$. The effect of Group was, for the first time, significant: the children produced more passives $(M=0.32)$ than the adults $(M=0.15)$ - this reflects the large increases noted above in the children's responses scored as Passive compared to barely any increase in the adults' scored responses; the children produced more short or reversed passives or incomplete, incorrect passive fragments than the adults scored as Passive in the Inclusive scoring. These increases are also reflected in a significant interaction between Prime and Group showing a stronger priming effect for children than adults. No other interactions were significant: in this scoring there is no longer an interaction between Prime and Verb Type.

Table 5.23: Experiment 3: Mean proportions of Passives in the Inclusive scoring

\begin{tabular}{llcccc}
\hline & \multirow{2}{*}{ Prime } & \multicolumn{2}{c}{ Children } & \multicolumn{2}{c}{ Adults } \\
\cline { 3 - 6 } & $\mathbf{M}$ & (SD) & $\mathbf{M}$ & (SD) \\
\hline \hline \multirow{2}{*}{ Active } & Subject-Experiencer & 0.22 & $(0.29)$ & 0.09 & $(0.16)$ \\
& Object-Experiencer & 0.19 & $(0.25)$ & 0.10 & $(0.20)$ \\
Passive & Subject-Experiencer & 0.42 & $(0.33)$ & 0.17 & $(0.22)$ \\
& Object-Experiencer & 0.45 & $(0.36)$ & 0.25 & $(0.26)$ \\
\hline
\end{tabular}

Table 5.24: Experiment 3: ANOVA of proportions of Passives in the Inclusive scoring

\begin{tabular}{lrrlrrrrr}
\hline & \multicolumn{4}{c}{ F1 Results } & \multicolumn{5}{c}{ F2 Results } \\
\cline { 2 - 9 } Effect & $\boldsymbol{d f}$ & $\boldsymbol{F 1}$ & $\boldsymbol{p}$ & $\boldsymbol{p} \cdot \eta^{2}$ & $\boldsymbol{d f}$ & $\boldsymbol{F 2}$ & $\boldsymbol{p}$ & $\boldsymbol{p} \cdot \eta^{2}$ \\
\hline \hline Prime & 1,46 & 36.10 & $<.001$ & 0.44 & 1,46 & 52.50 & $<.001$ & 0.53 \\
Verb Type & 1,46 & 1.18 & n.s. & 0.02 & 1,46 & 1.55 & n.s. & 0.03 \\
Group & 1,46 & 6.83 & $<.05$ & 0.13 & 1,46 & 43.28 & $<.001$ & 0.48 \\
Prime x Group & 1,46 & 3.92 & $=.05$ & 0.08 & 1,46 & 7.09 & $<.05$ & 0.13 \\
Verb Type x Group & 1,46 & 1.26 & n.s. & 0.03 & 1,46 & 0.49 & n.s. & 0.01 \\
Prime x Verb Type & 1,46 & 2.59 & n.s. & 0.05 & 1,46 & 0.81 & n.s. & 0.02 \\
PrimexVerbTypexGroup & 1,46 & 0.00 & n.s. & 0.00 & 1,46 & 0.11 & n.s. & 0.00 \\
\hline Prime (Children) & 1,46 & 31.90 & $<.001$ & 0.41 & 1,46 & 49.09 & $<.001$ & 0.52 \\
Prime (Adults) & 1,46 & 8.12 & $<.01$ & 0.15 & 1,46 & 10.50 & $<.01$ & 0.19 \\
Verb Type (Children) & 1,46 & 0.00 & n.s. & 0.00 & 1,46 & 0.15 & n.s. & 0.00 \\
Verb Type (Adults) & 1,46 & 2.43 & n.s. & 0.05 & 1,46 & 1.89 & n.s. & 0.04 \\
Prime (Subject-Experiencer) & 1,46 & 19.81 & $<.001$ & 0.30 & 1,46 & 16.32 & $<.001$ & 0.26 \\
Prime (Object-Experiencer) & 1,46 & 27.15 & $<.001$ & 0.37 & 1,46 & 26.48 & $<.001$ & 0.36 \\
\hline
\end{tabular}

Simple main effects again showed a significant effect of Prime for both the children and the adults but no effect of Verb Type for either group: both groups produced significantly more passives after passive primes than after active primes but did not 
produce more passives after object-experiencer primes than after subject-experiencer primes. There was also a simple main effect of Prime for both the subject-experiencer verb primes and the object-experiencer verb primes: participants were more likely to produce passive targets following subject-experiencer passive primes than subjectexperiencer verb active primes and likewise for object-experiencer verb primes.

\section{Other Responses}

Table 5.25 presents the mean raw numbers of Other responses from the Inclusive scoring. I repeated the ANOVAs with these results, the analyses are shown in Table 5.26. There was still a significant effect of Group: the children produced more Other responses $(M=0.96)$ than the adults $(M=0.05)$. No other main effects or interactions were significant: following this scoring there was no evidence that participants produced more Other responses following active or passive primes or following subjectexperiencer or object-experiencer primes. Simple main effects no longer showed an effect of Prime on the children's Other responses and no other effects were significant. This is perhaps not surprising given how few Other responses were left following the Inclusive scoring.

Table 5.25: Experiment 3: Mean numbers of Others in the Inclusive scoring

\begin{tabular}{llcccc}
\hline & \multirow{2}{*}{ Prime } & \multicolumn{2}{c}{ Children } & \multicolumn{2}{c}{ Adults } \\
\cline { 3 - 6 } & $\mathbf{M}$ & (SD) & $\mathbf{M}$ & (SD) \\
\hline \hline \multirow{2}{*}{ Active } & Subject-Experiencer & 0.96 & $(1.40)$ & 0.04 & $(0.20)$ \\
& Object-Experiencer & 1.04 & $(1.12)$ & 0.04 & $(0.20)$ \\
Passive & Subject-Experiencer & 0.71 & $(1.00)$ & 0.13 & $(0.34)$ \\
& Object-Experiencer & 1.13 & $(1.42)$ & 0.00 & $(0.00)$ \\
\hline
\end{tabular}

Table 5.26: Experiment 3: ANOVA of numbers of Others in the Inclusive scoring

\begin{tabular}{lrrlrrrrr}
\hline & \multicolumn{4}{c}{ F1 Results } & \multicolumn{5}{c}{ F2 Results } \\
\cline { 2 - 9 } Effect & $\boldsymbol{d} \boldsymbol{f}$ & $\boldsymbol{F 1}$ & $\boldsymbol{p}$ & $\boldsymbol{p} . \eta^{2}$ & $\boldsymbol{d f}$ & $\boldsymbol{F 2}$ & $\boldsymbol{p}$ & $\boldsymbol{p} . \eta^{2}$ \\
\hline \hline Prime & 1,46 & 0.13 & n.s. & 0.00 & 1,46 & 0.19 & n.s. & 0.00 \\
Verb Type & 1,46 & 1.04 & n.s. & 0.02 & 1,46 & 0.74 & n.s. & 0.02 \\
Group & 1,46 & 20.89 & $<.001$ & 0.31 & 1,46 & 47.32 & $<.001$ & 0.51 \\
Prime x Group & 1,46 & 0.35 & n.s. & 0.01 & 1,46 & 0.52 & n.s. & 0.01 \\
Verb Type x Group & 1,46 & 2.89 & n.s. & 0.06 & 1,46 & 2.06 & n.s. & 0.04 \\
Prime x Verb Type & 1,46 & 0.23 & n.s. & 0.00 & 1,46 & 0.33 & n.s. & 0.01 \\
PrimexVerbTypexGroup & 1,46 & 1.14 & n.s. & 0.02 & 1,46 & 1.61 & n.s. & 0.03 \\
\hline Prime (Children) & 1,46 & 0.45 & n.s. & 0.01 & 1,46 & 0.66 & n.s. & 0.01 \\
Prime (Adults) & 1,46 & 0.03 & n.s. & 0.00 & 1,46 & 0.04 & n.s. & 0.00 \\
Verb Type (Children) & 1,46 & 3.70 & n.s. & 0.07 & 1,46 & 2.64 & n.s. & 0.05 \\
Verb Type (Adults) & 1,46 & 0.23 & n.s. & 0.00 & 1,46 & 0.16 & n.s. & 0.00 \\
Prime (Subject-Experiencer) & 1,46 & 0.36 & n.s. & 0.01 & 1,46 & 0.58 & n.s. & 0.01 \\
Prime (Object-Experiencer) & 1,46 & 0.02 & n.s. & 0.00 & 1,46 & 0.03 & n.s. & 0.00 \\
\hline
\end{tabular}




\section{Additional Analyses}

I examined whether there was still a relationship between the participants' BPVS score and the number of passives they produced following the Inclusive scoring. The bivariate correlations were no longer significant $(r=.20, p=.18$, 1-tailed) in this scoring. There was also no relationship between the age of the participant and the number of passives they produced, $(r=.03, p=.44,1$-tailed $)$ and there was no evidence of a learning effect across the experiment: in fact, a paired-samples $t$-test suggests that the children produced significantly more passives following the first eight primes $(\mathrm{M}=$ $2.21, \mathrm{SD}=1.89)$ than following the last eight primes $(\mathrm{M}=1.54, \mathrm{SD}=1.67, t(23)=2.44$, $p<.05$, 1-tailed).

\section{Discussion}

Even when all the participants' potentially primed responses are scored as Active or Passive, the results show a similar pattern: there is an effect of the prime's structure on the participants' descriptions of the target pictures but there is not an effect of the prime's verb type; the participants still produced more passives after hearing passive primes than after hearing active primes but did not produce more after hearing primes with an object-experiencer verb than after hearing primes with a subject-experiencer verb. These results are discussed below.

\subsubsection{General Discussion of Experiment Three}

This priming experiment examined whether adults and children produced more passives after hearing passive primes with subject-experiencer and object-experiencer verbs than after hearing active primes with these verbs. As in Experiment 2 participants produced more passives following passive primes than following active primes. Experiment 3 also found that both groups produced more passives following subjectexperiencer passive primes than following subject-experiencer active primes and following object-experiencer passive primes than following object-experiencer active primes. This pattern of repetition should not occur if children are unable to process the prime; thus these results suggest that young children do not have difficulty with subject-experiencer non-actional verb passives in particular. Rather, they suggest that by four years of age, children have a syntactic representation for the passive which is not restricted to agent-patient and object-experiencer verbs but is also generalised to subject-experiencer verbs.

These results further extend the results of previous priming experiments by showing that subject-experiencer non-actional verb passives are also good primes of passive responses. These effects were found for both children and adults, suggesting that 
despite the non-canonical ordering of the thematic roles of the prime sentences, these primes effectively elicit passive target descriptions. Though adults tend not to produce passives with subject-experiencer verbs (Maratsos et al. 1985, Ferreira 1994), they and children are primed by them.

These results challenge the results of previous studies, which have shown that children younger than five perform poorly with subject-experiencer passives compared to actional verb passives in comprehension tests (Maratsos et al. 1985, Sudhalter \& Braine 1985, Fox \& Grodzinsky 1998, Hirsch \& Wexler 2006b). If children's passive construction is generalised to subject-experiencer verbs later than to actional verbs, four-year-old children should not be able to parse these primes therefore these passives should not reliably prime passive responses from them. Although priming was stronger from object-experiencer verb passives overall, there was not an effect of Verb Type on the children's or adults' results separately: neither group produced significantly fewer passives following subject-experiencer primes than following objectexperiencer primes. The fact that priming occurred, and occurred for primes of both verb types - passive responses were more likely following subject-experiencer passives than actives and following object-experiencer passives than actives - suggests that four-year-old children can process both types of passive and access a syntactic representation which they use in their subsequent production of the same structure.

\section{Additional Analyses}

There was a correlation between the children's vocabulary size and the number of passives that they produced. This effect was only significant in the Strict scoring when full, non-reversed passives were scored, this suggests that children with lower vocabulary scores produced more non-standard passives such that when these were scored as Passive, the difference with the children with higher vocabulary scores were lost. Children with larger receptive vocabularies produced more correct, full passives. This suggests that children with larger vocabularies have more developed syntax or more proficient processing of syntax. The number of passives children produced did not however correlate with age.

The children's results did not show a learning effect within the experiment: the children did not produce more passives towards the end of the experiment after they had heard many instances of object-experiencer and subject-experiencer primes. This suggests that children did not generalise their passive representation to subjectexperiencer verbs within the experiment following exposure to these primes, rather, that these primes activated children's syntactic representation for the passive leading to priming of their target responses. 


\section{Passive Tokens}

In this experiment the children and adults again produced a number of passives with non-actional verbs, in fact both groups produced more non-actional verb passives in this experiment than in previous experiments; this is probably because all the primes they heard involved non-actional verbs. The adults produced seven nonactional passives ${ }^{7}$, only one of which (with scare) occurred after a prime with that verb. In this experiment, children produced 21 non-actional verb passives; in fact the two verbs (non-actional or otherwise) that children most frequently used as passives were object-experiencer non-actional verbs: scare (8) and annoy (6). They also produced passives with the object-experiencer verbs frighten (2) and upset (1) and with the subjectexperiencer verbs love (3) and see (1). Only seven of the children's 74 passives occurred after a passive prime containing the same verb, two passives occurred after an active prime containing the same verb. The fact that children produced passives with objectexperiencer and subject-experiencer verbs, and that very few of these passives were produced following primes with the same verb, further supports the argument that before five, children's early passive representation is not restricted to actional verbs or based on item-specific representations.

\subsection{Experiment Four: Picture-Sentence Matching Task}

Experiment 2 showed no difference in the priming effect of agent-patient actional verb and object-experiencer non-actional verb passives and Experiment 3 showed a significant priming effect of subject-experiencer verb passives as well as object-experiencer passives, (even though the priming effect was stronger for the latter). Taken together these results do not suggest that children cannot understand passives with verbs other than actional verbs. For priming to occur from subject-experiencer and object-experiencer verb passives, children's comprehension of these primes must activate a syntactic representation which is common to all verbs, regardless of thematic roles, and which also underlies their production of this structure. This begs the question therefore, why do children perform poorly with these passives in other studies? One possible explanation is that previous results may be an artefact of experimental method. The tasks previously used to test children's comprehension may confound children's comprehension of sentences with particular verbs: for example, methods which involve depicting or acting-out sentences with subject-experiencer verbs may confound the results of these tests because such verbs (e.g. see or love) are harder to depict than actional verbs (such as kiss or push). The priming studies avoided these

\footnotetext{
${ }^{7}$ These verbs were: scare (3), frighten (2), love (1), annoy (1).
} 
problems because the experimenter described the subject-experiencer verb pictures and the children's comprehension was measured by whether they repeated the passive structure to describe their own pictures involving actional verbs, which previous studies showed were not problematic for children of this age. To investigate this, I used the same task as some of the previous studies which have shown this effect of verb type on children's comprehension of passives - a picture-sentence matching task - to test children's comprehension of passives with different verb types to see whether this replicated the results of similar previous studies, or whether it replicated the results of the priming experiments reported in this chapter. I tested the same children who completed Experiment 3's priming task in order to check that our results in the priming task were not related to our sample.

The picture-sentence matching task presents participants with two pictures depicting the same characters and the same event but with the characters' roles swapped across the two pictures. The participant hears a sentence which matches one of these pictures and must indicate which picture they think it matches. Thus their comprehension of the sentences is measured by how frequently they correctly match them to the pictures. Note that unlike in the priming tasks, where their comprehension is measured by whether or not they repeat the comprehended structure, in this type of experiment they must process the sentence and identify the correct picture to demonstrate comprehension. If children have difficulty distinguishing the pairs of pictures, not necessarily comprehending the sentences, they will perform poorly. Thus poor picture recognition could be misinterpreted as poor comprehension. This is particularly pertinent when one considers that children tended to perform poorly with verbs that are difficult to depict: compare subject-experiencer verbs such as see or love with actional verbs hit or pull or even object-experiencer verbs such as scare or upset.

Therefore I tested the same types of sentences as used for the primes of Experiments 2 and 3 to see whether the sentences, which were successful primes, were also correctly matched to pictures or whether, when tested in this task, the children's performance replicated previous studies. I also tested children's comprehension of objectexperiencer verb passives using this method as previous studies have not examined these but the explanations for children's difficulty with subject-experiencer verbs tend to predict better comprehension of object-experiencer verb passives.

As a further check on the results I also tested adults on the same task: if children's difficult with subject-experiencer passives in previous studies is related to the task, it is possible that this will also be reflected in the adults' results. I assume that, though passives with certain verbs may be dispreferred, even by adults, they are not incomprehensible for adults. Most previous studies have not tested adults on the same task as 
the children complete, though Hirsch and Wexler (2006b) did test adults' comprehension of actional and subject-experiencer verb actives and passives in a picture-sentence matching task. They also collected reaction times for these sentences. They found that adults were quicker and more accurate matching active sentences to pictures than passive sentences but they did not observe an effect of verb type.

\subsubsection{Method}

\section{Design}

This experiment had two within-participants factors: Structure (active vs. passive) and Verb Type (agent-patient actional vs. subject-experiencer non-actional vs. objectexperiencer non-actional) which created six conditions. As in the priming experiments, the form of the active test sentences was: $A$ SUBJECT is VERB-ing an OBJECT and the form of the passive test sentences was: A SUBJECT is being VERB-ed by an OBJECT.

\section{Participants}

The children and adult participants who completed Experiment 3 took part in this experiment ${ }^{8}$.

\section{Materials}

There were 36 experimental items, each comprising a target picture paired with a foil picture. The foil picture depicted the same characters and transitive event as the target picture but with the characters' roles swapped (see Figure 5.10 for examples of the target picture (left) and its foil (right)). The arguments for each verb consisted of 18 animal characters and 18 human characters; in addition to the 12 animal and 12 human characters used in the priming experiment items, there were six more animal characters (fox, giraffe, goat, monkey, mouse, penguin) and six more human characters (ballerina, builder, gnome, pirate, policeman, postman). The animal and human characters were paired twice each to create the thirty-six items, never repeating a given animalhuman pairing in another experimental item.

There were three versions of each pairing: one involved an agent-patient actional verb (bite, carry, hit, pat, pull, squash); the second involved a subject-experiencer non-actional verb (hate, hear, ignore, love, remember, see) and the third involved an object-experiencer non-actional verb (annoy, frighten, scare, shock, surprise, upset) (see Appendix B.4 for a complete list). I tested the same verbs as in the primes for Experiments 2 and 3 with the exception of like which was changed to hate in this task; it was easier to depict the

\footnotetext{
${ }^{8}$ All children and adults participated in the picture-sentence matching task at least one week before Experiment 3: this was done so that their performance on the picture-sentence matching task wasn't influenced by exposure to passives during the priming task.
} 
swap in roles across the target and foil for hate than it was for like. Each version had an associated active and passive description.

The depiction of the items was counterbalanced so that the object appeared on the left of half of the pictures and on the right for the other half and the presentation of the items was counter-balanced such that half of the target pictures were presented on the participants' right and half were presented on their left. Each child experienced six items in each of the six conditions; the order of presentation of the experimental items was randomized.

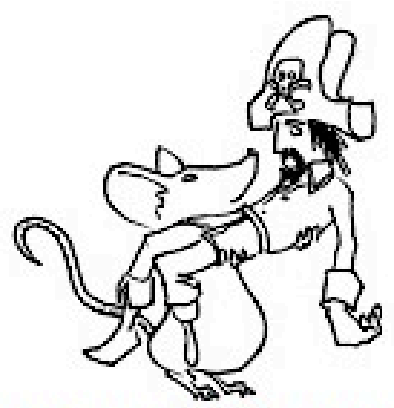

A mouse is carrying a pirate A pirate is being carried by a mouse

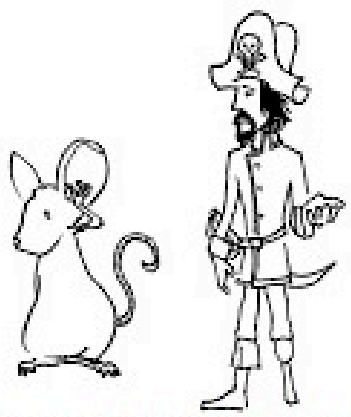

A mouse is hearing a pirate A pirate is being heard by a mouse

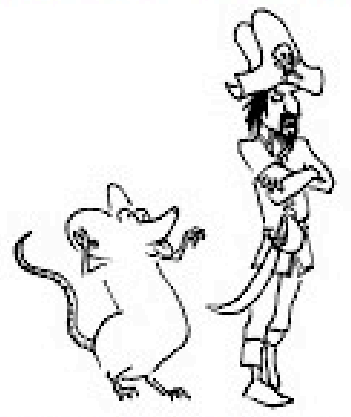

A mouse is annoying a pirate A pirate is being annoyed by a mouse

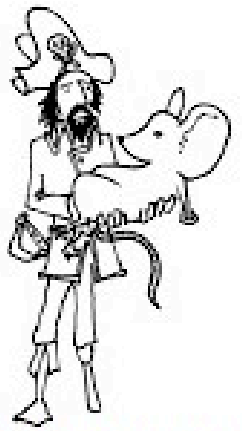

A pirate is carrying a mouse A mouse is being carried by a pirate
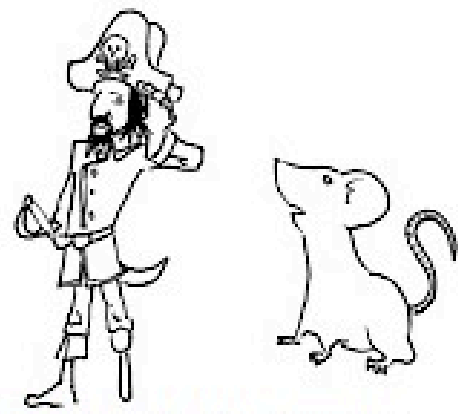

A pirate is hearing a mouse A mouse is being heard by a pirate

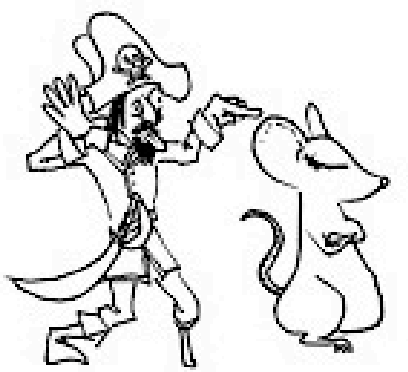

A pirate is annoying a mouse A mouse is being annoyed by a pirate

Figure 5.10: Experiment 4: Target and foil versions of a picture-sentence matching item 
Seven practice items (Appendix B.3) preceded the 36 experimental items; four of these were actives, three were passives. These involved more obviously different pairs of pictures to introduce the children to the picture-sentence matching task: the foil picture of the practice items involved either two (5.3a) or one (5.3b) different characters but the same action to the target picture or the same characters carrying out different actions (5.3c).
a. Target: A frog is poking a clown
Foil: A cat is poking a queen
b. Target: A donkey is waking a policeman
Foil: A donkey is waking a builder
c. Target: A monkey is following a gnome
Foil: A monkey is catching a gnome

The picture-sentence matching task was presented to the child as a sorting task they were asked to find the pictures that the experimenter wanted (described) and post them into a letterbox. The pictures were stacked in two piles in front of the child. The experimenter gave the description for the target picture and the child selected the picture it matched from the top of one of the two piles, the experimenter then removed the top picture from the other pile, such that two new pictures were on the top, and described the next target picture. I scored the pictures that the child had selected as correctly or incorrectly matched to the sentence and thus calculated a comprehension score out of six (the number of correctly matched pictures) for each condition.

\subsubsection{Results and Analysis}

\section{Results}

Table 5.27 presents the results of the picture-sentence matching task; it shows the mean score out of six for each condition and each group. These means suggest that the children found passives harder than actives and subject-experiencer verb sentences harder than the other sentences. The adults, by comparison, correctly matched all the actional verb sentences to their pictures but made some mistakes with the nonactional verb sentences.

\section{Analysis}

First the groups' performance was compared in repeated measures ANOVAs treating participants $\left(F_{1}\right)$ and items $\left(F_{2}\right)$ as random effects: Structure (active vs. passive) and Verb Type (agent-patient vs. subject-experiencer vs. object-experiencer) were 
Table 5.27: Experiment 4: Results of the picture-sentence matching task (mean scores out of six)

\begin{tabular}{lcccccccc}
\hline & \multicolumn{4}{c}{ Children } & \multicolumn{4}{c}{ Adults } \\
\cline { 2 - 9 } & \multicolumn{2}{c}{ Active } & \multicolumn{2}{c}{ Passive } & \multicolumn{2}{c}{ Active } & \multicolumn{2}{c}{ Passive } \\
& $\mathrm{M}$ & $(\mathrm{SD})$ & $\mathrm{M}$ & $(\mathrm{SD})$ & $\mathrm{M}$ & $(\mathrm{SD})$ & $\mathrm{M}$ & $(\mathrm{SD})$ \\
\hline \hline Agent-Patient & 5.00 & $(1.14)$ & 4.63 & $(1.47)$ & 6.00 & $(0.00)$ & 6.00 & $(0.00)$ \\
Subject-Experiencer & 3.75 & $(1.26)$ & 2.42 & $(1.56)$ & 5.88 & $(0.34)$ & 5.75 & $(0.44)$ \\
Object-Experiencer & 4.63 & $(1.21)$ & 4.13 & $(1.39)$ & 5.75 & $(0.53)$ & 5.96 & $(0.20)$ \\
\hline
\end{tabular}

within-participants and -items factors and Group (children vs. adults) was a betweenparticipants and within-items factor. The results of these ANOVAs are reported in Table 5.28; where Mauchly's Test of Sphericity was significant (indicated by *), results are reported with Greenhouse-Geisser correction. The analyses showed a significant effect of Structure: overall participants performed better with active sentences $(M=5.17)$ than with passive sentences $(\mathrm{M}=4.81)$; a significant effect of Verb Type: the means reported in Table 5.27 suggest that matching accuracy for subject-experiencer verb sentences was lower; and a significant effect of Group: the adults correctly matched more sentences to pictures $(M=5.89)$ than the children $(M=4.09)$. There was also a significant interaction of Structure and Group: children found passive sentences significantly harder than actives than the adults. There was also a significant interaction between Verb Type and Group: the differences in children's performance with agentpatient, object-experiencer and subject-experiencer verb sentences differed from the adults', as suggested by the means above. There was a significant interaction between Structure and Verb Type: the means suggest that passives were harder with certain verb types than with others. I carried out separate analyses on the groups' results to tease apart these effects.

Table 5.28: Experiment 4: ANOVA of picture-sentence matching results

\begin{tabular}{lcrlcrrrr}
\hline & \multicolumn{4}{c}{ F1 Results } & \multicolumn{5}{c}{ F2 Results } \\
\cline { 2 - 9 } Effect & $\boldsymbol{d f}$ & $\boldsymbol{F 1}$ & $\boldsymbol{p}$ & $\boldsymbol{p} . \eta^{2}$ & $\boldsymbol{d f}$ & $\boldsymbol{F 2}$ & $\boldsymbol{p}$ & $\boldsymbol{p} . \eta^{2}$ \\
\hline \hline Structure & 1,46 & 11.34 & $<.01$ & .20 & 1,70 & 11.15 & $<.01$ & .14 \\
Verb Type & $* 1.5,70.6$ & 17.64 & $<.001$ & .28 & $* 1.7,117.6$ & 22.61 & $<.001$ & .24 \\
Group & 1,46 & 175.03 & $<.001$ & .79 & 1,70 & 225.51 & $<.001$ & .76 \\
Structure x Group & 1,46 & 13.19 & $<.01$ & .22 & 1,70 & 12.96 & $<.01$ & .16 \\
Verb Type x Group & $* 1.5,70.6$ & 12.26 & $<.001$ & .21 & $* 1.7,117.6$ & 15.71 & $<.001$ & .18 \\
Structure x Verb Type & $* 1.8,81.7$ & 5.07 & $<.05$ & .10 & 2,140 & 5.41 & $<.01$ & .07 \\
Struct.xVerbTypexGroup & $* 1.8,81.7$ & 2.10 & n.s. & .04 & 2,140 & 2.25 & n.s. & .03 \\
\hline
\end{tabular}




\section{Children's Results}

I analysed the children's results further in separate two-way ANOVAs, (Structure (2) $x$ Verb Type (3)) with planned contrasts, the results of the main analyses of which are reported in Table 5.29. These showed a significant main effect of Structure; overall the children matched active sentences to pictures $(M=4.46)$ better than passives $(M$ = 3.72). The effect of Verb Type was also significant suggesting that sentences with certain verbs were matched better than others (see Table 5.27). There was also a significant interaction between Structure and Verb Type; passives were harder than actives with certain verbs than with others. Simple main effects showed an effect of Verb Type for both levels of Structure: children understood some actives worse than others and some passives worse than others.

Table 5.29: Experiment 4: ANOVA of children's picture-sentence matching results

\begin{tabular}{lcccccccc}
\hline & \multicolumn{4}{c}{ F1 Results } & \multicolumn{5}{c}{ F2 Results } \\
\cline { 2 - 9 } Effect & $d \boldsymbol{f}$ & $\boldsymbol{F 1}$ & $\boldsymbol{p}$ & $\boldsymbol{p} \cdot \eta^{2}$ & $\boldsymbol{d f}$ & $\boldsymbol{F 2}$ & $\boldsymbol{p}$ & $\boldsymbol{p} \cdot \eta^{2}$ \\
\hline \hline Structure & 1,23 & 13.20 & $<.01$ & 0.36 & 1,35 & 12.70 & $<.01$ & 0.27 \\
Verb Type & $* 1.5,34.6$ & 15.42 & $<.001$ & 0.40 & $* 1.6,57.1$ & 20.06 & $<.001$ & 0.36 \\
Structure x Verb Type & 2,46 & 3.61 & $<.05$ & 0.14 & 2,70 & 3.77 & $<.05$ & 0.10 \\
Verb Type (Actives) & 2,22 & 5.51 & $<.05$ & 0.33 & 2,34 & 8.86 & $<.01$ & 0.34 \\
Verb Type (Passives) & 2,22 & 8.96 & $<.01$ & 0.45 & 2,34 & 44.34 & $<.001$ & 0.72 \\
\hline
\end{tabular}

Planned comparisons compared the children's comprehension of actives and passives with different types of verbs separately. Previous studies suggested that children would perform badly with subject-experiencer passives but not with the actional passives; their explanations predict that object-experiencer passives would also be better understood than subject-experiencer passives. First therefore, I compared the children's score for subject-experiencer verb passives with their scores for the other passives (combined) and found a significant difference $\left(F_{1}[1,23]=17.80, p<.001\right.$, partial $\eta^{2}=.44, F_{2}[1,35]=79.13, p<.001$, partial $\left.\eta^{2}=.69\right)$; their matching accuracy for subject-experiencer passives was significantly worse compared to other passives. Second I compared their scores for agent-patient passives and object-experiencer passives but found that the difference was not significant $\left(F_{1}=3.29, p=.08, F_{2}=1.43\right.$, $p=.24)$ the children did not perform significantly better with agent-patient passives than with object-experiencer passives. Surprisingly, the same pattern of results was found for the children's scores for active sentences: their matching accuracy for subject-experiencer verb actives was significantly worse than for agent-patient verb and object-experiencer verb actives $\left(F_{1}[1,23]=11.51, p<.01\right.$, partial $\eta^{2}=.33, F_{2}[1,35]$ $=14.47, p<.01$, partial $\left.\eta^{2}=.29\right)$, however the difference between actional and objectexperiencer verb actives was not significant $\left(F_{\mathrm{S}}<2\right)$. 


\section{Adults' Results}

Table 5.30 reports the results of further analyses of the adults' results. These showed no effect of Structure; the adults matched passive sentences $(M=5.90)$ as accurately as active sentences $(M=5.87)$. There was however a significant effect of Verb Type: the adults matched sentences with certain verbs better than others (see Table 5.27). There was also a significant interaction between Structure and Verb Type. Simple main effects showed an effect of Verb Type for both levels of Structure.

Table 5.30: Experiment 4: ANOVA of adults' picture-sentence matching results

\begin{tabular}{lcccccccc}
\hline & \multicolumn{4}{c}{ F1 Results } & \multicolumn{5}{c}{ F2 Results } \\
\cline { 2 - 9 } Effect & $\boldsymbol{d} \boldsymbol{f}$ & $\boldsymbol{F 1}$ & $\boldsymbol{p}$ & $\boldsymbol{p} . \eta^{2}$ & $\boldsymbol{d f}$ & $\boldsymbol{F 2}$ & $\boldsymbol{p}$ & $\boldsymbol{p} \cdot \eta^{2}$ \\
\hline \hline Structure & 1,23 & 0.24 & n.s. & 0.01 & 1,35 & 0.33 & n.s. & 0.01 \\
Verb Type & $* 1.5,34.9$ & 4.22 & $<.05$ & 0.15 & $* 1.5,53.7$ & 4.04 & $<.05$ & 0.10 \\
Structure x Verb Type & 2,46 & 3.36 & $<.05$ & 0.13 & $* 1.6,57.8$ & 4.48 & $<.05$ & 0.11 \\
Verb Type (Actives) & 2,22 & 5.00 & $<.05$ & 0.31 & 2,34 & 4.41 & $<.05$ & 0.21 \\
Verb Type (Passives) & 2,22 & 3.67 & $<.05$ & 0.25 & 2,34 & 4.10 & $<.05$ & 0.19 \\
\hline
\end{tabular}

Since the adults made more errors matching non-actional verb sentences to pictures than matching the agent-patient actional verb sentences and pictures, planned comparisons first compared the adults' score for agent-patient verb passives with their scores for the non-actional verb passives combined and found a significant difference $\left(F_{1}[1,23]=6.75, p<.05\right.$, partial $\eta^{2}=.23, F_{2}[1,35]=8.45, p<.01$, partial $\left.\eta^{2}=.19\right)$; the adults' matching scores were better for actional verb passives than non-actional passives. There was also a significant difference between their scores for the two types of non-actional verb passives $\left(F_{1}[1,23]=6.05, p<.05\right.$, partial $\eta^{2}=.21, F_{2}[1,35]=3.85$, $p=.058$, partial $\eta^{2}=.10$ ); pair-wise comparisons showed that their object-experiencer passive scores were not different to their agent-patient passive scores ( $p s>32)$ but their subject-experiencer scores were different to their agent-patient passive scores $\left(p_{1}\right.$ $\left.<.05, p_{2}=.058\right)$. There was also a significant difference between the adults' actional verb active scores and their non-actional verb active scores $\left(F_{1}[1,23]=10.18, p<.01\right.$, partial $\eta^{2}=.31, F_{2}[1,35]=9.00, p<.01$, partial $\left.\eta^{2}=.21\right)$; they more accurately matched actional verb actives than non-actional verb actives. Second I compared their scores for subject-experiencer and object-experiencer actives but found that the difference was not significant $\left(F_{\mathrm{S}}<2\right)$ : adults showed no difference in their matching accuracy of subject-experiencer and object-experiencer actives.

\subsubsection{General Discussion of Experiment Four}

Experiment 4 tested three- and four-year-old children's and adults' comprehension of actives and passives with agent-patient, subject-experiencer and object-experiencer 
verbs in a picture-sentence matching task, of the type that has been extensively used in previous language acquisition research. It replicated the results of previous studies with children: they understood actives better than passives and they understood agent-patient actional verb passives better than subject-experiencer verb passives (see Table 5.27), although unlike previous studies, this experiment also found that children understood subject-experiencer verb actives more poorly than other active sentences. In addition, I extended previous studies by testing participants' understanding of object-experiencer verb sentences. This experiment showed that four-year-old children understood object-experiencer verb active and passive sentences as well as agent-patient verb sentences; this extends the results of previous studies which have not tested these sentences.

Experiment 4 also extended the results of previous studies by testing a control group of adults on the picture-sentence matching task: it was predicted that they should not have any difficulty interpreting the sentences or pictures. This experiment showed that overall the adults did perform better than the children and did not find passive sentences harder to match to pictures than active (see Table 5.27). However, surprisingly, the adults had a higher matching accuracy score for agent-patient actives than the non-actional actives and also for agent-patient and object-experiencer passives than for subject-experiencer passives.

These results are not, however, consistent with the findings from the priming experiments which showed that agent-patient, object-experiencer and subject-experiencer passives all primed passives responses suggesting that children and adults understood all of these types of passives. The fact that I replicated previous findings when using the same sort of experimental method as previous studies suggests that the effects previously found for children may be related to the task, particularly given that the same children who were primed to produce passives by subject-experiencer and object-experiencer primes performed poorly with these passives in the picturesentence matching task. The adults' results add some weight to the hypothesis that children's difficulty with these sentences is related to the task: I assume that adults are able to process subject-experiencer passives and actives. The fact that they make more mistakes matching these passive sentences to pictures than other passive sentences and also that they make more mistakes matching these active sentences to pictures than agent-patient active sentences suggests that even they may have had difficulty interpreting these particular pictures. This is discussed further below. 


\subsection{General Discussion of Experiments Two, Three and Four}

This chapter examined three- and four-year-old children's and adults' comprehension of passives with different verb types for evidence, using a syntactic priming methodology, that children's acquisition of the passive is semantically constrained. I measured their comprehension according to whether they were more likely to produce passives after comprehending passive primes than after active primes when the primes contained either agent-patient actional verbs or object-experiencer or subject-experiencer non-actional verbs. These experiments did not show evidence that before five years of age, children cannot understand non-actional verb passives in general; there was no difference between the agent-patient and object-experiencer primes; or that they cannot understand subject-experiencer non-actional verb passives in particular; these passives also primed passive responses from three- and four-year-old children.

As these results are not consistent with previous findings I carried out a further test with some of the same children to check whether they also performed better when tested in a similar task to previous studies. I tested their comprehension of the same types of passives in a picture-sentence matching task, which measured their comprehension according to whether they were able to select the picture that matched the description they heard. This experiment replicated the findings of previous studies (e.g. Maratsos et al. 1985): children showed better comprehension, as characterised by a higher matching accuracy, of agent-patient actional verb passives than of subject-experiencer verb non-actional verb passives. Unlike previous studies however, children's matching accuracy for subject-experiencer actives was also lower than for agent-patient actives. The same children who were primed to produce passives following object-experiencer and subject-experiencer passive primes did not accurately match subject-experiencer sentences to their pictures. Adults also made more mistakes with subject-experiencer sentences than with actional verb sentences.

Given these results, I propose that children's apparent difficulty understanding subject-experiencer verb passives may be an effect of the task previously used to test their comprehension. Previous studies have generally used one of two tasks for this test: a picture-sentence matching task or a 'sentence and question' task. These tasks may favour comprehension of actional verb passives and impede comprehension of non-actional verb passives. For example, the method of presenting the child with an active or passive sentence and then asking the child "Who VERB-ed? Which one VERB-ed?" may be more felicitous with action verbs than with subject-experiencer non-actional verbs. Compare for example the actional verb sentence "the pirate was hit by the penguin" - "Who hit? Which one hit?" and the subject-experiencer sentence 
"the pirate was seen / loved by the penguin" - "Who saw / loved? Which one saw / loved?": the child may find it easy to respond to a question about hitting since only one entity could carry out that action, however with experiential or perceptual verbs such as love and see, both entities might be logically deemed to be a perceiver or experiencer. In addition, Maratsos et al. (1985) report that this method is generally difficult; they found that questions such as "who liked whom/someone?" were more confusing than asking "who did it?", and also that this method produced lower scores than a simpler, picture-sentence matching task.

Picture-sentence matching tasks may also pose similar difficulties; Beilin (1975) notes lower scores with this method compared to other methods. In this task, the child is presented with two pictures showing the same action and the same characters but with the characters' roles swapped across the two pictures. Not only is it easier to depict action verbs such as hit or kiss than to depict experiential verbs such as love or hate or even perception verbs such as see, it is also easier to distinguish the verb's underlying subject - the causer of the event - for verbs like hit than it is for verbs like see and therefore to show a difference between the target picture and the picture with the roles swapped. Children's difficulty may lie in interpreting (and distinguishing) the pictures rather than the sentence they have heard. For example matching sentences with actional verbs such as "the pirate was hit by the penguin" to a pair of minimally different pictures is perhaps easier: it is very clear in which picture a penguin is hitting and in which it is not; however, for sentences with subject-experiencer verbs, such as "the pirate was loved by the penguin" it is perhaps less clear to the child which pictures this matches - the picture of a penguin loving a pirate or a pirate loving a penguin; in both the penguin is, to some extent, experiencing love. Similarly for "the pirate was seen by the penguin", in both pictures for this sentence the penguin is, presumably, seeing. This may explain the apparent split in children's ability — the task requires them to distinguish minimally different depictions of these events; I propose that this is easier for the child to do with actional verbs than with subject-experiencer nonactional verbs. This is supported by the finding of adults' poorer performance with these actives and passives.

One potential problem with this explanation is that it also predicts that children would score lower with subject-experiencer active sentences, which was not found in previous studies (e.g. Maratsos et al. 1985); recall, however, that the picture-sentence matching task reported above did find this pattern of results. But overall children do perform significantly worse with passives than actives in such tasks; at five children apparently still find passive sentences with any class of verb harder to interpret correctly than actives; this is reflected in the fact that they produce a number of in- 
complete and - or reversed passives, even following priming. To refine my earlier proposal therefore, I suggest that the further interaction with verb type observed in previous experiments may be caused by the task, not by semantic constraints on the development of the passive. That is, children's difficulty interpreting passive sentences is compounded in the subject-experiencer verb condition of these tasks by their difficulty to perceive any difference in these pictures. This is further supported by the participants' low matching accuracy for subject-experiencer actives in Experiment 4.

The priming task avoids these issues: the children must process the passive prime in order to be primed; that is, when they hear the passive prime, they must access a syntactic representation, which is common to all verbs, regardless of semantic class or thematic roles, and which they can use in their subsequent production of a target description. This task does not require children to distinguish minimally different pictures of subject-experiencer events for evidence of their comprehension; rather their comprehension of these passives is measured by whether or not they produced more passives following these primes. The fact that children did produce more passives following passive primes with all verb types compared to their active counterparts suggests that they were able to process all these primes well enough to activate the passive representation required for their description of transitive targets with passive sentences. Table 5.31 shows the percentage priming effects for the first three priming experiments: it shows that within both groups, the priming effects observed with the different verb types ranged around the priming effect found in Experiment 1 with the agent-patient verbs (which, itself, is similar to the mean priming effect across the experiments; $23 \%$ for the children, $15 \%$ for the adults). Overall, our results suggest that by four years of age, English-speaking children have acquired a syntactic representation for the passive that is generalised to both typically transitive, actional verbs and to non-actional verbs and that like adults, this representation underlies verbs with different thematic role configurations.

Table 5.31: Experiments 1-3: Percentage priming effects

\begin{tabular}{llcc}
\hline \multirow{2}{*}{ Experiment } & & \multicolumn{2}{c}{ Priming Effect } \\
\cline { 2 - 4 } Experiment 1 & Agent-Patient Passive & $21 \%$ & $12 \%$ \\
\cline { 2 - 4 } Experiment 2 & Agent-Patient Passive & $28 \%$ & $22 \%$ \\
& Object-Experiencer Passive & $20 \%$ & $15 \%$ \\
\cline { 2 - 4 } Experiment 3 & Object-Experiencer Passive & $29 \%$ & $18 \%$ \\
& Subject-Experiencer Passive & $16 \%$ & $8 \%$ \\
\cline { 2 - 4 } & Mean Priming Effect & $23 \%$ & $15 \%$ \\
\hline
\end{tabular}

Finally, the experiments reported in this chapter extended previous research in this area by also testing object-experiencer verb passives. In the picture-sentence match- 
ing task, the children performed as well with these items as with actional verb items and these passives primes elicited passive responses as effectively as agent-patient actional primes. These results also suggest that children do not constrain their representation of the passive to actional verbs in general. The lack of verb type effect with the object-experiencer passives in the picture-sentence matching task may be explained by the fact that, like actional verbs but unlike subject-experiencer verbs, these verbs (e.g. scare, upset) more clearly show which character is experiencing and which is the cause of the experiencing. Therefore children's difficulty with passives is not further confounded by this verb type as appears to be the case for subject-experiencer verb passives.

\section{Additional Analyses}

To rule out alternative explanations I checked for evidence of an effect of the children's age on their production of passives and for evidence of a learning effect with the experiment. There was no evidence of implicit learning within the experiments, as characterised by more passives being produced towards the end of the experiment than at the beginning. Given that children hear few subject-experiencer passives in particular, it was important to rule out the possibility that the intensive exposure of these passives during the experiment led to a priming effect at the end but not at the beginning of the experiment. There was also no evidence that the results mask differences within the groups: though the age range was large, older children did not produce more passives in either experiment than younger children suggesting that it was not the case that younger children within the groups did not comprehend the primes but older children did. Experiment 3 showed that children with larger vocabularies did produce more passives suggesting that their vocabulary size may relate to more developed syntactic representations or to more proficient syntactic processing.

\section{Passive Tokens}

In the two priming experiments, children and adults both used non-actional verbs to describe some of the pictures which all depicted actional events and both groups used both object-experiencer and subject-experiencer verb passives. Whilst this provides some evidence that children also produce non-actional verb passives as well as comprehending these primes, there is scope for further research with non-actional verb targets to show that different primes also elicit a variety of non-actional verb passives from young children when the primes do not involve non-actional verbs.

\section{Passive Types}

It is interesting to note that in these priming experiments, as in Experiment 1, children again showed a tendency to reproduce the form of the passive used in the primes full, be-passives - rather than either of the structural variants (short or get-passives). 
In Experiment 2, 62 (82\%) of the children's full passives were be-passives, compared to $14(18 \%)$ get-passives and they produced just three (4\%) short (be-) passives in Experiment 2, compared to 76 (96\%) full passives. In Experiment 3, 100\% of the children's full passives were be-passives and they produced only one (1.3\%) short (be-) passive, compared to $74(98.7 \%)$ full passives. The adult participants produced no short passives in either Experiment 2 or 3; 82 (98\%) of their full passives were be-passives in Experiment 2, they produced only 2 get-passives in Experiment 2 and they produced no get-passives in Experiment 3. The experiments presented in the following chapter examined whether the priming effect is related to the repetition of the function words of passives (the auxiliary and the preposition by) and whether there is evidence that children and adults' syntactic representation for the passive includes these possible variations in length and auxiliary.

\subsection{Summary and Conclusions}

In this chapter I examined whether syntactic priming experiments also show evidence that children's early syntactic representation for the passive is constrained to actional verbs as suggested by previous research. Experiments 2 and 3 found that passive primes elicited passive responses irrespective of the verb type of the prime. These experiments extended previous priming experiments by showing that objectexperiencer and subject-experiencer verb passives also prime (child and adult) participants to describe pictures of agent-patient events with passive sentences. These priming results suggest that children's early passives are not inherently actional verb passives. The fact that testing some of the same children using the same task as previous studies replicated previous findings suggests that these results may be related to the experimental method. Experiment 4 extended the results of these previous studies by testing object-experiencer sentences; these did not show the same problems as subject-experiencer sentences. This experiment also provides data from adults for this task: this showed that adults were less accurate at matching subject-experiencer sentences to pictures than actional verb sentences. Since one would not expect adults to be unable to process these sentences, and since adults also showed priming effects from these passives, this appears to be further evidence that this task may confound participants' performance. 


\section{Chapter 6}

\section{Abstract Structures Underlying Children's Passives}

\subsection{Introduction}

In the previous experiments it was noted that the children's passive responses were fairly uniform: participants tended to produce full rather than short passives and to use be as the passive auxiliary rather than get. In other words, the participants reproduced the same form of the passive as modelled in the prime despite the existence of possible alternatives. The evidence from the language acquisition literature suggests that, in fact, children may acquire structural variants of the passive before the full be-passive; the fact that they tended to produce full be-passives in the previous experiments would suggest that the priming effect observed in these experiment could be related to or influenced by the repetition of surface features - closed-class items. Chapter 6 examines priming from structural variants of the full be-passive for evidence of whether children's early representation of the passive underlies these possible variations and that the observed priming effect was indeed related to abstract syntactic representations or whether there is evidence that they acquire certain structural forms before others and that therefore the observed priming effect was related to the repetition of closed-class lexical items. Experiment 5 used short passive primes, describing pictures which did not depict an agent, for target pictures showing a patient and an agent, to test whether young children still used full passives to describe these when they only heard short passive primes, not containing a by-phrase. Experiment 6 examined the priming effect of get- and be-passives to test whether participants tended to repeat the auxiliary of the prime or whether priming shows evidence that a single 
representation underlies these two forms. This experiment also examined whether children showed a preference for get-passives.

As discussed in Chapter 2, research into children's early passives suggests that such alternative forms (get-passives and short passives) are used earlier and more frequently (e.g. Harris \& Flora 1982, Marchman et al. 1991), hence one may reasonably have expected to see more of these forms produced, particularly by the younger participants. The uniformity of the participants' responses in the previous experiments leaves open the question of whether the experiment showed completely abstract, syntactic priming or something that superficially appears to be syntactic but is in fact based on, or related to, lexical frames associated with repeated function words. If previous research suggests that children are more likely to produce short passives or passives with get at a young age but the participants in previous experiments were more likely to produce full passives with be as modelled in all the passive primes, then the possibility exists that children's early representation of the passive is different to the representation underlying the sentences they produced, and their responses to the primes were the result of lexical priming from repeated closed-class items (not the open-class argument noun phrases and verbs), such as the passive auxiliary, being, and the preposition of the oblique object phrase, by.

Another hypothesis is that these closed-class, function words can add a lexical boost to the priming effect. There is evidence that repeated open-class words can boost the syntactic priming effect with adults (Pickering \& Branigan 1998, Cleland \& Pickering 2003) however it is not clear whether function words (such as the passive auxiliary or the preposition of the oblique noun phrase) do or should influence priming. According to the model of linked lemma and combinatorial nodes (Pickering \& Branigan 1998) described in Chapter 3, repeating lemmas, such as the passivized verb, between prime and targets increases the likelihood of priming due to the increased activation of both the combinatorial node activated by the prime and the increased activation of the sentence's verb lemma. Repeated grammatical morphemes should not in this model influence priming and indeed Pickering and Branigan (1998) found no evidence that tense or aspect features of sentences influenced the priming effect. Other studies have also shown evidence that repeated function words do not influence priming: Bock (1989) found that for-prepositional dative primes produced the same priming effect as to-prepositional dative primes on dative targets.

These studies provide evidence showing that repeating function words does not boost the priming effect in the same way that repeating content words does in studies of adult priming. However, there is also some evidence to suggest that repeating function words may influence priming. Bock and Loebell (1990) found that locative primes 
(involving a post-verbal locative by-phrase: The construction worker was digging by the bulldozer) prime passive responses to the same extent as passive primes (involving a post-verbal agentive by-phrase: The construction worker was hit by the bulldozer). Bock and Loebell (1990) suggest that priming occurred between these structures as they share constituent structures (e.g. NP VP PP); however, an alternative possibility is that participants were primed to repeat the lexical item by which they heard in passive and locative primes. Similarly, Levelt and Kelter (1982) found that prepositional primes (e.g. At what time does the shop open?) elicited prepositional responses (e.g. At five o'clock) whereas primes without prepositions (e.g. What time does the shop close?) did not; note though that this may be interpreted as evidence of syntactic priming of prepositional phrases, not of individual prepositions (Bock 1986).

As such, adult syntactic priming studies provide mixed evidence for whether function words influence priming. In addition, it is possible that children behave differently from adults in this respect because their language is still developing and as such they may be sensitive to function word overlap. Savage et al. (2003) only found a significant priming effect for passives from young children when the primes involved repeated (closed-class) pronouns (e.g. It is pushing it) rather than full (open-class) noun phrases. Savage et al. (2006) suggest that children's early representations could be based on lexical items such as the auxiliary or preposition by which combined create a passive. Other child priming studies tend not to report the extent to which the target form contained the same morphemes as the prime forms although most state that they did score short passives (Huttenlocher et al. 2004, Savage et al. 2006, Shimpi et al. 2007, Bencini \& Valian 2008) and get-passives (Savage et al. 2003, Huttenlocher et al. 2004, Savage et al. 2006, Bencini \& Valian 2008) as passive targets suggesting that these different forms did occur. Other studies have shown an effect of the surface form of modelled sentences on children's language production: Turner and Rommetveit (1967b) found that children produced be-passives when be-passive questions were modelled to them but produced get-passives when an auxiliary-neutral question was modelled and Tomasello et al. (1998) found that children who heard full passives modelled were more likely to produce full passives whereas those who only heard fragments of passives, including short passives, were more likely to produce short passives. There is some evidence therefore that children may be sensitive to the surface form of modelled constructions. The possibility that previously observed priming effects are wholly or partially due to repeated function words needs to be ruled out before it can be confidently claimed that these priming studies show that children have acquired a completely abstract, syntactic representation of the passive. This chapter presents two experiments which investigate this: the first examined whether short passives prime full passives; the second investigated priming from get- and be-passives. 


\subsection{Experiment Five: Active Primes versus Short Passive Primes}

Transformational theories of syntax state that the short passive is a more derived structure, requiring more transformations than full passives: first the full passive structure is formed (6.1a), then the external noun phrase is removed (6.1b). Some accounts interpret this as meaning that short passives require more processing steps and should therefore be more difficult for young children (Maratsos 1978, de Villiers \& de Villiers 1978). A number of studies challenge this theory, however, showing that children find short passives easier to comprehend (Baldie 1976, Harris 1976, Fox \& Grodzinsky 1998) and produce (Slobin 1968, Hayhurst 1967, Harris \& Flora 1982, Marchman et al. 1991). It has been argued therefore that short passives are stored as a distinct form, separate from the representations of actives and full passives (e.g. Slobin 1968) or that short passives are acquired as adjectival phrases before the full passive is developed (Horgan 1978).
a. A doctor is being shaken by an elephant.
b. A doctor is being shaken $\varnothing$.

However, other studies have shown that when it is appropriate for a children to produce a full passive they are capable of doing so as young as 3;6 (Crain et al. 1987); this suggests that children do not necessarily acquire the full passive later than, or separately from, the short passive. Use of the passive is usually governed by discourse conditions: the speaker may wish to focus on the patient of the verb or maintain this entity as the topic, this would involve mentioning the patient first in the sentence and therefore entail a passive structure. The passive may also be used as a way of avoiding mention of the verb's agent, if only the patient is mentioned then a short passive is entailed. The reason that children may often produce short passives may be that they are using the passive to demote or delete the agent and topicalize the patient. There is evidence that short passives are the most frequent form of the passive amongst adults which suggests that the passive is frequently used in English to fullfil this function (Svartvik 1966, Brown 1973, Gordon \& Chafetz 1990) - therefore children's propensity to produce short passives may actually reflect adult-like use of this construction at a young age, that is, early knowledge of the discourse constraints of the structure. One obvious potential explanation for the results of previous experiments, therefore, is that they may simply be the result of the child trying to produce a felicitous description to describe the pictures in full; full passives were in these cases appropriate and modelled by the experimenter. 
On the other hand, Tomasello et al. (1998) taught three and a half year olds through discourse to produce full passives, comparing the type and amount of language required from the experimenter before the children produced their first full passives. They found that more children produced full passives in the condition where only full passives were modelled compared to those in the 'scaffolding condition' who heard the composite parts but never a full passive itself. Interestingly children in the full passive model condition tended not to produce short passives which were much more frequently used by all children in the scaffolding condition suggesting that children were strongly affected by the structures that they were immediately exposed to.

To rule out alternative possible explanations, for example that children acquire the full passive late and only produced full passives in the previous experiments because of a lexical priming effect based on the preposition by, Experiment 5 compared the effect of active primes and short passive primes on children's subsequent descriptions of the same target pictures as used in previous experiments. Hence it examined whether children would remain more likely to produce full passives following short passive primes or whether children would repeat the form of the prime and produced short passives following these short passive primes. Experiment 5 also tested how adults responded to these primes, to provide a control for developmental effects. It is assumed that by adulthood, English speakers have a passive representation that encompasses both forms: when a short passive is processed it is understood as entailing an agent of the event even if this is not overtly expressed: Example $6.1 \mathrm{~b}$ is understood as meaning a doctor is being shaken by something or someone - an external agent is shaking the doctor. If short passives share a syntactic representation with full passives this would allow them to be interpreted as short passives involving an implicit, agent-role. Hence the assumption that short passive primes would activate the syntactic representation underlying full passives; thus adults should be primed to produce full passives by short passive primes.

\subsubsection{Predictions for Experiment Five}

This experiment therefore aims to examine whether children process short passives as involving the same representations as full passives or as separate constructions and also whether priming is influenced by repeated function words. It compares the effect of short passive primes, used to describe pictures that do not depict an agent and for which therefore a short passive is felicitous, on targets that show both a patient and agent (the target items used in previous experiments) and for which therefore a full passive description is more felicitous. 
It was predicted that if participants' production of full passive targets following full passive primes is related to a lexical priming effect from the function word $b y$, then both groups should be less likely to produce full passive descriptions following short passive primes and instead should be more likely to reproduce the form of the prime - short passives. However, if adults' syntactic representation of the passive allows the subject by-phrase of passives to be omitted then it was predicted that adults would be primed to produce full passive descriptions following short passive primes.

Secondly it was predicted that if young children store the short passive structure separately to full passives or acquire a short passive structure before a full passive structure, then short passive primes would only elicit short passive descriptions. Note that, for the children, this prediction overlaps with the prediction that the priming effect is related to the repetition of function words; the adult group therefore provide crucial data to distinguish between these hypotheses.

Adopting Pickering and Branigan's (1998) model of grammatical processing, described in section 3.3, Figures 6.1 and 6.2 depict schemas for how this may occur if the children store a short passive structure separately to, or instead of, a full passive structure. The short passive primes would activate this and not the full passive syntactic representation and thus the children would be more likely to produce short passives following short passive primes.

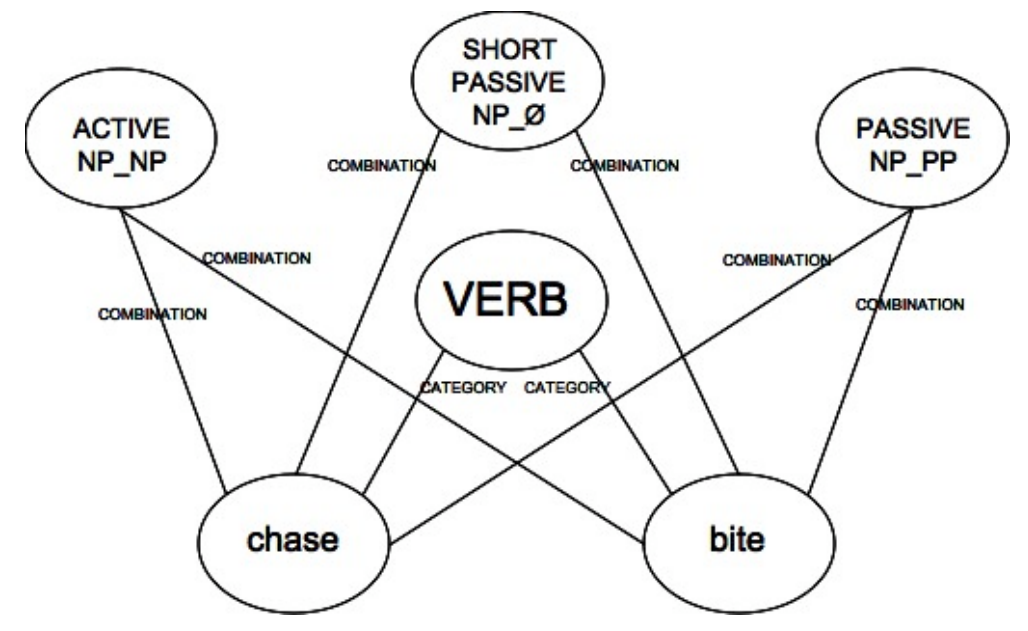

Figure 6.1: Model of syntactic representation: Short passives stored separately

For example, if children's early syntactic representations for the passive are related to the schema depicted in Figure 6.1 - they store short passives separately to full (e.g. Slobin 1968) - then hearing a prime such as "the mouse is being chased by the cat" would activate their full passive representation. If their target picture depicted a dog biting a cat this prime should (and did, in previous experiments) lead to full passive 


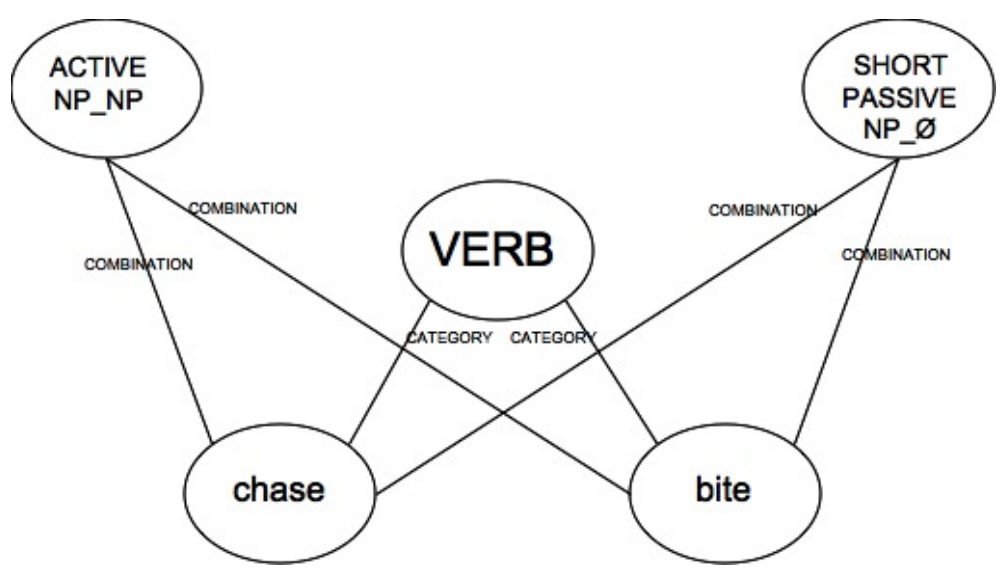

Figure 6.2: Model of syntactic representation: Short passives acquired earlier

responses like "the cat is being bitten by the dog". If they heard "the mouse is being chased", this would activate a different combinatorial node and lead to short passive responses: "the cat is being bitten".

If however a short passive form is acquired earlier than a full passive form (e.g. Horgan 1978), as depicted in Figure 6.2 then hearing short passives would also prime short passives but in this case it would entail that the priming of full passives observed in previous experiments was related to lexical priming of the preposition by (see Figure 6.3 for a proposal for how this might be represented).

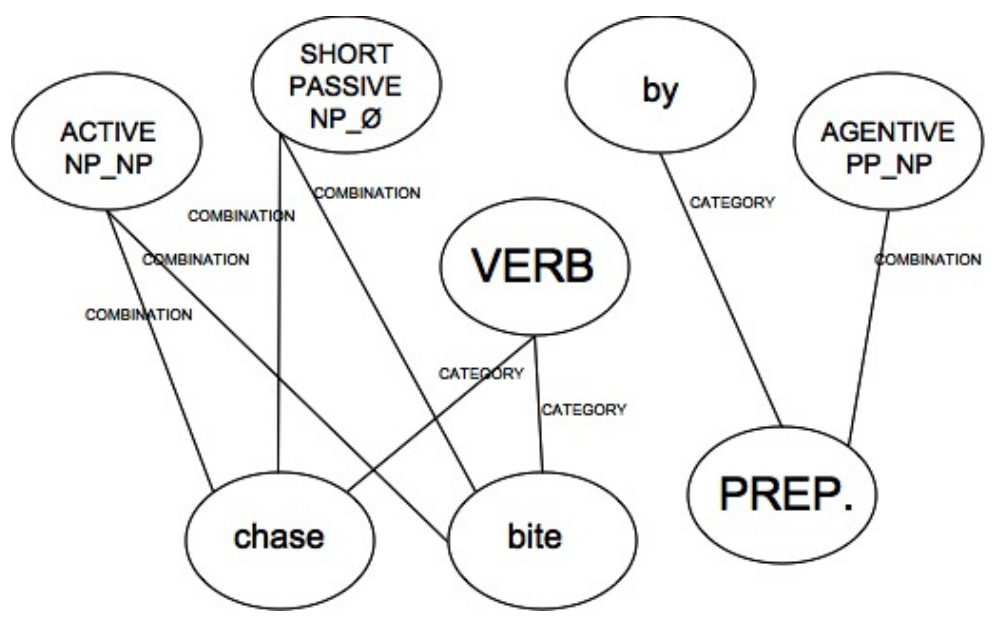

Figure 6.3: Model of syntactic representation: Priming from by

Recall that it was assumed that adults have a passive representation which underlies both forms (see above); this is represented in Figure 6.4. Therefore short passives 
should prime adults to produce a full passive to describe the target pictures. If children's syntactic representation of the passive is adult-like by four (Figure 6.4), and their use of full passives in previous experiments was simply because full passives provided felicitous descriptions of the pictures, then short passive primes should elicit full passive descriptions from adults and children in Experiment 5.

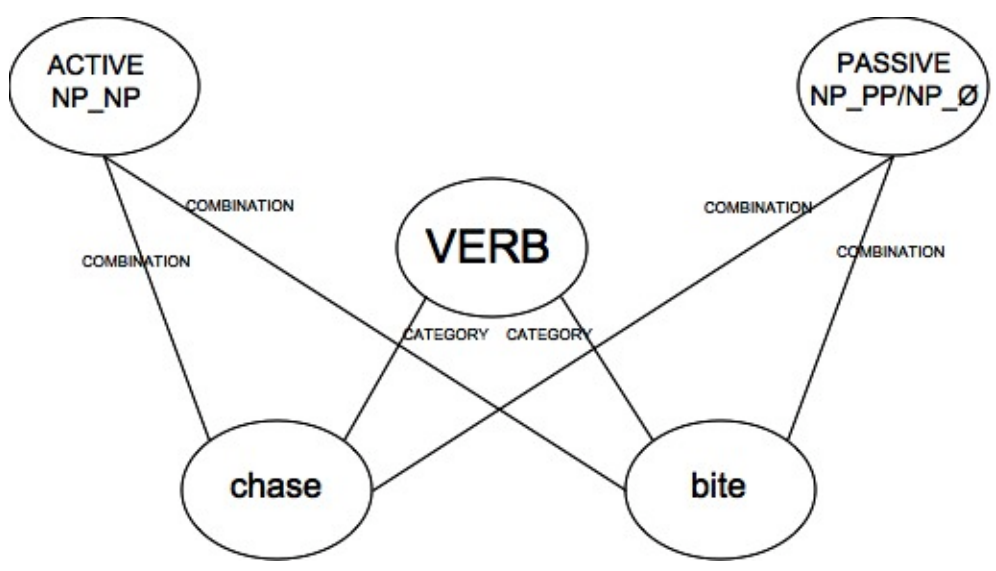

Figure 6.4: Model of syntactic representation: Adult passives

\subsubsection{Method}

\section{Design}

Experiment 5 used a repeated-measures design for this study: the within-participants factor was Prime, which had two levels: active and (short) passive. As in previous experiments, the active primes took the form: The AGENT is VERBing the PATIENT. In this experiment, the passive primes took the form: The PATIENTs are being VERBed: the use of a present progressive form of the auxiliary is in line with the previous experiments but also promotes a verbal interpretation of these short passives (Gordon \& Chafetz 1990). Compare (6.2a), which involves simple present morphology, and (6.2b), which is a present progressive form: (6.2a) has the same surface form as an adjective (6.2c) and therefore its status as a verbal or adjectival passive is ambiguous, it may be interpreted as a stative rather than as an eventive sentence; $(6.2 b)$, on the other hand, promotes the verbal, eventive, interpretation that another entity has caused the surprise, not that the doctor is in a state of surprise.
a. A doctor is surprised.
b. A doctor is being surprised.
c. A doctor is angry/hurt/upset. 
As the agents were not expressed in the passive primes, the agents were omitted from the pictures to avoid describing a picture showing a patient and an agent with a short passive which might lead the participant to assume that it is appropriate to use a short passive for their pictures, which did depict an agent as well as a patient. To control for other possible confounding effects, therefore the number of patients in the pictures for the passive primes were doubled, this meant that two characters remained in all prime pictures. Therefore, the passive primes were plural whilst the target items depict a singular event, however since Pickering and Branigan (1998) showed that verbal inflections for tense, aspect or number do not influence priming, I did not expect this to be problematic. The primes used the definite article, rather than the indefinite article, as the former is compatible with singular nouns (as in the active primes) and plural nouns (as in the passive primes). The targets depicted both a patient and an agent because the aim of this experiment was to see whether children repeated the prime form despite the presence of an agent or whether a short passive primed a full passive when a full passive was appropriate, i.e. when there was an agent to name.

\section{Participants}

A group of 16 nursery children (9 girls) took part. All children were aged between 3;4 and 4;10 (mean age 4;1). A control group of 16 adult participants ( 6 female, mean age 19) was also tested; they were recruited from the University of Edinburgh's student population.

\section{Materials}

For this experiment, the prime items involved the six object-experiencer verbs used in Experiments 2 and 3 (annoy, frighten, scare, shock, surprise, upset; see Appendix C.1 for a full list). These object-experiencer psychological verbs were used for the primes as it is not possible to depict actional verbs, such as those used in Experiment 1 (bite, carry, hit, pat, pull, squash), without depicting the agent, whereas it was possible to depict just the patient, the experiencer, of these psychological verbs (see Figure 6.5). These events were depicted with a patient and an agent for the active prime items and with two patients and no agent for the passive prime items (see Figure 6.5).

Experiment 5 used the twenty-four target items from Experiment 1 as the target items for this experiment (Appendix A.3) and the eight filler items from Experiment 1 as the 'Snap' cards again; half of these had active descriptions, half had full passive descriptions. Participants did therefore hear some full passives during the experiment; thus, in the analyses we also compare the number of passives that participants produced at the beginning and end of the experiment, this time to check that participants did not produce more passives at the end of the experiment after hearing more filler items than at the beginning when they have heard few filler items. Recall that previ- 

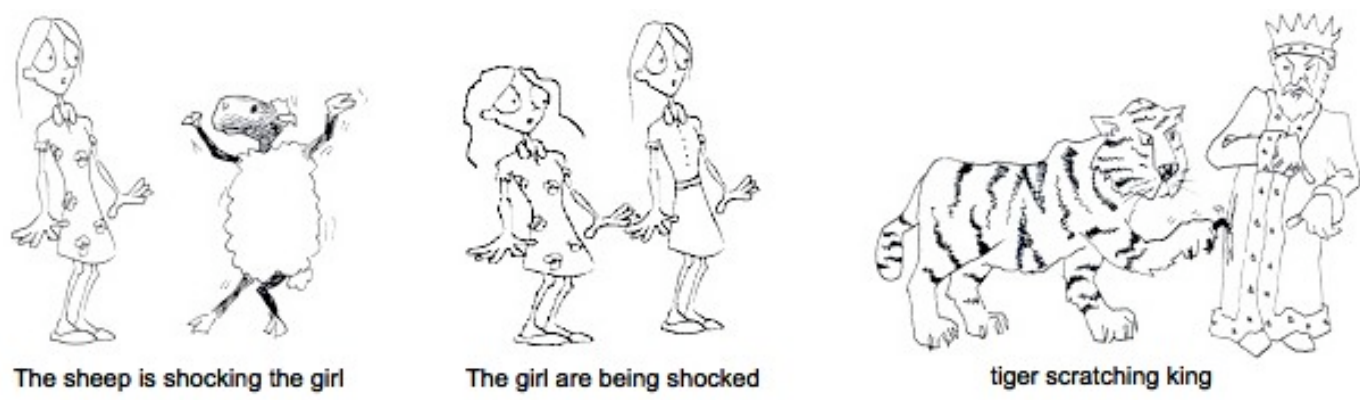

Figure 6.5: Experiment 5: Active and passive prime items and a target

ous experiments found that participants did not produce significantly more passives at the end of the experiment than at the beginning; however, if the short passives were not sufficient primes for full passive targets, participants might only produce full passive targets after hearing many full passive fillers. The additional analysis therefore checked for this possible confound.

Two lists were created of the experiment and filler items such that across the two lists each target occurred once in each of the two priming conditions and within a list an even number of the targets (twelve) were experienced in each of the two priming conditions. Sixteen randomized experiment lists were created from the two item lists (eight from each), these were used as scripts in the experiment.

\section{Procedure}

Experiment 5 used the same procedure as previous experiments. The participants' responses in the priming experiment were again scored and analysed according to the three sets of criteria laid out in Chapter 4: Strict (6.2.3), Lenient (6.2.4), Inclusive (6.2.5).

\subsubsection{Strict Scoring Results}

\section{Results}

First I scored the participants' responses according to the Strict criteria. Note that in this scoring, short passive responses were scored as Other. Out of each group's 384 target items, $22(6 \%)$ of the children's trials and $1(0.3 \%)$ of the adults' trials were eliminated when no response was given or it was lost due to recording problems or misplaced cards. The children produced 199 (52\%) Active, 27 (7\%) Passive and 136 (35\%) Other responses (see Table 6.1). Of their 136 Other responses, only 14 (10\%) were short passives (all produced by just four of the 16 children); the majority were 
non-transitive and incomplete utterances. The adults produced 319 (83\%) Active, 29 (7.6\%) Passive and 35 (9.1\%) Other responses, none of which were short passives.

Table 6.1: Experiment 5: Frequency of active, passive and other responses according to group and prime condition

\begin{tabular}{llrrrrrrr}
\hline & & \multicolumn{6}{c}{ Response } \\
\cline { 2 - 8 } Group & Prime & \multicolumn{2}{c}{ Active } & \multicolumn{2}{c}{ Passive } & \multicolumn{2}{c}{ Other } & Total \\
\hline \hline \multirow{2}{*}{ Children } & Active & 116 & $(64 \%)$ & 4 & $(2 \%)$ & 62 & $(34 \%)$ & 182 \\
& Short Passive & 83 & $(46 \%)$ & 23 & $(13 \%)$ & 74 & $(41 \%)$ & 180 \\
\hline \multirow{2}{*}{ Adults } & Active & 167 & $(87 \%)$ & 5 & $(3 \%)$ & 19 & $(10 \%)$ & 191 \\
& Short Passive & 152 & $(79 \%)$ & 24 & $(13 \%)$ & 16 & $(8 \%)$ & 192 \\
\hline
\end{tabular}

\section{Analysis}

As previously, I analysed the passive target descriptions in each condition as proportions of the total number of active and passive targets in that condition; the raw numbers of Other responses were analysed separately.

\section{Passive Responses}

Table 6.2 shows each group's mean proportion of passive responses in each condition. The results were analysed in two-way ANOVAs with the within-participants and within-items factor, Prime (active vs. passive) and the between-participants and within-items factor, Group (children vs. adults), treating participants $\left(F_{1}\right)$ and items $\left(F_{2}\right)$ as random effects. Table 6.3 shows the results of these ANOVAs: these yielded a significant main effect of Prime: participants produced significantly more passive descriptions following passive primes $(M=0.16)$ than following active primes $(M=$ 0.03). There was no effect of Group or interaction between Prime and Group; there was a simple main effect of Prime for both children and adults. Hence both groups were more likely to produce passives following passive primes than following active primes but neither group showed a stronger tendency to do this than the other.

Table 6.2: Experiment 5: Mean proportions of Passives in the Strict scoring

\begin{tabular}{lcccc}
\hline \multirow{2}{*}{ Prime } & \multicolumn{2}{c}{ Children } & \multicolumn{2}{c}{ Adults } \\
\cline { 2 - 5 } & $\mathbf{M}$ & (SD) & $\mathbf{M}$ & (SD) \\
\hline \hline Active & 0.03 & $(0.05)$ & 0.03 & $(0.05)$ \\
Short Passive & 0.19 & $(0.26)$ & 0.13 & $(0.15)$ \\
\hline
\end{tabular}


Table 6.3: Experiment 5: ANOVA of proportions of Passives in the Strict scoring

\begin{tabular}{lrrlcrrrc}
\hline & \multicolumn{4}{c}{$\boldsymbol{F 1}$ Results } & \multicolumn{4}{c}{$\boldsymbol{F 2}$ Results } \\
\cline { 2 - 9 } Effect & $\boldsymbol{d f}$ & $\boldsymbol{F 1}$ & $\boldsymbol{p}$ & partial $\eta^{2}$ & $\boldsymbol{d f}$ & $\boldsymbol{F 2}$ & $\boldsymbol{p}$ & partial $\eta^{2}$ \\
\hline \hline Prime & 1,30 & 15.69 & $<.001$ & 0.34 & 1,46 & 33.35 & $<.001$ & 0.42 \\
Group & 1,30 & 0.56 & n.s. & 0.02 & 1,46 & 2.08 & n.s. & 0.04 \\
Prime x Group & 1,30 & 0.75 & n.s. & 0.02 & 1,46 & 1.81 & n.s. & 0.04 \\
Prime (Children) & 1,30 & 11.65 & $<.01$ & 0.28 & 1,46 & 25.36 & $<.001$ & 0.35 \\
Prime (Adults) & 1,30 & 4.79 & $<.05$ & 0.14 & 1,46 & 9.80 & $<.01$ & 0.18 \\
\hline
\end{tabular}

\section{Other Responses}

The number of Other responses produced by the two groups are shown in Table 6.4. I examined these in the same two-way ANOVAs as above, the results of which are reported in Table 6.5. These showed a significant effect of Group: the nursery children produced more Other responses $(M=4.25)$ than the adults $(M=1.09)$. There was no effect of Prime or interaction between Group and Prime and neither group showed a simple main effect of Prime; neither group produced more Other responses following passive primes than active primes.

Table 6.4: Experiment 5: Mean numbers of Others in the Strict scoring

\begin{tabular}{lcccc}
\hline \multirow{2}{*}{ Prime } & \multicolumn{2}{c}{ Children } & \multicolumn{2}{c}{ Adults } \\
\cline { 2 - 5 } & $\mathbf{M}$ & (SD) & M & (SD) \\
\hline \hline Active & 3.88 & $(2.96)$ & 1.19 & $(0.98)$ \\
Short Passive & 4.63 & $(2.16)$ & 1.00 & $(0.82)$ \\
\hline
\end{tabular}

Table 6.5: Experiment 5: ANOVA of numbers of Others in the Strict scoring

\begin{tabular}{lrrlcrrrr}
\hline & \multicolumn{4}{c}{$\boldsymbol{F 1}$ Results } & \multicolumn{4}{c}{$\boldsymbol{F 2}$ Results } \\
\cline { 2 - 9 } Effect & $\boldsymbol{d} \boldsymbol{f}$ & $\boldsymbol{F 1}$ & $\boldsymbol{p}$ & partial $\eta^{2}$ & $\boldsymbol{d f}$ & $\boldsymbol{F 2}$ & $\boldsymbol{p}$ & partial $\eta^{2}$ \\
\hline \hline Prime & 1,30 & 0.68 & n.s. & 0.02 & 1,46 & 0.77 & n.s. & 0.02 \\
Group & 1,30 & 28.09 & $<.001$ & 0.48 & 1,46 & 22.15 & $<.001$ & 0.32 \\
Prime x Group & 1,30 & 1.89 & n.s. & 0.06 & 1,46 & 2.14 & n.s. & 0.04 \\
Prime (Children) & 1,30 & 2.42 & n.s. & 0.07 & 1,46 & 2.74 & n.s. & 0.06 \\
Prime (Adults) & 1,30 & 0.15 & n.s. & 0.01 & 1,46 & 1.71 & n.s. & 0.00 \\
\hline
\end{tabular}

Additional Analyses

I checked whether either group produced more passives at the end of the experiment, following the last eight primes, than at the beginning, following the first eight primes. This may be particularly pertinent in this experiment where the children mostly experience short passive primes but do hear some full passives for the filler (Snap) items: if hearing the full passive descriptions of the filler items, rather than the short passive primes, activated their syntactic representation for the passive, one might expect the 
number of full passive responses to increase towards the end of the experiment as they heard more of the filler items. Although there appear to be opposite numerical trends within the groups, with the children showing a larger mean number of passives at the end and adults showing a larger mean number at the beginning, paired-samples $t$-tests did not show significant differences: the children did not produce significantly more passives at the end of the experiment $(\mathrm{M}=.69, \mathrm{SD}=1.01)$ than the beginning $(\mathrm{M}=.38, \mathrm{SD}=.72 ; t(15)=-1.23, p=.12$, 1-tailed $)$. Likewise, the adults did not produce significantly more passives at the beginning of the experiment $(\mathrm{M}=.94, \mathrm{SD}=$ 1.06) than at the end $(\mathrm{M}=.63, \mathrm{SD}=1.20, t(15)=1.05, p=.16$, 1-tailed $)$.

Given the large age range in the nursery group $(3 ; 4-4 ; 10)$ I also carried out a bivariate correlation between age and the number of passives participants produced to check whether the number of passives participants produced increased with age. As in previous experiments there was no correlation for the Experiment 5 participants $(r=-.23$, $p=.20$, 1-tailed); see also Figure 6.6. There is no evidence here that the older children within the group were more likely to produce more passives than younger children. Indeed, as Figure 6.6 shows, the participants who produced the largest number of passives were the oldest and youngest participants. This suggests that the group's results were not confounded by the wide age range ${ }^{1}$.

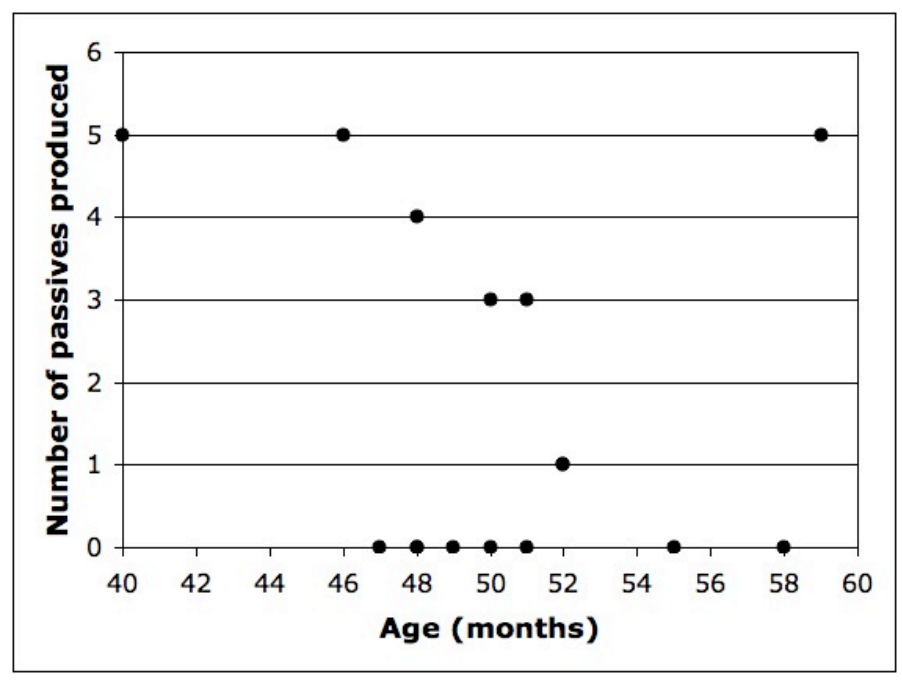

Figure 6.6: Experiment 5: Number of passives children produced by age

\section{Discussion}

The analyses show that the children (and adults) were more likely to produce passives following passive primes than following active primes. Even though the children did produce a number of short passive responses, these results were based on full pas-

\footnotetext{
${ }^{1}$ Though as previously, the group is small for correlation patterns.
} 
sive responses only. This experiment shows that children produced significantly more full passives following short passive primes, as did the adults. The results suggest therefore that short passive forms share the same underlying syntactic representation as full passives and are not interpreted by four-year-olds as adjectival descriptions. It also suggests that the priming effects observed in previous experiments were not wholly lexical, based in this case on the repetition of the preposition by of the external noun phrase. Furthermore, there was no evidence that the children or adults produced more passives at the end of the experiment, after hearing more full passive exemplars, nor was there evidence that the number of passives children produced increased with age. Separately, Experiment 5 found that unlike the previous experiments, though the children still produced more Other responses than the adults, they did not produce more Others following passive primes than following active primes. These findings are discussed in section 6.2 .6 below, following the results from the other scorings.

\subsubsection{Lenient Scoring Results}

\section{Results and Analysis}

Following the Lenient scoring, in which short passive responses were scored as Passive, the children's responses increased by +12 Active and +18 Passive (14 of which were short passives); the adults' results did not change in this scoring.

\section{Passive Responses}

Table 6.6 shows the mean proportion of passive responses in each condition following the Lenient scoring. The results of the statistical analyses are presented in Table 6.7 below. The analyses yielded a significant main effect of Prime: participants produced significantly more passive descriptions following passive primes $(M=0.20)$ than following active primes $(M=0.05)$. In contrast to the Strict scoring, the effect of Group was significant by items (marginal by participants) in this scoring: this reflects the increase in the children's, but not the adults', passive responses following the inclusion of short passive responses as Passive. The interaction between Prime and Group was not significant though it approached significance in the by-items analysis. There was still a simple main effect of Prime for both children and adults, hence both groups were more likely to produce passives following passive primes than following active primes.

Other Responses

Table 6.8 show the mean numbers of Other responses following the Lenient scoring. I repeated the analyses with the number of Other responses produced by the two groups, these results are reported in Table 6.9. These showed a significant effect of 
Table 6.6: Experiment 5: Mean proportions of Passives in the Lenient scoring

\begin{tabular}{lcccc}
\hline \multirow{2}{*}{ Prime } & \multicolumn{2}{c}{ Children } & \multicolumn{2}{c}{ Adults } \\
\cline { 2 - 5 } & $\mathbf{M}$ & (SD) & $\mathbf{M}$ & (SD) \\
\hline \hline Active & 0.07 & $(0.10)$ & 0.03 & $(0.05)$ \\
Short Passive & 0.27 & $(0.27)$ & 0.13 & $(0.15)$ \\
\hline
\end{tabular}

Table 6.7: Experiment 5: ANOVA of proportions of Passives in the Lenient scoring

\begin{tabular}{lrrlrrrrr}
\hline & \multicolumn{4}{c}{ F1 Results } & \multicolumn{4}{c}{ F2 Results } \\
\cline { 2 - 9 } Effect & $d f$ & $\boldsymbol{F 1}$ & $\boldsymbol{p}$ & partial $\eta^{2}$ & $d f$ & $\boldsymbol{F 2}$ & $\boldsymbol{p}$ & partial $\eta^{2}$ \\
\hline \hline Prime & 1,30 & 19.14 & $<.001$ & 0.39 & 1,46 & 33.48 & $<.001$ & 0.42 \\
Group & 1,30 & 3.61 & $=.07$ & 0.11 & 1,46 & 9.84 & $<.01$ & 0.18 \\
Prime x Group & 1,30 & 1.95 & $=.17$ & 0.06 & 1,46 & 3.68 & $=.06$ & 0.07 \\
Prime (Children) & 1,30 & 16.66 & $<.001$ & 0.36 & 1,46 & 29.67 & $<.001$ & 0.39 \\
Prime (Adults) & 1,30 & 4.44 & $<.05$ & 0.13 & 1,46 & 7.48 & $<.01$ & 0.14 \\
\hline
\end{tabular}

Group but no main effect of Prime, interaction between Group and Prime or simple main effect of Prime for either group; neither group produced more Other responses following passive primes than active primes but the nursery children still had more responses scored as Other than the adults.

Table 6.8: Experiment 5: Mean numbers of Others in the Lenient scoring

\begin{tabular}{lcccc}
\hline \multirow{2}{*}{ Prime } & \multicolumn{2}{c}{ Children } & \multicolumn{2}{c}{ Adults } \\
\cline { 2 - 5 } & $\mathbf{M}$ & (SD) & $\mathbf{M}$ & (SD) \\
\hline \hline Active & 3.13 & $(2.39)$ & 1.19 & $(0.98)$ \\
Short Passive & 3.50 & $(1.86)$ & 1.00 & $(0.82)$ \\
\hline
\end{tabular}

\section{Additional Analyses}

I repeated the additional analyses with the results once short passives were included in the calculation of passives. Since the children did produce a number of short passives, leading to an increase in their Passive score, the results under the Lenient scoring may show the effects predicted for these analyses in the Strict scoring. However, there was no difference between the mean number of passives the children produced at the beginning and at the end of the experiment $(\mathrm{M}=.94 \text { for each })^{2}$. I also examined whether there was a correlation between the number of passives in the Lenient scoring and the children's age but found no evidence that the number of passives they produced increased with age ( $r=.10, p=.36$, 1-tailed).

\footnotetext{
${ }^{2}$ Recall that the adults' results did not change following the Lenient scoring and showed no effect under the Strict scoring.
} 
Table 6.9: Experiment 5: ANOVA of numbers of Others in the Lenient scoring

\begin{tabular}{lrrlcrrrr}
\hline & \multicolumn{4}{c}{ F1 Results } & \multicolumn{4}{c}{$\boldsymbol{F 2}$ Results } \\
\cline { 2 - 9 } Effect & $\boldsymbol{d f}$ & $\boldsymbol{F 1}$ & $\boldsymbol{p}$ & partial $\eta^{2}$ & $\boldsymbol{d f}$ & $\boldsymbol{F 2}$ & $\boldsymbol{p}$ & partial $\eta^{2}$ \\
\hline \hline Prime & 1,30 & 0.08 & n.s. & 0.00 & 1,46 & 0.15 & n.s. & 0.00 \\
Group & 1,30 & 21.46 & $<.001$ & 0.42 & 1,46 & 11.08 & $<.01$ & 0.19 \\
Prime x Group & 1,30 & 0.73 & n.s. & 0.02 & 1,46 & 1.36 & n.s. & 0.03 \\
Prime (Children) & 1,30 & 0.65 & n.s. & 0.02 & 1,46 & 1.21 & n.s. & 0.03 \\
Prime (Adults) & 1,30 & 0.16 & n.s. & 0.00 & 1,46 & 0.30 & n.s. & 0.01 \\
\hline
\end{tabular}

\section{Discussion}

With short passives scored as Passive, the only variation in the pattern of results is that there is some suggestion that the children produced more passives than the adults; the effect of Group was significant by items only. This is not surprising given the adults did not produce any short passive responses. Despite the increase in the children's passives there was no evidence that passive responses increased with age or that participants produced more passives at the end of the experiment. This is discussed further below (section 6.2.6).

\subsubsection{Inclusive Scoring Results}

\section{Results and Discussion}

Following the Inclusive scoring the children's scores increased from the Lenient results by +28 Active and +8 Passive; the adults' increased by +21 Active. However, despite these increases, the pattern of results following the Inclusive scoring remains unchanged from the Lenient scoring: the inclusion of reversed passives and incomplete utterances did not change the findings, therefore for brevity, these analyses are reported in Appendix D.1. Though the children produced more of these types of utterances than the adults, leading to an effect of Group, they did not show a stronger priming effect than the adults; the interaction between Prime and Group was not significant. The results of the Other and Additional analyses did not change from the previous scorings. These findings are discussed in section 6.2 .6 below.

\subsubsection{General Discussion of Experiment Five}

Experiment 5 examined whether children and adults produced full passive target descriptions after hearing short passive primes. This experiment found that both children and adults produced significantly more full passive responses, including a by- 
phrase, after hearing short passive primes, without a by-phrase expressed, than after hearing active primes. This priming effect was the same for both children and adults. Experiment 5 showed no evidence that participants produced full passives only after hearing full passive fillers, i.e., towards the end of the experiment. These results suggest that participants' comprehension of the short passive prime must have accessed a representation for the passive that also enabled them to formulate a full passive sentence. Thus, these results suggest that the short passive shares the same underlying syntactic representation as the full passive (e.g. as suggested in Figure 6.4), in both young children's and adults' language representational system. These results also challenge the theory that children of this age store the short passive form separately to the full passive form - in this case it was predicted that short passives would prime short passive responses; instead, the children behaved like the adults: in the Strict scoring, in which only full passive responses were analysed, both groups showed reliable priming and this priming effect did not interact with age. These results challenge any possible explanation that the priming effect observed in previous experiments is reducible to lexical priming from repeating the preposition by: children and adults still produced full passives to describe pictures of transitive events after hearing short passive primes where no by-phrase was expressed. Adults always produced full passives and children produced nearly twice as many full passives (27) as short passives (14).

These results extend the previous priming literature: previous studies with adults and children have only shown priming from full passives to full passives; I show that short passive primes are sufficient to induce the production of full passives by adults and children. In addition this experiment adds evidence to the language acquisition literature challenging the suggestion that full passives and short passives are acquired separately or consecutively. Taken together, the priming experiments reported here show that three- and four-year-old children are able to use full passives to describe pictures depicting a patient and an agent after hearing both short and full passive primes, suggesting that by this age a single representation underlies the two forms. In sum, these results provide further evidence that by four years of age children have an adult-like, abstract syntactic representation for the passive.

Nonetheless, the children did produce some short passives: the only difference that occurred across the three scorings was that the effect of Group became significant across the more lenient scorings, once short passives and other non-standard passive (reversed passives, incomplete utterances) responses were scored as Passive. This is clearly related to the fact that the adults did not produce any short passives, (or other non-standard passives), which were included in the more lenient scorings of the data, 
thus increasing the difference between the children's and the adults' passive scores in the more lenient scorings. However, eight of the three- and four-year-old children participating in this experiment produced at least one full passive and only two of the four who produced short passives did not produce any full passives; at 4;1 and 4;2, these two were in the middle of the group age-wise, i.e. they were not the youngest children (see Figure 6.7). In addition, though they heard some full passives through the course of the experiment (as descriptions of the 'snap' filler items), it appears that the children did not produce full passive responses only after hearing these descriptions: the analyses showed that passives were not more likely at the beginning of the experiment (before many filler items were encountered) than at the end.

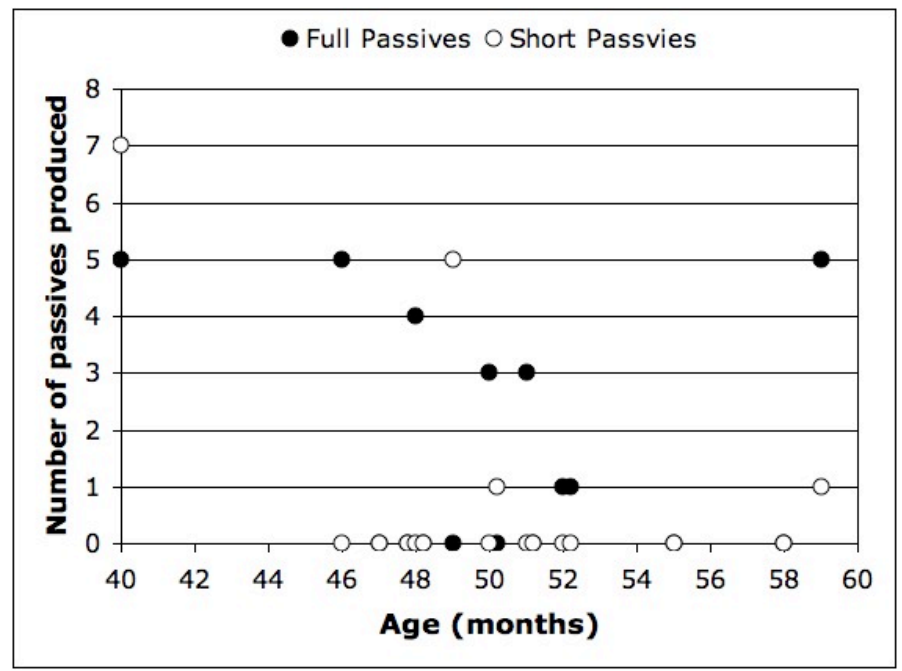

Figure 6.7: Experiment 5: Numbers of full and short passives children produced by age

It is also worth noting that the priming effect was smaller in this experiment than in Experiment 1. Though I do not directly compare the two experiments, because of the differences in group sizes, the priming effect for the children was numerically larger in Experiment 1 (21\%) than in Experiment 5 (16\%). In addition, in Experiment 1, the children described $21 \%$ of the target pictures with a full passive which contrasts with this experiment in which they described just $7 \%$ of the same pictures with full passives (though it is worth noting that by comparison, the adults showed a similar pattern suggesting that this is not necessarily a developmental issue: they described $24 \%$ of the Experiment 1 pictures and $8 \%$ of the Experiment 5 pictures with full passives). It may be that repeated closed-class lexical items can boost the priming effect. Another possible reason for the smaller priming effect is that, though related to full passives, the short passive primes did not contain the full syntactic form of the target response; it is possible that symmetry in the constituent structure and the number of arguments 
are both key for successful priming (Griffin \& Weinstein-Tull 2003). The constituent structure of the primes of Experiment 5 was NP VP and they contained only one overt argument whereas the target response required two overt arguments and a NP VP PP constituent structure. These differences may be responsible for the differences in the magnitude of the priming effect between the two experiments in both the child and adult groups. Nonetheless, though short passive primes produced a numerically smaller priming effect than full passive primes, there was no evidence that participants were primed by the surface form or basic constituent structure in Experiment 5: these primes did not elicit other structures with one argument and a verb phrase; for example, the participants did not produce more intransitive descriptions following short passive primes.

The following experiment, Experiment 6, examines whether the identity of the passive auxiliary influences the likelihood of children producing passives or the form of their passive responses. As in Experiments 1 to 3, in Experiment 5, the children tended to produce be-passives following be-passive primes: they produced 23 full and 10 short be-passives compared to 3 full and 4 short get-passives, or in other words, $83 \%$ of their full and short passives were be-passives. This tendency to use be rather than get as the passive auxiliary is examined in the following experiment.

\subsection{Experiment Six: Get-Passive Primes versus Be-Passive Primes}

Experiment 5 suggests that priming does not occur because of repeated function words but these may provide a lexical boost. The priming effects observed in Experiment 5 were smaller than in Experiment 1 when the prime included a by-phrase, although this may be related to differences in the number of arguments and constituent structure of the prime and target, as noted overleaf. Experiment 6 examines whether repeating the auxiliary has the same effect on the priming of passives from children and adults: it compares these groups' production of passives following be-passive primes (6.3a) and get-passive primes (6.3b). These have the same constituent structure and number of arguments but a different lexical item.
a. A doctor is being shaken by an elephant.
b. A doctor is getting shaken by an elephant.

There is reason to believe that the auxiliary might influence priming. In the previous experiments the participants nearly always produced be-passives after hearing only 
be-passive primes, however other studies suggest that children tend to use the passive with the get auxiliary earlier and more frequently than the be auxiliary (see for example Harris \& Flora 1982, Marchman et al. 1991). Marchman et al. (1991) elicited passive descriptions from adults and children ranging in age from three to eleven. Their results showed a tendency for the use of be-passives to increase with age and for get-passives to decrease with age. Harris and Flora (1982) showed that children aged 4;6 found get-passives easier to understand than be-passives and that they were more likely to produce get-passives than be-passives. They suggest that get marks the patient role of the subject more clearly than be, making the non-canonical word order of passive sentences easier to interpret, alternatively it may be that get provides a more salient clue to process the sentence as a passive since be is frequently used, as an auxiliary or copula, in other sentences but get is not so widely used. It may also be related to the high irregularity of be (is, was, were, being) being more difficulty to learn than get, which is more regular (get, got, getting). Whatever the reason, it is possible that children use get as a cue to recognising or understanding the passive early on, which would explain why they perform more reliably with get-passives before be-passives. The fact that they produce more be-passives in the priming experiments runs counter to this explanation and may be evidence of lexical priming from an auxiliary-based representation. Although it is possible that the use of be-passives in previous experiments is in fact related to the fact that these are more common than get-passives for children learning British English (Meints 2003).

Nonetheless, further evidence that the auxiliary might be repeated comes from Turner and Rommetveit (1967b), who used patient-focussing questions to elicit passive descriptions. They found that children would use be as the passive auxiliary when they heard be-passive models (i.e. "what is being done to the PATIENT?") but tended to switch to get-passives when they heard a neutral question (i.e. "what is happening to the PATIENT?"). This also suggests that children use get-passives as an earlier, default form: children produce these when no form of the passive is modelled, and only produce be-passives when they are modelled to them. Modelling may ease their production of the more irregular be forms, whereas children may not need to hear get models.

Taken together, these results suggest that despite this apparent early use of getpassives, the auxiliary of a prime or model sentence may influence the form of the elicited target sentence. Were it the case that the passive auxiliary of a prime does not exert any influence on the form of children's response, then, given this preference for get-passives, one would expect them to produce more get-passives than be-passives regardless of the form of the passive prime. Since this did not happen in the previous experiments - children mostly produced be-passives - then the exact nature of the 
observed priming effect in those experiments is called into question. There may have been some surface priming or lexical priming effect on the children's responses which overrode any overall preference for the get auxiliary. The pertinent question, therefore, is does the form of the passive itself influence whether children produce passives or does it only influence the form of the passive that they produce? Are they more likely to produce a passive because of repeated function words such as the auxiliary or do they only produce be-passives because this is the type of passive modelled? Experiment 6 therefore compared priming from both get- and be- passives to see whether, once exposed to both passive types, children only produced passives in the form that they had heard it in the prime.

\subsubsection{Predictions for Experiment Six}

It was predicted that if the priming effect previously observed is closely related to the repetition of items such as the auxiliary, the participants would be more likely to produce passive target responses that matched the prime in their lexical content with respect to the auxiliary. That is, get-passive responses would be more likely following get-passive primes than following be-passive or active primes; similarly, be-passive primes would be more likely following be-passive primes than following get-passive or active primes. If, however, the priming effect is related to an abstract syntactic representation that underlies both passive types, but children acquire the passive with get earlier than be, children should produce more get-passives than bepassives once exposed to passives with both auxiliaries, irrespective of the auxiliary of the prime. On the other hand, if it is the case that children speaking British English use be-passives rather than get-passives, then get-passives should not be as frequently used as be-passives even once children are exposed to passives with both auxiliaries.

\subsubsection{Method}

\section{Design}

As in previous experiments, Experiment 6 used a repeated-measures design: the three priming conditions that all participants experienced were active, get-passive and bepassive. The active primes took the form: An AGENT is VERB-ing a PATIENT, the getpassive primes took the form: A PATIENT is getting VERB-ed by an AGENT and the be-passive primes took the form: $A$ PATIENT is being VERB-ed by an AGENT.

\section{Participants}

A group of 18 children (11 girls) took part in this experiment. They were aged between 
3;4 and 4;10 (mean age 4;2). A control group of adult participants (12 female), recruited from the university population, also took part in this experiment (mean age 23.7, age range 18 to 42 years).

\section{Materials and Procedure}

Experiment 6 used a subset of the materials created for Experiment 1: 18 of the (agentpatient) prime and target picture cards (see Appendix C.2 for a full list of the primes; the first 18 targets from the list in Appendix A.3 were used). Six of the filler items from Experiment 1 were used as the Snap cards: two were active, two were get-passive and two were be-passive fillers (see Appendix C.3). Three lists of the experiment and filler items were created such that across the three lists each target occurred once in each of the three priming conditions and within a list an even number of the targets (six) were experienced in each of the three priming conditions; from these eighteen randomized experiment scripts were created from the three lists (six from each). Experiment 6 followed exactly the same procedure as described in Experiment 1.

\section{Scoring}

I scored responses as Active according to the criteria set out in Experiment 1. In addition to these criteria, in Experiment 6, I also scored passives according to the auxiliary used: get-passive responses were scored separately to be-passive responses. I scored responses that contained a be form of the passive auxiliary as Be-Passive (6.4a) assuming that they met the other criteria for passives set out previously (i.e. the utterance contained a patient in sentence-subject position, a passive auxiliary and an appropriate verb and an agent expressed in a by-phrase, and allowing for the participants morphological errors (6.4b) and omissions of the aspect auxiliary (6.4c)).
a. "A witch is being pushed by a pig"
"A burglar's been sprayed by a elephant"
b. "A doctor being lift by a tiger"
c. "A queen ø being kissed by a sheep"

Likewise, I scored passive responses that contained a get form of the passive auxiliary as Get-Passive (6.5a-c). I scored responses not containing an auxiliary (6.6a) as Other as they could not be scored as either Get- or Be-passive. The same criteria for scoring a response as Other in the previous experiments were used here also.

$$
\begin{aligned}
& \text { a. "A nurse is getting scratched by a cat" } \\
& \text { "A king got licked by a cow" }
\end{aligned}
$$


b. "A girl's getting hitted by a dog"

c. "A girl ø getting hugged by a rabbit"

\section{a. "A witch Ø picked up by a elephant" \\ "A baddie Ø watered by a elephant"}

\subsubsection{Strict Scoring Results}

\section{Results}

Out of each of the group's 324 target items, 23 (7\%) of the children's trials and $12(4 \%)$ of the adults' trials were excluded from the data because no response was given or it was lost due to recording problems or misplaced cards. The children produced 205 (63\%) transitive responses: 140 (43\%) Active, 40 (12\%) Get- and 25 (8\%) Be-Passive; and $96(30 \%)$ Other responses (see Table 6.10). The adults produced $303(93 \%)$ transitive responses: 217 (67\%) Active, 22 (7\%) Get- and 64 (20\%) Be-Passive; and 9 (3\%) Other responses.

Table 6.10: Experiment 6: Frequency of active, passive and other responses according to group and prime condition

\begin{tabular}{|c|c|c|c|c|c|c|c|c|c|c|}
\hline \multirow[b]{2}{*}{ Group } & \multirow{3}{*}{$\begin{array}{l}\text { Prime } \\
\text { Active }\end{array}$} & \multicolumn{9}{|c|}{ Response } \\
\hline & & \multicolumn{2}{|c|}{ Active } & \multicolumn{2}{|c|}{ Get-Passive } & \multicolumn{2}{|c|}{ Be-Passive } & \multicolumn{2}{|c|}{ Other } & \multirow{2}{*}{$\begin{array}{r}\text { Total } \\
105\end{array}$} \\
\hline \multirow{3}{*}{ Children } & & 67 & $(64 \%)$ & 3 & $(3 \%)$ & 4 & $(4 \%)$ & 31 & $(29 \%)$ & \\
\hline & Get-Passive & 37 & $(37 \%)$ & 26 & $(26 \%)$ & 4 & $(4 \%)$ & 32 & $(32 \%)$ & 99 \\
\hline & Be-Passive & 36 & $(37 \%)$ & 11 & $(11 \%)$ & 17 & $(18 \%)$ & 33 & $(34 \%)$ & 97 \\
\hline \multirow{3}{*}{ Adults } & Active & 91 & $(86 \%)$ & 2 & $(2 \%)$ & 11 & $(10 \%)$ & 2 & $(2 \%)$ & 106 \\
\hline & Get-Passive & 58 & $(56 \%)$ & 19 & $(18 \%)$ & 22 & $(21 \%)$ & 5 & $(5 \%)$ & 104 \\
\hline & Be-Passive & 68 & $(67 \%)$ & 1 & $(1 \%)$ & 31 & $(30 \%)$ & 2 & $(2 \%)$ & 102 \\
\hline
\end{tabular}

Only two children did not produce any passive responses at all; including the children's short passives ( 2 instances) and full passives with prepositions other than $b y^{3}$, four children produced just be-passives, seven produced only get-passives and five produced both. Overall, therefore, twelve out of the eighteen children produced at least one get-passive response whereas just nine of the eighteen children produced at least one be-passive. Of these 71 passive responses, $59 \%$ were get-passives compared to $41 \%$ be-passives. This is in stark contrast to the four previous experiments in which between $82 \%$ and $100 \%$ of the passive responses were be-passives; numerically, the children showed a tendency to produce more get- than be-passives once exposed to both passive auxiliaries. Unlike the children, despite exposure to both passive auxiliaries, the adults tended (as in the previous experiments, in which be-passives accounted

\footnotetext{
${ }^{3}$ There were four instances of these: 2 with from, 2 with with.
} 
for between $98 \%$ and $100 \%$ of the adults' passives) to produce more be-passives than get-, although compared to previous experiments, they did produce more get-passives once they heard get-passives primes: they produced 86 passive responses, of which $74 \%$ were be-passives compared to $26 \%$ get-passives.

The analyses were carried out on the get-passive responses and the be-passive responses separately. There was no way to control the form of the passive the participants produced, that is, the verbs used could take both get and be as the passive auxiliary and all participants heard passives with both auxiliaries. Therefore the data do not allow us to examine whether one particular form only was used in certain conditions since both forms were always available for use and were used by participants. As such both response types were analysed to determine in which conditions each occurred. For each type of passive I first compared the children and adults' performance in a mixed ANOVA and I then examined the effects within each group. The children produced more Other responses than the adults but they are evenly distributed across the three priming conditions (see Table 6.10 - approximately a third of the Other responses occur in each condition); this suggests that neither group produced more non-standard responses following a particular prime. First though I check that there was no effect of Prime on the Other responses, which might indicate a difficulty or miscomprehension of that structure.

\section{Analysis}

Other Responses

The raw numbers of the children and adults' Other results are presented in Table 6.11, the means suggest that the Other results were evenly distributed across the priming conditions. These means were analysed with a mixed, $3 \times 2$ ANOVA treating participants $\left(F_{1}\right)$ and items $\left(F_{2}\right)$ as random effects, with Prime (active vs. get-passive vs. be-passive) as a within-participants and within-items factor and Group (children vs. adults) as a between-participants and within-items factor. Table 6.12 reports the results of these analyses; where Mauchly's Test of Sphericity is significant (indicated by *), the results are reported with Greenhouse-Geisser correction. These showed a significant effect of Group, confirming that the children produced more Other responses $(\mathrm{M}=$ 1.78) than the adults $(\mathrm{M}=0.17)$. No other effects were significant; as in Experiment 5, but unlike the other experiments, there is no effect of Prime on the children's Other responses. These results confirm that though the children produced more Other responses than the adults, as in previous experiments, they did not produce more Other responses following either type of passive prime or following the active primes.

\section{Be-Passives}

For the statistical analyses I converted the participants' be-passive scores in each con- 
Table 6.11: Experiment 6: Mean numbers of Others in the Strict scoring

\begin{tabular}{lcccc}
\hline \multirow{2}{*}{ Prime } & \multicolumn{2}{c}{ Children } & \multicolumn{2}{c}{ Adults } \\
\cline { 2 - 5 } & $\mathbf{M}$ & (SD) & $\mathbf{M}$ & (SD) \\
\hline \hline Active & 1.72 & $(1.07)$ & 0.11 & $(0.32)$ \\
Get-Passive & 1.78 & $(1.52)$ & 0.28 & $(0.57)$ \\
Be-Passive & 1.83 & $(1.10)$ & 0.11 & $(0.32)$ \\
\hline
\end{tabular}

Table 6.12: Experiment 6: ANOVA of numbers of Others in the Strict scoring

\begin{tabular}{lrrlccccc}
\hline & \multicolumn{4}{c}{ F1 Results } & \multicolumn{4}{c}{ F2 Results } \\
\cline { 2 - 9 } Effect & $\boldsymbol{d} f$ & $\boldsymbol{F 1}$ & $\boldsymbol{p}$ & partial $\eta^{2}$ & $\boldsymbol{d f}$ & $\boldsymbol{F 2}$ & $\boldsymbol{p}$ & partial $\eta^{2}$ \\
\hline \hline Prime & 2,68 & 0.15 & n.s. & 0.00 & $* 1.7,57.4$ & 0.17 & n.s. & 0.01 \\
Group & 1,34 & 61.36 & $<.001$ & 0.64 & 1,34 & 68.41 & $<.001$ & 0.67 \\
Prime x Group & 2,68 & 0.15 & n.s. & 0.00 & $* 1.7,57.4$ & 0.17 & n.s. & 0.01 \\
Prime (Children) & 2,33 & 0.09 & n.s. & 0.01 & 2,33 & 0.06 & n.s. & 0.00 \\
Prime (Adults) & 2,33 & 0.18 & n.s. & 0.01 & 2,33 & 0.42 & n.s. & 0.02 \\
\hline
\end{tabular}

dition into proportions of the sum of active, get-passive and be-passive responses in that condition; the mean proportions are presented in Table 6.13. First a mixed, $3 \mathrm{x}$ 2 ANOVA treating participants $\left(F_{1}\right)$ and items $\left(F_{2}\right)$ as random effects, analysed the children and adults' be-passive results. Prime (active vs. get-passive vs. be-passive) was a within-participants and within-items factor and Group (children vs. adults) was a between-participants and within-items factor. Table 6.14 presents the results of these ANOVAs. These showed a significant effect of Prime, confirming that there was a priming effect on the proportion of be-passive responses. There was also a significant effect of Group (by items only) on the proportion of passives, suggesting that the adults produced more be-passive responses than the children (see Table 6.13) ${ }^{4}$. There was no interaction between Prime and Group. The analysis showed a simple effect of Prime for each level of Group: the priming conditions affected both the children's and adults' production of be-passives. I explored this effect of Prime within each group further by carrying out within-participants analyses with planned contrasts on the children's and adults' data separately.

Table 6.13: Experiment 6: Mean proportions of Be-Passives in the Strict scoring

\begin{tabular}{lcccc}
\hline & \multicolumn{2}{c}{ Children } & \multicolumn{2}{c}{ Adults } \\
\cline { 2 - 5 } Prime & $\mathbf{M}$ & (SD) & $\mathbf{M}$ & (SD) \\
\hline \hline Active & 0.05 & $(0.13)$ & 0.11 & $(0.19)$ \\
Get-Passive & 0.07 & $(0.15)$ & 0.22 & $(0.35)$ \\
Be-Passive & 0.26 & $(0.39)$ & 0.33 & $(0.34)$ \\
\hline
\end{tabular}

\footnotetext{
${ }^{4}$ The lack of effect by participants is likely to be due to power.
} 
Table 6.14: Experiment 6: ANOVA of proportions of Be-Passives in the Strict scoring

\begin{tabular}{lrrlrrrrr}
\hline & \multicolumn{4}{c}{ F1 Results } & \multicolumn{4}{c}{ F2 Results } \\
\cline { 2 - 9 } Effect & $d f$ & $\boldsymbol{F 1}$ & $\boldsymbol{p}$ & partial $\eta^{2}$ & $d f$ & $\boldsymbol{F 2}$ & $\boldsymbol{p}$ & partial $\eta^{2}$ \\
\hline \hline Prime & 2,68 & 9.93 & $<.001$ & 0.23 & $* 1.6,53.4$ & 16.15 & $<.001$ & 0.32 \\
Group & 1,34 & 1.56 & $=.22$ & 0.04 & 1,34 & 13.07 & $<.01$ & 0.28 \\
Prime x Group & 2,68 & 0.49 & n.s. & 0.01 & $* 1.6,53.4$ & 2.29 & n.s. & 0.06 \\
Prime (Children) & 2,33 & 3.93 & $<.05$ & 0.19 & 2,33 & 7.72 & $<.01$ & 0.32 \\
Prime (Adults) & 2,33 & 4.17 & $<.05$ & 0.20 & 2,33 & 6.95 & $<.01$ & 0.30 \\
\hline
\end{tabular}

\section{CHILDREN'S BE-PASSIVES}

Table 6.15 shows the results of one-way within-participants $\left(F_{1}\right)$ and within-items $\left(F_{2}\right)$ ANOVAs on the children's be-passive responses, (the means of which are shown in Table 6.13). These yielded a significant effect of Prime; planned contrasts explored this effect. First the effect of active primes on the be-passive responses was compared to the effect of the passive primes (get- and be-passive combined), active primes had a significantly different effect on the be-passive responses compared to passive primes. Secondly the effect of get-passive and be-passive primes was compared: these also had a significantly different effect (see the lower two lines of Table 6.15). Finally pairwise comparisons showed that the effect of get-passive primes on the proportion of bepassive targets was not significantly different to that of active primes ( $p s>.4)$. These results suggest that the children were only primed to produce a be-passive in the bepassive prime condition (21\% priming); get-passive primes did not differ in effect to active primes.

Table 6.15: Experiment 6: ANOVA and planned contrasts on children's Be-Passives

\begin{tabular}{lcccccccc}
\hline & \multicolumn{4}{c}{ F1 Results } & \multicolumn{5}{c}{ F2 Results } \\
\cline { 2 - 10 } Effect & $\boldsymbol{d} \boldsymbol{f}$ & $\boldsymbol{F 1}$ & $\boldsymbol{p}$ & $\boldsymbol{p} . \eta^{2}$ & $\boldsymbol{d f}$ & $\boldsymbol{F 2}$ & $\boldsymbol{p}$ & $\boldsymbol{p} \cdot \eta^{2}$ \\
\hline \hline Prime & $* 1.1,19.3$ & 6.12 & $<.01$ & 0.26 & $* 1.4,23.7$ & 13.44 & $<.001$ & 0.44 \\
Actives vs Passives & 1,17 & 5.99 & $<.05$ & 0.26 & 1,17 & 10.18 & $<.01$ & 0.37 \\
Get vs Be Passives & 1,17 & 6.18 & $<.05$ & 0.27 & 1,17 & 15.02 & $<.01$ & 0.47 \\
\hline
\end{tabular}

\section{Adults' Be-PAssives}

I repeated the same analyses with the adults be-passive responses, these results are presented in Table 6.16. Again these confirmed a significant effect of Prime. Planned contrasts showed a significant difference between passive primes and active primes but not between get-passive and be-passive primes (as shown by the lower two lines of Table 6.16). These results suggest that the adults were primed to produce more bepassives following a passive prime than following an active prime, irrespective of the form of the passive auxiliary.

The children and adults be-passive results differed: whilst the overall magnitude of 
Table 6.16: Experiment 6: ANOVA and planned contrasts on adults' Be-Passives

\begin{tabular}{lcccccrcc}
\hline & \multicolumn{4}{c}{ F1 Results } & \multicolumn{4}{c}{ F2 Results } \\
\cline { 2 - 9 } Effect & $\boldsymbol{d f}$ & $\boldsymbol{F 1}$ & $\boldsymbol{p}$ & $\boldsymbol{p} \cdot \eta^{2}$ & $\boldsymbol{d f}$ & $\boldsymbol{F 2}$ & $\boldsymbol{p}$ & $\boldsymbol{p} \cdot \eta^{2}$ \\
\hline \hline Prime & 2,34 & 4.47 & $<.05$ & 0.21 & 2,34 & 5.83 & $<.01$ & 0.25 \\
Actives vs Passives & 1,17 & 6.28 & $<.05$ & 0.27 & 1,17 & 10.86 & $<.01$ & 0.39 \\
Get vs Be Passives & 1,17 & 2.42 & n.s. & 0.12 & 1,17 & 1.53 & n.s. & 0.08 \\
\hline
\end{tabular}

the priming effect from be-passive primes was similar for the two groups ( $21 \%$ for the children, $22 \%$ for the adults), only the adults were primed to produce be-passive responses by the get-passive primes. That is, the children were only primed to produce be-passives following primes involving the same auxiliary (be-passive primes), whereas the adults were primed to produce be-passives following passive primes involving either auxiliary. This may reflect a lexical priming effect on the children's passive responses. These results are discussed further below, following the analysis of the get-passive responses.

\section{Get-Passives}

I calculated the proportions of get-passive responses in the same manner as the bepassive responses, the means of these proportions are presented in Table 6.17. I repeated the statistical tests used to analyse the be-passive data to test the get-passive responses; Table 6.18 shows the results of these ANOVAs. These showed an effect of Prime on the proportion of get-passives produced. The proportion of get-passive targets was also affected by the age of the participant: there was a significant effect of Group confirming that children produced significantly more get-passives than adults (see Table 6.17). The interaction between Prime and Group approached significance suggesting that the effect of Prime may have differed for the children and the adults (see Table 6.17: while both groups produced more get-passives following get-passive primes, the children but not the adults also produced more get-passives following bepassive primes than following the active primes). The analysis also showed a simple effect of Prime on the proportion of get-passives within each level of Group. In order to further explore this effect of Prime within each group, I carried out within-participants analyses with planned contrasts on the children and adults' data separately.

\section{CHILDREN'S GET-PASSIVES}

One-way within-participants $\left(F_{1}\right)$ and within-items $\left(F_{2}\right)$ ANOVAs on the children's get-passive responses confirmed the significant effect of Prime, see Table 6.19 for the results of these ANOVAs. Planned contrasts exploring the source of this priming effect showed that passive primes (get- and be-passive combined) had a significantly 
Table 6.17: Experiment 6: Mean proportions of Get-Passives in the Strict scoring

\begin{tabular}{lcccc}
\hline & \multicolumn{2}{c}{ Children } & \multicolumn{2}{c}{ Adults } \\
\cline { 2 - 5 } Prime & $\mathbf{M}$ & (SD) & M & (SD) \\
\hline \hline Active & 0.04 & $(0.08)$ & 0.02 & $(0.09)$ \\
Get-Passive & 0.35 & $(0.39)$ & 0.19 & $(0.21)$ \\
Be-Passive & 0.20 & $(0.28)$ & 0.01 & $(0.04)$ \\
\hline
\end{tabular}

Table 6.18: Experiment 6: ANOVA of proportions of Get-Passives in the Strict scoring

\begin{tabular}{lrrlcrrlcc}
\hline & \multicolumn{4}{c}{ F1 Results } & \multicolumn{4}{c}{ F2 Results } \\
\cline { 2 - 9 } Effect & $d f$ & $\boldsymbol{F 1}$ & $\boldsymbol{p}$ & partial $^{2}$ & $\boldsymbol{d f}$ & $\boldsymbol{F 2}$ & $\boldsymbol{p}$ & partial $^{2}$ \\
\hline \hline Prime & 2,68 & 14.00 & $<.001$ & 0.29 & 2,68 & 30.31 & $<.001$ & 0.47 \\
Group & 1,34 & 5.89 & $<.05$ & 0.15 & 1,34 & 10.49 & $<.01$ & 0.24 \\
Prime x Group & 2,68 & 2.00 & $=.14$ & 0.05 & 2,68 & 3.28 & $<.05$ & 0.09 \\
Prime (Children) & 2,33 & 9.44 & $<.01$ & 0.36 & 2,33 & 26.30 & $<.001$ & 0.61 \\
Prime (Adults) & 2,33 & 3.44 & $<.05$ & 0.17 & 2,33 & 7.67 & $<.01$ & 0.32 \\
\hline
\end{tabular}

different priming effect compared to active primes and that get-passive primes had a different priming effect (marginal by participants) to be-passive primes (see Table 6.19). Finally pairwise comparisons showed that the effect of active primes and bepassive primes on the proportion of get-passive targets was also significantly different ( $p s \leq .05)$. These results suggest the children were more likely to produce a get-passive in either passive prime condition compared to the active priming condition (see Table 6.17), that is, the children were primed to produce get-passives irrespective of the auxiliary of the prime passive. However there was stronger priming from the get-passive primes (31\% priming) than from the be-passive primes (16\% priming).

Table 6.19: Experiment 6: ANOVA and planned contrasts on children's Get-Passives

\begin{tabular}{lrrrrrrrr}
\hline & \multicolumn{4}{c}{ F1 Results } & \multicolumn{4}{c}{ F2 Results } \\
\cline { 2 - 9 } Effect & $\boldsymbol{d} \boldsymbol{f}$ & $\boldsymbol{F 1}$ & $\boldsymbol{p}$ & $\boldsymbol{p} \cdot \eta^{2}$ & $\boldsymbol{d f}$ & $\boldsymbol{F 2}$ & $\boldsymbol{p}$ & $\boldsymbol{p} \cdot \boldsymbol{\eta}^{2}$ \\
\hline \hline Prime & 2,34 & 7.10 & $<.01$ & 0.29 & 2,34 & 17.98 & $<.001$ & 0.51 \\
Actives vs Passives & 1,17 & 10.98 & $<.01$ & 0.39 & 1,17 & 28.45 & $<.001$ & 0.63 \\
Get vs Be Passives & 1,17 & 3.35 & $=.08$ & 0.16 & 1,17 & 11.31 & $<.01$ & 0.40 \\
\hline
\end{tabular}

\section{Adults' Get-Passives}

I conducted the same analyses with the adults' get-passive responses, see Table 6.20 for the results. Again these confirmed the significant effect of Prime on the adults' getpassive responses. Planned contrasts showed that there was also a significant difference between passive primes and active primes and a significant difference between get-passive and be-passive primes. Finally pairwise comparisons showed that there was no significant difference between the effect of active primes and be-passive primes on the proportion of get-passive targets ( $p s>.5$ ). These results suggest that there was 
a priming effect only in the get-passive condition (17\% priming): unlike the children, the adults were only primed to produce a get-passive following a get-passive prime; be-passive primes did not differ in effect to active primes (see also Table 6.17).

Table 6.20: Experiment 6: ANOVA and planned contrasts on adults' Get-Passives

\begin{tabular}{lcrcccrcc}
\hline & \multicolumn{4}{c}{ F1 Results } & \multicolumn{5}{c}{ F2 Results } \\
\cline { 2 - 9 } Effect & $\boldsymbol{d f}$ & $\boldsymbol{F 1}$ & $\boldsymbol{p}$ & $\boldsymbol{p .} \eta^{2}$ & $\boldsymbol{d f}$ & $\boldsymbol{F 2}$ & $\boldsymbol{p}$ & $\boldsymbol{p} \cdot \eta^{2}$ \\
\hline \hline Prime & $* 1.4,23.6$ & 11.51 & $<.01$ & 0.40 & $* 1.2,21.1$ & 14.25 & $<.01$ & 0.46 \\
Actives vs Passives & 1,17 & 7.54 & $<.05$ & 0.31 & 1,17 & 9.01 & $<.01$ & 0.35 \\
Get vs Be Passives & 1,17 & 13.21 & $<.01$ & 0.44 & 1,17 & 16.74 & $<.01$ & 0.50 \\
\hline
\end{tabular}

Again, the children and adults' results differed. Firstly, get-passive primes had a stronger priming effect amongst children (29\%) than adults (18\%). Secondly, and more surprisingly, only children were primed to produce get-passive responses by the bepassive primes. In contrast to the be-passive results, it was the children who were primed to produce get-passive responses by the passive primes with a different auxiliary, whereas the adults were only primed to produce get-passives when the prime contained the same auxiliary. These results are discussed further below.

\section{Discussion}

The pattern of results for the get-passive responses is clearly different to that of the be-passive responses, suggesting that the primes did not elicit passives in the same way. Examination of the percentage priming effects in Table 6.21 shows two different patterns of behaviour: the children's get-passives were primed more generally than $b e-$, in other words, they were primed to produce get-passives following both get- and $b e$-passive primes; however, they were only primed to produce be-passive responses in the be-passive priming condition. In contrast the adults' $b e$-passives were primed more generally than get- (both get- and be-passives primed be-passives), but they were only primed to produce get-passives in the get-passive priming condition. Furthermore, priming of the children's get-passive responses was boosted (significantly) by the same auxiliary prime. On a separate note in Experiment 6, like Experiment 5 but unlike previous experiments, there was no effect of prime on the children's Other responses. These findings are discussed further below in section 6.3.6.

Table 6.21: Experiment 6: Percentage priming effects

\begin{tabular}{llcc}
\hline \multirow{2}{*}{ Group } & \multirow{2}{*}{ Prime } & \multicolumn{2}{c}{ Response } \\
\cline { 3 - 4 } Children & Get-Passive & $31 \%$ & Be-Passive \\
\cline { 3 - 4 } & Be-Passive & $16 \%$ & 0 \\
\multirow{2}{*}{ Adults } & Get-Passive & $17 \%$ & $11 \%$ \\
& Be-Passive & 0 & $22 \%$ \\
\hline
\end{tabular}




\subsubsection{Lenient Scoring Results}

\section{Results and Analysis}

Following the Lenient scoring, which scored short passives, passives with a preposition other than by and incomplete but thematically correct actives or passives, there was little difference from the Strict scoring. There was a small increase in the children's results: +5 Active, +3 Get-Passive, +6 Be-Passive responses, the adults' results did not change. These changes did not lead to any change in the pattern of results from the analyses which, for this reason and in the interests of brevity, are reported in Appendix D.2.

\section{Discussion}

The statistical analyses confirm that the pattern of results from the Lenient scoring was the same as in the Strict scoring: for the children there was a stronger priming effect from get-passive primes (30\%) on get-passive responses and a marginal priming effect of be-passive primes (14\%). However, children were only primed to produce a be-passive in the be-passive prime condition (18\% priming); get-passive primes did not differ in effect to active primes. The adults' results did not change following the Lenient scoring.

\subsubsection{Inclusive Scoring Results}

\section{Results and Analysis}

The Inclusive scoring criteria scored responses that were complete and incomplete reversed actives or passives and responses without a possible alternative. Following this scoring the childrens results increased by +11 Active, +10 Get-Passive and +11 Be-Passive); there was also a slight change in the adults results: +3 Be-Passive. These changes did not however lead to differences in the overall pattern of results, reported in Appendix D.3.

\section{Discussion}

As in the previous scorings, the pattern of results was that the children were more likely to produce get-passives following a passive prime compared to an active prime, and more likely to produce get-passives following a passive prime with the same auxiliary than different but they were only primed to produce a be-passive in the be-passive prime condition; get-passive primes did not differ in effect to active primes. Adults were primed to produce be-passives following a passive prime compared to an active prime, irrespective of the form of the passive auxiliary but for get-passive responses there was only priming in the get-passive prime condition. 


\subsubsection{General Discussion of Experiment Six}

The key finding from Experiment 6 was that priming occurred between passives with different auxiliaries in both groups: be-passive primes elicited get-passive responses from the children and get-passive primes elicited be-passive responses from the adults. These results do not support the prediction that passive responses would only contain the same auxiliary as the prime. These results suggest, importantly, that the priming observed here and previously did not arise solely from lexical priming of the auxiliary but from a syntactic representation abstracted away from lexical items including the form of the auxiliary. Indeed, it suggests that a common representation underlies both be- and get-passives and that children have acquired this knowledge by the age of four.

These results support previous findings showing that young children tend to produce more get-passives than be-passives (e.g. Turner \& Rommetveit 1967b, Marchman et al. 1991) and also support Harris \& Flora (1982)'s proposal that get-passives are the preferred passive form early on: once exposed to both types of passives, the children produced get-passives more frequently than be-passives, following both get and be primes, whereas they tended only to use be following be-passives (this is illustrated in Figure 6.8 which shows the mean proportions of both the get- and be-passives produced by the children). It appears that by four, children have a passive representation that underlies both types, however, they prefer to use get as the auxiliary, only using be when they are exposed to be-passives, though clearly children also required exposure to get-passives to use them - they did not produce (many) get-passives in previous experiments. This preference is perhaps characterised by a stronger connection to or weight of the get auxiliary within the child representational system.

This is of further interest, given that the available evidence on children acquiring British English suggests that they do not show the same preference for get-passives as found in studies of American English-speaking children (Meints 2003). It is possible that children's tendency to use be-passives in the previous studies was related to their variety of English, though this does not sit well with the finding that once exposed to get-passives they tended to produce more get-passives. It may be that children predominant used be-passives in previous experiments because it was modelled and therefore easier to reproduce; given both models, they find get-passives easier to produce.

The adults' results would appear to imply that with age the be auxiliary takes prominence over get (as also suggested by Marchman et al.'s (1991) results). The adults were more likely to produce be-passives irrespective of the auxiliary of the passive prime and were only primed to produce get-passives after hearing get-passive primes 
(see Figure 6.9). Adults showed a clear preference for using be (even following active primes they produced more be-passives than get-passives), which suggests a preference for, a stronger connection to, the be auxiliary within the adult representational system.

Unlike the previous experiments where the pattern of results was the same between children and adults, in Experiment 6 the children did not respond to the different primes in the same way as the adults (compare Figures 6.8 and 6.9). This is interpreted as showing that children and adults have different preferences for the passive: both groups link the passive to both auxiliaries but the preference, the strength or weight of connection, for a particular auxiliary is different between the groups, with children appearing to prefer get and adults appearing to prefer $b e$.

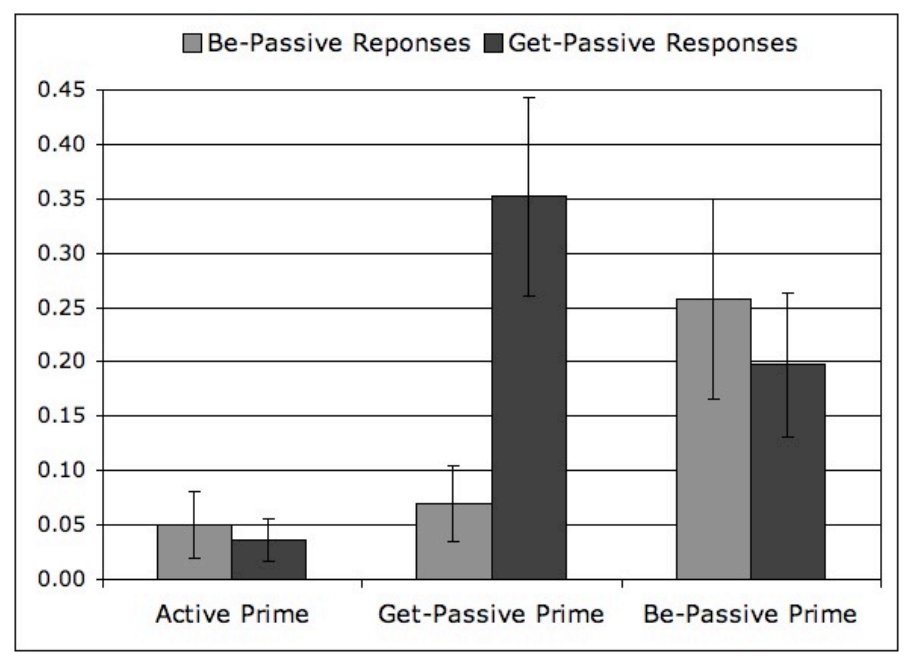

Figure 6.8: Experiment 6: Children's responses in each priming condition

In addition, both groups appear to show a lexical boost to the priming effect from the auxiliary: children were only more likely to produce be-passive descriptions after hearing a be-passive prime; in fact, there was no difference between the effect of active primes and get-passive primes on the proportion of be-passive responses produced (see Figure 6.8). The fact that this effect occurs in both groups (in adults the effect is with the get auxiliary) suggests it is not a developmental effect and the fact that both groups also showed priming from passives with different auxiliaries suggests that the priming effect is not wholly related to the repeated function word. These results do suggest, however, that repeated closed-class, function words can boost the priming effect in the same way that repeated open-class, content words can: the children did show a stronger priming effect for get-passives from get-passives than from be-passives; adults show a similar numerical difference in priming of be-passives from the two passive primes though the difference was not significant. 


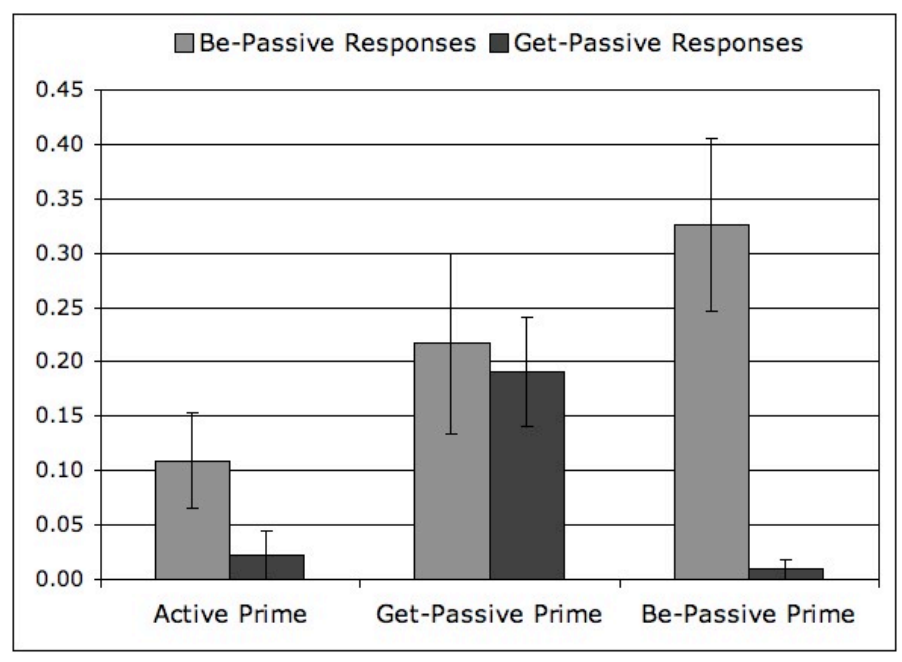

Figure 6.9: Experiment 6: Adults' responses in each priming condition

It is interesting to note that in this experiment the percentage priming effects (see Table 6.21) were more similar to the percentage priming effects observed in the first three experiments (see Table 5.31, the means from these were $23 \%$ for children and $15 \%$ for adults) when the auxiliaries overlapped (31\% and $21 \%$ for children and $22 \%$ and $17 \%$ for adults); when the auxiliaries did not overlap, the priming effects ( $16 \%$ for children, $11 \%$ for adults) are almost identical to those observed in Experiment 5 (16\% and 10\%). This lends further support to the hypothesis that repeating the auxiliary provided a lexical boost to the priming effect.

\section{Reversed Passives}

One proposal to explain children's early use of get-passives, made by Harris and Flora (1982), is that the use of get makes the patient role of the sentence subject in a passive more salient to the child. If this is the case, one outcome that could be anticipated is that children would produce fewer reversed passives with get than with be since they would presumably be less likely to make errors in assigning the arguments to each position if get gives them an additional cue. It might be predicted, therefore, that children would produce fewer reversed passives following get-primes or when producing get-passive responses if they are able to use get in the way proposed.

However, Table 6.22 suggests that this is not the case: children produced as many reversed get-passives as reversed be-passives and though they produced slightly more reversed passives following be-passive primes than following get-passive primes the fact that they also produced reversed passives following active primes suggests this 
Table 6.22: Experiment 6: Number of reversed passives produced

\begin{tabular}{lcc}
\hline & \multicolumn{2}{c}{ Reversed: } \\
Prime & Get-Passive & Be-Passive \\
\hline Get-Passive & 6 & 3 \\
Be-Passive & 5 & 8 \\
Active & 1 & 3 \\
\hline Total & 12 & 14 \\
\hline
\end{tabular}

problem does not necessarily occur from their miscomprehension of the prime but in their production of the passive. They are more likely to try to produce a passive after passive primes, hence there are more reversed passives following these compared to following active primes. The results below suggest that using get does not solve children's problem with mapping the correct thematic roles onto a structure. Children's use of get may therefore be related to other factors such as the fact that it is more regular than be and is not used as widely as an auxiliary as be.

\subsection{Summary and Conclusions}

The previous experiments showed that participants produced full be-passive descriptions after hearing full be-passive primes. The two experiments presented in this chapter examined whether the surface form of primes influences the priming effect of passives. Experiments 5 and 6 exclude two different closed-class, lexical priming explanations of the priming effect observed in previous experiments: one based on repetition of the preposition of the external noun phrase of passives and one based on the passive auxiliary. These experiments examined whether participants' descriptions of the same target pictures differed when they heard short passive primes or get-passive primes. Experiment 5 showed that when full passives were felicitous, participants were primed to produce full passive descriptions by short passives, that is, participants produced more full passives after hearing short passive primes than after hearing active primes. Furthermore, the adults only produced full passives despite these primes and the children produced twice as many full passives as short passives. In Experiment 5, the participants did not reproduce the surface form of the prime but did reproduce the underlying passive structure. Experiment 6 also showed that both groups did not just reproduce the same surface form as the prime: participants heard both be- and get-passive primes and I compared the form of the passives these primed. Experiment 6 showed that both groups produced more passives following passive 
primes with a different auxiliary than following active primes. Once again the participants did not simply reproduce the surface form of the prime but did reproduce the underlying structure. Taken together these results suggest that by four years of age, English speakers have a syntactic representation for the passive which underlies these different possible forms - short and full passives with get and be. They also suggest that syntactic priming occurs independently of these surface features.

However, Experiment 6 does suggest that surface features can boost the priming effect: whilst, for example, the children produced more get-passives following passive primes than active primes, they also produced more following the same auxiliary primes than following be-passive primes. There also appeared to be some lexical effect on the participants' choice of passive: children only produced be-passives following the be-passive primes and adults only produced get-passives following the get-passive primes. Given the fact that participants also produced passives following different auxiliary primes and that adults showed a similar effect to the children, albeit with get-passives rather than $b e-$, I do not interpret these results as suggesting the priming only occurred because of repetition of the lexical items. Rather, in line with the developmental literature, these results appear to suggest that young children are more likely to produce get-passives than be-, except when the latter are modelled (e.g. Turner \& Rommetveit 1967b, Harris \& Flora 1982), whereas adults tend to produce more bepassives (e.g. Marchman et al. 1991). This suggests that, though a syntactic representation seems to underlie these different forms, it is possible for different preferences for example, weightings or connections - to exist within the system. Children appear to prefer get whereas adults appear to prefer be.

Interestingly, in this and the previous experiment there was no effect of Prime on the participants' Other responses, unlike the previous experiments in which children tended to produce more Other responses following passive primes than following active. This lack of effect here may indicate that children less frequently attempted passive responses (in a sense were less strongly primed) following short passive or get- and be-passives primes and thus produced fewer non-standard passive responses, hence the lack of effect. Alternatively, it may be the case that they produced fewer Other responses in these experiments as short passive and get-passives act as better cues to the passive (as suggested by Harris (1976) and Harris and Flora (1982)) and these primes therefore provided a stronger activation of their passive representation. It is difficult to hypothesise the reasons behind a null effect, however, it is worth acknowledging that there was a difference in the children's performance in these experiments with non-standard passive primes. 


\section{Chapter 7}

\section{Older Children's Comprehension and Production of Passives}

\subsection{Introduction}

This chapter presents the final study, carried out with children older than those studied in the previous priming experiments. Previous research has shown that children continue to have difficulty comprehending and producing passives as late as six to seven years of age. Whilst passives begin to appear in children's spontaneous speech from around three years of age (Budwig 1990) and the earlier work in this thesis supports the finding that children have acquired some knowledge of the structure at three to four, other research suggests that children continue to have difficulty producing and comprehending passive structures until late in their language development: even in the preceding priming experiments, children made errors producing passives.

Some production experiments suggest that lexically-independent passives may not appear before six: Savage et al. (2003) tested four- and six-year-olds' production of passives following active and passive primes and did not find a lexically-independent priming effect at four, although these results have not been replicated by subsequent child priming studies (Huttenlocher et al. 2004, Shimpi et al. 2007, Bencini \& Valian 2008). Nonetheless, passives are rarely produced by young children, for example Beilin (1975) reports that $85 \%$ of seven-year-old children produced passives when directed to describe an enactment of a sentence, beginning their description with the verb's object, compared to just $21 \%$ of four-year-old children. Marchman et al. (1991) studied three- to eleven-year-old children's production of passives and found that just $23 \%$ of three-year-olds produced at least one full passive compared to $56 \%$ of seven- 
year-olds and $95 \%$ of nine-year-olds. They also found that though a number of threeand four-year-old children demonstrated some knowledge of the passive by using it at least once, the older children produced passives much more frequently when it was appropriate to do so suggesting a greater proficiency with the structure.

As was found in the previous experiments, young children make mistakes producing passives, even when they appear to have acquired the syntactic elements of the passive, frequently producing reversed passives. Horgan (1978), for example, found that for the two- to four-year-old children she tested, most of the passives they produced were reversed passives, whilst Baldie (1976) even found this error in children's imitations of passive sentences. Turner and Rommetveit (1967a) found that this semantic reversal of the agent and patient was the most common error made by children producing and comprehending passives in their study and it was more frequent in the younger children. The nine-year-olds they tested produced significantly fewer reversed passives than all other age groups; they produced between 90 and $100 \%$ correct passives compared to about $50-60 \%$ correct passives from the seven-year-olds and $20-30 \%$ from the four-year-olds.

Children also tend to have trouble comprehending passive until quite late; Turner and Rommetveit (1967a) also showed that comprehension of passives followed a similar developmental trajectory to production: nine-year-olds understood approximately $95-100 \%$ passives correctly, whilst the seven-year-olds understood about $60-80 \%$ and the four-year-olds understood about $30-40 \%$ passives. Similarly, Lovell and Dixon (1967) found that six-year-olds in their study of a variety of sentence types, understood twice as many passives (12 out of 40 test sentences) as three-year-olds (5 out of 40 test sentences), though both groups' comprehension of passives was poor compared to their comprehension of active sentences (38 out of 40 sentences correctly understood by the six-year-olds and 35 out of 40 sentences correctly understood by the threeyear-olds). Furthermore, Maratsos et al. (1985) showed that four-, five- and sevenyear-olds' comprehension of non-actional verb passives was unreliable but that nineand eleven-year-olds did reliably comprehend non-actional verb passives. Though the priming results from Chapter 5 challenge the theory that this is because children's syntactic representation of the passive is semantically constrained until this age, these results do suggest that whatever difficulty children have with non-actional passives, whether task related or otherwise, this persists until around seven years of age but is resolved by age nine.

Most of these studies show that children's comprehension and production of the passive improves with age: six- and seven-year-olds tend to perform better than threeand four-year-olds, though children are not proficient at producing and comprehend- 
ing this structure until around nine years of age (Turner \& Rommetveit 1967a, Baldie 1976, Horgan 1978, Marchman et al. 1991).

The previous experiments in this thesis showed priming in three- and four-year-olds, which supports the suggestion that children begin to acquire the passive from a young age and have at this age formed enough of a representation for priming to occur. Furthermore, there was no difference in the magnitude of the priming effect between the children and the adult controls. There were, however, qualitative differences between the groups' target responses. The adults rarely made errors producing passives and produced very few Other responses; most of their non-scored responses were otherwise correct non-transitive responses. On the other hand, despite responding to the primes successfully on other trials, the children produced a larger number of Other responses in each experiment and there was often an effect of Prime on these Other responses: they tended to produce more Others following passive primes than active primes. They made errors producing passives, such as reversing passives and producing (sometimes reversed) passive fragments. This suggests that they had difficulty actually producing passives even though they had an appropriate syntactic representation available to be primed and that appears in some cases to have been primed. That children continue to make errors producing passives, even after comprehending a passive prime, suggests that they do not fully master their production of this construction until a later age.

This evidence suggests that the notion of 'acquiring' the passive must be carefully defined. It appears to be a protracted process with different aspects developing at different rates. The evidence from the priming experiments with three- and four-yearolds suggests that the syntax is acquired relatively early with the children being able to produce the constituent structure by four. At this age though their use of the passive is still limited and they frequently make mistakes such as incorrectly mapping the thematic roles leading to reversed passives. A number of studies testing the development of the passive in older children also reach the conclusion that grammatical structure appears before full competence with this construction (e.g. Horgan 1978, Marchman et al. 1991). This study tested older children's description of the same pictures to see how late these difficulties persist when children's production of the passive is facilitated by priming. The present experiment examined whether at six and nine, children are still mastering the passive by examining the nature of the priming effect on their production of passives and also the nature of the Other responses that children of these ages produce. 


\subsection{Experiment Seven: Priming with Six- and Nine-year-olds}

This experiment examined six- and nine-year-old children's production of passives following agent-patient actional and object-experiencer non-actional verb actives and passives. Originally I planned to examine whether there was also a semantic effect on their comprehension of passives at this age, as suggested by Maratsos et al. (1985)'s results. However, given the lack of effects found with younger children in Chapter 5, I do not expect to see an effect of verb type in this experiment.

\subsubsection{Method}

\section{Design}

As in the previous chapter, therefore, this Experiment crossed Prime (active vs. passive) and Verb Type (actional vs. (object-experiencer) non-actional) as withinparticipants and -items factors, and Age (six vs. nine years) as a between-participants but within-items factor.

\section{Participants}

Two groups of children, recruited from a local school, participated: 16 six-year-olds (8 girls, mean age 6;7, range 6;2-6;11); and 16 nine-year-olds (8 girls, mean age $9 ; 6$, range $8 ; 8-10 ; 0)$. All children spoke English as their first and only language and none were reported to have any language or developmental difficulties.

\section{Materials and Procedure}

Experiment 7 used the materials from Experiment 2 (see Appendix B.1); the experiment followed the same procedure as the previous priming experiments. I scored and analysed the data according to the three sets of scoring criteria used in previous experiments: Strict (7.2.2), Lenient (7.2.3) and Inclusive (7.2.4).

\subsubsection{Strict Scoring Results}

\section{Results}

Of each group's 384 experimental trials, just 9 of the six-year-olds' trials and 14 of the nine-year-olds' trials were excluded because the recording failed, the wrong card was described or the participant did not provide a description of the target picture. The younger children produced 309 transitive responses: 246 Active (80\%) and 63 Passive (20\%). The older children produced 347 transitive responses: 280 Active (81\%) and 67 Passive (19\%). See Table 7.1 for a further breakdown of the scored responses. 
Table 7.1: Experiment 7: Frequency of active, passive and other responses according to group and prime condition

\begin{tabular}{lllllrrrr}
\hline & & \multicolumn{5}{c}{ Response } \\
\cline { 3 - 8 } Group & Prime & \multicolumn{2}{c}{ Active } & \multicolumn{2}{c}{ Passive } & \multicolumn{2}{c}{ Other } \\
\hline \hline \multirow{4}{*}{ 6-year-olds } & \multirow{2}{*}{ Active } & Actional & 77 & $(81 \%)$ & 9 & $(9.5 \%)$ & 9 & $(9.5 \%)$ \\
& & Non-Actional & 77 & $(82 \%)$ & 2 & $(2 \%)$ & 15 & $(16 \%)$ \\
& \multirow{2}{*}{ Passive } & Actional & 43 & $(47 \%)$ & 26 & $(28 \%)$ & 23 & $(25 \%)$ \\
& & Non-Actional & 49 & $(52 \%)$ & 26 & $(28 \%)$ & 19 & $(20 \%)$ \\
\hline \multirow{4}{*}{ 9-year-olds } & \multirow{2}{*}{ Active } & Actional & 85 & $(90 \%)$ & 5 & $(5 \%)$ & 4 & $(4 \%)$ \\
& & Non-Actional & 84 & $(91 \%)$ & 7 & $(8 \%)$ & 1 & $(1 \%)$ \\
& \multirow{2}{*}{ Passive } & Actional & 54 & $(58 \%)$ & 29 & $(31 \%)$ & 10 & $(11 \%)$ \\
& & Non-Actional & 57 & $(63 \%)$ & 26 & $(28 \%)$ & 8 & $(9 \%)$ \\
\hline
\end{tabular}

The younger children produced 66 Other responses (17\% of the total target items), $36 \%$ of which occurred following active primes and $64 \%$ of which occurred following passive primes. Of their 66 Other responses, 26 were non-transitive responses (e.g. 7.1a), 16 complete reversed passives (7.1b), 11 incomplete reversed passives (7.1c), 8 complete reversed actives (7.1d) and 5 incomplete actives (7.1e), one of which was reversed (7.1f).
a. "a elephant squirting water at a robber"
"there's a queen and a bunny rabbit"
b. "a cow's being licked by a king" (describing a picture of a cow licking a king)
c. "a lion's being - a doctor's being picked up from a lion"
d. "a girl is hugging a rabbit" (describing a picture of a rabbit hugging a girl)
e. "a elephant's poking the - the elephant's pet is a witch"
f. " a clown is wetting a a-a bear's wetting the clown"

The nine-year-olds by contrast produced just 23 Other responses $(6 \%$ of their total target items), most of which, (as in the younger group), occurred following passive primes: $22 \%$ occurred in the active conditions, whilst $78 \%$ occurred in the passive conditions. Of the older children's 23 Other responses, 15 were non-transitive responses (7.1a), 5 incomplete reversed passives (7.1c), 2 complete reversed actives (7.1d) and 1 incomplete reversed actives (7.1f). Unlike the younger group they did not produce any complete reversed passives. 


\section{Analysis}

Passive Responses

As in the previous experiments I analysed the proportions of passive target descriptions; Table 7.2 shows these mean proportions in each condition. The proportions of passives were analysed in three-way mixed ANOVAs with the factors Prime (active vs. passive) $x$ Verb Type (actional vs. non-actional) x Age (six years vs. nine years), treating participants $\left(F_{1}\right)$ and items $\left(F_{2}\right)$ as random effects. Table 7.3 presents the results of these ANOVAs; since I did not predict any effect of Verb Type, and in the interests of brevity, only the significant effects are reported.

Table 7.2: Experiment 7: Mean proportions of Passives in the Strict scoring

\begin{tabular}{llcccc}
\hline & & \multicolumn{2}{c}{ 6-years } & \multicolumn{2}{c}{ 9-years } \\
\cline { 2 - 5 } Prime & $\mathbf{M}$ & (SD) & M & (SD) \\
\hline \hline \multirow{2}{*}{ Active } & Actional & 0.11 & $(0.15)$ & 0.06 & $(0.20)$ \\
& Non-Actional & 0.03 & $(0.07)$ & 0.08 & $(0.18)$ \\
Passive & Actional & 0.35 & $(0.28)$ & 0.33 & $(0.35)$ \\
& Non-Actional & 0.31 & $(0.30)$ & 0.30 & $(0.31)$ \\
\hline
\end{tabular}

Table 7.3: Experiment 7: ANOVA of proportions of Passives in the Strict scoring

\begin{tabular}{lcccccccc}
\hline & \multicolumn{4}{c}{ F1 Results } & \multicolumn{4}{c}{ F2 Results } \\
\cline { 2 - 9 } Effect & $\boldsymbol{d f}$ & $\boldsymbol{F 1}$ & $\boldsymbol{p}$ & $\boldsymbol{p} \cdot \eta^{2}$ & $\boldsymbol{d f}$ & $\boldsymbol{F 2}$ & $\boldsymbol{p}$ & $\boldsymbol{p} \cdot \boldsymbol{\eta}^{2}$ \\
\hline \hline Prime & 1,30 & 37.42 & $<.001$ & 0.55 & 1,46 & 48.17 & $<.001$ & 0.51 \\
Prime (Actional) & 1,30 & 20.18 & $<.001$ & 0.40 & 1,46 & 27.24 & $<.001$ & 0.37 \\
Prime (Non-Actional) & 1,30 & 28.03 & $<.001$ & 0.48 & 1,46 & 38.11 & $<.001$ & 0.45 \\
Prime (6-years) & 1,30 & 19.76 & $<.001$ & 0.40 & 1,46 & 24.57 & $<.001$ & 0.35 \\
Prime (9-years) & 1,30 & 17.69 & $<.001$ & 0.37 & 1,46 & 23.60 & $<.001$ & 0.34 \\
\hline
\end{tabular}

The analyses yielded a significant main effect of Prime: the children produced significantly more passive descriptions following passive primes $(M=0.32)$ than following active primes $(\mathrm{M}=0.07)$. However, there was no effect of Age $\left(F_{\mathrm{S}}<1\right)$ : neither group produced significantly more passives than the other. Nor was there any significant effect of Verb Type $(F \mathbf{S}<2)$ : the children did not produce more passives following an actional verb prime $(M=0.21)$ than following a non-actional verb prime $(M=0.18)$. No interactions were significant $(F \mathrm{~s}<2)$. There was a simple main effect of Prime for both actional verbs and non-actional verbs: the children were more likely to produce passive targets following actional verb passive primes than following actional verb active primes, and likewise for non-actional verb primes. There was also a simple main effect of Prime for both six-year-olds and nine-year-olds. Hence both agegroups were more likely to produce passives following passive primes than following active primes. There was not a simple main effect of Verb Type within either group $(F \mathrm{~s}<3$, ps $>.12)$ : neither group produced more passives following actional primes 
than non-actional. These analyses show no differences between the groups and confirm the results of the previous chapter with regard to children's comprehension of passives with different verb types. Both six- and nine-year-olds were more likely to produce passives following passive primes regardless of any other factors.

Other Responses

Table 7.4 presents the mean number of Other responses. The means suggest that, on average, the younger children produced more Others than the older children and both groups produced more Others after passive primes than after active primes. I repeated the ANOVAs to analyse the raw numbers of Other responses that each group produced to see whether Age, Prime or Verb Type had a significant effect; see Table 7.5 for the results of these ANOVAs; again only the significant effects are reported. These showed a significant effect of Prime but no effect of Verb Type $(F \mathbf{S}<1)$; irrespective of the verb type, the children produced more Other responses following passive primes $(M=0.94)$ than active primes $(M=0.45)$. There was also a significant effect of Age: the six-year-olds produced more Other responses $(\mathrm{M}=1.03)$ than the nine-year-olds $(\mathrm{M}$ $=0.36)$. No interactions were significant $\left(F_{\mathrm{S}}<3\right)$. There was a simple main effect of Prime on both groups' Other responses: both produced more Others following passive primes than following active primes but there was no simple main effect of Verb Type for either group $(F \mathrm{~s}<1)$.

Table 7.4: Experiment 7: Mean numbers of Others in the Strict scoring

\begin{tabular}{llcccc}
\hline & & \multicolumn{2}{c}{ 6-years } & \multicolumn{2}{c}{ 9-years } \\
\cline { 3 - 6 } & Prime & $\mathbf{M}$ & (SD) & M & (SD) \\
\hline \hline \multirow{2}{*}{ Active } & Actional & 0.56 & $(0.63)$ & 0.25 & $(0.58)$ \\
& Non-Actional & 0.94 & $(0.99)$ & 0.06 & $(0.25)$ \\
Passive & Actional & 1.44 & $(1.26)$ & 0.63 & $(0.72)$ \\
& Non-Actional & 1.19 & $(1.05)$ & 0.50 & $(0.73)$ \\
\hline
\end{tabular}

Table 7.5: Experiment 7: ANOVA of numbers of Others in the Strict scoring

\begin{tabular}{lcrlcrrrr}
\hline & \multicolumn{4}{c}{ F1 Results } & \multicolumn{5}{c}{ F2 Results } \\
\cline { 2 - 9 } Effect & $d f$ & $\boldsymbol{F 1}$ & $\boldsymbol{p}$ & $\boldsymbol{p} \cdot \eta^{2}$ & $\boldsymbol{d f}$ & $\boldsymbol{F} \mathbf{p}$ & $\boldsymbol{p} \cdot \boldsymbol{\eta}^{2}$ \\
\hline \hline Prime & 1,30 & 16.63 & $<.001$ & 0.36 & 1,46 & 11.74 & $<.01$ & 0.20 \\
Age & 1,30 & 9.44 & $<.01$ & 0.24 & 1,46 & 26.27 & $<.001$ & 0.36 \\
Prime (6-years) & 1,30 & 11.21 & $<.01$ & 0.27 & 1,46 & 7.91 & $<.01$ & 0.15 \\
Prime (9-years) & 1,30 & 5.85 & $<.05$ & 0.16 & 1,46 & 4.13 & $<.05$ & 0.08 \\
\hline
\end{tabular}

\section{Additional Analyses}

As in previous experiments, I conducted additional analyses to examine for other possible effects or differences in the groups. First I checked whether the number of passives the children produced increased with age within either group; this might suggest that the age range was too large and the children within the group were at different 
stages of language development. Bivariate correlations showed a significant correlation between the number of passives the six-year-olds produced and their age $(r=$ $-.53, p<.05,1$-tailed); as illustrated in Figure 7.1, there is in fact a negative correlation between age and the number of passives: passives decreased with age, it is not clear why this should be the case, particularly given the quite small age range for this group: $6 ; 2-6 ; 11$. Within the nine-year-old group, whose age range was larger $(8 ; 8-10 ; 0)$ and therefore more susceptible to encompass different stages of language development, the correlation between age and the number of passives the participants produced was not significant $(r=.02, p=.47$, 1-tailed; see also Figure 7.2).

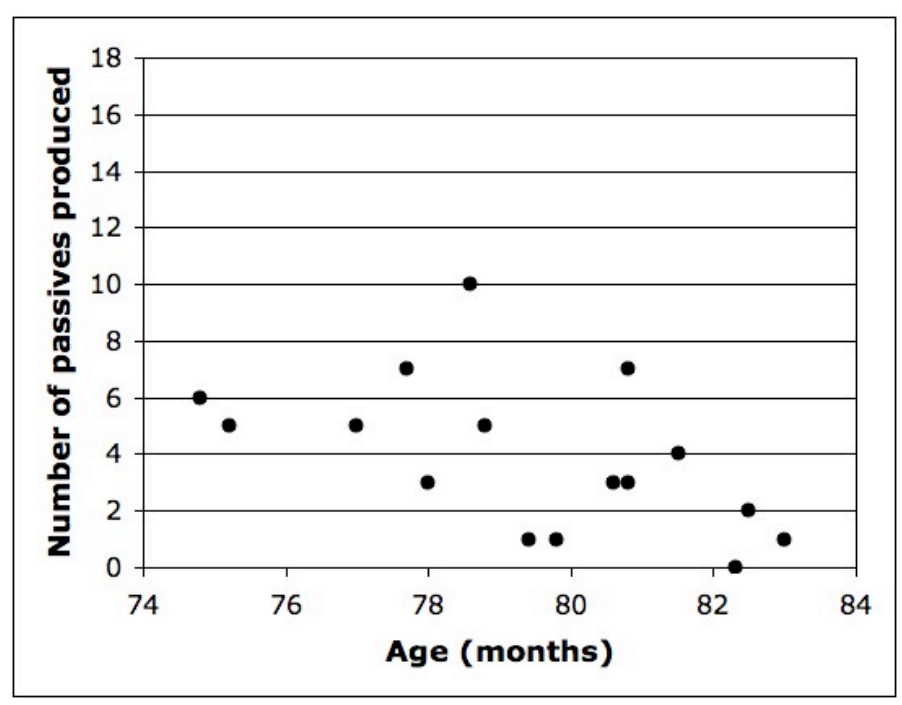

Figure 7.1: Experiment 7: Number of passives six-year-olds produced by age

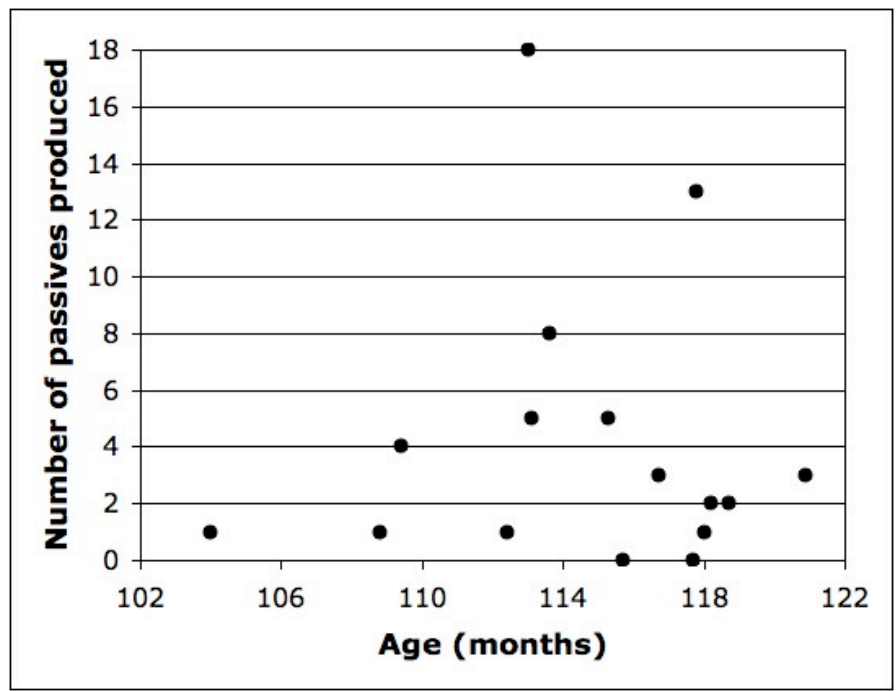

Figure 7.2: Experiment 7: Number of passives nine-year-olds produced by age 
Furthermore, neither group showed any learning effect during the experiment, as characterised by an increase in the number of passives produced at the end of the experiment following exposure to more passive exemplars than at the beginning when few exemplars have been heard. If, at six, children are still establishing their representation for the passive they may be more susceptible to a learning effect within the experiment (though recall that younger children did not show this effect). I compared the number of passives that participants produced following the first eight and last eight primes in paired samples $t$-tests. These showed that the younger group did not tend to produce significantly more passives at the end of the experiment $(\mathrm{M}=1.37, \mathrm{SD}$ $=1.5)$ than at the beginning $(\mathrm{M}=1.31, \mathrm{SD}=1.1 ; t(15)=-.13, p=.45,1$-tailed $)$. The older group also produced as many passives at the beginning of the experiment $(\mathrm{M}=$ $1.0, \mathrm{SD}=1.5)$ as at the end $(\mathrm{M}=1.5, \mathrm{SD}=2.6 ; t(15)=-1.22, p=.12$, 1-tailed $)$.

Finally I examined whether there was any indication that the number of passives the children produced was influenced by whether the patient was depicted on the left of the picture (half of the targets) or on the right. If children show a tendency to 'read' from left to right across the picture they may be more likely to produce passives when the patient occurs on the left of the picture than when it appears on the right. Again these tests are speculative given that neither the experiments nor materials, though counterbalanced, were designed to test this specifically. An independent samples $t$ test showed that the younger children produced significantly more passives when the patient appeared on the left of the target picture $(\mathrm{M}=3.50, \mathrm{SD}=1.6)$ than when it was on the right $(\mathrm{M}=1.75, \mathrm{SD}=1.7, t(22)=-2.61, p<.01,1$-tailed $)$. There was a marginal effect in the older children (left: $\mathrm{M}=3.25, \mathrm{SD}=1.42$, right: $\mathrm{M}=2.33, \mathrm{SD}=1.30, t(22)=$ $-1.65, p=.06,1$-tailed). Recall that in Experiment 2, which used the same materials, the nursery-aged children and adults both produced numerically more passives when the patient was depicted on the left than when it was on the right but the difference was not significant for either group. Interestingly, all groups produced numerically more passives when the patient was on the left-hand side of the picture than when it was on the right-hand side, however this difference was only significant for 6-yearolds.

\section{Discussion}

These analyses show that, as in previous experiments, children of six and nine were more likely to produce passives after hearing a passive description compared to when they had just heard an active, regardless of whether it contained an actional verb or a non-actional verb. In addition, the magnitude of the priming effect was not different between the two groups; this is perhaps not surprising given this difference was not observed between younger children and adults in the previous experiments of this 
thesis. There were however some differences between the two groups in this study - as in previous experiments, the younger children produced more targets scored as Other compared to the older group. The six-year-olds, unlike the nine-year-olds, produced significantly more passives when the patient was depicted on the left than when it appeared on the right. The implications of these findings are discussed in section 7.2.5 below following the results from the other scorings.

\subsubsection{Lenient Scoring Results}

\section{Results and Analysis}

Following the Lenient scoring, the pattern of results did not change greatly, +10 of the six-year-olds' responses were scored as Active and +1 was scored as Passive. The nine-year-olds' scores increased by just +3 Active. The paucity of changes in the distribution of responses is indicative of the fact that the children did not produce short passives and they rarely failed to complete a correct utterance.

\section{Passive Responses}

Table 7.6 shows the mean proportions of passives following the Lenient scoring. I repeated the analyses from the Strict scoring with these results, presented in Table 7.7; again, I report only the significant effects from the results of the ANOVAs.

Table 7.6: Experiment 7: Mean proportions of Passives in the Lenient scoring

\begin{tabular}{llcccc}
\hline & & \multicolumn{2}{c}{ 6-years } & \multicolumn{2}{c}{ 9-years } \\
\cline { 2 - 5 } Prime & M & (SD) & M & (SD) \\
\hline \hline \multirow{2}{*}{ Active } & Actional & 0.11 & $(0.15)$ & 0.06 & $(0.20)$ \\
& Non-Actional & 0.03 & $(0.07)$ & 0.08 & $(0.18)$ \\
Passive & Actional & 0.33 & $(0.27)$ & 0.32 & $(0.35)$ \\
& Non-Actional & 0.30 & $(0.30)$ & 0.30 & $(0.31)$ \\
\hline
\end{tabular}

Table 7.7: Experiment 7: ANOVA of proportions of Passives in the Lenient scoring

\begin{tabular}{lcccccccc}
\hline & \multicolumn{4}{c}{ F1 Results } & \multicolumn{4}{c}{ F2 Results } \\
\cline { 2 - 9 } Effect & $\boldsymbol{d f}$ & $\boldsymbol{F 1}$ & $\boldsymbol{p}$ & $\boldsymbol{p} \cdot \boldsymbol{\eta}^{2}$ & $\boldsymbol{d f}$ & $\boldsymbol{F 2}$ & $\boldsymbol{p}$ & $\boldsymbol{p} \cdot \boldsymbol{\eta}^{2}$ \\
\hline \hline Prime & 1,30 & 35.52 & $<.001$ & 0.54 & 1,46 & 49.07 & $<.001$ & 0.52 \\
Prime (Actional) & 1,30 & 19.26 & $<.001$ & 0.39 & 1,46 & 29.06 & $<.001$ & 0.39 \\
Prime (Non-Actional) & 1,30 & 27.30 & $<.001$ & 0.48 & 1,46 & 37.47 & $<.001$ & 0.45 \\
Prime (6-years) & 1,30 & 18.10 & $<.001$ & 0.38 & 1,46 & 25.03 & $<.001$ & 0.35 \\
Prime (9-years) & 1,30 & 17.42 & $<.001$ & 0.37 & 1,46 & 24.04 & $<.001$ & 0.34 \\
\hline
\end{tabular}

Three-way ANOVAs (as above) yielded a significant main effect of Prime but no significant effect of Verb Type $\left(F_{\mathbf{S}}<2\right)$. Under the Lenient scoring there is no evidence to suggest that children's responses were influenced by verb type, only that they were 
more likely to produce passive descriptions following passive primes $(\mathrm{M}=0.31)$ than following active primes $(\mathrm{M}=0.07)$. The Lenient scoring results did not show an effect of Age $(F \mathbf{s}<1)$ either and no interactions were significant $\left(F_{\mathbf{S}}<2\right)$. There was still a simple main effect of Prime for both actional verbs and non-actional verbs: passive targets were more likely following actional verb passive primes than following actional verb active primes and likewise for non-actional verb primes. There was also a simple main effect of Prime for both six-year-olds and nine-year-olds; in both age-groups passives were more likely following passive primes than following active primes. There was no simple main effect of Verb Type within either group $(F \mathbf{s}<2.5)$.

\section{Other Responses}

The mean numbers of remaining Other responses from the Lenient Scoring are reported in Table 7.8. I repeated the analyses with these results; these showed the same pattern of results as in the Strict scoring, see Table 7.9 for the significant results from these ANOVAs. There was a significant effect of Prime but no effect of Verb Type ( $F_{\mathbf{S}}<$ 1); there was still a significant effect of Age. Despite the changes in the scorings, there were still more Other responses produced in the passive prime conditions than the active, irrespective of the verb-type condition; the younger children produced more Other responses than the older children. No interactions were significant $\left(F_{\mathbf{S}}<1\right)$. Simple main effects showed an effect of Prime on both groups' Other responses but no effect of Verb Type $(F \mathbf{s}<1)$.

Table 7.8: Experiment 7: Mean numbers of Others in the Lenient scoring

\begin{tabular}{llcccc}
\hline & & \multicolumn{2}{c}{ 6-years } & \multicolumn{2}{c}{ 9-years } \\
\cline { 3 - 6 } & Prime & $\mathbf{M}$ & (SD) & M & (SD) \\
\hline \hline \multirow{2}{*}{ Active } & Actional & 0.50 & $(0.63)$ & 0.13 & $(0.34)$ \\
& Non-Actional & 0.69 & $(0.87)$ & 0.06 & $(0.25)$ \\
Passive & Actional & 1.19 & $(1.28)$ & 0.56 & $(0.63)$ \\
& Non-Actional & 1.06 & $(1.06)$ & 0.50 & $(0.73)$ \\
\hline
\end{tabular}

Table 7.9: Experiment 7: ANOVA of numbers of Others in the Lenient scoring

\begin{tabular}{lcrlllllll}
\hline & \multicolumn{4}{c}{ F1 Results } & \multicolumn{4}{c}{ F2 Results } \\
\cline { 2 - 9 } Effect & $\boldsymbol{d f}$ & $\boldsymbol{F 1}$ & $\boldsymbol{p}$ & $\boldsymbol{p} \cdot \eta^{2}$ & $\boldsymbol{d f}$ & $\boldsymbol{F 2}$ & $\boldsymbol{p}$ & $\boldsymbol{p} \cdot \eta^{2}$ \\
\hline \hline Prime & 1,30 & 13.93 & $<.01$ & 0.32 & 1,46 & 11.99 & $<.01$ & 0.21 \\
Age & 1,30 & 7.32 & $<.05$ & 0.20 & 1,46 & 23.34 & $<.001$ & 0.34 \\
Prime (6-years) & 1,30 & 8.38 & $<.01$ & 0.22 & 1,46 & 7.21 & $<.05$ & 0.14 \\
Prime (9-years) & 1,30 & 5.68 & $<.05$ & 0.16 & 1,46 & 4.89 & $<.05$ & 0.10 \\
\hline
\end{tabular}

\section{Additional Analyses}

I repeated the other analyses with the results of the Lenient scoring however because of the limited change in the groups' results following this scoring, there was no change in the results of these further analyses. 


\section{Discussion}

The analyses of the Lenient scoring yield the same pattern of results as in the Strict scoring showing that no effects appeared in the data when the criteria for scored responses were relaxed. However, these criteria did not lead to particularly large changes in the scored results, therefore I scored and analysed the data a third time with the most inclusive scoring criteria.

\subsubsection{Inclusive Scoring Results}

\section{Results and Analysis}

Following the Inclusive scoring, the six-year-olds' results increased by +5 Active and +26 Passive responses. The nine-year-old children's responses increased by +5 Active and +6 Passive responses. The larger increase in the number of the younger children's passive responses reflects the fact that they produced a number of reversed passive utterances that were scored as Passive only in this scoring. The older children did not produce any reversed passive utterances.

\section{Passive Responses}

Table 7.10 shows the mean proportion of passive responses in each condition following the Inclusive scoring. The significant results of the analyses are reported in Table 7.11. The ANOVAs showed a significant main effect of Prime but not of Verb Type $(F \mathbf{s}<3)$ nor of Age $(F \mathbf{s}<1)$ : overall the children produced more passives following passive primes $(M=0.37)$ than following active primes $(M=0.07)$. No interactions were significant $(F \mathrm{~s}<2.2)$. There was a simple main effect of Prime for both actional verbs and non-actional verbs and for both six-year-olds and nine-year-olds; there was no simple main effect of Verb Type for the nine-year-olds $(F s<1)$, though there was for the six-year-olds in the Participants analysis: they produced slightly more passives following actional primes $(M=0.28)$ than non-actional $(M=0.21)$. This difference between the two verb types is quite small, given the lack of interactions or verb type effect in previous analyses of both Passive and Other responses, this effect is probably not due to systematic variance. Even with the differences following the Inclusive scoring in the six- and nine-year-olds' results, the analyses still show that passives were more likely following passive primes than following active primes but that neither group was more susceptible to priming.

Other Responses

Table 7.12 shows the mean proportions of Other responses remaining following the Inclusive scoring. These showed a different pattern of responses to the previous scorings: following the most lenient scoring, the number of Others left in each condition 
Table 7.10: Experiment 7: Mean proportions of Passives in the Inclusive scoring

\begin{tabular}{llcccc}
\hline & & \multicolumn{2}{c}{ 6-years } & \multicolumn{2}{c}{ 9-years } \\
\cline { 3 - 6 } & Prime & $\mathbf{M}$ & (SD) & M & (SD) \\
\hline \hline \multirow{2}{*}{ Active } & Actional & 0.10 & $(0.13)$ & 0.06 & $(0.20)$ \\
& Non-Actional & 0.05 & $(0.11)$ & 0.08 & $(0.18)$ \\
Passive & Actional & 0.46 & $(0.24)$ & 0.35 & $(0.35)$ \\
& Non-Actional & 0.38 & $(0.29)$ & 0.32 & $(0.30)$ \\
\hline
\end{tabular}

Table 7.11: Experiment 7: ANOVA of proportions of Passives in the Inclusive scoring

\begin{tabular}{lcccccccc}
\hline & \multicolumn{4}{c}{ F1 Results } & \multicolumn{5}{c}{ F2 Results } \\
\cline { 2 - 9 } Effect & $\boldsymbol{d f}$ & $\boldsymbol{F 1}$ & $\boldsymbol{p}$ & $\boldsymbol{p} \cdot \eta^{2}$ & $\boldsymbol{d f}$ & $\boldsymbol{F 2}$ & $\boldsymbol{p}$ & $\boldsymbol{p} \cdot \boldsymbol{\eta}^{2}$ \\
\hline \hline Prime & 1,30 & 53.86 & $<.001$ & 0.64 & 1,46 & 69.45 & $<.001$ & 0.60 \\
Prime (Actional) & 1,30 & 39.37 & $<.001$ & 0.57 & 1,46 & 41.25 & $<.001$ & 0.47 \\
Prime (Non-Actional) & 1,30 & 39.42 & $<.001$ & 0.57 & 1,46 & 47.03 & $<.001$ & 0.51 \\
Prime (6-years) & 1,30 & 33.92 & $<.001$ & 0.53 & 1,46 & 40.63 & $<.001$ & 0.47 \\
Prime (9-years) & 1,30 & 20.74 & $<.001$ & 0.41 & 1,46 & 29.28 & $<.001$ & 0.39 \\
Verb Type (6-years) & 1,30 & 5.04 & $<.05$ & 0.14 & 1,46 & 2.71 & $=.11$ & 0.06 \\
\hline
\end{tabular}

was evened out. Table 7.13 shows the results of the ANOVAs. These showed no effect of Prime $\left(F_{\mathbf{s}}<1\right)$, no effect of Verb Type $\left(F_{\mathbf{s}}<1\right)$ but a marginal effect of Age, reflecting the fact that the six-year-olds still produced numerically more Other responses. No simple main effects were significant $\left(F_{\mathbf{s}}<2.2\right)$.

Table 7.12: Experiment 7: Mean numbers of Others in the Inclusive scoring

\begin{tabular}{llcccc}
\hline & & \multicolumn{2}{c}{ 6-years } & \multicolumn{2}{c}{ 9-years } \\
\cline { 3 - 6 } & Prime & $\mathbf{M}$ & (SD) & M & (SD) \\
\hline \hline \multirow{2}{*}{ Active } & Actional & 0.31 & $(0.48)$ & 0.13 & $(0.34)$ \\
& Non-Actional & 0.44 & $(0.63)$ & 0.00 & $(0.00)$ \\
Passive & Actional & 0.31 & $(0.79)$ & 0.19 & $(0.40)$ \\
& Non-Actional & 0.44 & $(0.89)$ & 0.25 & $(0.58)$ \\
\hline
\end{tabular}

\section{Additional Analyses}

I again examined for further effects on the children's results following the Inclusive scoring. Bivariate correlations showed that the relationship between the children's age and the number of passives they produced was only marginal within the six-yearold group following the Inclusive scoring $(r=-.40, p=.06$, 1-tailed) but still was not significant within the nine-year-old group $(r=-.02, p=.47$, 1-tailed $)$.

Nor did either group show any learning effect during the experiment, characterised by an increase in the number of passives following the last eight primes compared to the first eight. Paired samples $t$-tests showed that the younger group did not produce 
Table 7.13: Experiment 7: ANOVA of numbers of Others in the Inclusive scoring

\begin{tabular}{lcrlllccc}
\hline & \multicolumn{3}{c}{ F1 Results } & \multicolumn{4}{c}{ F2 Results } \\
\cline { 2 - 9 } Effect & $d f$ & $\boldsymbol{F 1}$ & $\boldsymbol{p}$ & $\boldsymbol{p} \cdot \eta^{2}$ & $d f$ & $\boldsymbol{F} 2$ & $\boldsymbol{p}$ & $\boldsymbol{p} \cdot \eta^{2}$ \\
\hline \hline Age & 1,30 & 3.64 & $=.07$ & 0.11 & 1,46 & 6.82 & $<.05$ & 0.13 \\
\hline
\end{tabular}

significantly more passives at the end of the experiment $(\mathrm{M}=2.00, \mathrm{SD}=1.5)$ than at the beginning $(\mathrm{M}=1.94, \mathrm{SD}=1.6, t(15)=-.11, p=.45,1$-tailed $)$. The older group also produced as many passives at the beginning of the experiment $(\mathrm{M}=1.12, \mathrm{SD}=1.59)$ as at the end $(\mathrm{M}=1.56, \mathrm{SD}=2.5, t(15)=-1.00, p=.17,1$-tailed $)$.

Finally independent samples $t$-tests showed that neither group produced more passives when the patient was on the left of the picture than when it was on the right. This effect was no longer significant for the six-year-olds (left: $\mathrm{M}=4.33, \mathrm{SD}=1.5$, right: $\mathrm{M}$ $=3.17, \mathrm{SD}=2.2, t(22)=1.53, p=.07,1$-tailed) or for the nine-year-olds (left: $\mathrm{M}=3.33$, $\mathrm{SD}=1.4$, right: $\mathrm{M}=2.75, \mathrm{SD}=1.4, t(22)=1.00, p=.16,1$-tailed).

\section{Discussion}

Following the Inclusive scoring, the analyses of the Passive responses remains unchanged, excluding the marginal effect of Verb Type for the six-year-olds. The analyses of the Other responses did not show the same effects as previous scorings, even the effect of Age was reduced.

\subsubsection{General Discussion of Experiment Seven}

In Experiment 7, as in the previous priming experiments, children tended to repeat the structure of a sentence that they had previously comprehended in their own description of a target picture: they produced more passive picture descriptions after hearing a passive sentence than after hearing an active sentence. This tendency occurred between unrelated items, irrespective of the age of the children and irrespective of whether the verb in the prime sentence contained an actional verb involving an agent and a patient, or a non-actional verb involving an experiencer and a theme.

These results suggest that children of six and nine have an abstract syntactic representation for the passive that is drawn upon during both comprehension and production. They furthermore suggest that this syntactic representation is common to actional and non-actional passives: the children were as likely to produce actional passives after hearing non-actional verb primes as after hearing actional verb primes. Also, there was no effect of age. The absence of any differences in the priming between the age 
groups supports the findings from the previous experiments suggesting that syntactic aspects of passive use are developed before six (and not constrained to particular classes of verbs).

However there were some qualitative differences between the groups' responses: the six-year-olds produced more Others and showed a stronger sensitivity to the depiction of the items than the older children suggesting some differences between the two groups' competence. Firstly, the younger children, but not the older children, produced more passives when the patient was depicted on the left than when it was on the right. This may indicate that they used the characteristics of the pictures and order of fixation when forming their response structure. This may be further evidence that the two groups were behaving differently in the experiment and in their language processing; it is plausible that when children are learning to read and write they adopt a left-to-right fixation strategy which they used when examining the pictures and furthermore that their scanning of the pictures influenced their language production ${ }^{1}$. However, these results and interpretation are tentative since the experiment did not set out to test this factor: there is no evidence that the children fixated the pictures from left to right or that they formulated their response whilst doing this. The materials, though counterbalanced for whether the patient appeared on the left or right, were not designed to test this specifically: some of the pictures show a clear left and right distinction between the agent and patient, for example, chasing, whereas others do not, for example, hugging. In addition, the timing of presentation of the target item was not controlled, sometimes children looked at these during the prime utterances which may effect how they looked at their picture. Furthermore, the fact that this effect was only in found in six-year-olds may be a chance finding in a small sample, given that older children (and the nursery-aged children and adults) did produce numerically more passives when the patient was on the left. This pattern of results might indicate a potential underlying influence of the task and would be an interesting area for further study. A more appropriate experimental method may shed light on whether there is a relationship between how children look at a picture and how they describe it. Of further interest is whether this would interact with a priming manipulation (note that these results are collapsed over priming conditions).

A second area of difference between the two groups is the nature of their Other responses. Whilst both groups produced various Other responses, and both groups produced more Others after passive primes than after active primes, there were some differences in what the two groups produced. The six-year-olds produced almost three

\footnotetext{
${ }^{1}$ Although recall that even the nursery-aged children showed a numerical tendency to produce more passives when the patient was on the left, which may suggest that this effect is not specific to children who are learning to read
} 
times as many Other responses as the nine-year-olds (compare $17 \%$ and $6 \%$ respectively of their target utterances). Most (65\%) of the older children's Other responses were, like the adults' in the previous experiments, otherwise correct, non-transitive responses (such as dative or intransitive utterances). Even though there was an effect of Prime on the nine-year-olds' Other responses - they produced more following passive primes - their Other responses were not structurally related to the structure of the prime, such as incorrect passive forms, as the six-year-olds' were. The younger children's Other responses were mostly reversed (active and passive) sentences and (reversed and non-reversed) incomplete utterances (61\% errors) rather than non-transitive responses (39\%); this pattern of behaviour is more similar to the nursery children's in the previous experiments than the adults'. The fact that the younger group produced more incorrect or incomplete passive responses suggests they have not fully mastered production of the passive. By nine, however, this difficulty no longer exists: like the adults in the previous experiments, the older children rarely made errors producing passives, their Other responses were just that - responses that were neither active or passive structures.

Unlike the nine-year-olds, the six-year-olds produced a number of reversed passives (i.e., with the agent and patient roles reversed). They produced 16 complete reversed passives ( $24 \%$ of their errors) as well as 11 (17\% errors) incomplete reversed passives, compared with the older children who produced 0 complete reversed passives and 5 ( $22 \%$ of their errors) incomplete reversed passives. The younger children corrected $64 \%$ of their incomplete reversed passives with correct passive responses, $27 \%$ with actives and 9\% with another response form; none of their complete reversed passives were corrected suggesting that though sometimes they were aware of making the error, they more often completed the utterance incorrectly without realising it. The older children corrected $60 \%$ of their incomplete reversed passives with active responses, $20 \%$ with passives and $20 \%$ with other responses. That the two groups tended to correct their incomplete utterances differently may be further indication of the developmental path of the passive: the younger children tended to stick to the constituent structure of the passive once selected and correct the thematic role assignment (7.2a) whereas the older children tended to maintain the argument positioning and switch the structure to fit it (7.2b).

$$
\begin{aligned}
& \text { a. "a bunny is being tickl-a queen is being tickled by a bunny" } \\
& \text { b. "a frog is getting — being kissed — kiss-a frog kissed the doctor" }
\end{aligned}
$$

This may indicate that a generally lack of proficiency in language processing persists until six resulting in the children's inability to change the structure once selected. By 
nine, children's language processing is more proficient and they have no difficulty switching structures. In particular, these results would suggest that at six, children have not yet completely mastered the semantics of the passive though its syntax is acquired: they continue to have difficulty mapping thematic roles onto syntactic positions even though they have acquired a syntactic representation that can be primed. By nine, however, children have acquired the semantics of the passive: they are less likely to produce reversed passives.

These differences suggest that although the strictly syntactic aspects of the passive structure were comparable in the two age groups (and similar to the younger children of previous experiments), yielding the same pattern of priming in both groups, there were important differences between them in other respects which suggest that not all aspects of the passive were fully mastered by the younger group.

\subsection{Summary and Conclusions}

Experiment 7 suggests that children of six and nine have acquired an abstract syntactic representation for the passive that is independent of lexical content but common to actional and non-actional passives and both production and comprehension. The results support the findings of previous experiments suggesting that syntactic aspects of passive use are well-developed before six; however, they also show that other aspects may not be fully developed. Taken in conjunction with the previous experiments the evidence suggests that children acquire the syntax of the passive relatively early but they continue to have difficulty with the non-canonical mapping of a patient role to the subject position and an agent role to the object position of a sentence. 


\section{Chapter 8}

\section{Conclusions}

This thesis investigated children's production and representation of the passive. The results of previous language acquisition research have suggested that children's early passives tend to involve structural variations from the full be-passive, for example, short passives or get-passives, but are usually restricted to a semantic core of actional verbs, such as those with agent and patient thematic roles. Because children have performed better with short passives, get-passives and actional verb passives, language acquisition researchers have suggested that these forms are acquired earlier or used by young children to form a representation for the passive. This thesis examined whether syntactic priming experiments can shed further light on these issues: I used priming experiments as a method of examining the nature of children's syntactic representations. The underlying premise is that syntactic priming effects reflect the repeated use of the same syntactic representation across successive utterances (Branigan et al. 1995, Pickering \& Branigan 1998). Therefore priming should occur if children have acquired a syntactic representation for the passive. By varying the priming conditions and examining the effect this has on the children's responses, it is possible to make further inferences as to the nature of this representation. Therefore in addition to examining these issues in children's development of a syntactic structure, this thesis also provides further insight into syntactic priming effects.

Experiment 1 established children's use of passives before and after priming and also the methodology and method of analysis for the subsequent experiments. Experiments 2 and 3 examined priming from different classes of verb - agent-patient actional verbs and object-experiencer and subject-experiencer non-actional verbs. The results of these priming experiments were then compared to results obtained in Experiment $4-$ an experiment using a more traditional language acquisition research method, a picture-sentence matching task. Experiment 5 examined priming from short 
passives and 6 compared priming from get- and be-passives. Finally, Experiment 7 examined priming of passives with older children for evidence of a developmental path. In this chapter I present an overview of the experiments and consider some potential issues arising from them. I then summarise and discuss the implications of the findings from these experiments and directions for further research.

\subsection{Overview of the Experiments}

Experiment 1 provided a baseline measure of participants' descriptions of pictures depicting transitive events. I examined three- and four-year-old children's and adults' use of passives to describe such pictures when they did not hear any primes and when they described similar pictures following active and passive primes. This experiment found that the children never used passive structures to describe the transitive event pictures when not primed by a preceding passive; passives were almost never (one passive by one adult) used by the adults. Though passives are rare in spontaneous speech, this does not necessarily indicate that the structure has not been acquired; previous studies have shown priming effects for passives with children aged between three and five (Huttenlocher et al. 2004, Savage et al. 2006, Shimpi et al. 2007, Bencini \& Valian 2008). Experiment 1 tested children's and adults' descriptions of similar pictures after they heard active and passive primes and found significant priming effects of actives and passives in the same children (and adults) who did not use passive structures spontaneously, even when, unlike previous priming studies with children, priming was a within-participants manipulation. This experiment also provides evidence that Branigan et al. (2005)'s adaptation of the confederate-scripting priming technique, which has previously only been used with noun phrase structures, also works with more complex sentences, such as the transitive sentences tested here. Thus this experiment provides evidence that priming is effective when children hear both alternative structures and are not required to repeat the prime before describing their target. Finally, Experiment 1 also established a method of scoring and analysis which takes into account the children's Other responses which appear to be related to the primes, whilst also establishing priming effects when children's responses are scored as strictly as in adult experiments.

Experiments 2 and 3 examined whether priming showed any evidence of semantic constraints on children's acquisition of the passive. Previous studies suggest that children do not show reliable comprehension of passives containing subject-experiencer non-actional verbs even at five years, an age at which they do understand agentpatient verb passives (Maratsos et al. 1985, Sudhalter \& Braine 1985, Gordon \& Chafetz 
1990, Fox \& Grodzinsky 1998, Hirsch \& Wexler 2006b). Experiments 2 and 3 tested three- and four-year-old children's comprehension of passives with different verb types through examining which types of passives primed actional passive targets; this also extends previous priming studies, which have only tested agent-patient actional verb primes and targets. Experiments 2 and 3 showed that agent-patient actional verb and object-experiencer and subject-experiencer non-actional verb passives all primed actional verb passive targets. Given the difference between these results and the results of previous research, Experiment 4 tested some of the same children's understanding of these types of passive in a non-priming task. Using a similar task to previous studies, this experiment replicated previous results. Specifically, a picturesentence matching task found that children understood subject-experiencer passives and actives less well than actives and passives with other verbs; that is they correctly matched significantly fewer of these sentences to their target picture.

The next set of experiments examined whether the priming was related to repetition of other lexical items. A number of studies have shown that children tend to produce more short passives and understand these better than full passives (Hayhurst 1967, Slobin 1968, Baldie 1976, Harris 1976, Harris \& Flora 1982, Marchman et al. 1991, Fox \& Grodzinsky 1998) and also that they tend to produce get-passives more frequently than be-passives (Turner \& Rommetveit 1967a,b, Menyuk 1969, Harris \& Flora 1982, Marchman et al. 1991, Crain \& Fodor 1993, Slobin 1994). In Experiments 1 to 3, however the passives that the children produced tended to have the same form as the prime: full, be-passives. If children acquire this form later than other structural variants then it is possible that the priming effect observed in the previous experiments is related to repetition of function words such as the passive auxiliary or the preposition by in the post-verbal noun phrase - or to lexical schemas based on these items - rather than abstract syntactic representations. Experiment 5 tested the priming effect of short passive primes, which described pictures without an agent, on participants' description of target pictures, that had an agent and a patient. This experiment showed that after hearing short passive primes, children (and adults) produced more passives than after they heard active primes; this effect was significant when only the participants' full passive responses were analysed. Experiment 6 examined the priming effect of get-passives and be-passives: both primed passive responses, however they elicited targets differently. The children were only primed to produce be-passive targets following be-passive primes, whereas they were primed to produce get-passive targets following both be- and get-passive primes. The adults showed a reversed pattern of the results to the children: they were only primed to produce get-passives following get-passive primes but they were primed to produce be-passives following both be and get-passive primes. 
Experiment 7 examined older children's processing of passives. Though the previous experiments suggest that English speakers have formed a syntactic representation for the passive by four, at this age they still display some difficulty with this construction: even following priming they do not always produce complete passives or they produce erroneous passive forms such as reversed passives. The final experiment reported here compared six- and nine-year-old children's production of passives following priming. Not surprisingly this experiment did not show a difference in the priming effect in the two groups: the preceding experiments with younger children and adults did not show this difference either. Whilst both groups showed a tendency to produce more passives following passive primes than following active primes, regardless of the verb type of the prime, there were other differences between the groups. The six-year-olds produced more Other responses than the nine-year-olds and they produced different types of Other responses: nine-year-olds' Other responses tended to consist of non-transitive descriptions but six-year-olds' Other responses included more reversed passives and incomplete utterances.

\subsection{Considerations for Future Research}

Before I discuss the implications of the findings of these experiments I will consider some potential issues arising from these experiments. First, recall that in the first experiment it was observed that there was a carry-over effect (referred to in section 4.3.7 as 'bleeding') of the priming effect: children sometimes produced passives following active primes. This carry-over effect may have implications not previously discussed for some of the findings. For example, for the results of Experiment 6 with get-passive and be-passive primes, was children's production of, for example, get-passives after be-passive primes related to a carry-over from a previous get-passive target response? If this were the case it could be argued that the results reflect a more lexically-based priming effect: children generally repeated the auxiliary of the passive (producing more get-passives following get-passive primes and more be-passives following bepassive primes) but sometimes there was a carry over effect such that a passive response was produced following the alternative passive prime - get-passives were produced following be-passives as the result of previous get-passive targets.

However, if it were the case that get-passives were produced as the result of 'bleeding' of the priming effect, one might expect to see get-passives carrying-over into active prime trials also, as in Experiment 1, however the children produced significantly more get-passives following be-passive primes than following active primes suggesting some relation between the be-passive primes and the get-passive targets. An ex- 
planation would also be required as to why the be-passive targets were not susceptible to this carry-over effect and also whether the adults' pattern of results (a tendency to produce more be-passives) also reflected a carry-over effect. However, in order to rule out the possibility of a carry-over effect confounding these results, one possible solution would be to run the experiment as a between-subjects design, with half the participants experiencing only passive primes with get and half experiencing only passive primes with $b e$, although, as discussed previously the between-subject design with children participants leaves the data open to other criticisms, such as the possibility that the results are confounded by individual differences in the children's language. Alternatively, future research could examine whether the occurrence of target responses relates to the order of the prime trials within each experiment session, that is, in this case whether get-passives follow be-passive primes only after a get-passive was recently produced. Future work could perhaps employ a more controlled ordering of experiment items than the completely random ordering used here in order to examine whether children still produce get-passives following be-passive primes when they have not recently experienced a get-passive.

Also for further consideration is the magnitude of priming and how this relates to the level of language development. Some attempt was made in the experiments reported here to examine whether the participants' stage of language development was related to their performance in the experiment: recall that Experiment 3 collected a measure of the children's receptive vocabulary to compare to the number of passives they produced and other experiments examined whether the priming effect or number of passives a participant produced correlated to their age; recall that the number of passives produced rather than individual priming effect was generally examined due to potential confounds of negative priming effects associated with using the individual priming effect. Nonetheless, the fact that the size of children's vocabulary showed a correlation with the number of passives they produced in Experiment 3 (children with larger vocabularies produced more passives) suggests that further research in this area would be of interest. Furthermore, given the large variability in individual priming effects, it would be both interesting and informative to investigate potential reasons for this variability, particularly when using this method to assess language development. Future research should consider collecting additional data on each participant's stage of language development in order to examine whether a larger sample can show a reliable relation between a measure of language development and any observed priming effect, although both the issues with negative priming effects and the fact that such variation in the magnitude of priming occurs with adult participants also and therefore may not be wholly related to stages of language acquisition should be kept in mind. See also sections 8.3.1 and 8.3.2 for discussion of this issue as ad- 
dressed in this thesis.

Other issues that future work should consider relate to controls on the experiment method itself. For example, the data was only coded and scored by the experimenter. Though extensive scoring guidelines were set, the reliability of the coding of the data would be further supported by the use of a measure of coder reliability such as independent scoring of the data by a second coder and providing an inter-coder reliability measure such as the Cohen's Kappa statistic (Cohen 1960) to confirm that the data was consistently scored. This would rule out any possibility of bias in the scoring and increase our confidence in the results.

For further consideration is how the depiction of the items themselves may have influenced the data. Recall that half of the target items depicted the patient on the righthand side of the picture and half of the pictures depicted the patient on the left-hand side of the picture. Therefore for half of the target items the picture showed the characters in the left-to-right order which aligns with the order of arguments as they occur in active sentences (i.e. agent left/first, patient right/second) and half showed the characters in the left-to-right order which aligns with the order of arguments in passive sentences (i.e. patient left/first, agent right/second). The items were thus counterbalanced to allow for the influence of the pictures on the participants' choice of sentence structure. It is possible however that the ordering of arguments in the pictures did influence the likelihood of a participant producing a passive sentence: it has been suggested that speakers of a language with a left-to-right writing system tend to scan pictures from left to right (Dobel et al. 2007) and though most of the children tested would have been pre-reading age they would have plenty of experience in the nursery at least of looking at books and following books being read from left to right. It is possible then that from a quite early age children adopt a left-to-right scanning of pictures and that this could interact with the prime: after hearing a passive prime a participant is more likely to produce a passive target response, this likelihood may increase if the first entity they see is the patient which occurs at the beginning of the passive sentence. Where tested in these experiments, there is some suggestion that this may have occurred: in Experiment 2 both children and adults produced numerically more passives when the patient was on the left than when it was on the right though the difference was not significant. In Experiment 7, both six- and nine-year-old children also produced numerically more passives when the patient was on the left than when it was on the right and the difference for the six-year-olds was significant. It may be that this difference was not reliable for all groups because the pictures were not designed to specifically control for this factor: some pictures showed a clearer left to right arrangement, e.g. chasing, kicking but others did not, e.g. hugging, carrying, 
alternatively it may be that the priming effect was the overriding factor for the likelihood of a passive being produced. Future work could look for reliable evidence for whether children of three and four do scan pictures in a left-to-right order and whether this behaviour interacts with a priming manipulation.

\subsection{Implications of these Findings and Directions for Further Research}

First I will discuss the implications of the main findings of the experiments; subsequently, I discuss some other areas of interest which have emerged from these experiments. Taken together, it is possible to draw a number of conclusions from the results of the experiments reported here. The fact that children produced more passives after hearing passive primes than after hearing active primes suggests that by four, they have acquired a syntactic representation for the passive which is common to comprehension and production processes. This priming occurred in the absence of repeated verbs or nouns suggesting that by this age children's passive representation is abstracted over specific lexical items. Priming also occurred as a within-participants manipulation: children were exposed to both passives and actives. The fact that the priming effects reported here were similar to previous studies testing priming as a between-participants factor confirms that children of this age can produce passives following a single exemplar, not just as the result of cumulative exposure to the structure, and that they can alternate their use of transitive structures in line with alternations in the prime structure.

This suggests that English-speaking children acquire an abstract, syntactic representation for the passive at a rather young age, which is perhaps surprising given the paucity of passives children hear in everyday speech. Syntactic priming allows us to tap into younger children's syntactic representations by facilitating children's production of a rare, structurally complex and pragmatically-constrained structure. Thus it is possible to show evidence for acquisition at a younger age to other studies; these experiments provide evidence suggesting the passive is not acquired as late as previously suggested. These experiments do not provide further evidence about children's earlier development of this structure, in terms of whether it is formed from item-specific schemas based on the input or from the setting of innate grammatical principles, but they do support previous experiments which suggest that by four, children have acquired an abstract, syntactic representation for the passive with which they can comprehend the passive primes and which they can use to produce passive 
descriptions.

The evidence from Experiments 2 and 3 suggests that by four, children's syntactic representation for the passives is not restricted to certain semantic classes of verbs, such as actional verbs which involve agent and patient thematic roles; passives involving agent-patient thematic roles and theme-experiencer roles (object-experiencer and subject-experiencer non-actional verbs) primed agent-patient actional verb passive responses. I interpret these results as suggesting that, contra the evidence of previous research (Maratsos et al. 1985, Sudhalter \& Braine 1985, Fox \& Grodzinsky 1998, Hirsch \& Wexler 2006b), participants younger than five could reliably comprehend these primes involving different types of verbs and that this comprehension activated a syntactic representation which participants used to produce passives with actional verb targets. This suggests that both children and adults have a common passive representation which underlies transitive verbs with different thematic role configurations and that priming does not rely on the repetition of the same thematic roles. These results also suggest that at four, children do not have a semantically constrained representation for the passive as suggested by previous research (Maratsos et al. 1985). The follow up experiment, using a picture-sentence matching task as in previous studies, replicated the results of these previous studies: children performed better with actional passives than subject-experiencer non-actional passives. Unlike previous studies I found they also performed better with actional actives than subjectexperiencer non-actional actives and I also tested adults who also performed poorly with non-actional verb sentences in this alternative task. This suggests that the findings from previous studies could be related to the experimental method: I found the same effects as previous studies when using the same task as some of these studies use but not in the priming experiments. I propose an alternative explanation for the results of previous studies, which is that they are an artefact of the experimental method: children's general difficulty processing passive sentences is confounded in this task because the task requires them to distinguish minimally different pairs of pictures and this is more difficult for subject-experiencer verbs. The priming results suggest that the priming method does not pose the same difficulties as other methods but rather provides a more direct measure of children's syntactic representations which is less contingent on other cognitive abilities.

Experiments 5 and 6 provide evidence that by four, children's (and adults') syntactic representation for the passive is common to full and short passive forms and underlies both get- and be-passives. Experiment 5 showed that short passives primed full passives responses, supporting previous research which suggests that full passives do not follow short passives in children's language development (Maratsos \& Abramovitch 
1975, Crain et al. 1987, Budwig 1990, 2001). Both groups produced passives with a different auxiliary to that of the prime passive which suggests that get- and be-passives share a common representation. There were however differences in the groups' responses to the primes: once exposed to both auxiliaries, children tended to produce more get-passives and these responses were primed by both passive primes (get and $b e$ ), whereas adults tended to produce more be-passives and these responses were also primed by both passive primes (get and be). These results are in line with previous findings showing that children tend to produce more get-passives than be-passives but that adults tend to produce be-passives (e.g. Marchman et al. 1991). Despite this apparent preference for get-passives, the evidence also suggest that by four, children do also comprehend be-passives and their production of get-passives following bepassives suggests that the observed priming effects are not reducible to the repetition of lexical items such as the auxiliary. Nonetheless there was a lexical boost from the auxiliary: participants tended to produce more be-passives after be-passives and more get-passives after get-passives compared to other primes; in addition, the priming effect of the short passives in Experiment 5 was numerically smaller than that of full passives in other experiments, which suggests that repetition of this preposition in the full passives may also provide a lexical boost to the syntactic priming effect. Nonetheless, the significant effect without repetition of the preposition and the priming effect between passives with different auxiliaries suggests that participants' repetition of these lexical items in other experiments with full, be-passive primes was not responsible for the observed priming effects. The fact that the adults showed the same type of effects as the children lends further support to the hypothesis that these are not developmental effects.

Finally, the study with older children did not show any difference in priming effects between six- and nine-year-old children, however there were differences in the two groups' Other responses in this experiment: younger children produced more Other responses and different types of Other responses, most notably reversed passives and incomplete utterances. These differences suggest that at six, children still have some difficulty producing passives, even following priming; for example, they still have difficulty with mapping the semantic roles onto the syntactic positions of the passive structure. By nine, the children's responses to the primes are more adult-like: they made fewer mistakes than the younger children and did not show any difficulty producing passives: their Other responses were more frequently otherwise correct but non-transitive utterances. Taken together, these results suggest a developmental path for the passive: though the previous experiments suggest that four-year-old children have already acquired a syntactic representation for the passive which is sufficient for syntactic priming to occur, at six, children still make errors similar to those of three- 
and four-year-old children; they have still not fully mastered the semantics of this construction. By nine, their production of the structure is more adult-like. These priming results therefore support previous studies showing a protracted acquisition or mastery of this construction (Turner \& Rommetveit 1967a, Baldie 1976, Marchman et al. 1991).

In sum, these experiments provide evidence that by four, children have a passive representation which is common to comprehension and production processes, which underlies different semantic classes of verbs with different thematic role configurations and which underlies structural variants of the passive. Though children have an abstract syntactic representation at this age and are susceptible to priming, they nonetheless show some difficulties producing passives, frequently producing incomplete passives or reversed passives. This suggests that the semantics of the passive that the patient thematic role is mapped onto the sentence subject and the agent to the sentence object - are not mastered at the same time as the structure, in terms of the constituent structure. It also suggests that even with priming, passives are difficult to produce. This appears to be resolved by nine but not before six years. One natural line of further research is to investigate whether children younger than three have a syntactic representation for passives. It less clear whether younger children would also be susceptible to priming of passive structures, given the difficulties that threeand four-year-olds have producing passives.

These results contribute therefore to both the language acquisition and priming literature. They extend the results of previous child priming studies (Huttenlocher et al. 2004, Shimpi et al. 2007, Bencini \& Valian 2008) by showing within-participants priming with young children. They also add to the general priming literature by showing priming between short and full passives and get- and be-passives and from passives with different thematic roles to the target verbs. They also support previous findings from other studies of children's language production (Turner \& Rommetveit 1967a, Baldie 1976, Crain et al. 1987, Marchman et al. 1991, Brooks \& Tomasello 1999, Shimpi et al. 2007, Bencini \& Valian 2008) and spontaneous speech research (Budwig 1990, 2001, Slobin 1994) which suggest that children have acquired at least the syntactic form of the passive by around three to four years of age.

\subsubsection{Size of the Priming Effect}

Unlike previously reported child priming studies, I also collected priming data from adults for each of the experiments in this thesis using the same method with which I tested the children. This allows direct comparison of the priming effects between the 
two groups. Interestingly there was never a significant difference in the priming effect between the two groups (apart from when the children's non-standard responses were included in the scoring). Previous child priming studies tend to show numerically larger priming effects than are typically found in adult priming studies, however, given these results were found using different methods of testing it has not been possibly to carry out a direct comparison. Though there were sometimes numerical differences in the priming effects for each group in these experiments, these did not reach significance: these experiments do not show evidence that children are more susceptible to priming, in the strictest scorings, than adults. One possible explanation is that the lack of difference is due to the stricter scoring used for the children's responses here, compared to other priming studies with children; however if this were the case one would expect the interaction of priming and age to emerge in the Lenient scoring analyses, which were more like the scoring used in previous child priming studies, but this did not always happen.

Alternatively, this absence of an age difference may be related to the experimental method: adult priming experiments typically have many more filler items between prime items whereas in these experiments the primes were only broken by active or passive 'snap' items (not traditional, unrelated, filler items). It may be the case that the adult priming effect was inflated by a cumulative priming effect across the experiment, though recall that there was no evidence that passive descriptions increased in number at the end of the experiments compared to at the beginning. Alternatively it may be that by testing prime as a within-participants factor and exposing children to both of the transitive structures, the priming effect was weakened in the child population compared to previous experiments which exposed children to either active or passive primes. These experiments might show larger priming effects because children who heard active primes were very unlikely to produce passives, whereas in the experiments reported here the priming effect sometimes 'bled' - participants sometimes continued to produce passives following active primes thus reducing the magnitude of the priming effect. Again, recall however that in Experiment 1, which, like previous studies, only manipulated prime structure, I reported that the priming effects found with the within-participants priming manipulation were numerically similar to between-participants priming experiments.

An alternative explanation is that this lack of difference may be related to the structure being tested. The passive is a more marked alternative than the active - they are not directly interchangeable, rather the use of the passive is usually conditioned by discourse conditions. It is also structurally more complex than the active form and it is rarely used in spoken English (Svartvik 1966). For these reasons, the priming effect 
of passives with children may be reduced compared to other structures which do not pose these difficulties. The experiments certainly showed that even with priming, children did not always produce correct, complete passive descriptions. On the other hand, adults may be more susceptible to priming because the priming experiment artificially raises this structure which is otherwise quite rare. Thus no differences are observed between the groups. This is one clear area for investigation to see whether the magnitude of the priming effect is related to participant age, experiment design or the structure itself.

\subsubsection{Individual Variation in the Priming Effect}

On the other hand, it may be misleading to expect to see a between-groups difference in the magnitude of priming when within the groups there is a wide range in the size of the priming effect for individuals. In the first experiment, for example, the priming effects for the children ranged from $-13 \%$ to $+56 \%$ with some children showing no priming effect of passives; this highlights one problem with examining the priming effect, which is that though some participants actually produce the target description, they showed a negative priming effect caused by their producing more passives following active primes than following passive primes. There was a relationship between age and priming in the first experiment, though this may be unreliable given there were only eight participants; in addition an even larger variation occurred with adults $(-22 \%$ to $+83 \%)$ which cannot be explained by age-related differences in language development. Another direction for further research may be to examine why there is variation in priming effects. Other factors, not necessarily developmental, may account for the differences, such as attention to a task or willingness to interact with the experimenter. Children who comply with the experimenter may be more susceptible to priming, whereas children who are paying less attention to what the experimenter says and more attention to the game, may be less susceptible to priming.

\subsubsection{Other Responses}

Another area of variation observed across these experiments is in the form of the Other responses that participants produce: firstly, the younger children produced more Other responses than older children or than adults and secondly, in most experiments there was an effect of priming condition on children's Other responses (they produced more following passive primes than following active primes) but not on adults' Other responses. This is related to the fact that adults rarely made errors producing pas- 
sives rather they occasionally used other structures to describe the pictures, whereas younger children tended to produce more non-standard passive responses, such as short passives, reversed passives, incomplete (reversed or not) passives, scored as Other in the strict scorings. These Other responses provide further insight into children's development of the passive structure. The priming data suggests that children have a syntactic representation from a relatively young age but their Other responses suggest that children have difficulty producing passives despite this underlying representation. They do not always complete the passive descriptions and they often make errors mapping the thematic roles to the argument positions. Further research might investigate why passives are particularly difficult: one possible explanation is that the fronting of the verb's patient role is so rare in English that children are late to develop this facet of the language (see below for further discussion).

The fact that some of the children's Other responses were related to the passive primes has implications for the way these experiments are analysed; clearly priming sometimes occurs, in the sense that the children appear to correctly process the prime sentence and re-select the structure for their subsequent description, but their target response is not the standard form that is measured in typical adult experiments. In this way, some of the Other responses appear to be related to the prime though they are not correct or complete target utterances. Analyses that exclude all Other responses may miss this relationship; in experiments which tested other factors the inclusion of non-standard passive responses might have revealed the predicted effects. On the other hand, analyses which include all Other responses may weaken the priming effect by including responses unrelated to the primes in the calculation of the priming effect. In this thesis I resolve this by excluding the Other responses from the analyses but by carrying out the analyses with increasingly more lenient scorings of the data. Thus the Other responses that were related to the prime were separated from Other responses which did not show any syntactic relation to the prime. This way it is possible to check that the results of the Strict scoring analyses did not mask potential effects in the data by also carrying out analyses which include children's (primed) non-standard responses. Though I did not find that this occurred in the present experiments, this method of analysis does provide a further check on the results.

\subsubsection{Reversible Verbs}

A common error in young children's production of passives is to produce the correct constituent structure but with the wrong role assigned to each argument position, i.e. to produce a reversed passive. The experiments with get and be passives and short pas- 
sives exclude the possibility that these occur because children do not have a syntactic representation for the passive and that they produce a passive based on repeating the function words that they hear in the prime. In addition, evidence of priming from the different types of verbs suggest that children's early syntactic representation for the passive underlies verbs with different thematic roles and that they can understand sentences with different thematic role arrangements.

A possible explanation for these reversed passives is that I used reversible verbs in all the primes and all the targets: both the agent and patient could plausibly swap roles of the verb, e.g. chase, hit. A number of studies have shown that reversible verb passives are more difficult for children than non-reversible passives, with verbs such as eat, drink or break. Further research could examine children's production of passives with non-reversible target verbs: these provide an additional semantic clue as to which entity takes which role; which entity is plausibly the agent or patient. An interesting line of research would be to test whether, with these types of verbs, the children would produce fewer reversed passives in their production of passives.

\subsubsection{Psycholinguistic Investigations of Language Acquisition}

The experiments in this thesis suggest that psycholinguistics methods can be applied to language acquisition research with interesting results; Chapter 5, for example, shows the benefit of using more than one method to test children's language development. The priming experiments reported here suggest that priming is a useful tool for studying language development; this method allows us to examine children's syntactic representations without requiring the child to perform any meta-linguistic tasks or physical tasks such as acting out sentences which they may find more difficult to complete. A further advantage is that children's production of difficult or rare structures is facilitated by the prime: their level of production of passives is raised compared to spontaneous speech but one would not expect this to occur if children have not acquired the structure. By facilitating their production of these structures, it is possible to try to demonstrate earlier acquisition than suggested by spontaneous speech data. Similar studies have also investigated priming children's comprehension of structures: Thothathiri and Snedeker (2008) showed successful priming of young children's comprehension of dative structures; further research might use this method to examine younger children's comprehension of passives, given even at three and four, children had difficulty with their production of complex structures such as passives. 


\subsection{Conclusion}

Children's acquisition of the passive has attracted a lot of interest in language acquisition research, the results of which have suggested both semantic effects and structural variations in children's early comprehension and production of passive structures. The aim of this thesis has been to examine children's early representation of the passive using a psycholinguistic experimental method, syntactic priming. The results of these experiments therefore add to the syntactic priming literature as well as the language acquisition literature. These results provide evidence that children acquire a broadly abstract representation for the passive structure which underlies different structural forms and different classes of transitive verbs and therefore enables children to comprehend and produce passives from a relatively young age. As such this thesis also provides an example of how the fields of language acquisition research and psycholinguistics may be of mutual benefit to each other. 


\title{
Appendix A
}

\section{Experiment One Materials}

\author{
A.1 Pre-Test Items \\ 1. lion shaking soldier \\ 2. pig washing girl \\ 3. cat scratching fireman \\ 4. tiger licking clown \\ 5. sheep pushing king \\ 6. frog pinching robber \\ 7. elephant hugging doctor \\ 8. bear tickling nurse \\ 9. rabbit kicking fairy \\ 10. dog chasing queen \\ 11. horse kissing witch \\ 12. cow punching boy
}

\section{A.2 Experiment One: Active and Passive Primes}

P1. a bear is patting a girl/a girl is being patted by a bear

P2. a rabbit is biting a doctor/a doctor is being bitten by a rabbit

P3. a horse is pulling a fairy/a fairy is being pulled by a horse

P4. a lion is hitting a fireman/a fireman is being hit by a lion

P5. a cow is carrying a queen/a queen is being carried by a cow

P6. a pig is squashing a boy/a boy is being squashed by a pig

P7. a cat is patting a witch/a witch is being patted by a cat

P8. a dog is biting a robber/a robber is being bitten by a dog

P9. a tiger is pulling a soldier/a soldier is being pulled by a tiger 
P10. a frog is hitting a king/a king is being hit by a frog

P11. an elephant is carrying a clown/a clown is being carried by an elephant

P12. a sheep is squashing a nurse/a nurse is being squashed by a sheep

P13. a dog is patting a king/a king is being patted by a dog

P14. a horse is biting a fireman/a fireman is being bitten by a horse

P15. a bear is pulling a witch/a witch is being pulled by a bear

P16. a cat is hitting a clown/a clown is being hit by a cat

P17. a frog is carrying a boy/a boy is being carried by a frog

P18. an elephant is squashing a queen/a queen is being squashed by an elephant

P19. a rabbit is patting a soldier/a soldier is being patted by a rabbit

P20. a tiger is biting a nurse/a nurse is being bitten by a tiger

P21. a lion is pulling a doctor/a doctor is being pulled by a lion

P22. a sheep is hitting a girl/a girl is being hit by a sheep

P23. a pig is carrying a robber/a robber is being carried by a pig

P24. a cow is squashing a fairy/a fairy is being squashed by a cow

\section{A.3 Targets Items}

T1. tiger shaking doctor

T2. elephant washing robber

T3. lion scratching nurse

T4. cow licking king

T5. pig pushing witch

T6. bear pinching soldier

T7. rabbit hugging girl

T8. frog tickling fairy

T9. horse kicking clown

T10. cat chasing boy

T11. sheep kissing queen

T12. dog punching fireman

T13. elephant shaking witch

T14. bear washing clown

T15. tiger scratching king

T16. pig licking fairy

T17. dog pushing girl

T18. cat pinching nurse

T19. sheep hugging boy

T20. rabbit tickling queen

T21. cow kicking fireman

T22. horse chasing soldier

T23. frog kissing doctor

T24. lion punching robber 


\section{A.4 Filler Items}

F1. a bear is picking-up a king

F2. a rabbit is feeding a witch

F3. a cat is poking a queen

F4. a dog is dropping a fairy

F5. a girl is being picked-up by an elephant

F6. a boy is being fed by a lion

F7. a clown is being poked by a frog

F8. a robber is being dropped by a tiger

\section{A.5 Practice Items}

E1. a penguin is tripping a pirate

P1. mouse tripping pirate

E2. a donkey is waking a builder

P2. donkey waking policeman

E3. a gnome is being followed by a monkey

P3. monkey catching gnome

E4. a ballerina is being stung by a bee

$\mathrm{P} 4$. bee stinging ballerina 


\section{Appendix B}

\section{Experiments Two, Three and Four Materials}

\section{B.1 Experiment Two: Object-Experiencer Verb Primes}

1. a bear is frightening a girl/a girl is being frightened by a bear ${ }^{1}$

2. a rabbit is surprising a doctor/a doctor is being surprised by a rabbit

3. a horse is scaring a fairy / a fairy is being scared by a horse

4. a lion is shocking a fireman/a fireman is being shocked by a lion

5. a cow is annoying a queen/a queen is being annoyed by a cow

6. a pig is upsetting a boy/a boy is being upset by a pig

7. a cat is frightening a witch/a witch is being frightened by a cat

8. a dog is surprising a robber/a robber is being surprised by a dog

9. a tiger is scaring a soldier/a soldier is being scared by a tiger

10. a frog is shocking a king/a king is being shocked by a frog

11. an elephant is annoying a clown/a clown is being annoyed by an elephant

12. a sheep is upsetting a nurse/a nurse is being upset by a sheep

13. a dog is frightening a king/a king is being frightened by a dog

14. a horse is surprising a fireman/a fireman is being surprised by a horse

15. a bear is scaring a witch/a witch is being scared by a bear

16. a cat is shocking a clown/a clown is being shocked by a cat

17. a frog is annoying a boy/a boy is being annoyed by a frog

18. an elephant is upsetting a queen/a queen is being upset by an elephant

19. a rabbit is frightening a soldier/a soldier is being frightened by a rabbit

20. a tiger is surprising a nurse/a nurse is being surprised by a tiger

21. a lion is scaring a doctor/a doctor is being scared by a lion

22. a sheep is shocking a girl/a girl is being shocked by a sheep

23. a pig is annoying a robber/a robber is being annoyed by a pig

24. a cow is upsetting a fairy/a fairy is being upset by a cow

\footnotetext{
${ }^{1}$ Also used in Experiment 5 and Experiment 7.
} 


\section{B.2 Experiment Three: Subject-Experiencer Verb Primes}

1. a bear is ignoring a girl/a girl is being ignored by a bear

2. a rabbit is remembering a doctor/a doctor is being remembered by a rabbit

3. a horse is seeing a fairy/a fairy is being seen by a horse

4. a lion is loving a fireman/a fireman is being loved by a lion

5. a cow is hearing a queen/a queen is being heard by a cow

6. a pig is liking a boy/a boy is being liked by a pig

7. a cat is ignoring a witch/a witch is being ignored by a cat

8. a dog is remembering a robber/a robber is being remembered by a dog

9. a tiger is seeing a soldier/a soldier is being seen by a tiger

10. a frog is loving a king/a king is being loved by a frog

11. an elephant is hearing a clown/a clown is being heard by an elephant

12. a sheep is liking a nurse/a nurse is being liked by a sheep

13. a dog is ignoring a king/a king is being ignored by a dog

14. a horse is remembering a fireman/a fireman is being remembered by a horse

15. a bear is seeing a witch/a witch is being seen by a bear

16. a cat is loving a clown/a clown is being loved by a cat

17. a frog is hearing a boy/a boy is being heard by a frog

18. an elephant is liking a queen/a queen is being liked by an elephant

19. a rabbit is ignoring a soldier/a soldier is being ignored by a rabbit

20. a tiger is remembering a nurse/a nurse is being remembered by a tiger

21. a lion is seeing a doctor/a doctor is being seen by a lion

22. a sheep is loving a girl/a girl is being loved by a sheep

23. a pig is hearing a robber/a robber is being heard by a pig

24. a cow is liking a fairy/a fairy is being liked by a cow

\section{B.3 Experiment Four: Picture-Sentence Matching Practice Items}

P1. a bear is picking up a king

F1. an elephant picking up a girl

P2. a dog is dropping a fairy

F2. a tiger dropping a robber

P3. a witch is being fed by a rabbit

F3. a lion feeding a boy

$\mathrm{P} 4$. a queen is being poked by a cat

F4. a frog poking a clown

P5. a policeman is being woken by a horse

F5. a horse waking a builder 
P6. a mouse is tripping up a pirate

F6. a penguin tripping up a pirate

P7. a monkey is catching a gnome

F7. a monkey following a gnome

\section{B.4 Experiment Four: Picture-Sentence Matching Target Items}

For each target item there is a corresponding foil item showing the same action and characters but with the characters' roles reversed, as in Figure 5.10.

1. a bear is ignoring/frightening/patting a soldier a soldier is being ignored/frightened/patted by a bear

2. a cat is ignoring/frightening/patting a girl

a girl is being ignored/frightened/patted by a cat

3. a dog is ignoring/frightening/patting a witch

a witch is being ignored/frightened/patted by a dog

4. a rabbit is ignoring/frightening/patting a king

a king is being ignored/frightened/patted by a rabbit

5. a giraffe is ignoring/frightening/patting a postman

a postman is being ignored/frightened/patted by a giraffe

6. a goat is ignoring/frightening/patting a policeman

a policeman is being ignored/frightened/patted by a goat

7. a penguin is remembering/surprising/biting a postman

a postman is being remembered/surprised/bitten by a penguin

8. a monkey is remembering/surprising/biting a gnome

a gnome is being remembered/surprised/bitten by a monkey

9. a rabbit is remembering/surprising/biting a fireman

a fireman is being remembered/surprised/bitten by a rabbit

10. a dog is remembering/surprising/biting a nurse

a nurse is being remembered/surprised/bitten by a dog

11. a horse is remembering/surprising/biting a doctor

a doctor is being remembered/surprised/bitten by a horse

12. a tiger is remembering/surprising/biting a robber

a robber is being remembered/surprised/bitten by a tiger

13. a horse is seeing/scaring/pulling a soldier

a soldier is being seen/scared/pulled by a horse

14. a tiger is seeing/scaring/pulling a fairy

a fairy is being seen/scared/pulled by a tiger

15. a bear is seeing/scaring/pulling a doctor

a doctor is being seen/scared/pulled by a bear

16. a lion is seeing/scaring/pulling a witch

a witch is being seen/scared/pulled by a lion

17. a mouse is seeing/scaring/pulling a policeman

a policeman is being seen/scared/pulled by a mouse 
18. a giraffe is seeing/scaring/pulling a ballerina a ballerina is being seen/scared/pulled by a giraffe 19. a lion is loving/shocking/hitting a girl a girl is being loved/shocked/hit by a lion 20. a penguin is loving/shocking/hitting a pirate a pirate is being loved/shocked/hit by a penguin 21. a monkey is loving/shocking/hitting a builder a builder is being loved/shocked/hit by a monkey 22. a frog is loving/shocking/hitting a fireman a fireman is being loved/shocked/hit by a frog 23. a cat is loving/shocking/hitting a king a king is being loved/shocked/hit by a cat 24. a sheep is loving/shocking/hitting a clown a clown is being loved/shocked/hit by a sheep 25. a cow is hearing/annoying/carrying a robber a robber is being heard/annoyed/carried by a cow 26. an elephant is hearing/annoying/carrying a boy a boy is being heard/annoyed/carried by an elephant 27. a frog is hearing/annoying/carrying a clown a clown is being heard/annoyed/carried by a frog 28. a pig is hearing/annoying/carrying a queen a queen is being heard/annoyed/carried by a pig 29. a fox is hearing/annoying/carrying a builder a builder is being heard/annoyed/carried by a fox 30. a mouse is hearing/annoying/carrying a pirate a pirate is being heard/annoyed/carried by a mouse 31. a pig is hating/upsetting/squashing a nurse a nurse is being hated/upset/squashed by a pig 32. a goat is hating/upsetting/squashing a ballerina a ballerina is being hated/upset/squashed by a goat 33. a fox is hating/upsetting/squashing a gnome a gnome is being hated/upset/squashed by a fox 34. a sheep is hating/upsetting/squashing a boy a boy is being hated/upset/squashed by a sheep 35. an elephant is hating/upsetting/squashing a fairy a fairy is being hated/upset/squashed by an elephant 36. a cow is hating/upsetting/squashing a queen a queen is being hated/upset/squashed by a cow 


\section{Appendix C}

\section{Experiments Five and Six Materials}

\section{C.1 Experiment Five: Active and Short Passive Primes}

P1. the bear is frightening the girl/the girls are being frightened P2. the rabbit is surprising the doctor/the doctors are being surprised P3. the horse is scaring the fairy/the fairies are being scared $\mathrm{P} 4$. the lion is shocking the fireman/the firemen are being shocked P5. the cow is annoying the queen/the queens are being annoyed P6. the pig is upsetting the boy/the boys are being upset

P7. the cat is frightening the witch/the witches are being frightened

P8. the dog is surprising the robber/the robbers are being surprised P9. the tiger is scaring the soldier/the soldiers are being scared P10. the frog is shocking the king/the kings are being shocked P11. the elephant is annoying the clown/the clowns are being annoyed P12. the sheep is upsetting the nurse/the nurses are being upset

P13. the dog is frightening the king/the kings are being frightened

P14. the horse is surprising the fireman/the firemen are being surprised

P15. the bear is scaring the witch/the witches are being scared

P16. the cat is shocking the clown/the clowns are being shocked

P17. the frog is annoying the boy/the boys are being annoyed

P18. the elephant is upsetting the queen/the queens are being upset

$\mathrm{P} 19$. the rabbit is frightening the soldier/the soldiers are being frightened P20. the tiger is surprising the nurse/the nurses are being surprised P21. the lion is scaring the doctor/the doctors are being scared P22. the sheep is shocking the girl/the girls are being shocked P23. the pig is annoying the robber/the robbers are being annoyed $\mathrm{P} 24$. the cow is upsetting the fairy/the fairies are being upset 


\section{C.2 Experiment Six: Active, Get- and Be-Passive Primes}

P1. a bear is patting a girl/a girl is getting/being patted by a bear.

P2. a rabbit is biting a doctor/a doctor is getting/being bitten by a rabbit.

P3. a horse is pulling a fairy/a fairy is getting/being pulled by a horse.

P4. a lion is hitting a fireman/a fireman is getting/being hit by a lion.

P5. a cow is carrying a queen/a queen is getting/being carried by a cow.

P6. a pig is squashing a boy/a boy is getting/being squashed by a pig.

P7. a cat is patting a witch/a witch is getting/being patted by a cat.

P8. a dog is biting a robber/a robber is getting/being bitten by a dog.

$\mathrm{P} 9$. a tiger is pulling a soldier/a soldier is getting/being pulled by a tiger.

P10. a frog is hitting a king/a king is getting/being hit by a frog.

P11. an elephant is carrying a clown/a clown is getting/being carried by an elephant.

P12. a sheep is squashing a nurse/a nurse is getting/being squashed by a sheep.

P13. a dog is patting a king/a king is getting/being patted by a dog.

P14. a horse is biting a fireman/a fireman is getting/being bitten by a horse.

P15. a bear is pulling a witch/a witch is getting/being pulled by a bear.

P16. a cat is hitting a clown/a clown is getting/being hit by a cat.

P17. a frog is carrying a boy/a boy is getting/being carried by a frog.

P18. an elephant is squashing a queen/a queen is getting/being squashed by an elephant.

\section{C.3 Experiment Six: Active, Get- and Be-Passive Fillers}

F1. a bear is picking-up a king

F2. a cat is poking a queen

F3. a witch is being fed by a rabbit

F4. a girl is being picked-up by an elephant

F5. a clown is getting poked by a frog

F6. a boy is getting fed by a lion 


\section{Appendix D}

\section{Experiments Five and Six Analyses}

\section{D.1 Experiment Five: Inclusive Scoring Analyses}

\section{Passive Responses}

The results of the Inclusive scoring are reported in Table D.1. We repeated the analyses from the previous scorings, these results are reported in Table D.2. These showed a significant main effect of Prime: participants produced significantly more passive descriptions following passive primes than following active primes. The effect of Group was significant which reflects the fact that the children produced both short and reversed passives, scored as Passive in the Inclusive scoring, but the adults did not, thus in this scoring the children produced significantly more passives than the adults. There was no interaction between Prime and Group showing that the priming effect was not stronger for the children than the adults. There was a simple main effect of Prime for both children and adults; both groups produced significantly more passives following passive primes than following active primes.

Table D.1: Experiment 5: Mean proportions of Passives in the Inclusive scoring

\begin{tabular}{lcccc}
\hline \multirow{2}{*}{ Prime } & \multicolumn{2}{c}{ Children } & \multicolumn{2}{c}{ Adults } \\
\cline { 2 - 5 } & $\mathbf{M}$ & (SD) & $\mathbf{M}$ & (SD) \\
\hline \hline Active & 0.10 & $(0.15)$ & 0.03 & $(0.05)$ \\
Short Passive & 0.28 & $(0.28)$ & 0.13 & $(0.15)$ \\
\hline
\end{tabular}

Table D.2: Experiment 5: ANOVA of proportions of Passives in the Inclusive scoring

\begin{tabular}{lrrlcrrrc}
\hline & \multicolumn{4}{c}{ F1 Results } & \multicolumn{4}{c}{ F2 Results } \\
\cline { 2 - 9 } Effect & $\boldsymbol{d f}$ & $\boldsymbol{F 1}$ & $\boldsymbol{p}$ & partial $\eta^{2}$ & $\boldsymbol{d f}$ & $\boldsymbol{F 2}$ & $\boldsymbol{p}$ & partial $\eta^{2}$ \\
\hline \hline Prime & 1,30 & 15.03 & $<.01$ & 0.33 & 1,46 & 38.75 & $<.001$ & 0.46 \\
Group & 1,30 & 4.95 & $<.05$ & 0.14 & 1,46 & 18.04 & $<.001$ & 0.28 \\
Prime x Group & 1,30 & 1.27 & $=.27$ & 0.04 & 1,46 & 5.36 & $<.05$ & 0.10 \\
Prime (Children) & 1,30 & 12.51 & $<.01$ & 0.29 & 1,46 & 36.48 & $<.001$ & 0.44 \\
Prime (Adults) & 1,30 & 3.79 & $=.06$ & 0.11 & 1,46 & 7.64 & $<.01$ & 0.14 \\
\hline
\end{tabular}




\section{Other Responses}

The mean number of Other responses following the Inclusive scoring are shown in Table D.3. We repeated the analyses, reported in Table D.4; these showed the same effects as the previous scorings: there was a significant effect of Group but no effect of Prime or interaction between Group and Prime: the nursery children still had more responses scored as Other than the adults (see Table D.3).

Table D.3: Experiment 5: Mean numbers of Others in the Inclusive scoring

\begin{tabular}{lcccc}
\hline \multirow{2}{*}{ Prime } & \multicolumn{2}{c}{ Children } & \multicolumn{2}{c}{ Adults } \\
\cline { 2 - 5 } & $\mathbf{M}$ & (SD) & M & (SD) \\
\hline \hline Active & 2.25 & $(2.27)$ & 0.50 & $(0.63)$ \\
Short Passive & 2.12 & $(1.78)$ & 0.38 & $(0.62)$ \\
\hline
\end{tabular}

Table D.4: Experiment 5: ANOVA of numbers of Others in the Inclusive scoring

\begin{tabular}{lrrlrrrlr}
\hline & \multicolumn{4}{c}{ F1 Results } & \multicolumn{4}{c}{ F2 Results } \\
\cline { 2 - 9 } Effect & $d f$ & $\boldsymbol{F 1}$ & $\boldsymbol{p}$ & partial $\eta^{2}$ & $\boldsymbol{d f}$ & $\boldsymbol{F 2}$ & $\boldsymbol{p}$ & partial $\eta^{2}$ \\
\hline \hline Prime & 1,30 & 0.18 & n.s. & 0.01 & 1,46 & 0.37 & n.s. & 0.01 \\
Group & 1,30 & 15.35 & $<.001$ & 0.34 & 1,46 & 26.44 & $<.001$ & 0.36 \\
Prime x Group & 1,30 & 0.00 & n.s. & 0.00 & 1,46 & 0.00 & n.s. & 0.00 \\
Prime (Children) & 1,30 & 0.09 & n.s. & 0.00 & 1,46 & 0.18 & n.s. & 0.00 \\
Prime (Adults) & 1,30 & 0.09 & n.s. & 0.00 & 1,46 & 0.18 & n.s. & 0.00 \\
\hline
\end{tabular}

\section{Additional Analyses}

Following the Inclusive scoring, the mean number of passives that the children produced at the beginning and end of the experiment were the same $(\mathrm{M}=1.13)$ and the number of passives the adults produced did not change from the previous scorings, thus we did not run further comparisons. In the Inclusive scoring the number of passives (including non-standard passive utterances) still did not increase with age $(r=$ $.16, p=.27,1$-tailed). 


\section{D.2 Experiment Six: Lenient Scoring Analyses}

\section{Be-Passive Responses}

Table D.5 presents the mean proportions of be-passives following the Lenient scoring. We used the same statistical tests as in the Strict scoring to test the be-passives data following the Lenient scoring, the results of these ANOVAs are presented in Table D.6. There was a significant effect of Prime on the participants' be-passive responses though the effect of Group was significant by items only; although the adults produced numerically more be-passive responses than the children this did not reach significance. The analysis showed a simple effect of Prime for each level of Group: children and adults.

Table D.5: Experiment 6: Mean proportions of Be-Passives in the Lenient scoring

\begin{tabular}{lcccc}
\hline \multirow{2}{*}{ Prime } & \multicolumn{2}{c}{ Children } & \multicolumn{2}{c}{ Adults } \\
\cline { 2 - 5 } & $\mathbf{M}$ & (SD) & $\mathbf{M}$ & (SD) \\
\hline \hline Active & 0.05 & $(0.13)$ & 0.11 & $(0.19)$ \\
Get-Passive & 0.08 & $(0.15)$ & 0.22 & $(0.35)$ \\
Be-Passive & 0.28 & $(0.40)$ & 0.33 & $(0.34)$ \\
\hline
\end{tabular}

Table D.6: Experiment 6: ANOVA of proportions of Be-Passives in the Lenient scoring

\begin{tabular}{lcccccccc}
\hline & \multicolumn{4}{c}{ F1 Results } & \multicolumn{4}{c}{ F2 Results } \\
\cline { 2 - 9 } Effect & $d f$ & $\boldsymbol{F 1}$ & $\boldsymbol{p}$ & partial $\eta^{2}$ & $d f$ & $\boldsymbol{F 2}$ & $\boldsymbol{p}$ & partial $\eta^{2}$ \\
\hline \hline Prime & 2,68 & 11.11 & $<.001$ & 0.25 & $* 1.5,51.6$ & 20.24 & $<.001$ & 0.37 \\
Group & 1,34 & 1.14 & $=.29$ & 0.03 & 1,34 & 6.81 & $<.05$ & 0.17 \\
Prime x Group & 2,68 & 0.53 & $=.59$ & 0.01 & $* 1.5,51.6$ & 3.47 & $=.05$ & 0.09 \\
Prime (Children) & 2,33 & 4.82 & $<.05$ & 0.23 & 2,33 & 11.01 & $<.001$ & 0.40 \\
Prime (Adults) & 2,33 & 3.99 & $<.05$ & 0.19 & 2,33 & 6.69 & $<.01$ & 0.29 \\
\hline
\end{tabular}

Children's Be-Passives

Within-participants ANOVAs with planned contrasts examined the priming effect within the children's results, see Table D.7 for the results of these ANOVAs. There was a significant effect of Prime on the children's be-passive responses. Planned contrasts showed a significant difference between active primes and passive primes (combined) and also between get-passive and be-passive primes. Finally pairwise comparisons showed that the effect of get-passive primes on the proportion of be-passive targets was not significantly different to that of active primes ( $p s>.2)$.

Table D.7: Experiment 6: ANOVA and planned contrasts on children's Be-Passives

\begin{tabular}{lcccccccc}
\hline & \multicolumn{4}{c}{ F1 Results } & \multicolumn{5}{c}{ F2 Results } \\
\cline { 2 - 9 } Effect & $d f$ & $\boldsymbol{F 1}$ & $\boldsymbol{p}$ & $\boldsymbol{p} . \eta^{2}$ & $\boldsymbol{d f}$ & $\boldsymbol{F 2}$ & $\boldsymbol{p}$ & $\boldsymbol{p} \cdot \eta^{2}$ \\
\hline \hline Prime & $* 1.1,19.4$ & 7.43 & $<.05$ & 0.30 & $* 1.3,22.3$ & 18.39 & $<.001$ & 0.52 \\
Actives vs Passives & 1,17 & 7.22 & $<.05$ & 0.30 & 1,17 & 15.46 & $<.01$ & 0.48 \\
Get vs Be Passives & 1,17 & 7.55 & $<.05$ & 0.31 & 1,17 & 19.86 & $<.001$ & 0.54 \\
\hline
\end{tabular}

Adults' Be-Passives

The adults' scores did not change under the Lenient scoring therefore the results and analyses are the same as the Strict scoring. 


\section{Get-Passive Responses}

We then tested the proportions of get-passive responses following the Lenient scoring, see Table D. 8 for the means. Table D.9 shows the results of these analyses; there was a significant effect of Prime and a significant effect of Group though the interaction between Prime and Group was not significant. The analysis also showed a strong simple effect of Prime for both groups: children and adults.

Table D.8: Experiment 6: Mean proportions of Get-Passives in the Lenient scoring

\begin{tabular}{lcccc}
\hline \multirow{2}{*}{ Prime } & \multicolumn{2}{c}{ Children } & \multicolumn{2}{c}{ Adults } \\
\cline { 2 - 5 } & $\mathbf{M}$ & (SD) & M & (SD) \\
\hline \hline Active & 0.05 & $(0.10)$ & 0.02 & $(0.09)$ \\
Get-Passive & 0.37 & $(0.38)$ & 0.19 & $(0.21)$ \\
Be-Passive & 0.20 & $(0.28)$ & 0.01 & $(0.04)$ \\
\hline
\end{tabular}

Table D.9: Experiment 6: ANOVA of proportions of Get-Passives in the Lenient scoring

\begin{tabular}{lcrlrrrrr}
\hline & \multicolumn{4}{c}{ F1 Results } & \multicolumn{5}{c}{ F2 Results } \\
\cline { 2 - 9 } Effect & $\boldsymbol{d f}$ & $\boldsymbol{F 1}$ & $\boldsymbol{p}$ & partial $\eta^{2}$ & $\boldsymbol{d f}$ & $\boldsymbol{F 2}$ & $\boldsymbol{p}$ & partial $\eta^{2}$ \\
\hline \hline Prime & 2,68 & 15.75 & $<.001$ & 0.32 & 2,68 & 33.80 & $<.001$ & 0.50 \\
Group & 1,34 & 6.62 & $<.05$ & 0.16 & 1,34 & 12.73 & $<.01$ & 0.27 \\
Prime x Group & 2,68 & 2.01 & $=.14$ & 0.06 & 2,68 & 2.87 & $=.06$ & 0.08 \\
Prime (Children) & 2,33 & 10.13 & $<.001$ & 0.38 & 2,33 & 22.67 & $<.001$ & 0.58 \\
Prime (Adults) & 2,33 & 4.06 & $<.05$ & 0.20 & 2,33 & 7.75 & $<.01$ & 0.32 \\
\hline
\end{tabular}

\section{Children's Get-Passives}

We explored this effect of Prime using within-participants ANOVA with planned contrasts, the results of which are shown in Table D.10. These confirmed the significant effect of Prime on the children's get-passives. The planned contrasts showed that the effect of active primes and passive primes (combined) on the get-passive responses was significantly different, as was the effect of get-passive primes and be-passive primes. Pairwise comparisons showed that the effect of active primes and be-passive primes on get-passive responses approached significance $\left(p_{1}=.06, p_{2}=.08\right)$.

Table D.10: Experiment 6: ANOVA and planned contrasts on children's Get-Passives

\begin{tabular}{lcrrrrrrr}
\hline & \multicolumn{4}{c}{ F1 Results } & \multicolumn{4}{c}{ F2 Results } \\
\cline { 2 - 9 } Effect & $\boldsymbol{d f}$ & $\boldsymbol{F 1}$ & $\boldsymbol{p}$ & $\boldsymbol{p} \cdot \eta^{2}$ & $\boldsymbol{d f}$ & $\boldsymbol{F 2}$ & $\boldsymbol{p}$ & $\boldsymbol{p} \cdot \eta^{2}$ \\
\hline \hline Prime & 2,34 & 8.14 & $<.01$ & 0.32 & 2,34 & 20.61 & $<.001$ & 0.55 \\
Actives vs Passives & 1,17 & 10.69 & $<.01$ & 0.39 & 1,17 & 24.56 & $<.001$ & 0.59 \\
Get vs Be Passives & 1,17 & 5.14 & $<.05$ & 0.23 & 1,17 & 17.48 & $<.01$ & 0.51 \\
\hline
\end{tabular}

Adults' Get-Passives

Again, there were no changes to the adults' results following the Lenient scoring. 


\section{D.3 Experiment Six: Inclusive Scoring Analyses}

\section{Be-Passive Responses}

Table D.11 shows the mean proportions of be-passive responses following the Inclusive scoring. We repeated the statistical tests from previous scorings, see Table D.12 for the results. These showed a significant effect of Prime though the effect of Group was significant by items only. The analysis did show a simple effect of Prime for each level of Group: children and adults. We explored the effect of Prime within each group in within-participants analyses with planned contrasts.

Table D.11: Experiment 6: Mean proportions of Be-Passives in the Inclusive scoring

\begin{tabular}{lcccc}
\hline \multirow{2}{*}{ Prime } & \multicolumn{2}{c}{ Children } & \multicolumn{2}{c}{ Adults } \\
\cline { 2 - 5 } & $\mathbf{M}$ & (SD) & $\mathbf{M}$ & (SD) \\
\hline \hline Active & 0.08 & $(0.15)$ & 0.11 & $(0.19)$ \\
Get-Passive & 0.10 & $(0.17)$ & 0.23 & $(0.35)$ \\
Be-Passive & 0.33 & $(0.38)$ & 0.33 & $(0.34)$ \\
\hline
\end{tabular}

Table D.12: Experiment 6: ANOVA of proportions of Be-Passives in the Inclusive scoring

\begin{tabular}{lcccccccc}
\hline & \multicolumn{4}{c}{ F1 Results } & \multicolumn{3}{c}{ F2 Results } \\
\cline { 2 - 9 } Effect & $\boldsymbol{d} \boldsymbol{f}$ & $\boldsymbol{F 1}$ & $\boldsymbol{p}$ & partial $\eta^{2}$ & $\boldsymbol{d f}$ & $\boldsymbol{F} 2$ & $\boldsymbol{p}$ & ${\text { partial } \eta^{2}}$ \\
\hline \hline Prime & 2,68 & 12.95 & $<.001$ & 0.28 & $* 1.6,53.0$ & 18.05 & $<.001$ & 0.35 \\
Group & 1,34 & 0.52 & $=.48$ & 0.01 & 1,34 & 4.37 & $<.05$ & 0.11 \\
Prime x Group & 2,68 & 1.27 & $=.29$ & 0.04 & $* 1.6,53.0$ & 3.23 & $=.06$ & 0.09 \\
Prime (Children) & 2,33 & 6.31 & $<.01$ & 0.28 & 2,33 & 9.48 & $<.01$ & 0.36 \\
Prime (Adults) & 2,33 & 5.18 & $<.05$ & 0.24 & 2,33 & 7.45 & $<.01$ & 0.31 \\
\hline
\end{tabular}

Children's Be-Passives

Table D.13 shows the results of the analyses on the children's be-passive responses. There was a significant effect of Prime. Planned contrasts showed a significant difference between active primes and passive primes and also between get-passive and $b e$-passive primes. Finally pairwise comparisons showed that the effect of get-passive primes on the proportion of be-passive targets was not significantly different to that of active primes ( $p s>.6)$.

Table D.13: Experiment 6: ANOVA and planned contrasts on children's Be-Passives

\begin{tabular}{lcccccccc}
\hline & \multicolumn{4}{c}{ F1 Results } & \multicolumn{5}{c}{ F2 Results } \\
\cline { 2 - 10 } Effect & $\boldsymbol{d f}$ & $\boldsymbol{F 1}$ & $\boldsymbol{p}$ & $\boldsymbol{p} . \eta^{2}$ & $\boldsymbol{d f}$ & $\boldsymbol{F 2}$ & $\boldsymbol{p}$ & $\boldsymbol{p} \cdot \eta^{2}$ \\
\hline \hline Prime & $* 1.1,19.5$ & 10.96 & $<.01$ & 0.39 & $* 1.3,21.8$ & 15.80 & $<.001$ & 0.48 \\
Actives vs Passives & 1,17 & 10.33 & $<.01$ & 0.38 & 1,17 & 11.93 & $<.01$ & 0.41 \\
Get vs Be Passives & 1,17 & 11.24 & $<.01$ & 0.40 & 1,17 & 17.54 & $<.01$ & 0.51 \\
\hline
\end{tabular}

Adults' Be-Passives

Table D.14 shows the results of the analyses of the adults' be-passive responses. These showed that there was a significant effect of Prime. Planned contrasts showed a significant difference between passive primes and active primes but not between get-passive and be-passive primes. 
Table D.14: Experiment 6: ANOVA and planned contrasts on adults' Be-Passives

\begin{tabular}{lcccccrcc}
\hline & \multicolumn{4}{c}{ F1 Results } & \multicolumn{4}{c}{ F2 Results } \\
\cline { 2 - 9 } Effect & $d f$ & $\boldsymbol{F 1}$ & $\boldsymbol{p}$ & $\boldsymbol{p} . \eta^{2}$ & $\boldsymbol{d f}$ & $\boldsymbol{F 2}$ & $\boldsymbol{p}$ & $\boldsymbol{p} \cdot \eta^{2}$ \\
\hline \hline Prime & 2,34 & 4.60 & $<.05$ & 0.21 & 2,34 & 6.20 & $<.01$ & 0.27 \\
Actives vs Passives & 1,17 & 7.27 & $<.05$ & 0.30 & 1,17 & 11.17 & $<.01$ & 0.40 \\
Get vs Be Passives & 1,17 & 1.71 & n.s. & 0.09 & 1,17 & 1.39 & n.s. & 0.07 \\
\hline
\end{tabular}

\section{Get-Passive Responses}

Secondly we analysed the get-passive responses following the Inclusive scoring, the mean proportions following this scoring are shown in Table D.15. The results of the mixed ANOVAs (as in previous analyses) are shown in Table D.16. These showed a significant effect of Prime on the participants' get-passives, a significant effect of Group and a significant interaction between Prime and Group, though there was also a simple effect of Prime within each group: children and adults. We explored the effect of Prime within each group separately.

Table D.15: Experiment 6: Mean proportions of Get-Passives in the Inclusive scoring

\begin{tabular}{lcccc}
\hline \multirow{2}{*}{ Prime } & \multicolumn{2}{c}{ Children } & \multicolumn{2}{c}{ Adults } \\
\cline { 2 - 5 } & $\mathbf{M}$ & (SD) & M & (SD) \\
\hline \hline Active & 0.04 & $(0.08)$ & 0.02 & $(0.09)$ \\
Get-Passive & 0.42 & $(0.37)$ & 0.19 & $(0.21)$ \\
Be-Passive & 0.19 & $(0.24)$ & 0.01 & $(0.04)$ \\
\hline
\end{tabular}

Table D.16: Experiment 6: ANOVA of proportions of Get-Passives in the Inclusive scoring

\begin{tabular}{lcccccccc}
\hline & \multicolumn{4}{c}{ F1 Results } & \multicolumn{5}{c}{ F2 Results } \\
\cline { 2 - 9 } Effect & $\boldsymbol{d} \boldsymbol{f}$ & $\boldsymbol{F 1}$ & $\boldsymbol{p}$ & partial $\eta^{2}$ & $\boldsymbol{d f}$ & $\boldsymbol{F 2}$ & $\boldsymbol{p}$ & partial $\eta^{2}$ \\
\hline \hline Prime & $* 1.6,55.8$ & 23.53 & $<.001$ & 0.41 & $* 1.7,56.9$ & 36.06 & $<.001$ & 0.51 \\
Group & 1,34 & 8.22 & $<.01$ & 0.19 & 1,34 & 21.13 & $<.001$ & 0.38 \\
Prime x Group & $* 1.6,55.8$ & 3.42 & $<.05$ & 0.09 & $* 1.7,56.9$ & 4.56 & $<.05$ & 0.12 \\
Prime (Children) & 2,33 & 14.03 & $<.001$ & 0.46 & 2,33 & 30.81 & $<.001$ & 0.65 \\
Prime (Adults) & 2,33 & 4.97 & $<.05$ & 0.23 & 2,33 & 7.13 & $<.01$ & 0.30 \\
\hline
\end{tabular}

\section{Children's Get-Passives}

Table D.17 shows the results of within-participants ANOVAs with planned contrasts on the children's get-passives. These showed a significant effect of Prime on the children's proportions of get-passives. The planned contrasts showed that the effect of active primes and passive primes (combined) on the get-passive responses was significantly different, as was the effect of get-passive primes and be-passive primes. Pairwise comparisons showed that there was a significantly different effect of active primes and be-passive primes on get-passive responses $(p s<.05)$.

\section{Adults' Get-Passives}

The results of the analyses on the adults' get-passive responses following the Inclusive scoring are shown in Table D.18. There was a significant effect of Prime. The 
Table D.17: Experiment 6: ANOVA and planned contrasts on children's Get-Passives

\begin{tabular}{lcccccccc}
\hline & \multicolumn{4}{c}{ F1 Results } & \multicolumn{4}{c}{ F2 Results } \\
\cline { 2 - 9 } Effect & $\boldsymbol{d} \boldsymbol{f}$ & $\boldsymbol{F 1}$ & $\boldsymbol{p}$ & $\boldsymbol{p} \cdot \eta^{2}$ & $\boldsymbol{d f}$ & $\boldsymbol{F 2}$ & $\boldsymbol{p}$ & $\boldsymbol{p} \cdot \eta^{2}$ \\
\hline \hline Prime & 2,34 & 14.19 & $<.001$ & 0.45 & 2,34 & 24.17 & $<.001$ & 0.59 \\
Actives vs Passives & 1,17 & 15.22 & $<.01$ & 0.47 & 1,17 & 48.19 & $<.001$ & 0.74 \\
Get vs Be Passives & 1,17 & 12.64 & $<.01$ & 0.43 & 1,17 & 12.55 & $<.01$ & 0.42 \\
\hline
\end{tabular}

planned contrasts showed that there was also a significant difference between passive primes and active primes and a significant difference between get-passive and be-passive primes. Finally pairwise comparisons showed that there was no significant difference between the effect of active primes and be-passive primes on the proportion of get-passive targets ( $p s>.5)$.

Table D.18: Experiment 6: ANOVA and planned contrasts on adults' Get-Passives

\begin{tabular}{lcrcccrcc}
\hline & \multicolumn{4}{c}{ F1 Results } & \multicolumn{5}{c}{ F2 Results } \\
\cline { 2 - 9 } Effect & $d f$ & $\boldsymbol{F 1}$ & $\boldsymbol{p}$ & $\boldsymbol{p} \cdot \eta^{2}$ & $\boldsymbol{d f}$ & $\boldsymbol{F 2}$ & $\boldsymbol{p}$ & $\boldsymbol{p} \cdot \eta^{2}$ \\
\hline \hline Prime & $* 1.4,23.6$ & 11.51 & $<.01$ & 0.40 & $* 1.2,21.0$ & 13.82 & $<.01$ & 0.45 \\
Actives vs Passives & 1,17 & 7.54 & $<.05$ & 0.31 & 1,17 & 8.53 & $<.05$ & 0.33 \\
Get vs Be Passives & 1,17 & 13.21 & $<.01$ & 0.44 & 1,17 & 16.40 & $<.01$ & 0.49 \\
\hline
\end{tabular}




\section{References}

Allen, S. \& Crago, M. (1996), 'Early passive acquisition in Inuktitut', Journal of Child Language 23, 129-155.

Babyonyshev, M. \& Brun, D. (2003), 'Acquisition of Russian passive constructions', Paper presented at GALA 2003, Utrecht.

Babyonyshev, M., Ganger, J., Pesetsky, D. \& Wexler, K. (2001), 'The Maturation of grammatical principles: Evidence from Russian accusatives', Linguistic Inquiry $32(1), 1-44$.

Baker, N. \& Nelson, K. (1984), 'Recasting and related conversational techniques for triggering syntactic advances by young children', First Language 5, 3-22.

Baldie, B. (1976), 'The Acquisition of the passive voice', Journal of Child Language 3, 331348.

Beilin, H. (1975), Experiments on the passive, in H. Beilin, ed., 'Studies in the Cognitive Basis of Language Development', Academic Press, New York, pp. 39-83.

Beilin, H. \& Sack, H. (1975), The Passive: Linguistic and psychological theory, in H. Beilin, ed., 'Studies in the Cognitive Basis of Language Development', Academic Press, New York, pp. 6-38.

Bencini, G. \& Valian, V. (2008), 'Abstract sentence representations in 3-year-olds: Evidence from language production and comprehension', Journal of Memory and Language 59, 97-113.

Bever, T. (1970), The Cognitive basis for linguistic structures, in J. R. Hayes, ed., 'Cognition and the Development of Language', John Wiley, New York, pp. 279-362.

Bock, K. (1986), 'Syntactic persistence in language production', Cognitive Psychology 18, 355-387.

Bock, K. (1989), 'Closed-class immanence in sentence production', Cognition 31, 163 186. 
Bock, K., Dell, G., Chang, F. \& Onishi, K. (2007), 'Persistent structural priming from language comprehension to language production', Cognition 104, 437-358.

Bock, K. \& Griffin, Z. (2000), 'The Persistence of structural priming: Transient activation or implicit learning', Journal of Experimental Psychology: General 129(2), 177-192.

Bock, K. \& Levelt, W. (1994), Language production: Grammatical encoding., in M. Gernsbacher, ed., 'Handbook of Psycholinguistics', Academic Press, San Diego, pp. 945-984.

Bock, K. \& Loebell, H. (1990), 'Framing sentences', Cognition 35, 1-39.

Bock, K., Loebell, H. \& Morey, R. (1992), 'From conceptual roles to structural relations: Bridging the syntactic cleft', Psychological Review 99(1), 150-171.

Borer, H. \& Wexler, K. (1987), The Maturation of syntax, in T. Roeper \& E. Williams, eds, 'Parameter Setting', D. Reidel Publishing Company, Dordrecht, pp. 123-172.

Branigan, H., McLean, J. \& Jones, M. (2005), A Blue cat or a cat that is blue? evidence for abstract syntax in young children's noun phrases, in A. Brugos, M. Clark-Cotton \& S. Ha, eds, 'The Proceedings of the Twenty-Ninth Boston University Conference on Language Development', Cascadilla Press, Somerville, MA, pp. 109-121.

Branigan, H., Pickering, M. \& Cleland, A. (2000), 'Syntactic co-ordination in dialogue', Cognition 75, B13-25.

Branigan, H., Pickering, M., Liversedge, S., Stewart, A. \& Urbach, T. (1995), 'Syntactic priming: Investigating the mental representation of language', Journal of Psycholinguistic Research 24(6), 489-506.

Brooks, P. \& Tomasello, M. (1999), 'Young children learn to produce passives with nonce verbs.', Developmental Psychology 35(1), 29-44.

Brown, I. (1976), 'Role of referent concreteness in the acquisition of passive sentence comprehension through abstract modelling', Journal of Experimental Child Psychology 22, 185-199.

Brown, R. (1973), A First Language: The Early Stages, Allen and Unwin, London.

Budwig, N. (1990), 'The Linguistic marking of nonprototypical agency: An exploration into children's use of passives.', Linguistics 28, 1221-1252.

Budwig, N. (2001), An Exploration into children's use of passives, in M. Tomasello \& E. Bates, eds, 'Language Development: The Essential Readings', Blackwell Publishers: Malden, MA, pp. 227-247. 
Chang, F., Dell, G., Bock, K. \& Griffin, Z. (2000), 'Structural priming as implict learning: A comparison of models of sentence production', Journal of Psycholinguistic Research 29, 217-229.

Cleland, A. \& Pickering, M. (2003), 'The Use of lexical and syntactic information in language production: Evidence from the priming of noun-phrase structure', Journal of Memory and Language 49, 214-230.

Cohen, J. (1960), 'A Coefficient of agreement for nominal scales', Educational and Psychological Measurement 20(1), 37-46.

Collins, P. (1996), 'Get-passives in English', World Englishes 15, 43-56.

Cook, V. \& Newson, M. (1996), Chomsky's Universal Grammar: An Introduction., 2nd edn, Oxford: Blackwell Publishers Ltd.

Crain, S. \& Fodor, J. (1993), Competence and performance in child language, in E. Dromi, ed., 'Language and Cognition: A Developmental Perspective', Ablex, Norwood, N.J., pp. 141-171.

Crain, S., Thornton, R. \& Murasugi, K. (1987), 'Capturing the evasive passive', Paper presented at the 12th Annual Boston University Conference on Language Developnment, Boston, M.A.

de Villiers, J. \& de Villiers, P. (1973), 'Development of the use of word order in comprehension', Journal of Psycholinguistic Research 2(4), 331-341.

de Villiers, J. \& de Villiers, P. (1978), Language Acquisition, Harvard University Press, Cambridge, MA.

de Villiers, P. \& de Villiers, J. (1979), Early Language, London: Fontana.

Demuth, K. (1989), 'Maturation and the acquisition of the Sesotho passive', Language 65(1), 56-80.

Demuth, K. (1990), 'Subject, topic and the Sesotho passive', Journal of Child Language $17,67-84$.

Dobel, C., Diesendruk, G. \& Bölte, J. (2007), ‘How writing system and age influence spatial representations of actions: A developmental, cross-linguistic study', Psychological Science 18(6), 487-491.

Dunn, L., Dunn, L., Whetton, C. \& Burley, J. (1997), The British Picture Vocabulary Scale, 2nd edn, National Foundation for Educational Research. 
Ferreira, F. (1994), 'Choice of passive voice is affected by verb type and animacy', Journal of Memory and Language 33, 715-736.

Ferreira, F. \& Engelhardt, P. (2006), Syntax and production, in M. Traxler \& M. Gernsbacher, eds, 'Handbook of Psycholinguistics', 2nd edn, Academic Press, Amsterdam, pp. 61-91.

Ferreira, V. \& Bock, K. (2006), 'The Functions of structural priming', Language and Cognitive Processes 21, 1011-1029.

Flett, S. (2006), A Comparison of syntactic representation and processing in first and second language production, $\mathrm{PhD}$ thesis, University of Edinburgh.

Fox, D. \& Grodzinsky, Y. (1998), 'Children's passive: A view from the by-phrase', Linguistic Inquiry 29(2), 311-332.

Fox, D., Grodzinsky, Y. \& Crain, S. (1995), An Experimental study of children's passive, in 'MIT Working Papers in Linguistics 26: Papers on Language Processing and Acquisition', MITWPL, Department of Linguistics and Philosophy, MIT, Cambridge, Mass, pp. 249-264.

Fraser, C., Bellugi, U. \& Brown, R. (1963), 'Control of grammar in imitation, comprehension and production', Journal of Verbal Learning and Verbal Behavior 2, 121-135.

Gertner, Y., Fisher, C. \& Eisengart, J. (2006), 'Learning words and rules: Abstract knowledge of word order in early sentence comprehension', Psychological Science 17, 684-691.

Gordon, P. \& Chafetz, J. (1990), ‘Verb-based versus class-based accounts of actionality effects in children's comprehension of passives', Cognition 36, 227-254.

Greenbaum, S. \& Quirk, R. (1990), A Student's Grammar of the English Language, Longman.

Griffin, Z. \& Weinstein-Tull, J. (2003), 'Conceptual structure modulates structural priming in the production of complex sentences', Journal of Memory and Language 49, 537-555.

Harris, F. \& Flora, J. (1982), 'Children's use of get passives.', Journal of Psycholinguistic Research 11(4), 297-311.

Harris, M. (1976), 'The Influence of reversibility and truncation on the interpretation of the passive voice by young children', British Journal of Psychology 67(3), 419-427. 
Harris, M. (1978), 'Noun animacy and the passive voice: A developmental approach', Quarterly Journal of Experimental Psychology 30, 495-504.

Hartsuiker, R. \& Kolk, H. (1998), 'Syntactic facilitation in agrammatic sentence production', Brain and Language 62, 221-254.

Hartsuiker, R., Pickering, M. \& Veltkamp, E. (2004), 'Is syntax separate or shared between languages? cross-linguistic syntactic priming in Spanish-English bilinguals', Psychological Science 15(6), 409-414.

Hayhurst, H. (1967), 'Some errors of young children in producing passive sentences', Journal of Verbal Learning and Verbal Behavior 6(4), 654-660.

Hirsch, C. \& Wexler, K. (2006a), By the way, children don't know by, in D. Bamman, T. Magnitskaia \& C. Zaller, eds, 'BUCLD 30: Proceedings of the 30th annual Boston University Conference on Language Development', Cascadilla Press, Somerville, MA, pp. 249-261.

Hirsch, C. \& Wexler, K. (2006b), Children's passives and their resulting interpretation, in K. Deen, J. Nomura, B. Schulz \& B. Schwartz, eds, 'The Proceedings of the Inaugral Conference on Generative Approaches to Language Acquisition-North America', Vol. University of Connecticut Occasional Papers in Linguistics, 4, pp. 125-136.

Hirsh-Pasek, K. \& Golinkoff, R. (1996), The Preferential looking paradigm reveals emerging language comprehension., in D. McDaniel, C. McKee \& H. Cairns, eds, 'Methods for assessing children's syntax', MIT Press, Cambridge, MA, pp. 105-124.

Horgan, D. (1978), 'The Development of the full passive', Journal of Child Language $5,65-80$.

Huttenlocher, J., Vasilyeva, M. \& Shimpi, P. (2004), 'Syntactic priming in young children', Journal of Memory and Language 50(2), 182-195.

Lee, L. (1974), Developmental Sentence Analysis: A Grammatical assessment procedure for speech and language clinicians, Northwestern University Press, Evanston.

Levelt, W. \& Kelter, S. (1982), 'Surface form and memory in question answering', Cognitive Psychology 14, 78-106.

Levin, B. (1993), English Verb Classes and Alternations: A Preliminary Investigation, University of Chicago Press, Chicago, IL.

Lovell, K. \& Dixon, E. (1967), 'The Growth of the control of grammar in imitation, comprehension and production', Journal of Child Psychology and Psychiatry 8, 31-39. 
MacWhinney, B. (2000), The CHILDES project: Tools for analyzing talk, third edn, Lawrence Erlbaum Associates, Mahwah, NJ.

Maratsos, M. (1978), New models in linguistics and language acquisition, in M. Halle, J. Bresnan \& G. Miller, eds, 'Linguistic Theory and Psychological Reality', The MIT Press, Cambridge, MA, pp. 246-263.

Maratsos, M. (1979), How to get from words to sentences, in D. Aaronson \& R. Rieber, eds, 'Psycholinguisitic Research: Implications and Applications', Lawrence Erlbaum Associates, Hillsdale: NJ, pp. 285-353.

Maratsos, M. \& Abramovitch, R. (1975), 'How children understand full, truncated and anomalous passives', Journal of Verbal Learning and Verbal Behavior 14, 145-157.

Maratsos, M., Fox, D., Becker, J. \& Chalkley, M. (1985), 'Semantic restrictions on children's passives', Cognition 19, 167-191.

Marchman, V., Bates, E., Burkardt, A. \& Good, A. (1991), 'Functional constraints of the acquisition of the passive: toward a model of the competence to perform', First Language 11, 65-92.

McClure, K., Pine, J. \& Lieven, E. (2006), 'Investigating the abstractness of children's early knowledge of argument structure', Journal of Child Language 33, 693-720.

Meints, K. (1999), Prototypes and the acquisition of the English passive, in B. Kokinov, ed., 'Perspectives on Cognitive Science', Vol. 4, NBU Press, Sofia, pp. 67-77.

Meints, K. (2003), To get or to be? Use and acquisition of get-passives versus bepassives: Evidence from children and adults, in H. Cuyckens, T. Berg, R. Dirven \& K. Panther, eds, 'Motivation in Language: Current Issues in Linguistic Theory', John Benjamins Publishing Company, Amsterdam, pp. 123-150.

Menyuk, P. (1963), 'Syntactic structures in the language of children', Child Development 34(2), 407-422.

Menyuk, P. (1969), Sentences Children Use, The MIT Press, Cambridge.

Morrison, C., Chappel, T. \& Ellis, A. (1997), 'Age of acquisition norms for a large set of object names and their relation to adult estimates and other variables', Quarterly Journal of Experimental Psychology 50A(3), 528-559.

Pickering, M. \& Branigan, H. (1998), 'The Representation of verbs: Evidence from syntactic priming in language production', Journal of Memory and Language 39, 633651. 
Pierce, A. (1992), 'The Acquisition of passives in Spanish and the question of a-chain maturation', Language Acquisition 2(1), 55-81.

Pinker, S. (1994), The Language Instinct: The New science of language and mind, Penguin, London.

Pinker, S., Lebeaux, D. \& Frost, L. (1987), 'Productivity and constraints in the acquisition of the passive', Cognition 26, 195-267.

Pye, C. \& Quixtan Poz, P. (1988), 'Precocious passives (and antipassives) in Quiche Mayan', Papers and Reports on Child Language Development, Stanford 27, 71-80.

Savage, C., Lieven, E., Theakston, A. \& Tomasello, M. (2003), 'Testing the abstractness of children's linguistic representations: lexical and structural priming of syntactic constructions in young children', Developmental Science 6(5), 557-567.

Savage, C., Lieven, E., Theakston, A. \& Tomasello, M. (2006), 'Structural priming as implict learning in language acquisition: The persistence of lexical and structural priming in 4-year-olds', Language Learning and Development 2(1), 27-49.

Schenkein, J. (1980), A Taxonomy of repeating action sequences in natural conversation, in B. Butterworth, ed., 'Language Production, Volume 1: Speech and Talk', Academic Press, London, pp. 21-47.

Shimpi, P., Gamez, P., Huttenlocher, J. \& Vasilyeva, M. (2007), 'Syntactic priming in 3- and 4-year-old children: Evidence for abstract representations of transitive and dative forms.', Developmental Psychology 43(6), 1334-1346.

Slobin, D. (1966), ‘Grammatical transformations and sentence comprehension in childhood and adulthood', Journal of Verbal Learning and Verbal Behavior 5, 219-227.

Slobin, D. (1968), 'Recall of full and truncated passive sentences in connected discourse', Journal of Verbal Learning and Verbal Behavior 7, 876-881.

Slobin, D. (1994), Passives and alternatives in children's narratives in English, Spanish, German and Turkish, in B. Fox \& P. Hopper, eds, 'Typological Studies in Language, Volume 27: Voice: Form and Function', John Benjamins Publishing Company, Amsterdam, pp. 341-364.

Snyder, W., Hyams, N. \& Crisma, P. (1995), Romance auxiliary selection with reflexive clitics: evidence for early knowledge of unaccusativity, in E. Clark, ed., '26th Annual Child Language Research Forum', CSLI Publications, Stanford, California, pp. 127136. 
Sudhalter, V. \& Braine, M. (1985), 'How does comprehension of passive develop? a comparison of actional and experiential verbs.', Journal of Child Language 12, 455470 .

Sussex, R. (1982), 'A Note on the get-passive construction', Australian Journal of Linguistics 2(1), 83-95.

Svartvik, J. (1966), On Voice in the English Verb, Mouton \& Co., The Hague.

Terzi, A. \& Wexler, K. (2002), 'A-chains and s-homophones in children's grammar: Evidence from Greek passives', Paper presented at North East Linguistic Society (NELS) 32nd Annual Meeting, New York.

Thothathiri, M. \& Snedeker, J. (2008), 'Syntactic priming during language comprehension in three- and four-year-old children.', Journal of Memory and Language 58(2), 188213.

Tomasello, M. (2000), 'Do young children have adult syntactic competence?', Cognition 74, 209-253.

Tomasello, M., Brooks, P. \& Stern, E. (1998), 'Learning to produce passive utterances through discourse.', First Language 18, 223-237.

Turner, E. \& Rommetveit, R. (1967a), 'The acquisition of sentence and voice and reversibility', Child Development 38(3), 649-660.

Turner, E. \& Rommetveit, R. (1967b), 'Experimental manipulation of the production of active and passive voice in children', Language and Speech 10, 169-180.

Vasilyeva, M., Huttenlocher, J. \& Waterfall, H. (2006), 'Effects of language intervention on syntactic skill levels in preschoolers.', Developmental Psychology 42(1), 164-174.

Weiner, E. \& Labov, W. (1983), 'Constraints on the agentless passive', Journal of Linguistics 19, 29-58.

Whitehurst, G., Ironsmith, M. \& Goldfein, M. (1974), 'Selective imitation of the passive construction through modeling', Journal of Experimental Child Psychology 17, 288-302. 